\title{
Rethinking the Politics of Social Capital: Challenging Tocquevillian Perspectives
}

Link to publication record in Manchester Research Explorer

\section{Citation for published version (APA):}

Savage, M., Li, Y., \& Tampubolon, G. (2006). Rethinking the Politics of Social Capital: Challenging Tocquevillian Perspectives. In R. E., J. F., \& J. H. (Eds.), Asessing Social Capital: Concept, Policy and Practice (pp. 70-94). Cambridge Scholars Press.

\section{Published in:}

Asessing Social Capital: Concept, Policy and Practice

\section{Citing this paper}

Please note that where the full-text provided on Manchester Research Explorer is the Author Accepted Manuscript or Proof version this may differ from the final Published version. If citing, it is advised that you check and use the publisher's definitive version.

\section{General rights}

Copyright and moral rights for the publications made accessible in the Research Explorer are retained by the authors and/or other copyright owners and it is a condition of accessing publications that users recognise and abide by the legal requirements associated with these rights.

\section{Takedown policy}

If you believe that this document breaches copyright please refer to the University of Manchester's Takedown Procedures [http://man.ac.uk/04Y6Bo] or contact uml.scholarlycommunications@manchester.ac.uk providing relevant details, so we can investigate your claim.

\section{OPEN ACCESS}


Assessing Social Capital 



\title{
Assessing Social Capital: \\ Concept, Policy and Practice
}

\author{
Edited by
}

Rosalind Edwards, Jane Franklin and Janet Holland

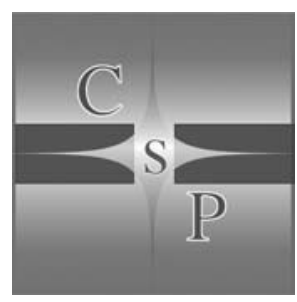

CAMBridge SCHOlars PRESS 
Assessing Social Capital: Concept, Policy and Practice, edited by Rosalind Edwards, Jane Franklin and Janet Holland

This book first published 2006 by

Cambridge Scholars Press

15 Angerton Gardens, Newcastle, NE5 2JA, UK

British Library Cataloguing in Publication Data

A catalogue record for this book is available from the British Library

Copyright (C) 2006 by Rosalind Edwards, Jane Franklin and Janet Holland and contributors

All rights for this book reserved. No part of this book may be reproduced, stored in a retrieval system, or transmitted, in any form or by any means, electronic, mechanical, photocopying, recording or otherwise, without the prior permission of the copyright owner.

ISBN 1-84718-072-8 


\section{TABLE OF CONTENTS}

Acknowledgements...................................................................................................... vii

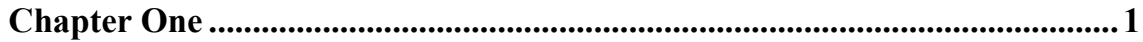

W(h)ither Social Capital?

Jane Franklin, Janet Holland and Rosalind Edwards

Chapter Two 14

Capitalising Sociability: Rethinking the Theory of Social Capital

Joseph D. Lewandowski

Chapter Three

The Meaning and Utility of 'Social' in Social Capital

Barbara Arneil

Chapter Four.

Social Capital as a Capacity for Collective Action

Pedro Ramos-Pinto

Chapter Five

Rethinking the Politics of Social Capital: Challenging Tocquevillian

Perspectives

Mike Savage, Yaojun Li and Gindo Tampubolon

Chapter Six 95

Banking on Families: How Families Generate and Distribute Social Capital

Frank F. Furstenberg

Chapter Seven

The Prospects of Social Capital: Networks in Bosnia and Herzegovina Iva Božović

Chapter Eight

The Weakest Link?: Social Capital in Australian Regional Development

Keri Chiveralls 
Chapter Nine 146

What are we Playing at? Social Capital and Music Therapy

Simon Procter

Chapter Ten. 163

Fragmented Youth: Social Capital in Biographical Context in Young

People's Lives

Janet Holland

Chapter Eleven

Children's Geographic Movements and Social Capital: Does Space Matter?

Nicole Schaefer-McDaniel

Chapter Twelve

The Role of Family Background and Social Capital in the Social Mobility of Migrant Ethnic Minorities

Lucinda Platt and Paul Thompson

Chapter Thirteen

Assessing Social Capital and Care Provision in Minority Ethnic

Communities: A Comparative Study of Caribbean and Italian

Transnational Families

Tracey Reynolds and Elisabetta Zontini

References

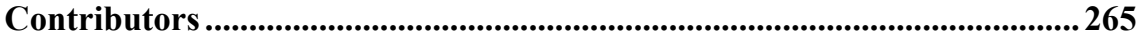

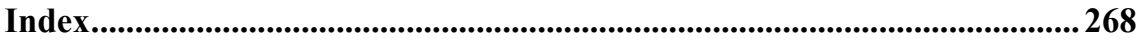




\section{ACKNOWLEDGMENTS}

The contributions to this edited collection are selected from a number of papers presented at the 'W(h)ither Social Capital? Past, Present and Future' international conference held in April 2005. We and our contributors have thus benefitted from discussion of these and the other papers at the conference. The conference was supported by the Economic and Social Research Council, as part of their investment in the Families \& Social Capital ESRC Research Group, and we would like to thank them.

Our colleagues in the Families Group have also provided us with opportunities to develop our thinking on social capital. In addition to those represented in this edited collection, we would like in particular to thank Irene Bruegel, Claire Callender, Pauline Cheong, Val Gillies, Anne Gray, Harry Goulbourne, Sheila Henderson, Helen Lucey, Kanwal Mand, Sheena McGrellis, Sue Sharpe, John Solomos, Rachel Thomson, Jeffrey Weeks, and Susie Weller.

Finally, our gratitude to Jane Williams and Anosua Mitra for organising the conference so smoothly, and even more thanks to Anosua for undertaking the task of converting manuscripts in different formats into the one required by the publisher.

Rosalind Edwards, Jane Franklin and Janet Holland 



\section{CHAPTER ONE}

\section{W(H)ITHER SOCIAL CAPITAL?}

\section{JANE FRANKLIN, JANET HOLLAND AND ROSALIND EDWARDS}

\section{Introduction}

In recent years, social capital has become a key concept in academic theories and research, and influential as a framework for guiding policy-making that seeks to shape everyday practices in relation to building social integration. A range of related reasons have been put forward for this attention. These include a concern with the excesses of current individualism and nostalgia for a lost cohesive past; the desire to reintroduce a normative and social dimension to understandings of how society works; the impulse to control contemporary liberal societies that are increasingly diverse and undergoing rapid social change; and the way that social capital enables governments to leave aside redistributive economic policies in favour of (less expensive) informal, community-based social relations. As will become clear from a perusal of this volume, social capital can be defined in various ways, but arguably, its central preoccupation allows a focus on social relationships, the values held as part of these relationships, and access to resources in families, communities, regions and even nations. But does the concept, with its focus on particular aspects of social life and thus the thrust of its influence on policy initiatives, hide more than it illuminates or is it even harmful? Can social capital ideas be amended or adapted to bring other pertinent issues into view, or are there alternative concepts that are better able to address the diversity and complexity of contemporary social, economic and political life?

This edited collection brings together a series of papers that assess social capital, variously as concept, policy and/or practice. They address a variety of national contexts: Australia, Bosnia Herzegovina, the Caribbean, Canada, Italy, the United Kingdom, and the United States, from a range of disciplinary perspectives - anthropology, economics, musicology, politics and sociology. The collection is based on some of the papers presented at the "W(h)ither Social 
Capital? Past, Present and Future" conference, organised by the Families \& Social Capital ESRC Research Group at London South Bank University in 2005. The conference was called to address questions concerning the relevance, viability and implications of notions of social capital. The resulting contributions are illustrative of the tenor of the responses to those questions. Some reveal social capital's conceptual lacks and the concomitant drawbacks of policies directed towards social capital building, and put forward alternative ways to understand social relationships and their economic and political implications. Others pursue the function of mainstream models in grasping various aspects of social capital, albeit noting that these models may need to be adapted if they are to gain full purchase. The authors draw on a diversity of evidence to make their points: theoretical considerations of particular manifestations of the concept, associated political philosophies and methodologies for its study, as well as empirical investigations of forms of social capital among different social groups in different local, national and transnational contexts.

This introductory chapter provides an overview of these assessments of the usefulness of social capital, placing them in the framework of concerns around social capital as concept, policy and practice.

\section{Social Capital as Concept}

Social capital theories, concerned with the effects of social change and fragmentation, set out to explain the motivations and effects of social action and interaction, and their contribution to social cohesion and economic growth. As we see from the chapters in this book, to work with the concept, theorists, researchers and policy makers draw on a range of perspectives to capture its meaning, identify its purpose, and connect it to different social and political values and positions. There are, as Joseph Lewandowski points out in his chapter, "dominant strains" of social capital theory, which flow from the work of James Coleman, Robert Putnam and Pierre Bourdieu. Coleman and Putnam, with a focus on values and networks, inform what has become known as "mainstream" social capital theory. Bourdieu who represents the critical wing of this trio, brings issues of inequality and social justice into the picture. From the perspective of social theory, in her chapter Janet Holland argues, the three tend to fall into two major sociological traditions: the "integrative", functionalist or consensus tradition in the work of Coleman and Putnam and, following Bourdieu, the critical or conflict tradition.

Perhaps the common focus for these three major approaches is the condition of the social sphere, and the function and effects of social action and behaviour. Lewandowski points to the central focus of each of the dominant strains, 
understanding them as models of human action. In Coleman's rational model, the choices we make about how to live and relate to each other, are based on self interest. He sees the function of social capital, as values and shared norms, to underpin and sustain social order. With Putnam's political strain of social capital, the focus is on social networks, and the role of mutual obligation and cooperative action. Bourdieu's theory of practice, provides a critical perspective, sharing an interest in the cohesive function of social norms and networks, but stressing the ways that social capital supports and maintains capitalist society and its inequalities. Writing with a vocabulary of class and social practice, he shows how people's lives, and their access to economic, cultural and social and symbolic resources, are constrained by social systems. As Holland suggests, Bourdieu's work allows for a supple use of the concept to analyse the relation between social capital and social class, and the significance of the social and material context in which resources are generated.

In his chapter on the ways families generate and distribute social capital, Frank Furstenberg draws on the perspectives of Durkheim, Coleman and Bourdieu. Families operate, he argues, "as tiny social systems", a sort of microcosm of the wider community. He is interested in how families are built, how couples get together and stay together, and how they interact and develop a reciprocal understanding of values and practices, especially when they have children. In this sense, social capital operates as a resource, generated within families that, at its best, functions to create meaningful and sustaining relationships. Furstenberg defines social capital as "the stock of social goodwill created through shared social norms and a sense of common membership from which individuals may draw in their efforts to achieve collective or personal objectives". At a tangent, Pedro Ramos-Pinto's chapter focuses on social capital more as the capacity for individual and collective action, than a resource. $\mathrm{He}$ argues that social capital needs to be understood as "a combination of networks of individuals and sets of collective norms embedded in those networks". Collective action is then understood in relation to the interplay between social structures that organise around identity, power and social relationships, and the reciprocal meanings and values that flow from them, shaping and constraining social behaviour. Similarly, with her chapter's focus on children and young people, Nicole Schaefer-McDaniel recognises the value of Coleman's attention to shared norms and how social capital facilitates the actions of individuals, as well as the network perspective found in Putnam's work. Pointing to the limitations of mainstream approaches, as we discuss further below in relation to practice, her methodology is sensitive to the dynamic between social and physical worlds. She argues for a new way of thinking about social capital that addresses gender and ethnic difference, and the importance of a sense of place and of belonging. 
To understand its contemporary popularity, Barbara Arneil looks at the meaning of the "social" in social capital theory and the political utility of the concept. Working with Bourdieu, she separates out the "constitutive threads" of Putnam's social capital theory, identifying liberal, republican and nostalgic threads, which, she argues, coalesce towards a vision of the social as a lost unity of participating and engaged citizens. Its current political popularity and utility lies in the way social capital "speaks to the times", in effect carving out an image of the social in decline and in need of political attention. She shows how the social capital thesis parallels communitarianism and Third Way theory, supporting the "social turn" (Tonkiss 2000) in current political projects in Britain and the United States. In their chapter, Mike Savage, Yaojun Li and Gindo Tampubolon agree that as politics and economics turn to the social world, social capital becomes a means through which economistic assumptions are "smuggled into the city of the social".

In her critique, Arneil values the contribution of Bourdieu, especially in the way he treats social capital as resources. She feels, however, that he does not go far enough and his approach could be extended to include gendered and cultural aspects of social capital, as well as economic; and to pay more attention to the historical struggles of subordinated groups. With these extensions of Bourdieu's work, Arneil argues, we might arrive at a different definition of the social than that which underpins the functional school of social capital. Savage and colleagues agree with Arneil that Bourdieu provides a useful position on social capital. Examining how Bourdieu is set up as the critical wing of the dominant trio, they point out that he was only marginally interested in social capital. They suggest that Bourdieu's work is limited by his greater concern with how inequalities are reproduced, than how they might be contested. With an eye to the relationship between the theoretical and empirical, Savage and his colleagues argue for a rethinking of the politics of social capital, drawing on the sociology of structural inequalities of race, gender and class. While they agree with Putnam that networks and associations are important, for them such networks are more complex and contradictory than he suggests. They argue that we need to understand associations in social and historical perspective. Through examining social movements like the feminist movement, and the link between social movements and social change, we can see social capital as associational, complex and contradictory.

For Arneil, the meaning of social in social capital theory carries social, cultural and political assumptions that need to be revealed. For example, she challenges the claim in Putnam's social capital theory that social change since the Second World War has pulled civil society apart, undermining social cohesion and participation. She argues that history tells us more than this. Seen from the perspective of marginalised social groups, changes in society brought 
about through feminist politics and campaigns for racial equality reflect the unfinished and, at times, profoundly divisive story of realizing justice. The nostalgia for unity and cohesion in the social capital story stands in sharp contrast to the complexity and diversity of contemporary societies. It supports a politics in which multiculturalism and diversity are always "challenges". These challenges are posed as difficulties to be managed, overcome and transcended, replaced by a common centre that will provide a cohesive, cooperative and united society.

Rather than stressing the potential unity of the social, then, as Arneil, Savage and colleagues, and others in the book suggest, we might pay attention to inequality and diversity, recognising how ethnicity, gender, disability and social class shape the experiences of different groups. Empirical research enables us to listen to these experiences, in order to understand rather than judge the effects of social change. For Arneil, this means being attentive to the nature of connections between people rather than merely their aggregative number, as is the case in Coleman's and Putnam's functional concerns.

Research that has been attentive to the nature of connections bears this out. For example, Holland shows how the social and material environment in which young people grow up acts to shape the values and identities they adopt. Again, working with Bourdieu she develops a nuanced understanding of how individuals build relations within their own communities and how they move beyond them. Similarly Tracey Reynolds and Elisabetta Zontini show that norms and values are important in shaping community and transnational caring practices, but that they are also fluid and subject to change, and to social and material conditions. They argue that by understanding social capital as locality based and operating solely within the confines of local networks, Coleman and Putnam overlook everyday complex negotiations, resources and opportunities.

The theoretical and empirical issues explored in the contributions to this book suggest that social capital theory is opening up and broadening out. Our authors move the debate on in different ways, to fracture the Coleman/Putnam/Bourdieu triangle. Lewandowski recognises the limited potential of the "cause and effect" approach of the dominant strains and, working with Simmel explores the idea of sociability, which emphasises the creativity and expression of social action rather than its normativity or its rationality. Integrating ideas from different traditions and perspectives, others stress the importance of more rigorous definition of the concept of social capital and the significance of difference, history and structural inequalities, asking us to be wary of assuming the neutrality of the concept in politics and policy making. It is our contributing authors' discussions of the employment of social capital ideas to guide policy-making that we turn to now. 


\section{Social Capital as Policy}

Inspired particularly by Putnam's link between social capital and economic development, but also by Coleman's rational action model (and in the case of Canada at least, Bourdieu's more nuanced approach), politicians and policy makers have clasped the concept of social capital to their hearts with even more zeal and greater alacrity than academics, finding it of immense use in dealing with many and varied problems. It has been at the core of Third Way politics, embraced by many western governments in the face of what some see as the crisis of the welfare state and the more recent failures of the free market economy to deal with issues of social and economic disadvantage and exclusion. In this context the concept bridges the political gap between market and state, or liberal free market policies and welfare statism, and brings the social into the economic sphere.

For others, in a slight change of perspective, social capital represents a shift to the civic space between state and citizen. As Arneil points out in her chapter, this shift enables a critique of both the defence of the welfare state by the left, and neo-liberal demands for the pure market model, thus providing support for both Tony Blair's new left, and George Bush's compassionate conservatism. Several authors in this book are passionately concerned about social justice and inequality and illustrate the ways that they see governments slipping out of responsibility for these issues by using "weasel words" such as social capital. Keri Chiveralls, echoing Arneil, argues that it subsumes the social and the political within economic discourse and enables policy makers to address the concerns of both sides of the political spectrum, while committing to nothing.

The concept of social capital has been influential in shaping governments' policy narratives. These narratives structure a picture of the social world, of individuals, families and communities, from which ideas for policy are drawn, justified and legitimised. Policy narratives may well contain contradictions. For example, in the UK there is a clash between a discourse of social capital and community cohesion, and individualised social mobility. It is argued that social capital can conserve and enhance particularly excluded communities. Whereas for individualised social mobility, the individual needs to "get out" of socially excluded and disadvantaged communities to "get on" (Thomson et al. 2003; and see also Holland in this book). In this sense social capital contains the seeds of its own destruction (Edwards 2005). There is also the case that the policy narrative in its legitimising process can move into classic blaming the victim territory where the excluded and disadvantaged are seen as responsible, indeed to blame, for their lack of social capital and excluded status (Chiveralls in this book. See too Skeggs 2004, and Gillies 2005 on political discourse derived from sociological theory in relation to new formations of class). Some chapters in this 
book illustrate how this narrative fails to capture or deal with the complexity of everyday life. Others examine how the concept of social capital underpins the policy narratives of the UK, USA, Canada and Australia, and the costs this dependency has for the lives of the citizens of these countries, particularly the diverse or disadvantaged. There is also a discussion of a simple failure of the World Bank's use of social capital in the context of war and social destruction in Bosnia Herzegovina.

Elements of US policy based on social capital involve an appeal to civic renewal and community. As Arneil reports, the White House is explicit about their goal of energizing civil society and rebuilding social capital. One strand of US policy (after 9/11) combines nationalism, national security and civic renewal, and is exemplified by the USA Freedom Corps. A second shifts responsibility for social services from state to faith-based organisations, emphasising the crucial relationship of religion and community. The policy also then blurs the line between state and civic society and state and church: "Faith based communities remain such a crucial reservoir of social capital in America that it is hard to see how we could redress the erosion of the last several decades without a major religious contribution" (Putnam 2000: 409). Arneil sees dangers in allowing the "community" revival to blur into an idea of a reawakened church that is saving souls or a nation state seeking security within its borders. And in this drive for national cohesion, difference and diversity become suspicious; as George Bush famously averred, if you are not with us you are against us. As we noted earlier, the model also loses the distinctive history of difference, diversity and struggle, and cleavages around race, class, gender, ethnicity and disability in US society, as the stories of subordinated groups such as women and cultural minorities are subsumed in this generalized narrative of community.

In the UK, Tony Blair aligns the liberal left with Putnam and Bush and shares their ambition of civic renewal. The UK policy narrative similarly links national security and civic society, poses common enemies both outside and within society, and buttresses New Labour's critique of the welfare state. It explicitly calls up an identity of "Britishness" (in speeches and writing by Blair and his ministers) based on shared values that are rooted in history, and provides an antidote to the divisiveness posed by terrorism and multicultural demands. As Arneil points out, as with the USA, British history has many different sides. The invocation of a glorious past can only be sustained by ignoring the powerful forces of exclusion, assimilation and colonial rule that sustained the unity of Britain and its wider empire. Once again stories of difference and diversity, historically and in the present, are lost.

In Canada, the social capital policy narrative is carried through by civil servants, who no doubt started with similar concerns to those of the USA and UK about the welfare state and neo-liberalism, drawing on the functionalist 
versions of the concept favoured by Coleman and Putnam and employed by the World Bank. But the crisis over national unity in the 1990s caused by Quebec's desire for secession brought the embedded multiculturalism of Canada to the fore. This led policy makers to shift towards a network and resources definition of social capital drawing on the work of Bourdieu. In this context, whilst the federal government did seek "social cohesion" or "social union", they did not demand shared identity, values and norms. The Policy Research Initiative (a policy making group) made this change in the concept of social capital employed explicit: “[Bourdieu's] definition is, in many respects, more parsimonious than that offered by either the World Bank or the OECD, excluding, for example, both norms and attitudes" (PRI 2004). But whilst preferring Bourdieu's definition, Canada did not incorporate into their policy narrative his critical stance, which theorises networks and access to resources as shaped by history and power. Once again challenges to power by the subordinated are written out of the story.

The Australian policy narrative is also built on Third Way politics. As Chiveralls says, it represents a "whole of government, whole of community, social partnerships approach to human service provision", as well as a focus on the devolution of government. An important element in the social capital discourse is that of mutual obligation, exemplified by programmes such as Work for the Dole. As noted above, combined with the trend for devolution of responsibility for social problems to the local level, this can lead to a passing of moral responsibility from the state to the disadvantaged. In practical terms, "As government attempts to reduce its expenditure on human services, it shifts responsibility to the local level through community programs at a much lower cost through virtue of volunteers and low paid community workers" (Hase et al. 2004: 9). Chiveralls provides a trenchant critique of the concept of social capital, and the Australian government's deployment of the "weasel word" particularly in the context of regional development. She points out that the current use of the concept in Australian politics often represents disadvantaged and marginalized groups as lacking in individualized values, and largely to blame for their lack of social power. To retrieve the social democratic element of social capital, for Chiveralls, would require the historical and contextual nature of the social, the impact of political and economic processes, and issues of power, class and structural inequality to come back into the frame.

Iva Božović favours a network approach to social capital. She uses a World Bank (2002) study of Bosnia Herzegovina, which evaluated social capital and local institutions, to illustrate the failures of the functionalist approach, particularly in the specification of bridging and bonding social capital in relation to the notion of generalised trust. Inward looking "bonding" social capital, links people into families and communities, and outward looking "bridging" social 
capital, makes links across different groups. Božović criticises the circularity of arguments about bridging social capital, for employing researcher-imposed categories to assess its presence. In the case of Bosnia, the presence of bridging social capital is inferred if relationships between individuals from different ethic groups are observed, missing other potential linkages and leading to failure of social policy to enable bridging social capital. Her work also highlights people's everyday, informal social capital practices. We now turn to the ways that contributions to this volume have addressed both these researcher and everyday social capital practices.

\section{Social Capital as Practice}

As we have already seen, one theme of many of the contributions to this collection is how we can recognise social capital? As is obvious from our discussion above, authors variously place stress on particular aspects of what constitutes social capital, for example social networks and collective action, common norms and expectations, rewards in the form of resources and sanctions that restrict access to them, and trust and reciprocity. These emphases may differ somewhat, but all point towards the importance of understanding how social capital works - the everyday, routine and regular, grounded "practice" of social capital generation, maintenance and use.

The concept of "practice" was developed by Bourdieu $(1977,1990)$ as part of a broader understanding of social and cultural fields, and associated reproduction of inequalities. While some of our authors, including Chiveralls and Holland, find Bourdieu's approach to social capital illuminative, others have been somewhat critical. In particular, as we noted earlier, Lewandowski, and Savage, Li and Tampubolon, argue that Bourdieu's focus on social stratification is overly deterministic, cutting out alternatives and resistance. Nonetheless, the concept of practice is useful here in two ways. First, it draws attention to the relationship between theories of society that define what is of interest and importance, and social life as it is lived - in other words, the methodology of investigating social capital. Second, it enables a focus on how people comprehend, negotiate and nurture social capital in specific geographical and social contexts, over time and across generations. The contributors to this collection have something to say about practice on both these counts: methodology and everyday process.

Notions of social capital do not just assume a particular way that social life works or fails to work, they also construct the nature of the social actors involved, with implications for methods of study. In their respective chapters, Lewandowski and Chiveralls argue that dominant accounts of social capital construct human actors who are rational, self-interested and instrumental. This 
narrowly predetermines how researchers define the object of their study and how they investigate it. As already noted, Lewandowski offers an alternative account placing at its core how sociability is transformed into social capital, which is methodologically open. Simon Procter's exploration of the possibilities of social capital generation as an aim of "musicking" in the context of the practice of music therapy, provides an illustration of such an alternative concern. He acknowledges the infiltration of the rhetoric of social capital into professional practice, providing him with a legitimating rationale for his work that will instrumentally secure resources for service provision. Nonetheless, Procter's elaboration of the process of a group music therapy session with psychiatric hospital in-patients, in which he ponders a non-individualised, nonrational "pre-social musical capital", is akin to Lewandowski's ideas about sociability as a necessary precursor of social capital generation.

A focus on social capital resources as practices points to everyday fluid processes in specific locations, rather than static indicators and outcomes. Furstenberg chastises the unreflexive quality of the current state of social capital measurement. He finds it makeshift and individualised, confused about process and outcome, and in need of measures tailored respectively to the macro, meso or micro level manifestations of social capital under investigation. Furstenberg feels that until there is clarity about what constitutes social capital and therefore agreement about how it can best be researched, judgement about the usefulness of the concept must be suspended. Some contributions to this collection can be read in this light, as efforts towards Furstenberg's identification of the need to separate process from outcome, and to address setting and time, within the mainstream endeavour. Schaefer-McDaniel reworks Coleman's and Putnam's social capital frameworks to look at children's social capital in neighbourhoods, identifying issues of networks and interaction, trust and reciprocity, sense of belonging and place attachment as the focus of social capital investigation. Lucinda Platt and Paul Thompson draw on Coleman as well as Bourdieu to develop the analytic concept of "family social capital" to address generational ideas about success, trace adaptive family patterns in context and over time, and capture within-group variation.

Several authors champion social network approaches as the methodological way forward because social capital flows through networks rather than being a free-standing measurable resource. Ramos Pinto, Savage and colleagues, and Božović maintain that placing social networks at the centre of social capital investigation overcomes the limitations of dominant ideas, including in relation to bonding and bridging forms of social capital. Both Ramos Pinto and Božović, argue that the way bonding and bridging social capital is conceptualised and operationalised in much research leads to methodological blind spots, creating and imposing either/or categorical social identities and 
obscuring power intersections not only between but also within categorical groups. Meanwhile, as Schaefer-McDaniel points out, the social category of children is left aside in dominant conceptions. The complexity of, and tensions between, bonding and bridging social capital practices are a feature of several contributions to the collection, confirming these methodological points. Their arguments reveal the social and historical dimensions to people's lived social capital practices that are located in and built on shifting understandings, institutions, and economic and political frameworks.

As discussed earlier, several authors question mainstream social capital's preoccupation with consensus and common values in bridging associational activities. Savage and colleagues point to the value of tensions and conflicts in the everyday bridging associational activities they studied in a British city, which are generated around issues of real concern to the people involved (rather than the fixations of policy-makers). As part of these struggles, people coming together collectively create the definition of "outsiders" from whom they distinguish themselves. Thus what constitutes bridging is created through everyday practice involving tensions, rather than reflected in the categories imposed by researchers searching for shared values, trust and reciprocity. They also demonstrate that any decline in social capital in Britain is linked to the demise of working class collectivity, embodied in trade unions and working men's clubs, and the rise of more middle class individual lifestyle associations. As noted above, through her reinterpretation of data from the World Bank study of Bosnia and Herzegovina, Božović similarly demonstrates a critique of simplistic notions of bonding and bridging. She explains how, post-transition, historic ethnic divisions and everyday ethnic-specific bonding social capital practices that enable access to resources are reinforced by the failure of social policies.

In contrast, focusing on families, Furstenberg regards social capital as linked to practices involving common norms and expectations. His exploration of the creation of bonding social capital teases out the complexity of family formation and functioning as involving greater or lesser social capital, notably around the balancing act between separateness and unity in partnerships. But he also argues that the setting for these family relationships needs investigation. In a longitudinal study of young people living in contrasting locations in Britain, Holland too identifies families as important in providing them with bonding support and bridging networks, as do the communities in which they live. She introduces a complex understanding of these forms of social capital, as not merely a feature of everyday practice that creates disadvantage but also a result of it. For working class young people in areas of social exclusion, family support and withdrawal from the local community, breaking with local bonding 
networks were key to any social mobility, which was not the case for those from the middle class.

Links between social capital and issues of social mobility involving geographical mobility are also the concern of other chapters in this collection, again requiring a more nuanced understanding of bonding and bridging practices. As with Holland's contribution, gendered and classed social capital practices are a feature within both bonding and bridging forms (rather than constituting them). Schaefer-McDaniel explores how place and the generation and maintenance of social capital are linked for minority ethnic children in a low-income city neighbourhood in the United States, in the gendered practice of everyday spatial mobility. Children whose parents restricted their movement within their neighbourhood, which largely applied to girls, relied far more on school for their bonding social capital building, while those who had greater mobility sustained or envisaged more widespread and bridging social capital.

Platt and Thompson, and Reynolds and Zontini, move us beyond the local to the transnational in considering social and geographical mobility in relation to social capital. Platt and Thompson map the ways that family social capital (a form of bonding) can work variably for ethnic groups, in the case of Indian and Caribbean migrants in Britain. Looking in-depth at the latter group, they show how social mobility following on geographical mobility is related to social class and gender, and to structures and norms in the country of migration. They draw attention to the way that aspects of social capital and associated values, helpful in providing resources in one context, may be counterproductive in another particularly in terms of career trajectories. They also stress the importance of gender in understanding ethnically differentiated mobility patterns. Platt and Thompson note how families play an important role in the migration process and through later exchanges of help, and Reynolds and Zontini consider this issue in-depth. They look at inter and intra-generational reciprocal care as a bonding social capital resource, comparing transnational links for AfricanCaribbean and Italian families settled in Britain. They argue that, in contrast to mainstream assumptions, geographical mobility in the form of migration does not undermine this form of social capital across and within generations for either ethnic group, despite their different orientations to kinship - relational for Caribbeans and interconnected for Italians. There are also similar gendered differences in the nature of caring responsibilities within these ethnic groups, such as "flying grandmothers" moving back and forth geographically to help provide child care, shaping caring for and about as part of bonding social capital resources. Overall then, people's social capital practices are active, fluid, negotiated and cross-cut with class gender and ethnic practices, as part of the routine of everyday life. 


\section{Conclusion}

There has been somewhat of a feeding frenzy around the notion of social capital. Academics have leapt upon it to extol its virtues across a range of disciplines, they have expanded, contracted and critiqued it from a multitude of perspectives, and having chewed it well, may now be in the process of digesting and moving on. Policy-makers perhaps are still in a process of pre-digestion; seeing social capital development as the way forward in dealing with difficult current issues, including globalisation and individualisation, fragmenting and increasing diverse societies, declining and alienated communities and neighbourhoods, and forms of social exclusion. Meanwhile, people live out their lives, over time and within and across different places,

In this vein, the contributions to this edited collection provide a range of assessments of the nature, viability and ramifications of social capital as a theoretical concept, its shaping of policy developments in several national contexts, and its practice in research that seeks to understand how everyday life works. 


\title{
CHAPTER TWO
}

\section{CAPITALISING SOCIABILITY: RETHINKING THE THEORY OF SOCIAL CAPITAL}

\author{
JOSEPH D. LEWANDOWSKI
}

\section{Introduction}

What is social capital? What, if anything, does such a notion explain about the facts and norms of social life? And how, exactly, is social capital causally related to the growth of a market economy, the health of a democracy, or the quality of a neighbourhood? The generic answer to such questions is that social capital consists of those networks of trust and social norms that facilitate human actions of various kinds. Of course the question of what, exactly, "networks of trust" and "social norms" are, and the causal connection between such networks and norms and the "various kinds" of actions they can be said to "facilitate", is less easily answered, and remains one of the central issues in social capital theory and research. It also begs the more probing question of the future of social capital as a viable explanatory concept in the social sciences.

This essay shares with current critiques of social capital theory an overarching sense that much of what is contained in and purportedly measured by the notion of social capital suffers from empirical and theoretical shortcomings. At the empirical level, the causal force of social capital is difficult to chart with any analytic clarity. Indeed, insofar as social capital can be said to "facilitate" or cause anything, its causal map is lined with arabesques, not arrows. At the theoretical level, claims about the causes and effects of social capital are characteristically dependent upon one of the two contrasting images of human actors - homo economicus and homo sociologicus - that have always polarised the social sciences. Here the extent to which actions facilitated by social capital are pulled by individual reason or pushed by shared norms is presupposed in opposing but equally one-sided conceptions of the nature of human action.

Yet however problematic, it is the underlying premise of the present inquiry that such empirical and theoretical shortcomings need not necessarily signal the 
failure or demise of social capital research programmes. Rather, they invite and help to justify a renewed attempt to rethink and develop an alternative account of the core notions contained within those programmes. The goal of this essay is to outline such an account. As my title indicates, I shall argue that social capital is best understood as the harnessing or "capitalizing" of a distinct form of social interaction or human association that Georg Simmel called "sociability" (Geselligkeit).

It should be made clear at the outset, nonetheless, that I am not proposing here anything like a "Simmelean account" of social capital. For Simmel would view any attempt to harness or capitalise sociability as deeply symptomatic of the ways in which modern life - with its over-determining material demands and instrumental rationality - negates the impulse to sociability in human beings. But there is no need to adopt such a general - and rather one-sided - reactionary pessimism regarding the life-world colonising imperatives of modernity here. On my account, the capitalising of sociability does not entail the instrumental negation of sociability but rather its practical transformation into the fungible resource that is social capital. Thus, while the account of social capital to be developed in what follows is inspired by Simmel, it is decidedly not "Simmelean".

The argument is divided into four sections. I begin by summarising what I take to be the three dominant strains in contemporary social capital theory and research; here I highlight the ways in which conceptions of human action profoundly shape current social capital theory and research programmes (Section I). In a subsequent move I argue that the weaknesses of contemporary theories of social capital stem directly from the shortcomings of their actiontheoretical presuppositions (Section II). From there I go on to elaborate relevant features of Simmel's provocative "sociology of sociability" (Section III). In closing, I brush Simmel against the grain in suggesting an alternative account of social capital as the capitalising of sociability (Section IV).

\section{Contemporary Theories of Social Capital}

For all their diverse theoretical origins and empirical applications, it is possible to identify three prevalent strains in contemporary work in social capital theory. ${ }^{1}$ First, there is an economic or rational strain of social capital, found most notably in the rational choice theory of Gary Becker and James Coleman, and central to policy-oriented theories of growth and economic development such as those pursued at the World Bank. ${ }^{2}$ Second, there is a political or democratic strain of social capital, developed most prominently by Robert Putnam, which is one of the hallmarks of contemporary neoTocquevillean political science and democratic theories of associations. ${ }^{3}$ Third, 
there is a critical or Marxist strain of social capital theory, exemplified by the work of Pierre Bourdieu, in which theories of social groups, power, and class conflict are applied in the empirical study of cultural practices. ${ }^{4}$ In this section I focus on the action-theoretical assumptions and notions of social capital peculiar to each strain. ${ }^{5}$

Central to the economic or rational strain in contemporary social capital theory is the rational choice conception of the actor as an essentially selfinterested individual whose behaviour, guided by instrumental reason, always takes the form of strategic action. Gary Becker calls this the "rationality assumption" (1990: 41) upon which the rational choice theory of action is based. In this conception of human action, the "utility function", as Becker describes it, serves to minimise transaction costs and maximise outcomes of individual actors as they pursue the realisation of their self-interests. Such minimising and maximising behaviour is taken to be the fundamental and governing aspect of all human action. Human action, it is assumed, is essentially economic action. ${ }^{6}$

Similarly, James Coleman's influential rational choice sociology of action begins with universal assumptions about human beings as radically individualistic utility-maximising reasoners. In his Foundations of Social Theory, Coleman adheres to a rational conception of action in which all types of action are subsumed under "a single purpose - to increase the actor's realisation of interests" (1990a: 32). Of course Coleman differs from Becker in his attempt to introduce social structure - or what he calls the "social organization of trust"-into economic analyses of action $\left(1984 ;\right.$ 1990a). ${ }^{7}$ In so doing, Coleman seeks to explain how individual rational action is translated into systemic or collective action via shared norms. But this micro to macro translation does not alter so much as it extends the core assumptions of Becker's economic approach to individual human action to the discipline of sociology and the study of how individual rational action is collectively organised to ensure the effective realisation of self-interested utility-maximisers. ${ }^{8}$

Such individualistic rationality assumptions regarding the nature of human action profoundly affect how networks of trust and social norms are understood, and how these notions are incorporated into the theory and empirical study of social capital. Indeed, as a consequence of its conception of human actors as utility-maximisers, this strain of social capital theory understands trust among actors as a horizontally thin, organisational network which functions to bridge and coordinate individual actions. ${ }^{9}$ In a related way, social norms are construed as outcome-oriented conditional constraints that enable the efficient coordination and realisation of individual preferences and self-interests within a social structure. Thus, viewed from within the framework of the rational choice conception of action, social capital amounts to those organised bridging connections between and among individuals that have functional utility. Or, in 
Coleman's parsimonious definition, social capital consists of "some aspect of a social structure" and it facilitates "certain actions of individuals who are within the structure" (1990a: 302). Here social capital is one of many functional resources, including physical and human capital, needed to make possible the efficient realisation of individual ends. It is that store of functional bridging connections or resources upon which individuals may choose to draw to optimise their interests and behaviours to achieve ends difficult if not impossible to attain in the absence of such resources.

Deploying this rational account of social capital in empirical research on education and the family, Becker (1957; 1964; 1981) and Coleman (1990a; 1990b), among others, have sought to explain the causal connection between the resource of social capital and the uses - and abuses, as in the case of social inequality and discrimination - that resource facilitates within particular social structures. This rational sense of social capital has also made its way into economic development debates and planning at global monetary policy-making institutions such as the World Bank, where social capital surveys of trust and the efficient use of norms are taken to measure the stability and growth potential of market economies. $^{10}$

It would not be an exaggeration to say that in both its conception of human action and sense of the effects of social capital, the political or democratic strain in contemporary social capital theory runs largely counter to the strain found in Becker and Coleman and other social capital theorists who adhere to the rational choice model of action. Indeed, where the rational strain focuses exclusively on the utility-maximising potential of the action-facilitating resource of social capital, the political or democratic strain in contemporary social capital theory has followed Tocqueville in arguing for a causal link between networks of trust and social norms and the practical realisation of the political ideals of democracy. This strain in social capital theory, popularised by Robert Putnam, takes as its action-theoretical starting point not the dissociated utilitymaximising individual of rational choice theory but a contrasting Tocquevillean image of the voluntarily associated citoyen of $19^{\text {th }}$ century American townships.

Now, however coarse, this initial contrast between the conception of action in the rational and democratic strains of social capital theory reveals more than the persistent split in the social sciences between the methodological individualism of rational choice theory and more holistic approaches in the disciplines of the social sciences. It also helps to illustrate the source of the differing account of social capital found in the democratic strain. For in the democratic strain, voluntary associations are "plural subjects" or "we"phenomena. ${ }^{11}$ That is to say that in this strain of social capital theory, associated actors are not rationally organised individual atoms. Rather, they are social facts that cultivate what Tocqueville described as the "habits of acting together in the 
affairs of daily life" upon which democratic society depends (1969: 514). Here the "technique of association" (Tocqueville 1969: 522) creates normatively thick forms of mutual trust in which intersubjective moral obligationsTocqueville called these "mores"-are acquired and reinforced in the day-byday working together and associating with others. ${ }^{12}$ Consequently, for Tocqueville, and for neo-Tocquevillean democratic theory, trust networks are not - or not only - thin horizontal bridges that facilitate connections among individual utility-maximisers. Rather, such networks have a bonding intersubjective moral function: they constitute the normative glue of the kind of communal plural subject - or civil society - that is a necessary condition of collective self-rule.

Moreover, as a result of its plural subject conception of human action, social norms are understood differently in the democratic strain of social capital theory. Such norms do not function exclusively to facilitate the efficient individual realisation of private goods within a particular social structure. They also retain the universalising core of a democratic ethos. Indeed, to the extent that social norms foster reflexive social cooperation-or what Tocqueville called "self-interest rightly understood"- they are viewed as the unconditional constraints that govern the collective articulation and practical realisation of the social structure transcending "public good". In the democratic strain in social capital theory social norms are understood as nothing less than those "we"constraints that enable the collective realisation of democratic ideals.

Thus informed by its normative assumptions about the social facts of associations, the democratic strain in current social capital theory conceives of social capital as the communal inventory of "generalized trust" and social norms which facilitate the kinds of mutual obligations and cooperative actions that, to borrow Putnam's phrase, make democracy work. In fact, for Putnam social capital enables the democratic resolution of collective action problems ("prisoner's dilemmas" and "free-rider" problems), "greases the wheels that allow communities to advance smoothly", and develops and maintains "character traits that are good for the rest of society" (2000: 288). In fact, in the democratic strain of social capital theory, the explicitly normative effects of associational life are considered so crucial to democratic existence that a numerical decrease in associational memberships is thought to imperil democracy. Put in the metaphoric terms of Putnam, in a society where generalised trust and social norms have eroded - where, that is, individuals are increasingly "bowling alone"-democracy is inevitably in decline and community is in need of revival. Putnam $(1993 ; 2000)$ has sought to deploy precisely this causal argument about the democratic effects of social capital in his empirical studies of Italy and the United States. 
In many ways the account of action and social capital developed in the work of Pierre Bourdieu presents a unique alternative to the opposing rational and democratic strains in contemporary social capital theory. To be sure, Bourdieu's theory of action - what he calls a "theory of practice" - shares with the rational strain in social capital theory a general sense of the embeddedness of action in social structures. But throughout his work Bourdieu has persistently rejected the rational choice reduction of collective action to behavioural aggregations of rational individuals whose choices are governed only by a utility function ${ }^{13}$. In this way the conception of practice that underlies the Marxist strain of social capital theory not only marks a polemical departure from rational choice models of individual action; it also shares with the democratic strain a general commitment to a kind of collectivist account of associations as distinctly social facts.

Yet it would be a mistake to see Bourdieu's holism as merely a rejection of rational choice and somehow commensurate with a Tocquevillean sense of the voluntarily associated citizen upon which democracy depends. For Bourdieu, the plural subjects of associations-Bourdieu calls them "social groups"-do not come about simply through the voluntary cooperative actions of individuals who have rightly understood their self-interest. Rather, social groups are for Bourdieu "classes" in a neo-Marxist sense. That is to say that for Bourdieu social groups are not, as Marx maintained, actual classes mobilised explicitly for the common purpose of dominating or confronting an opposing class. Instead, social groups are implicit or probable classes in the sense that their existence, identity, and membership are determined by non-voluntary predispositions shaped by everyday struggles over the consumption and distribution of limited economic, social and cultural resources. ${ }^{14}$ Social norms in this strain are thus primarily pre-reflective, stratifying norms of consumption that, for example, predispose some actors to "choose" to drink beer instead of wine, or to "join" rugby clubs rather than bird-watching societies. ${ }^{15}$

Bourdieu's action-theoretical account of how such non-voluntary predispositions ineluctably shape individual and collective practices is elaborated in his notions of "habitus" and "field". Habitus is the shared set of durable dispositions, perceptive schemes, and ingrained orientations that, according to Bourdieu, function as the structuring structure for the production and reproduction of human action or practice. Habitus is for Bourdieu a preintentional "feel for the game" that enables and limits individual and collective practices within particular contexts. Habitus facilitates and constrains action inasmuch as it equips actors with, as Bourdieu describes it, a sens pratique for what is to be done in given situations. Bourdieu characterises such given situations as "fields" or "fields of struggle". By this he means arenas of social (re)production-academia, journalism, sport, politics, culture, etc.- that require 
a specific practical sense for their successful navigation, and in which particular associations or social groups emerge, seek to establish themselves, and inevitably clash with one another for positions of dominance.

Not surprisingly, given the class-based logic of its theory of practice and social norms, the Marxist strain conceives of social capital as a socially shared "credit" that facilitates intra-group identification and trust (mutual recognition and solidarity among group members) and inter-group action and struggle (antagonisms and conflict between groups). ${ }^{16}$ Social capital is therefore neither simply rationally bridging (utility-maximising) nor normatively bonding (causally democratising). Instead, in its Marxist strain social capital is a highly group-specific, context-dependent, and socially stratifying resource. Using this conception of social capital, Bourdieu's wide-ranging empirical-critical studies of culturally embedded practices have sought to explain how, why, and in what concrete forms, social capital has historically facilitated the irrational and undemocratic consumption and distribution of social power among bourgeois groups and their proletariat counterparts. ${ }^{17}$

\section{The Weaknesses of Contemporary Theories of Social Capital}

Characterising the three prevailing strains in social capital theory and research vis-à-vis the senses of human action that underpin them, as I have sought to do in the previous section, helps not only to make explicit the actiontheoretical presuppositions that inform their respective notions of social capital. It also, or so I want to argue in this section, brings into focus the central weaknesses of each strain. In the case of the rational strain in contemporary social capital theory, the problem is not only that its model of rational choice reduces the social to the individual, as critics of rational choice theories of social capital rightly argue. ${ }^{18}$ Difficulties arise when this strain reduces social norms to rational norms, and conceives of trust horizontally, as merely a bridging resource that facilitates individuals' realisations of their rational interests. ${ }^{19} \mathrm{In}$ reducing social norms to rational ones, the rational strain's theoretical assumptions about the universality of the utility function of human action rules out in advance any consideration of the kind of non-outcome oriented, unconditional constraints that are the hallmarks of genuinely social norms. ${ }^{20}$ In horizontalising trust, this strain similarly eliminates any account of the thickness (or normative density) of trust relations. Such theoretical short-circuiting leads to a levelling of social capital to rational capital. An analysis of the social character of action, norms and trust is thus omitted entirely in the rational strain in contemporary social capital theory. The result is that this strain suffers from what I want to call "rational reductionism". 
Conversely, the core problem with the normative or democratic strain in contemporary social capital theory is what might be best described as "moral inflationism". Here a normatively overloaded conception of the social facts of associations leads to universalising claims about the causal, democratically salutary, effects of such associations. Far from reducing social norms to rational norms, this strain errs in the other direction: it inflates the morally bonding function of such norms into association-transcending democratic ideals. To be sure, plural subject associations such as bowling teams and bird-watching clubs, may not, as Amitai Etzioni (2001) has argued, be "morally trivial". But neither can their normative force be puffed up as causally democratic. The resolution of collective action problems and the promotion of "character traits" that may take place in many associations and social groups do not in any necessary way entail the fostering of democratic mores among individual association members or between associations and social groups. Put simply, what the rational strain in social capital theory reduces, the democratic strain morally over-inflates.

The Marxist strain in current social capital theory does not suffer from the rational reductionism or moral inflationism of its rational and democratic contemporaries; indeed, Bourdieu's unique theory of practice allows him to side-step both problems. But there is nevertheless a persistent weakness in the Marxist strain's theory of practice and social capital. That weakness stems from the overly close fit between habitus and field upon which Bourdieu's account of social capital depends. To be sure, these two elements of the theory of action in the Marxist strain avoid the atomism of rational choice and the voluntarism of recent neo-Tocquevillean political science and democratic theory: Bourdieu's conception of social capital depends neither on a reductive conception of rational individualism nor on overblown appeals to the democratic effects of the social facts of voluntary associations. ${ }^{21}$

But with its heavy emphasis on the non-voluntary predispositional constitution of social groups, it is difficult to see how Bourdieu's theory of practice can conceive of human actions and associations as anything other than the more or less seamless reproduction of an objectively stratified social structure or field. ${ }^{22}$ Here the practical sense of human action can only mimicBourdieu would say "embody" - the stratifying norms of consumption that serve as powerful markers of class distinction, division and conflict in a given field. This strict correspondence between habitus and field places profound limits on the Marxist strain's attempt to enlist a notion of social capital in a materialist critique of culture. For here the intra-group bonding and inter-group stratifying "credit" of social capital is a function of a pre-reflective habitus-field homology. Consequently, in this strain social capital does not facilitate actions; rather, it determines them. Hence, while avoiding the rational reductionism and moral inflationism of the other strains in social capital theory, the Marxist strain 
suffers from a tendency towards functionalistic homologism. Rather than criticise the stratifying effects of social capital, its theory of practice deterministically reproduces them in an analysis of social groups.

An empirically adequate and theoretically robust alternative account of social capital needs to avoid the reductive, inflationary and deterministic tendencies that severely weaken the current strains in social capital theory and research. To be sure, such an account can and should include what is right about contemporary notions of social capital. The rational strain's insight - shared but nevertheless overdrawn by Bourdieu, as we have seen - that social capital is a structurally embedded resource; the democratic strain's insight that, however embedded, social capital contains the normatively rich potential to alter human interaction and the locations in which that action takes place; the Marxist strain's powerful suggestion that social capital plays a fundamental role in defining and determining the trajectory of social struggle and group conflictall these need to be incorporated into any viable alternative account of social capital. It is in an attempt to outline such an account that I want next to turn to Simmel's work on sociability.

\section{The Sociology of Sociability}

The model of action that underlies Simmel's sociology of sociability shares little with the action-theoretical presuppositions that inform the dominant strains of contemporary social capital theory. In fact, Simmel's thinking on social interaction and association explicitly rejects the kind of reduction of human action to rational individual action that is the universal assumption upon which the rational strain in social capital theory is based. It is also, as we shall see directly, cautious not to over-inflate the normative potential of human interaction and association in the ways characteristic of the democratic strain. Moreover, Simmel, however attentive to the problem of class, does not conceive of human interaction and association as so many homologous functions of social struggle and class conflict, as the Marxist strain in social capital theory mistakenly does.

Instead, in his discussion of the sociability of human interaction Simmel foregrounds the social creativity of action - a model of action that is sorely missing in contemporary social capital theory. Simmel's account of sociability examines the creative relations between and among actors. Sociability is thus an aesthetic - rather than rational, normative, or class-determined-actiontheoretical model of human association. Indeed, for Simmel, as we shall see directly, sociability is a distinctly expressive form of human interaction-an integrative "art" or social "play"- that is neither purely individualistic nor wholly collectivist. Indeed, operating within the alternate framework of the 
sociology of creative action, Simmel is able to pursue the striking thesis that sociability is a "play-form of association and is related to the contentdetermined concreteness of association as art is related to reality" (1949: 255).

In this section I want to elaborate relevant aspects of Simmel's thesis more fully, and then argue by way of a conclusion that social capital should be reconceived as the result of the harnessing - or capitalisation - of sociability. Specifically, I shall focus on three intertwined elements of Simmel's aesthetic of sociability that provide the conceptual resources needed for an alternative account of social capital. First, Simmel stresses the formal character of sociability - it is form, not content, play, not purpose, expression, not argument, creativity, not rationality or normativity, that are constitutive of sociability. Second, sociability is on Simmel's account a synthetic form of association that tames individualism without dissolving individual autonomy-in sociability, individual expression is enabled and limited by associational form. Third, sociability has a kind of sociologised Kantian core - cooperation among equals inheres in the formal structure of this "play-form" of association. I want to take up Simmel's discussion of each of these features in turn.

1) In order to capture the formal aesthetic structure of sociability, Simmel focuses on the dimensions of art and play inherent in certain forms of human interaction and association. He singles out, for example, social arts (such as the art of conversation), social games (such as coquetry), and social forms of play (such as gymnastics and other sports) in which human expression is not adequately conceived of as a by-product of the pull of rational interests, the push of pre-established communal norms, or the power of socioeconomic class. Instead, in these kinds of play-forms of association creative expression constitutes human interaction not as a means to an end but rather as an end in itself. Sociability is a form of association whose formal expressive character cannot be reduced to any strategic interest or determinate content. It is human interaction freed of instrumental purpose and objective content - a kind of relation that, as Simmel says, is nothing but relationship (1949: 259). In sociability, the concrete aims of individuals and groups recede, and, argues Simmel, the "contents and purposes of human intercourse... have their meanings in themselves...in the excitement of the play of relations which they establish between individuals" (1949: 259). More concretely, Simmel's point here is that the formal structure of sociability is akin to that of dancing the tango: the relationship between the dancers is the dance. Like "the tango", sociability exists and has meaning only in the relations between those individual actors whose interactions constitute it.

2) This insistence on the aesthetics of human interaction and association allows Simmel to address the question of what happens to individuals engaged in such associational relations unhampered by the kinds of presuppositions 
characteristic of the rational, normative, and class-determined models of action we saw in the previous section. For Simmel, the formal character of sociability means that sociability's only content is individuals, or what Simmel calls "personalities"; indeed, Simmel says that insofar as sociability has "no ulterior end, no content, and no result outside of itself, it is oriented completely about personalities" (1949: 255). And yet it is precisely because of its formal dependence on its individual elements that the personalities that comprise the content of sociability "must not emphasize themselves too individually" (1949: 255). Those individuals who present themselves as holders of social position, cultural prestige, and economic power, have no place in sociability because they destroy the play-form character of sociability with the concrete weight of their determinate content and specific aims.

What prevents actors from such individualist over-determining of their sociable interactions is a unique form of constraint that emerges within sociability itself. Simmel calls this situationally emergent constraint on individualism "good form" and a "sense of tact" (1949: 255-256). Good form "is mutual self-definition, interaction of the elements, through which a unity is made" (Simmel 1949: 255). While tact is what "guides the self-regulation of the individual in his personal relations with others where no outer or directly egoistic interests provide regulation" (Simmel 1949: 256). Put somewhat differently, sociability cultivates and relies upon autonomous individuals' mutual exercising of a highly reflexive sense of appropriateness. Such a reflexive sense marks out not only what is fit for a particular individual but also circumscribes for that individual "those limits which the rights of others require" (Simmel 1949: 256). Sociated actors are thus not unlike musicians in a jazz ensemble: their expressive freedom is both enabled and limited by a kind of self- and other-monitoring reflexive individuality.

3) Along with its aesthetic form and cultivation of reflexive individuality, Simmel's conception of sociability also retains in its very features the nonoutcome oriented social norm characteristic of shared cooperative action. Simmel calls this the "principle of sociability" and, paraphrasing Kant, formulates that principle in the following way: in sociability "everyone should guarantee to the other that maximum of sociable values (joy, relief, vivacity) which is consonant with the maximum of values he himself receives" (1949: 257). Or, as Simmel puts it a bit later in his essay, the "free interaction and equivalence among the elements... is the fundamental condition of sociability" (1949: 258). Yet for Simmel such a principle is not an a priori ethical duty applied by a rational will in itself, as it is for Kant. The cooperative principle of sociability is not generated by a dissociated mind engaged only in rational justification. Instead, the transcendent social norm of cooperation is immanent in the very aesthetic activity of sociability itself (Simmel 1949: 257). Here we may 
draw together the previous allusions to the tango and jazz to clarify Simmel's sociological adaptation of Kant. What makes possible the unique kind of shared cooperation dancing the tango and playing jazz requires is not a rational (or duty-bound) agreement among individuals established in advance of their creative joint endeavours; rather, such cooperation emerges in and is in fact principally constitutive of sociability.

\section{Capitalising Sociability}

Understood in the way elaborated above, Simmel's aesthetic model of association may be productively contrasted and compared with the actiontheoretical assumptions of the current strains in social capital theory, and the beginnings of an alternative account of social capital can be brought into view by way of a conclusion. In eschewing a rational model of action in favour of a sociological conception of creativity, Simmel does not reduce social norms to rational ones. Yet Simmel also does not err in the other direction by normatively over-inflating such social norms as causal powers of democracy tout court.

To be sure, Simmel does, like Tocqueville before him and Putnam after him, see the "democratic structure of all sociability" (Simmel 1949: 257) implicit in the social norm of cooperation. But unlike the democratic strain in social capital theory, Simmel takes seriously the difficulty of generalising the democratic structure of sociability between and among social classes; indeed, for Simmel, this democratic structure can at best be realised only within social strata, not up and down the social ladder (1949: 257). Moreover, however aware of the problem posed by social stratification for the generalisability of the democratic structure of sociability, Simmel does not, a la Bourdieu, homologise the relationship between sociability and social class. Play-forms of association do not merely mimic social hierarchies and their stratifying norms of consumption, any more than art and play merely mimic reality.

For these reasons Simmel's sociology of sociability does not encounter the action-theoretical limitations of the dominant strains in contemporary social capital theory. Simmel's thinking on sociability-which, as we have seen, pursues an aesthetic theory of association from within the framework of the sociology of creative action - has none of the reductive, inflationary, or deterministic elements that weaken contemporary work in social capital theory and research. In fact, such a socio-aesthetic theory of human association provides fertile action-theoretical ground for theorising social capital anew.

Specifically, an alternative theory of social capital that draws on and yet seeks to move beyond Simmel's account of sociability rests on two parsimonious premises. First, sociability is human association in its aesthetically distilled or formally concentrated state; it is inchoate social energy. Second, the 
harnessed or capitalised form of that energy is social capital. This sense of social capital thus turns on a fundamental distinction badly obscured in all three of the current strains in social capital theory - a distinction between the inchoateness of sociability and the second-order harnessing or capitalisation of that play-form by those whose interactions constitute it. Maintaining such a crucial analytic distinction allows social capital theory and research to hold open, rather than predetermine in its action-theoretical assumptions, what is ultimately an empirical question about the rational uses, democratic effects, or stratifying power of human interaction and association.

It also allows social capital research programmes to pursue new questions using more ethnographic approaches. Indeed, rather than founder on one-sided theories of the rationality or normativity of human action and empirical confusions about how best to survey the ostensible causes and effects of social capital, social scientific research devoted to the study of capitalising sociability requires meso- or street-level ethnographic descriptions of sites of sociability and analyses of the ways in which sociability is harnessed (or remains unharnessed) by actors situated in such sites. Though not developed within the framework of social capital theory, a potential model for what a social capital research programme carried out using an ethnographic approach to the study of sites of sociability might look like can be found in Loic Wacquant's fine-grained participant-observer account of boxing clubs in the United States. Wacquant shows how boxing gyms function as sites of sociability or, as he says, the loci of "forms of social interaction devoid of significant purpose or endowed with socially anodine contents, processes of pure sociation that are their own ends" (Wacquant 2004b: 37).

Admittedly, the sociability specific to these particular sites remains, as Wacquant's work makes painfully clear, largely un-capitalised. Yet it is precisely for this reason that an ethnographic approach to the study of social capital also needs to make explicit the embeddedness of sites of sociability and processes that harness (or obstruct the harnessing of) sociability in larger institutional contexts and socioeconomic structures. Such an approach, that is to say, must consider the complex role that various macro-level forces play in shaping sites of sociability and how sociability is capitalised at the meso-level. But in so doing, ethnographies of sociability and social capital formation need not reiterate the deterministic tendencies that, for all their descriptive richness, so often plague the work done within the Marxist strain in contemporary social capital theory. The embeddedness of sites of sociability and processes of sociability capitalisation does not, at least not on the alternative account I have begun to outline here, homologistically determine how sociability is harnessed or goes un-harnessed at street-level. On the contrary, to rethink the theory of social capital in the way that I have sought to in this essay is to claim that it is 
ultimately the effervescent sociability of human interaction and association, not macro-structural forces, that is the creative source of social capital. ${ }^{23}$

${ }^{1}$ For a fine-grained conceptual history of the origins of social capital theory, see Farr (2004).

${ }^{2}$ Perhaps the best single volume collection devoted to elaborating the rational strain in contemporary social capital theory is that edited by Dasgupta and Serageldin (2000). Contributions of particular relevance here include Solow's notes on social capital and economic performance, Coleman's discussion of social capital and human capital, and Dasgupta's exceptional overview of the link between economic progress and social capital.

${ }^{3}$ The democratic strain in social capital theory, which has its origins in Tocqueville, is examined in a comparative perspective in Edwards et al (2001), and developed most fully by Putnam $(1993 ; 1995 ; 2000)$.

4 The defining texts in the Marxist strain of social capital theory remains Bourdieu's own studies of taste (1984) and higher education in France (1988; 1996).

${ }^{5}$ A schematically similar summary but rather different critique of contemporary social capital theory can be found in Baron et al (2000).

${ }^{6}$ Indeed, Becker maintains that the "combined assumptions of maximizing behavior, market equilibrium and stable preferences, used relentlessly and unflinchingly...provides a valuable unified framework for understanding all human behavior" (1976: 5-14).

${ }^{7}$ For a related attempt to situate the model of economic action in social structures, see Granovetter (1985).

${ }^{8}$ Becker has also made the social turn in his recent work on "social economics" (2001).

${ }^{9}$ For a more far-reaching discussion of the epistemology of trust in the theory of rational choice, see Hardin (1993; 2000).

${ }^{10}$ For a fine discussion of the implications of social capital for development theory, research, and policy, see Woolcock and Narayan (2000); for the World Bank's 'Integrated Questionnaire for the Measurement of Social Capital', see also Grootaert, et al (2002).

11 The concept of plural subject phenomena is developed in Gilbert (1989); wephenomena are extensively elaborated in Tuomela (1995).

${ }^{12}$ For an attempt to specify what types and features of associations are most likely to produce democratic effects, see Warren (2001).

${ }^{13}$ See especially Bourdieu $(1977 ; 1990 ; 1998)$.

${ }^{14}$ On the theoretical and practical existence of groups as "social classes", see especially Bourdieu (1987). For a fine historical account of how classes are made largely independent of the intentions and associations of those who belong to them, see Thompson (1966).

${ }^{15}$ In this context, see especially Bourdieu's study of the social character of taste (1984).

${ }^{16}$ Bourdieu's attempt to define his use of the term social capital appears throughout his work, but is most concisely formulated in his essay on the forms of capital: "social capital is the aggregate of the actual or potential resources which are linked to possession of a durable network of more or less institutionalized relationships of mutual acquaintance and recognition - or in other words, to membership in a group - which provides each of its members with the backing of the collectivity-owned capital, a 
"credential" which entitles them to credit, in the various senses of the word" (1986: 248249).

${ }^{17}$ For a more detailed discussion of Bourdieu's critical method of reflexive sociology see Bourdieu and Wacquant (1992); see also Lewandowski (2001).

${ }^{18}$ For a critique of the individualism of rational choice in the context of social capital theory, see especially Fine and Green (2000).

${ }^{19}$ For a useful discussion of thick and thin logics of trust, and the limited relevance of trust levels for democracies, see Uslaner (2001).

${ }^{20}$ For a persuasive discussion of the distinction between rational norms and social norms, see especially Elster (1989).

${ }^{21}$ Recent attempts to link Bourdieu's thinking to democratic politics include Lee (1998) and Wacquant (2004a).

${ }^{22}$ For a more detailed critique of Bourdieu's theory of practice, see Lewandowski (2000).

${ }^{23}$ I am grateful to those conference co-participants at the "Whither Social Capital?" International Conference who offered helpful comments on and insightful criticisms of a much earlier draft of this paper, and willingly shared their own research with me. 


\section{CHAPTER THREE}

\section{THE MEANING AND UTILITY OF 'SOCIAL' IN SOCIAL CAPITAL}

\section{BARBARA ARNEIL}

In recent years there has been a surge of academic and political interest in the "social" sphere, as represented by the rising popularity of the terms "social capital" in Canada, America and the UK and "social cohesion" in continental Europe. The question I want to address is twofold: what is the meaning of social within "social capital" and why does it have such utility at this particular juncture in history? In order to answer the first part of this question it is necessary to examine the text of Robert Putnam's Bowling Alone as well as the scholarly tradition from which it emerged ${ }^{1}$; to answer the second we shall explore the general social, cultural and economic forces currently at work in a select number of industrialised liberal democracies who deploy the idea of social capital and their specific political concerns to discover why social capital has become so useful for framing domestic policy initiatives.

\section{The Three Constitutive Threads of "Social"}

Three normative threads constitute the "social" of Robert Putnam's social capital theory. The first thread is a liberal thread of citizen participation and association, the goal of which is a vibrant and robust civic society. Stretching from Alexis de Tocqueville through Sidney Verba and Gabriel Almond's Civic Culture, Putnam's theory is the most recent iteration of this American idea of democracy as a "nation of joiners". But while Putnam's theory (and his definition of the "social" sphere) is most often interpreted in this vein as neoTocquevillian (including by the author himself), a second important dimension is a neo-republican commitment to the goal of cohesion or unity within civic society. While dating back to the very foundations of the American state, the ideal of transcending difference has a particular appeal at this point in history as we shall discuss. The third thread is nostalgia for the past - in this sense the 
social is inevitably in decline in social capital theory and practice with scholars and political actors comparing the current state of community or the social sphere as one of collapse or crisis in relation to some mythical point in the past when the community is seen to be more united and/or robust. Let us consider each of these threads in more detail in order to determine the specific meaning of "social" in social capital.

\section{The Liberal Thread: "A Nation of Joiners"}

To the extent that Putnam emphasises civic participation and joining, the "social" in social capital is neo-Tocquevillian. The social is a diversity of voluntary relations between individuals in the private sphere and is the opposite of the coercive and unifying power of public law. Will Kymlicka comments: "Liberalism involves a 'glorification of society', since it supposes that the private (non-state) associations which individuals freely form and maintain in civil society are more meaningful and satisfying than the coerced unity of political association." (2002: 388-9) While rooted in a long tradition in America, this renewed focus on civic society has a particular meaning in contemporary western political theory and practice. It represents an important shift in focus away from either the state or citizen to the civic space in between. In this regard, the social capital thesis parallels two influential schools of thought within contemporary liberal democratic theory, namely communitarianism and third way theory. In all three cases, civic space or community is the starting point of analysis, rather than either the rights bearing citizen of liberalism or the equality bearing state of socialism or social democracy.

This theoretical shift is relatively young, but its potential significance is profound. It provides a theoretical platform from which to critique both the "old" left and its commitment to a universal welfare state and the "new" right's commitment to hyper-individualism/ materialism and neo-liberal ideology as shall be discussed in more detail below. In the American context, this focus on civic society and its revival has a particular religious focus. As Putnam comments at the conclusion of Bowling Alone: "Faith based communities remain such a crucial reservoir of social capital in America that it is hard too see how we could redress the erosion of the last several decades without a major religious contribution" (2000: 409). This idea of what is now being called "spiritual capital" or "faith based initiatives" underpins both Bush's compassionate conservatism and to a lesser extent Blair's idea of community cohesion, but in very different ways. 


\section{The Republican Thread: "E pluribus unum"}

Putnam's definition of "social" goes well beyond participation and free association to simultaneously endorse a more republican vision of civic cohesion and unity. This aspect of the "social" is explicit in Putnam's theory, as he makes clear in describing the dominant theme of Bowling Alone in its introduction:

The dominant theme [of Bowling Alone] is simple: For the first two-thirds of the twentieth century a powerful tide bore Americans into ever deeper engagement in the life of their communities, but a few decades ago - silently, without warning - that tide reversed and we were overtaken by a treacherous rip current. Without at first noticing, we have been pulled apart from one another and from our communities over the last third of the century. The impact of these tides on all aspects of American society, their causes and consequences and what we might do to reverse them, is the subject of the rest of this book (2000: 27, emphasis added)

This ideal of America "coming together" underpins the original motto of the United States: "e pluribus unum" which means "from many comes one". Thus, like the Tocquevillian liberal thread, the republican thread also has a long pedigree in the history of American ideas. Indeed, one of the central debates amongst historians of American ideas is whether the original philosophical foundations of the American state were republican (emphasis on unity and virtue) or liberal (emphasis on individual rights, conflict and materialism). At the heart of Putnam's neo-republicanism is the ideal of a national unity that transcends difference and a civic virtue that counters narrowly defined selfinterest.

The republican ideal of unity is also implicit in the functional use of "shared norms" and trust in Putnam's theory. Putnam's norms (or reciprocity and trustworthiness) seem to be nothing more than procedural rules that simply arise from greater connectedness rather than normative or substantive norms. ${ }^{2}$ But underlying the norms of reciprocity and trustworthiness are, as we shall discuss, a set of substantive cultural norms in American society. While Putnam is not willing to admit that there are substantive as opposed to procedural norms necessary for social capitalisation, other academics and institutions do generally recognise and even enumerate the kind of norms required for the functional model of social capital to work. For example, the OECD definition of social capital is "networks together with shared norms, values and understandings that facilitate co-operation within or among groups" (OECD 2001). This definition confirms that it is not just reciprocity or trustworthiness that is at stake but also the unmistakably normative and substantive "values and understandings" of functional social capital. 
Because Putnam's definition of social capital theory sees norms as simply "arising from" connections, there is no explicit reference to the need for enforcement. But, once again, other scholars argue that there is a need for sanctions if norms are to work. James Coleman is the first to refer to socially capitalised communities as ones that have "social structures that make possible social norms and the sanctions that enforce them." (1988: 116, emphasis added) A discussion paper prepared by the UK government follows Coleman, and concludes that sanctions defined as "processes that help to ensure that network members keep to the rules" are required for functional social capital to work (Aldridge et al. 2002: 11). There is at least one example of an explicitly enumerated list of enforceable "shared norms" underpinning social capital. Rosalyn Harper, of the British Office for National Statistics (ONS) states: "the role of sanctions in underpinning norms is important. Examples of how these manifest themselves are: not parking in a disabled parking space at a supermarket; giving up your seat for an elderly person; tolerance of people of a different race, religious group or sexual orientation; looking after each other's house when neighbours are absent; and doing voluntary work." (2002: 3) As Harper suggests, "shared norms" are not simply procedural rules that "attend" social capital theory but cultural norms embedded in the "majority" of any particular society. While one might not want to argue with the particular list of "norms" provided by Harper, one needs to assume that these are indeed the shared norms of the majority in British society. Are there other majority norms that might be more threatening to various minority groups? While he is not as explicit, the shared norms underpinning Putnam's theory are also those of the majority culture in America. I am not sure therefore, given the results of the referendum questions in the 2004 American elections on same sex marriage whether "tolerance for people of a different sexual orientation" would necessarily be part of the cohesive norms that bring people together or whether this norm is one that would profoundly divide.

Ultimately, it is assumed in social capital theory that whatever general values and understandings a majority share in a liberal democracy must be good for all and the sanctioning of those who do not conform is a legitimate price to pay in order to reap the benefits of a more connected community that both glues people together as a whole and lubricates interactions between them. Taken together, however, the functional need for enforceable shared norms points toward a potentially coercive aspect of social capital theory in which the norms of the majority are enforced through the weight of civic society rather than the state itself. As J. S. Mill once observed, public opinion may be as threatening to individual and minority freedom as anything the state might do, or as Alexis de Tocqueville noted, it is majority will that constitutes the most threatening feature of American democracy both to minorities' rights and individual dissent. 
The republican focus on unity is also embedded in Putnam's theory in the role that "trust" plays in his functional model; specifically, as social capital is transformed from individual participation to generalised trust (the lynchpin of his theory). First, despite references to "well tossed spaghetti", Putnam's theory is rooted in a causal relationship that goes from participation/connections to trust. Putnam and Goss comment: "Dense networks of social interaction appear to foster sturdy norms of reciprocity ... Social interaction ... [encourages] people to act in a trustworthy way when they might not otherwise do so" (Putnam and Goss 2002: 7, emphasis added). Because Putnam assumes that "trusting" arises naturally from participation, he seems to assume that it is nothing more than a functional vehicle through which to create cooperation. But, it turns out that a trusting community as opposed to a community of "joiners" actually transforms the meaning of "social" from the liberal idea of voluntary association (where there will be conflict, diversity and deep differences in values) to a republican idea of community that tends towards transcendence of difference through cultural homogeneity and shared moral values.

Eric Uslaner provides evidence from aggregative data analysis of the empirical difference between a liberal society of "joiners" and a republican community of "trusters". Trusters, he concludes, exhibit a "unitary temperament" towards the community as a whole and a fundamental belief in the need to share a "common culture" (2002: 197). Trusting people therefore are "especially likely to say that ethnic politicians should not serve their own communities... [and] are wary of the claim that high school and college students spend too much time reading classic literature" (2002: 197). Trusting individuals therefore are tolerant of difference so long as those differences fall within the dominant understanding of shared values and are prepared to sanction those who want to differentiate a particular group from the whole. Uslaner concludes: "Trusters walk a fine line between empowering minorities and telling them how their politicians should conduct themselves and what the curriculum in their schools should be. This tension is the 'price' of a common vision underlying the culture." (2002: 197) Secondly, as Ronald Inglehart makes clear, trust is highly correlated in cross-national comparisons with Protestantism. Indeed, he concludes it may be that religion is one of two determining factors in the level of trust. "The results of this analysis suggest that a given society's religious heritage may be fully as important as its level of economic development in shaping interpersonal trust." (1999: 96)

Thus, if one wished to construct the most trusting hypothetical community in America, it would be a culturally homogenous community, with a reawakened Protestant church and dominated by a middle class set of values. Multiculturalism and diversity in this social capitalised community are always "challenges" to be managed, overcome and transcended in the search for a 
common centre that will yield both the necessary lubrication for cooperation and glue to unite all. What Putnam fails to do in this functional push towards a more trusting society is either acknowledge the role that majority cultural norms play in underpinning his model, or explore the extent to which a civically united society will come at the expense of cultural diversity. Ultimately, functional social capital theory built upon trust and shared norms threatens a liberal civic society rooted in difference and conflict but, to an even greater degree, a multicultural society rooted in the recognition and preservation of group difference. Michael Mosher describes these two distinct ways of understanding civil society in the following way: "Either you want civil society because it is a transmission belt for the dominant republican values... or you want civil society because it entrenches diverse values." (Mosher 2002: 208) Putnam's social capital theory ultimately gives rise to the former meaning of social over the latter.

\section{The Nostalgic Thread: The Social as Decline}

Finally, there is within Putnam's social capital theory (in both its participatory and republican threads) an underlying nostalgia for the past. This nostalgia has both an empirical and normative dimension. Empirically, the past provides the reference point from which to measure quantitatively the decline in the present. The Progressive Era (the first two decades of the $20^{\text {th }}$ century) also provides in chapter 23 of Bowling Alone, Putnam's normative model for a socially connected and united community of the future. This vision of a glorious socially capitalised past, however, overlooks the extent to which participation was constituted in profoundly exclusionary ways (based on race, class, gender and religion) and unity was rooted in both discrimination (against African Americans and women) and assimilation (of non Protestant immigrants and indigenous Americans) and it causes those who adopt this vision of social capital as one of decline to see history through rather rose-tinged glasses. Ultimately the vision of a glorious past is largely myth, for the norms that held such communities together were unjust and, as such, contested by those subject to them. In other words, civil society in the Progressive Era was not so much united but "pulling apart" in the name of diversity and justice, a process which only intensified over the second half of the century.

\section{The Impact of 9/11 on Social Capital Theory and Practice}

In Bowling Alone, Putnam argues that the biggest reason for the decline of social capital in America is generational change, because the older generation participates more than the younger generation. The single most important 
variable is the impact of the Second World War. ${ }^{3}$ Putnam goes on to argue, based on this historical model, that a national crisis like World War II would be the best thing for civic renewal. The aftermath of the tragic events of September 11, 2001 provided that opportunity. "In the aftermath of September's tragedy, a window of opportunity has opened for a sort of civic renewal that occurs only once or twice a century." (2002) Thus, after 2001, a new nationalist spin is added to the goal of civic renewal and rather than a liberal vision of civic society as a check on the state, this new world vision sees civic society as a vehicle for furthering the state's interests. In an op-ed article in the New York Times about a month after September 11, Putnam uses Pearl Harbour as his historical metaphor, arguing that such attacks against a nation, while terrible in their own right, also represent opportunities for new kinds of "cooperation between the federal government and civic society", if young people are "taught practical civic lessons"; churches "plan interfaith services over Thanksgiving weekend" and adults ensure "resurgence of community involvement" through an appeal to "deeper community connections" (Putnam 2001).

This new spin of social capital: a marriage between national crisis and civic renewal coupled with the power of faith raises troubling questions. The republican thread of social capital is now linked to a goal of national as opposed to community cohesion or unity; and the liberal thread of civic participation is now linked to "national security". Secondly, civic solidarity at a time of national crisis is always constructed in opposition to an enemy. Unlike the Second World War, the enemy that attacked on 9/11 was not a foreign state across the ocean but members of a network who lived within the very communities they attacked. As such, the civic service expected of American citizens in light of 9/11 becomes vigilance against an internal threat within their own communities, creating a particular kind of dynamic in American communities that could threaten both the civil rights of individuals and the collective rights of cultural minorities, most particularly Islamic and/or Arab Americans.

As Cathy Young argues in an op-ed piece in the Boston Globe, in response to Putnam's article in the New York Times: "War-inspired civic virtue also has its less attractive side. For one, what brings us together is not just love of our country but hatred and fear of the enemy...Could it be that what we gain in shared values, we may lose in pluralism and healthy dissent?" (2001: A23) Moreover, history attests to the impact on specific ethnic minorities within American communities when civic solidarity is built upon patriotic foundations at comparable historical junctures. John Sanbonmatsu (2001), writes in a letter to the editor of the New York Times:

Robert Putnam's case for cherishing World War II and our present crisis as boons to the American civic spirit would have been far more convincing had he acknowledged the violence, xenophobia and racism that typically attend such 
unifying moments....the convivial spirit in America did not extend to all, particularly to the 100,000 Japanese-Americans herded into camps (including my own family). Today of course, it is Arab-Americans who are bearing the brunt of the "deeper community connections" that Mr. Putnam celebrates.

Putnam's own post 9/11 survey demonstrates that these concerns are well founded. In the fall of 2001, the Saguaro Seminar at Harvard conducted a follow up interview to the Social Capital Community Benchmark Survey of 2000 to measure any changes in attitudes that had occurred as a result of 9/11. At first glance, the changes from one year to the next seemed to be positive in relation to multiculturalism. Putnam finds that across most racial and class boundaries, people seemed to trust each other more than before September 11 (Putnam 2002). But consistent with the worries of John Sanbonmatsu, is that ArabAmericans are being treated differently. Thus Putnam found that the level of trust towards Arab-Americans as a whole was about $10 \%$ less than other ethnic minorities. The other finding in the 2001 study that gives further cause for concern is the change in attitude towards immigrants. The change in the percentage of Americans supporting immigrant rights before September 11 and after is $-11 \%$ (Saguaro Seminar 2000). New immigrants are clearly facing significant antipathy within the broader American society.

\section{The Rise of Social Capital: Why Now?}

\section{The Liberal Thread: Civic Society as Alternative to Left and Right}

The liberal thread of Putnam's theory, as argued above, defined the social as the civic sphere. This focus on civic society provides a platform for critiquing both the old left's defence of the welfare state and the neo-liberal's championing of a pure market model thus providing a vehicle for both the "new left" of Tony Blair and the "compassionate conservatism" of George Bush. On the one hand, the rise of such terms as social capital, social cohesion and social development in the 1990's (around the UN Summit on Social and Economic Development in Copenhagen in 1995) provided the "new left" with a language to respond to the hyper-individualism, market discourse and materialism of the 1980's, as defended by neo-conservatives Margaret Thatcher and Ronald Reagan. The emphasis on the "social" sphere and relations between people serves as a corrective to the idea that "there is no such thing as society" (Thatcher 1987). On the other hand, the critique of the universal welfare state and social spending was also useful both to the new left and "compassionate conservative" right as they continued to engage in fiscal restraint particularly of the social spending envelope but sought the means for cushioning these cuts in the language of "welfare reform" through expansion of the "voluntary" sector. The post war 
ideal of social citizenship rooted in T.H. Marshall's social rights and the universal welfare state is replaced at the end of the $20^{\text {th }}$ century by social capital where the state transfers delivery of social services to community organisations. Thus, a revived civic society is used to critique the state and justify shrinking it in both financial and ideological terms (often couched in the language of "reforming" or "modernizing" the welfare system). ${ }^{4}$

\section{The Republican and Nostalgic Threads: Unity or Cohesion in Insecure Times}

The republican appeal of "unity" or "cohesion" in social capital theory speaks to the times we are living through, most particularly the backlash against those forces that are seen as dividing communities around the world: cultural politics and multiculturalism, immigration and demographic change, as well as 9/11 and the threat of terrorism. First, with respect to multiculturalism, the language of fraternity, solidarity and unity pushes in direct opposition to the emphasis on difference and diversity in post-modern "cultural politics". This is true not only for those on the right, but increasingly for many who count themselves as part of the "new left". Social capital's emphasis on unity and social connections speaks to those on the left who identify with what Nancy Fraser (1998) has described as the politics of redistribution over the politics of recognition. In this sense, social capital is part of a struggle within the modern liberal left over its agenda, most particularly to counter the movement towards cultural or identity politics in favour of fraternity or solidarity. ${ }^{5}$

The specifically nationalist and nostalgic spin on social capital in the wake of 9/11 has particular appeal to state actors in the United States and Britain. It is worth nothing, in this context, that both George Bush and Tony Blair (to launch USA Freedom Corps and the lead article of Renewal, respectively) quote Putnam's shorter post 9/11 pieces linking social capital to national security rather than Bowling Alone. In both cases, the appeal to patriotism and national solidarity are often nostalgic, rooted in some kind of transcendent "traditional values" of the American and British peoples respectively that are under attack by this new phenomenon of "radical" terrorism. Thus the liberal and republican threads of social capital, and in particular the new spin since 9/11 on civic renewal in the face of national crisis make Putnam's theory appealing to politicians and public servants on both sides of the Atlantic. Let us now turn to look in detail how social capital is deployed in the US, UK and Canada. 


\section{The United States: Social Capital and Domestic Policy Initiatives}

In the United States, the Bush administration has deployed the theory of social capital in two key domestic policy initiatives: the USA Freedom Corps and the Faith-based Community Initiatives. In the former, social capital provides Bush with a theoretical basis upon which to marry national security interests with civic renewal. In the latter, social capital provides a theoretical justification for shifting the responsibility for social services away from the welfare state to faith-based organisations. In both cases, the legitimate lines that should be drawn between state and civic society or state and church are not only blurred but somewhat hidden behind the appeal to community and civic renewal.

\section{USA Freedom Corps: The Marriage of National Security and Civic Service}

On January 29, 2002, President George Bush gave his first State of the Union Address since September 11, 2001. Not surprisingly, the events of that day were a central theme in his speech before Congress. "We want to be a nation that serves goals larger than self. We've been offered a unique opportunity and we must not let this moment pass. My call tonight is for every American to commit at least two years - 4000 hours over the rest of your lifetime - to the service of your neighbours and your nation." "President Bush then announced the new USA Freedom Corps, incorporating the AmeriCorps, Senior Corps, a redefined Peace Corps and a brand new civic service/homeland security programme called the Citizen Corps. The USA Freedom Corps handbook, issued within days of the State of the Union Address in January 2002 begins with an explicit reference to Bowling Alone and quotes directly from Putnam's New York Times op-ed piece. "There is more that we can do to tap this spirit [Putnam's call for civic renewal] and one key strategy is for individuals in communities to seek greater involvement with fellow citizens". 7 Putnam, in turn, supported the USA Freedom Corps initiative in the wake of $9 / 11$ as an example of the federal government facilitating social capital building (Sander and Putnam 2002). Thus, Bush and Putnam both see this conflation of national security interests and community service (drawing on the example of the Second World War civic generation) as largely positive.

The worrying implications of blurring civic service with a national security agenda on the civil liberties of individuals and multicultural diversity become concrete in both the Citizens Corps and newly mandated Peace Corps. Within the initial Citizens Corps, the Whitehouse recommended the establishment of a 
Terrorist Information and Prevention System (TIPS) - "a nationwide mechanism for reporting suspicious activity - enlisting millions of American transportation workers, truckers, letter carriers, train conductors, ship captains and utility employees in the effort to prevent terrorism". ${ }^{8}$ In an editorial published in July 2002, the Washington Post challenged the TIPS programme: "Americans should not be subjecting themselves to law enforcement scrutiny merely by having cable lines installed, mail delivered or meters read. Police cannot routinely enter people's houses without either permission or a warrant. They should not be using utility workers to conduct surveillance they could not lawfully conduct themselves". 9 Beyond the implications for all citizens, with respect to their civil liberties, there is the particular impact on Arab and Muslim Americans. It is not all Americans who will be targeted by this act but a particular cultural group, which Putnam's research shows, is already subject to more negative views. Thus, the state can package its initiative as "community" programmes knowing that the community will profile groups within the neighbourhood in a way that policy are legally forbidden to do. While TIPS was ultimately shelved when Congress passed the Homeland Security Act in November, 2002 (House Resolution 5005), it nonetheless provides evidence of how far the White House would be willing, particularly in the event of another attack, to use the community as "spies" on their own neighbours, and through an appeal to civic society, sidestep the limitations placed on state actors (police, FBI) with respect to the civil rights.

In addition to the Citizens corps is the Peace Corps with a new emphasis: "the administration will work with other countries that do not have Peace Corps volunteers, including more Islamic countries". ${ }^{10}$ President Bush clarifies the underlying reasons for this shift in a public appearance in Philadelphia in March 2002:

If there are any people interested in spreading US values around the world, the Peace Corps is a wonderful place to do so.... Our goal is...to make sure we have the Peace Corps go to nations, particularly Muslim nations, that don't understand America. They don't understand our heart; they don't understand our compassion; they don't understand that we share the same values...the Peace Corps is a good way to spread that message. ${ }^{11}$

Thus, under the Bush administration, the Peace Corps shifts from "helping others to help themselves" to "spreading" American values particularly in Islamic countries. Once again the mixing of political objectives with civic service, packaged under the rubric of "helping others" expands to include an Islamic world that lacks understanding with respect to American values and 
once again social capital is used to serve larger political agendas of the Bush administration.

\section{Faith-based Initiatives: The Marriage of Church and State}

Robert Putnam's Saguaro Seminar at Harvard published a report entitled Better Together in 2001 with recommendations as to how to rebuild American communities. The first recommendation in chapter five (on religion and social capital) is to "increase secular funds for faith based organizations" (Saguaro Seminar 2000). It is worth noting that the Saguaro Seminar included amongst its participants, John J. Dilulio, the first Director under President Bush of the White House Office of Faith-Based and Community Initiatives, serving as assistant to the President during 2000-2001 and Stephen Goldsmith, chief domestic policy advisor to George Bush during the 2000 campaign, and a Special Advisor after the election to the President on "faith-based and not-for profit initiatives". ${ }^{2}$ Within a month of the publication of Better Together, President Bush (on January 29, 2001) signed two Executive Orders that created a high-level White House Office of Faith-Based and Community Initiatives. The White House was explicit in making the link between social capital and these new initiatives: "Our goal is to energize civil society and rebuild social capital". ${ }^{13}$

The debate that ensued between the House, Senate and White House largely centred around discrimination in hiring versus religious organisations' right to hire adherents of its faith, but as an editorial in the Washington Post points out, the deeper questions raised by these initiatives fell out of view in these skirmishes:

The real question is how engaged the government should be in the first place with groups whose religious missions are hard to separate from the secular functions the government wishes them to serve. Can America have a partnership between federal agencies and religious groups that harnesses the promise of faith-based action without the government sponsoring religious doctrine, coercing its citizens or otherwise endorsing religion? The issue of religious discrimination is only one feature of this larger question -one it should not be permitted to dominate. ${ }^{14}$

Under existing executive orders and with the potential expansion of the programme either under the auspices of the White House or through state budgets, troubling questions remain about the overlap between church and state and its impact on vulnerable cultural minorities. For example, the degree to which churches (or other religious organisations) may use federal funds to proselytise their religious message is still unclear or the impact of de-regulation of social service delivery in the name of religious freedom has on vulnerable populations. On this latter point, there is some evidence that deregulation puts 
those who are most vulnerable at risk as a report into George Bush's faith based initiatives in Texas concludes:

Faith based deregulation endangers vulnerable populations. It has proven dangerous to exempt social service providers - simply because they are faithbased - from the health and safety regulations expressly created to protect vulnerable populations like children and chemically dependent people. There is no question that eliminating basic health and safety standards made operations easier for a few faith-based programmes in Texas, but it has also jeopardized the well being of clients served by these facilities. ${ }^{15}$

Perhaps the most troubling aspect of the faith-based initiatives is the way in which, like the TIPS programme, the Bush administration uses the social capital language of civic renewal and community as a way to potentially circumvent the proper limitations on the state, in this case, the church/state separation. As Don Eberly, former deputy director of the White House Office for Faith Based Initiatives comments in an interview on National Public Radio in the US: "Let us sort out the issues of church and state in the context of public policy, but separate out those questions from the issue of the relationship of religion to community." (Emphasis added) This suggestion is deeply worrying, for it would seem to follow that if the federal government delivers social services through the community, the issue of church/state boundaries need not apply in the same way.

Thus both the republican emphasis on unity and the liberal emphasis on participation are reflected in President Bush's deployment of social capital. What I have tried to show is the extent to which the invocation of "community" as a soft and fuzzy concept can be used by the state to achieve goals that might otherwise be challenged. With faith based initiatives, the church is used to soften the blow from cuts to the welfare state; as such social capital provides the means by which Bush can reduce resources going to the needy while still defending himself as a "compassionate conservative". Social capital also provides a way of getting around the church/state problem; by invoking the idea of "community" and using local churches as its surrogate, Bush's goal of changing the "hearts and souls" of its citizens through religion is made much easier constitutionally. Similarly, the national security/civil liberties problem, particularly for Muslim Americans, is more easily circumvented if you ask neighbours in "neighbourhood watch programmes" or community members in a TIPS programme to do the investigative work of federal authorities. These are the potential dangers of allowing "community" revival to blur too easily into the idea of either a reawakened church saving souls or a nation state seeking security within its borders. 


\section{Britain - Social capital, Civic renewal and "Britishness"}

Tony Blair, like George Bush, has championed social capital and civic renewal with the same emphasis on "active citizenship" and "national cohesion" (Blair 2002). In the lead essay of a special volume on the subject of social capital in the Labour journal, Renewal, (2002), Blair begins with a reference to Putnam's American Prospect article linking social capital with the response to terrorism and speaks of a similar need in Britain for strong communities in the wake of 9/11. "Just as 11 September forces us to deal with the consequences of global inter-connectedness, it gives us a chance to renew bonds between individuals". (2002:18) Blair aligns the liberal left of Britain with both Putnam and Bush: "I share that ambition of civic renewal for our country. It is a central goal of New Labour in the second term and it require engagement from all on the centre-left". (2002: 9) As was suggested above, the link between national security and civic society is premised upon a common enemy both outside and within the communities of Britain.

The liberal thread of social capital, and more particularly the critique of the welfare state comes through in Blair's observation that "the state can sometimes become part of the problem, by smothering the enthusiasm of its citizens." (2002: 12) Thus Blair concludes: "We...need to do more to give power directly to citizens...the key now is to [free] up the public sector" (2002: 11). Social capital provides the language of civic renewal to buttress New Labour's critique of the welfare state while justifying its reform in softer packaging. ${ }^{17}$ Like Bush, Blair has championed the power of faith in reviving communities and civic renewal. Thus in a speech to Faithworks in March 2005, Blair argues:

The voluntary sector, including the churches and faith communities, have always played a significant role in social action in Britain...But in terms of social action and commitment, community by community, it is your revival and adaptation which are striking...I would like to see you play a bigger not a lesser role in the future.

The republican thread of unity is also central to the appeal of social capital in the British context. As Blair comments: "Labour believes in a 'fraternal' community, where our relationship with each other is not just instrumental or efficient, but based on inter-connectedness and common values." (2002: 9) This republican emphasis on common values and even a common identity, first expressed as "e pluribus unum" in the United States finds a strange resonance in the current British context, with a new focus on "Britishness". Tony Blair, in the conclusion of his article on social capital is the first to enunciate a possible set of norms that might defined "Britishness": "We share a fundamental belief in creating a fraternal community based on values of equality, freedom, fairness 
and diversity. Pursued without dogma, those are also the values of the British people" (2002: 14: emphasis added). David Blunkett, in a speech given July 7, 2004, also speaks to the need for shared values in a section entitled "An Inclusive Notion of "Active' British Citizenship": "We want people from all backgrounds to feel confident about their identity and to have respect for other people's identity, within a positive, inclusive sense of Britishness, underpinned by values that we all share." (Blunkett, 2004:7)

In the most elaborate articulation of these national values, Gordon Brown on the very same day defines what he means by "Britishness". ${ }^{18}$ The "shared values" of Britain, according to Brown, are rooted in history but provide a balm and antidote to divisiveness posed in today's world by terrorism and multicultural demands.

I want to suggest that our success as Great Britain - our ability to meet and master not just the challenges of a global marketplace but also the international, demographic, constitutional and social challenges ahead - and even the security challenges facing a terrorist threat that has never been more challenging and demands upon those charged with our security never greater - depends upon us rediscovering from our history the shared values that bind us together and on us becoming more explicit about what we stand for as a nation.

Brown's search for commonality speaks to what he calls the "challenges" of multiculturalism. Thus, he creates a dichotomy between those who wish to "retreat into more exclusive identities rooted in 19th century conceptions of blood, race and territory"19 and those that would rather "celebrate a British identity which is bigger than the sum of its parts". Brown is thus part of the new left that uses the idea of solidarity to challenge the sway of the cultural left in contemporary politics. Moreover, like Putnam, Brown's search for civic unity in the present takes him to Britain's past: "The [union] is strong because of the values we share and because of the way these values are expressed through our history and our institutions" (emphasis added). By invoking history in this way, Brown is tapping into the nostalgia (particularly amongst the majority traditional community) for a period in Britain's past which was market by shared values rather than divided by the demands of multicultural politics. As in America, British history has many different sides and the invocation of a glorious past can only be sustained if one ignores the powerful forces of exclusion, assimilation and colonial rule that were necessary to sustain the unity of the kingdom itself as well as the wider British Empire.

Thus what is worrying about nostalgia is the tendency to overlook, as Putnam did with respect to the Progressive Era, the negative aspects of previous periods of history, particularly for women and cultural minorities as well as, in the case of Britain, colonised peoples of the British Empire. The rose-coloured nature of Brown's nostalgia comes into sharp relief when we see his vision of 
the British empire and what it says about the British people in comparison with Linda Colley's in her 1999 Millennium speech on "Britishness" (with the Prime Minister in attendance) from which Brown seems to have selectively borrowed for his own speech. Colley observes of the multifaceted character of the British Empire and people:

The different peoples of these islands have not in the past been a particularly anodyne bunch. English, Welsh, Scots and Irish have all, to differing degrees, been greedy, pushy, intrusive traders and warmongers, aggressive, violent, frequently oppressive, often arrogant and perfidious. They have also been markedly creative, innovative, curious, energetic, outward-looking, busy (Colley: 1999).

Colley's is an interpretation of the British character, that is complex and contradictory, but perhaps most importantly it speaks not only to the positive characteristics of the British entrepreneurs that went from these islands to explore the world but equally to the negative characteristics experienced by those subject to the colonial rule that resulted from these expeditions. Compare this to Brown's version of Britishness:

I believe that because these islands - and our maritime and trading traditions have made us remarkably outward looking and open, this country has fostered a vigorously adaptable society and has given rise to a culture both creative and inventive.

Thus, Brown uses Colley's language selectively in the summer of 2004 to define Britishness eliminating the negative half of her description in order to give the common British identity, rooted in historical shared values, a positive spin. The danger of nostalgia (whether its model is the Progressive Era in the US or the British Empire in the UK) particularly when it is used to define common values in the present and prescribe a "united" future is the tendency to simply rewrite history and erase the experiences of those who were its historically subordinated subjects.

\section{Canada - Moving from Putnam's Function to Bourdieu's Network}

The interest in social capital in Canada is quite distinct from either the UK or USA for a number of reasons. First, in Canada, it is not politicians that have used the language of "social capital" as in Britain or America, but civil servants. The idea has been percolating, at the highest levels of the civil service, as a result of the decision of the Policy Research Initiative (the research wing of the Privy Council Office in Canada) to make "social capital" one of its central 
projects. Like the ONS in Britain, the PRI in Canada held a conference on measurement and co-sponsored a conference with the OECD on the theme of "diversity and social capital". Indeed the twin questions of measurement and the reconciliation of civic unity with multiculturalism and diversity dominate the debate in Canada. The problems posed by both these challenges eventually led the PRI to adopt a different definition of social capital than the functional model deployed by Coleman and Putnam.

The initial interest in Canada in "social capital" was no doubt motivated by the same kinds of concerns we have seen in liberal democratic states including using the empowerment of civic society to critique both the welfare state of the 1970 's and the neo-liberalism of the 1980's. But unique to the Canadian experience was the profound crisis in the 1990's over national unity (a referendum of secession was held in Quebec in 1995) and the decision by the Canadian federal government to respond to this threat by seeking vehicles through which "national unity" could be bolstered. Social programmes, and Canada's commitment to universal access to health, education and basic subsistence is central to the Canadian identity and thus "social cohesion" or "social union" became key discursive tools in the federal government's endless search for national unity. Specifically, in the late 1990's, the federal civil service deployed the idea of "social" union (including the Social Union Framework Agreement, social cohesion and social capital) as alternative ways of framing the federal government's response to the cuts that have occurred in the social spending envelope in the mid 1990's as well as the centrifugal forces in federal/provincial relations. The short cut formula was to transfer more "flexibility" to the provincial governments to deliver social services but within an overarching framework of "social unity". Thus national unity was ironically served through a devolution of power within an overarching federal commitment to social union. Ultimately, however, there is little appetite in Canada, beyond the "I am Canadian" beer ads, for defining a common identity or values that might constitute "Canadianness".

Along with this federal devolution of power in the social arena to provinces is a general orientation of multiculturalism with respect to both national minorities and new immigrants (Helliwell 2003). As the PRI has grappled with these questions of multiculturalism and devolution along with the measurement of social capital, it has shifted its working definition from Putnam or Coleman's functional version towards Pierre Bourdieu's theory of "networks" and resources. Thus, a PRI discussion paper in October 2003 argues: "In contrast to functional conceptualizations, network-based approaches to social capital may offer a much cleaner definition. To this end, many scholars have come to 'rediscover' the work of Pierre Bourdieu on social capital." (2003: 13) One reason for preferring Bourdieu is that his definition avoids the problem of 
circularity, referred to above, where cause and effect, participation and trust are intertwined. But in a second report (2004), the PRI argues that this clearer definition also eliminates the need for "shared norms" and the challenges this poses for a nation state rooted in multiculturalism. Thus the paper compares the need for "norms" in functionalist versions of social capital represented by the definitions used by both the World Bank and OECD with Bourdieu's theory: "[Bourdieu's] definition is, in many respects, more parsimonious than that offered by either the World Bank or the OECD, excluding, for example, both norms and attitudes." Put simply, the network definition of social capital is easier to reconcile with the deep multicultural diversity of Canada and the federal government's rejection of any transcendent shared values, norms or common identity that might define "Canadianess".

But, while the Canadian government has used Bourdieu to anchor its working definition of social capital ${ }^{20}$, it does so without incorporating the critical theory within which the idea of networks is embedded. For Bourdieu, networks and access to resources are shaped by history and power, and those groups that historically have accumulated power are able to define the limits of groups as well as shape the norms by which civic society is governed. Those who bear the weight of this kind of power (either through exclusion or assimilation) in turn have challenged these limits and norms. This is really the story that Bourdieu allows us to tell regarding civic society in the $20^{\text {th }}$ century, not one of common purpose but one marked by cultural power on the one hand and contestation and division on the other. Understood as such, the "pulling apart" of civil society over the course of the last century is not nearly as negative as Putnam assumes but a necessary by-product of the quest for justice by those groups (women and cultural minorities) excluded from or assimilated to the community. Put simply, the central theme in the narrative of the $20^{\text {th }}$ century (pulling apart) when seen from the perspective of historically subordinated groups may not be one of "collapse" or "pulling apart" at all but the, as yet, unfinished and, at times, profoundly divisive story of realising justice.

\section{Conclusion}

To the extent that social capital theory encourages people to join organisations and participate in the lives of their communities, both Putnam and Coleman's theories and those that champion this aspect of their thought are heading in the right direction. But when "civil society" or community and civic renewal is used to either off-load social responsibilities on over stretched community actors without sufficient resources, or to blur what should be hard lines between church and state, or put at risk our most vulnerable populations 
(like children in unregulated child care centres or addicts needing publicly funded counselling), this new emphasis on civic society as social service provider and regulator raises serious concerns about the appropriate lines between government, community and religion. Ultimately, however, the greatest danger of the functionalist social capital model lies in its republican aspirations to unity and cohesion rooted in a nostalgia for the past. There is enormous danger, in response to the "pulling apart" over the last thirty years and the assertion of some "traditional shared" values or identity of a past era, of reversing the important achievements that have been made during this period by both cultural minorities and women in the name of multiculturalism and feminism.

It is necessary, therefore, as a first step, to reject the tendency in the transcendent unity of the "social" in social capital to efface the historical and contemporary reality of profound cleavages in liberal democratic society along the lines of race, class, gender, ethnicity and disability. When talking about the changes in community over the $20^{\text {th }}$ century (which after all is the subject of Putnam's book), it is imperative that the experiences of different groups who were historically subordinated (women and cultural minorities) in America and Britain, as well as those of colonised peoples in the British empire, be separated out and analysed apart from a generalised theory of the community as a whole. Otherwise, in the case of America, the very different experiences of women, gay and lesbian Americans, African Americans, Asian Americans, disabled Americans and Hispanic Americans in relation to the American community and its norms will be entirely lost in a meta-narrative of contemporary "decline" and collapse. In the case of Britain, it means both the good and bad of British Empire will be recognised and embraced. When this history is fully recognised, the social capital vision and its appeal to unity in both the past and present are profoundly altered.

In a post 9/11 world there are additional concerns with the republican nature of social capital. In the United States, it becomes all too easy for the federal government to use the language of civic renewal and community engagement to justify something like the Terrorism Information Prevention System in which community members are to spy on their neighbours suspected of engaging in "terrorist activity" and a renewed mandate of the Peace Corps in which American volunteers are to "spread American values" throughout the world, but most particularly to Islamic nations. The threats to both the civil rights of individuals along with the group rights of particular cultural or religious minorities are clear. Indeed, as was discussed, civic solidarity that is created at a time of national crisis is always done in opposition to "enemies" both without and within. If the Japanese Americans were the target fifty years ago, it's Arab and Muslim Americans that are the potential target now. More broadly, the idea 
first proposed by Putnam that the federal government should be using this renewed civic interest for its own national security purposes dangerously blurs the line between the private world of voluntary associations and networks and the public coercive power of the state. If the line between church and state in relation to faith based initiatives must be made cleaner and harder (and not hidden behind the language of community), the same is true of the line between voluntary service and national security as well as state and civic society.

In the UK, 9/11 has a different but equally worrying impact as deployed by New Labour. The link first made by Putnam between civic renewal and national interests works its way through the speeches and articles of the Prime Minister and senior Cabinet Ministers in relation to defining and defending a common Britishness. This notion of a common set of values and their importance in the wake of 9/11 is first articulated by Tony Blair in his article on social capital in Renewal, but is taken up, as discussed, by David Blunkett and Gordon Brown and given new impetus with the London bombings of July 2005. The search for common values to transcend whatever divides British citizens from one another often involves ignoring, as Linda Colley argued, the constantly evolving, multifaceted and contradictory nature of the British past, not to mention the deep cultural diversity that characterises its present. Ultimately it is to push back the cultural margins and reassert the traditional centre. I would argue that the search for a transcendental national identity rooted in shared norms, particularly one conducted by government ministers is not only futile but fraught with dangers, particularly for those national and polyethnic minorities that seek to either protect or preserve their cultural differences from the assimilating power of the majority culture.

Finally, I would suggest that the Canadian government's decision to adopt Bourdieu's theory of social networks provides an alternative model to those scholars and political actors who see utility in the idea of social capital for addressing the problem of economic exclusion by studying the power of networks for newly arrived immigrants or economically deprived citizens to gain ground. To the extent that Bourdieu foregoes either "shared norms" or "trust" in his analysis, it makes his theory of social capital much easier to reconcile with difference and diversity and avoids the republican push towards cohesion and unity. What is required, however, is to go beyond the simple idea of "networks and resources" as the Canadian PRI has done, to include the fully developed critical aspects of Bourdieu's theory including the accumulation of capital through relations of power. Thus, those interested in social capital must be attentive to the nature of connections between people rather than just their aggregative number, which is, of course the functional focus of Coleman and Putnam. It may be, with this more critical analysis that the challenge will be not 
simply to build up some networks but also to break down or challenge other kinds of associations or networks.

I would supplement Bourdieu's theory in two ways. First, important noneconomic factors involved in the accumulation of social capital need to be addressed; namely the gendered and cultural dimensions of social capital. Secondly, it is necessary to incorporate the idea of resistance or agency by historically subordinated groups into Bourdieu's theory which, as Schuller, Baron and Field (2000: 2) comment:

strangely lacks a sense of struggle: the various forms of dominant capital are presented as simply dominant without account of the subordinated forms of capital, how they resist dominant capitals and how they come actively to be subordinated.

As Bourdieu ultimately argues, all forms of capital, including social capital, must be analysed in terms of the effect that accumulated power has on different groups of people, particularly those who were, and are, negatively affected by such boundaries. But the shape of social capital accumulation in the past, present and future must equally be examined in light of the growing resistance by the marginalised over the $20^{\text {th }}$ century to just such boundaries and norms. ${ }^{21}$

Ultimately such a theoretical framework would lead to a very different vision of the social than the one currently underpinning the more popular functional school of social capital. While retaining the belief in a robust civic society as a check on both the democratic state as well as globalised capital, it would be in direct contrast to the republican appeal to unity and cohesion. The social would be fundamentally defined by conflict and contestation as those who in the past subjected to injustice fight for justice. Jean Cohen articulates the new meaning of social as she describes her definition of civic society rooted in Antonio Gramsci's theory of hegemony:

[Gramsci's] most important category hegemony...is meaningless without its corollary concept civil society...the cultural dimension of civil society is not given or natural. Rather it is a stake of social contestation: Its associations and networks are a terrain to be struggled over and an arena wherein collective identities, ethic values and alliances are forged. Indeed, competing conceptions of civil society are deployed in a continual struggle either to maintain cultural hegemony by dominant groups or to attain counter-hegemony on the part of subordinate collective actors (Cohen 1999: 214).

Ultimately, I believe Bourdieu's supplemented theory of social capital will provide us with a contested and divided vision of the "social"; one that has the potential to create, within contemporary diverse societies, not only robust communities but just ones. 
${ }^{1}$ The most influential school in contemporary debates, and the one therefore that will be the focus of this paper, is the American school of social capital, as articulated by sociologist James Coleman, and more recently political scientist, Robert Putnam. Putnam defines social capital as the 'connections among individuals - social networks and the norms of reciprocity and trustworthiness that arise from them' (2000:19) Underpinning this definition is a 'functional' model of social capital, in which it is assumed that an increase in participation and connectedness between individuals (association, participation, networks) will lead to an increased level of generalized trust, which, in turn, will yield better educational outcomes (Coleman) or individual well-being, economic growth and robust democracies (Putnam). Embedded within this functional model of social capital is a particular conceptualization of the 'social' that has received less attention then it should.

2 Putnam's definition of norms in social capital appears to be procedural and arise naturally from greater connectedness. Thus social capital is defined as 'connections among individuals... and the norms of reciprocity and trustworthiness that arise from them' (2000:19),

3 Americans who came of age just before and during World War II were enduringly moulded by that crisis. All their lives, these Americans have voted more, joined more, given more. 'Bowling Together', American Prospect, February 2002.

${ }^{4}$ What is interesting is the degree to which this language is also reflected in the European debate around social cohesion. The 2004 Social Cohesion Strategy highlights the role of civic society and family in achieving social cohesion. In an interview in the Council of Europe's magazine entitled Social Cohesion in September 2004, Krysztof Pater, the Polish Minister of Social Policy, describes the problems with the 'European social model' in the following terms: 'The traditional 'welfare state' which had originated as an agent of social justice, has turned into a mechanism of spiraling social aspirations impossible to fulfill, while producing debt for future generations to pay and strangling our economies with high taxes. The 2000 Lisbon Strategy has put his problem on the European Union agenda. (3)

${ }^{5}$ The final report of Robert Putnam's Saguaro Seminar on Civic Renewal at Harvard, entitled Better Together calls for a resurgence of the "AWOL" middle through the church at the expense of the cultural margins.

${ }^{6}$ www.whitehouse.gov/news/releases/2002/01/20020129-11.html, July, 2002.

${ }^{7}$ USA Freedom Corps Policy Book, January 2002: www.whitehouse.gov/news/releases/2002/01/freedom-corps-policy-book.pdf; p. 9.

${ }^{8}$ USA Freedom Corps Policy Book, p. 17.

9 'What is Operation TIPS?, Washington Post, Sunday July 14, 2002: B06. Any and all activities of the Federal Government to implement the proposed component programme of the Citizen Corps known as Operation TIPS (Terrorism Information and Prevention System) are hereby prohibited. (2002: 280) United States Senate: 'An Act to Establish the Department of Homeland Security and for other Purposes', November, 2002: H.R. 5005, Sec. 880: 280.

${ }^{10}$ USA Freedom Corps Policy Book, January 2002:

www.whitehouse.gov/news/releases/2002/01/freedom-corps-policy-book.pdf; p. 27. 
${ }^{11}$ Remarks by the President in Conversation on Service, Kimmel Centre for the Performing Arts, Philadelphia, Pennsylvania:

www.whitehouse.gov/news/releases/2002/03/20020312-3.html, July 4, 2002. It is important to note that many of the volunteers in the Peace Corps do not necessarily endorse this new thrust and find the reality is often very different on the ground. For example, one volunteer Jay Davidson who went to the Muslim country of Mauritius found that both religion and government was less important than the concrete relationships he established with people. 'Davidson said that when people deal with each other on a one-to-one basis, labels like 'American', 'Muslim' or 'Christian' fall by the wayside. "When we express our friendship to each other, we do it because of the way we treat each other and not because of anything our governments do'. Gaurav Ghose (UPI), 'Muslim Countries Ask for Peace Corps' The Washington Times, October, 18, 2004.

12 www.ksg.harvard.edu/saguaro. (July 23, 2002). It should be noted that George Bush, as governor of Texas was already a proponent of faith based initiatives before they were endorsed by Putnam's social capital theory of the Saguaro Seminar, but the language of civic renewal and service which becomes part of Bush's language around faith based initiatives is rooted in the social capital literature.

${ }^{13}$ www.whitehouse.gov/news/reports/faithbased.html, July 2, 2002.

14 'Faith based battle', Editorial, p. A18, The Washington Post, May 12, 2003.

${ }^{15}$ Ibid. 'Texas Lessons'. Lesson 2.

${ }^{16}$ What is communitarianism?' Talk of the Nation, with guests Robert Putnam, Don Eberly, and Amitai Etzioni, National Public Radio, Monday February 5, 2001: Minute 42.

${ }^{17}$ This is not to say that there is no merit to the idea that community groups or faith based groups can be important players with respect to the care of 'vulnerable populations' but we need to be wary of the other agendas that underling the shift from 'state' to civil society in social capital theory.

18 All references taken from speech by Gordon Brown July 72004 at British Council: http://www.hm-treasury.gov.uk/newsroom_and_speeches/press/2004/press_63_04.cfm (no page references available)

${ }^{19}$ Brown is not only one speaking to the threat of cultural politics. As Shukra et al. argue there is a general perception that 'Britain has moved 'too far' in the direction of multiculturalism and diversity for the good of political and social cohesion'. (Shukra et al, 2004:187) They point to Trevor Phillips (2004), head of the Commission of Racial Equality, who argues that the problem with multiculturalism is its emphasis on 'separateness' and David Goodhart (2004) who famously argued that Britain has become 'too diverse'.

${ }^{20}$ In September 2005, the PRI published its final report in which it stood by its notion of social capital as networks and separated it out from trust and norms but now makes no reference to Bourdieu at all in relation to the network version of social capital theory.

${ }^{21}$ Michel Foucault is perhaps most closely associated with this theory of resistance as integral to a full understanding of the way power works in society. "There are no relations of power without resistance" $(1980,142)$ Robert Wuthnow (2002) in a more recent iteration of this idea of marginalization sees the central normative question in social capital today as: 'Can social capital in the US be developed in ways that do a better 
job of bridging the privileged and the marginalized than appears to be the case at present?' (60) Wuthnow tends to be more concerned with race and class, than other forms of marginalization such as disability, sexual orientation or ethnicity, but the question still holds. 


\section{CHAPTER FOUR}

\section{SOCIAL CAPITAL AS A CAPACITY FOR COLLECTIVE ACTION ${ }^{1}$}

\section{PEDRO RAMOS-PINTO}

\section{Introduction}

This chapter examines the relationship between social capital and collective action, presenting a model of how the former can create varying capacities for different types of cooperative actions through the interplay of four characteristics of the norms and networks that compose it. Thus far, social capital research has presented contrasting definitions and uses of the concept. As such, before discussing this model it must be made clear what the basic assumptions regarding social capital used here are, and how they relate to other uses of the concept.

The conceptualization of social capital has been largely crystallized into three broadly defined families of research. Although these share the concern with the effects of social relationships originally highlighted by Bourdieu, developed by Coleman and extensively used by Putnam (Bourdieu 1986; Coleman 1988; Coleman 1990a; Putnam, Leonardi, and Nanetti 1993), each of these families presents very different claims as to what social capital is and does, focusing in turn on socially accessed goods, social trust, and finally on networks and the norms bounded by them.

The first approach sees social capital as socially accessed resources, or goods acquired through networks, and is traceable to Pierre Bourdieu's definition of the concept. Bourdieu saw social capital as subsidiary to physical and cultural capital: individuals use their personal networks to mobilize other types of goods (Bourdieu 1980; Bourdieu 1986). A similar approach has been taken by sociologists working on social capital, especially those with a background in network theory, such as Nan Lin and Ronald Burt (Lin 1999; Burt 2000). This conceptualization is fundamentally different from the others to the extent that it sees the resource in social capital as being the goods accessed 
through networks; while the others see the social capital as resource in its own right. As Szreter and Woolcock wrote:

...the "mainstream" social capital literature, represented pragmatically by the work of Putnam, regards social capital as the "wires" while network theorists regard it as the "electricity" (Szreter and Woolcock 2004).

The further two strands of social capital research take an interest in its capacity to facilitate cooperation and collective action, rather than in its capacity to mobilize other resources. The social trust approach privileges the role of trust dispositions across whole societies taking a macro-level approach; the norms and networks approach takes a predominantly meso perspective on the same issue, looking for the sources of collective action in bounded groups and middle-order organisations both formal and informal.

Definitions of social capital that privilege the role of social trust as a source of cooperation and mutually beneficial collective action take a variety of forms. Some see social capital as cultural features of societies in general that facilitate these actions, expressed through social trust and adherence to civic norms (Knack and Keefer 1997; Fukuyama 2001); others follow Robert Putnam's early definitions of the concept and see social capital as the combination of networks with norms and values, usually expressed as individual responses to social trust and civic norms survey questions. Here the relationship between trust and networks is hypothesised either one of two ways: in some cases participation in social networks are said to be the source of social trust and civic norms (Stolle 2003: 22-25), whilst other authors see social participation as a consequence of a society's level of trust and adherence to civic norms (Uslaner 2001; 2002).

The social trust approach has attracted widespread criticism, whichever way the relationship between the elements of social capital are posited. Many authors have failed to find any clear relationship between individual cooperative acts, such as membership of voluntary associations, and social trust. Glaeser and his colleagues found little evidence of trust embedded in networks being "scaledup" to social trust; in a comparative survey of association members, Stolle also found little evidence of membership being strongly related to social trust, as opposed to the usual variables of income, age, education and personal experience (Glaeser et al. 1999; Stolle 2001; Stolle 2003). Studies using longitudinal data have also found no evidence of social trust having an influence on the joining of voluntary associations and only small effects of joining on trust (Claibourn and Martin 2000).

This can perhaps be explained by recent theoretical analyses which suggest that the concept of trust is not an a priori moral predisposition, but rather a highly contextualised decision regarding the trustworthiness of potential partners, largely independent of the elements that are said to be part of social 
capital (Hardin 2002; O'Neill 2002). This is supported by experimental work that suggests that social trust questionnaires may be conflating trust with caution (Miller and Mitamura 2003). As such, it becomes extremely difficult and potentially fruitless to try to integrate social trust into a definition of social capital. Trust, trustworthiness and norms are certainly crucial to social capital, but before attempting to integrate its macro-level expressions with individual networks in a grand concept that attempts to explain a variety of phenomena at a number of levels, it is essential to have a strong theory of how these interact at the same level of analysis.

The final "school" of social capital research focuses on the confluence of norms and networks within particular groups, and how these affect their capacity for collective action or cooperation. Such an interpretation is an important part of both James Coleman's and Robert Putnam's definitions of the concept, although neither approach can be reduced to such a sparse concept. For Putnam, social norms and networks are "... an institutional mechanism with the power to ensure compliance with the collectively desirable behaviour" (Putnam 2000: 288).

Taking this as their starting point, a small but growing number of authors have been developing an understanding of social capital that builds on the combination of norms and networks at the group level. Michael Woolcock began by drawing the attention of the field to the types of networks that may constitute social capital and how different combinations of these may affect their impact on society (Woolcock 1998). Uphoff, while still reserving a role for social trust and general societal values, specified that primary forms of social capital included social relationships and the norms that facilitated mutually beneficial collective action (Uphoff 2000). This understanding was later incorporated into the social capital assessment tool developed by the World Bank team (Krishna and Schreder 1999; Krishna and Uphoff 1999; Krishna 2002). This extremely interesting body of work has influenced measurements of social capital that, through individual questionnaires, combine assessment of membership in networks with respondent's evaluation of the norms that rule such relationships.

A meso-level norms and networks approach is particularly refreshing because it is able to defend itself from the criticisms most often levied at social capital. It answers Portes' doubts by clearly distinguishing what social capital is - a set of attributes of individuals and their relationships - from what it does, which is to influence collective action (Portes 1998). A second major criticism has been the suggestion that social capital is a politically loaded concept, advancing a narrow-minded communitarian view that small is best, and that social capital always produces positive results (Portes 1998; Schuller, Baron, and Field 2000). The fact that social capital can have potentially negative results 
is by now widely accepted, particularly in reinforcing inequalities by shutting out those outside social capital rich groups from its benefits (Putnam 2000; Field 2003). However, seeing social capital as a capacity for collective action is putting the questions in an altogether different perspective. Social capital does not produce "good" or "bad" results, rather it is a resource that can be put to many uses, good, bad or indifferent, even by the same group of people: this is why Krishna sees social capital as a "politically neutral multiplier" (Krishna 2002: 24). Finally, it has the potential to avoid the confusion of levels of analysis - individual, group and society - that has been criticised in the social capital literature (Dasgupta 2000: 327). In order to do this a productive definition of social capital needs to start with the basic building blocs of social capital at the level at which observation is easiest and most rewarding. Only from such foundations is it possible to go on to test wider claims for societylevel effects and causes.

Above were some of the questions left unanswered by the social trust perspective for which a norms and networks approach can provide plausible answers. However, this chapter does not aim to discuss the relationship between social trust and social capital, rather to focus on the specific norms and networks at the group level that constitute a capacity for collective action. Whilst leaving an open verdict on the social trust "school" of social capital, this very brief introduction to the concept does not intend to imply that a norms and networks approach to social capital is superior to the accessed resources school mentioned first in this review. Two points are necessary here: firstly, the role of norms and networks in providing access to resources, and in being resources themselves that can be activated for collective action are not mutually exclusive dimensions, rather two sides of the same coin. Secondly, it must be recognized that access to resources is both a component and often an objective of collective action (a perspective that has, to my knowledge, been so far neglected by the network analysts discussed above, other than by treating groups as single individual units).

How these two sides of social capital may work together may best be understood if we accept that they refer to different aspects of collective action. Using Charles Tilly's definition of collective action as composed of five elements - interest, organisation, mobilisation, opportunity and collective action itself as an outcome (Tilly 1978: 7) - it can be argued that the socially accessed resources school of social capital tends to deal with individuals (and in some cases groups) mobilizing resources, whereas other perspectives deal with the organisational characteristics of groups that impact on their capacity to act collectively.

If the accessed resources approach to social capital can boast a firm theoretical and methodological grounding, the same cannot be said of the norms 
and networks perspective. The aim of this chapter is to propose a foundation upon which such a theoretical grounding can be built, although it cannot hope but to be a modest contribution to that end.

\section{Towards a typology of norms and networks}

Whilst the meso-level norms and networks approach to social capital has so far given us an idea and has the potential to advance our knowledge of the relationship between social capital and collective action, it nevertheless requires further theoretical and empirical development. In particular, three steps must be taken in order to further the discussion: (a) we must explore with more theoretical clarity typologies of norms and of networks, and how these create capacity for collective action; and (b), we must examine which combinations of norms and networks produce different kinds of collective action, and (c), how do these combinations relate (by influencing and being influenced by) wider social, economic and political contexts.

Networks have been promoted as a central element of social capital since Bourdieu and Coleman independently developed the concept. Despite James Coleman's steps in defining the characteristics of such networks - namely in proposing the concept of closure - the network aspect of social capital where it relates to collective action has been relatively neglected in relation to other elements such as trust and access. A more systematic approach to networks, and the norms that rule them, can bring benefits in terms of clarity and application of the concept. The key argument is that the characteristics of the networks and norms that compose social capital have an impact in the characteristics of collective action for which they are mobilised.

That there could be different types of social ties, putting forward a typology of elements of social capital, was part of Putnam's argument in Making Democracy Work (Putnam, Leonardi, and Nanetti 1993: 173). However, the specific terminology of bonding and bridging ties was first introduced by Gittell and Vidal (1998) as a specification of Granovetter's ideas on the importance of strong and weak ties. Granovetter defined the strength of ties as: "a (probably linear) combination of time, the emotional intensity (mutual confiding), and the reciprocal services which characterize the tie" (Granovetter 1973: 1361). Granovetter argued that strong and weak ties played different functions in individuals' lives to the extent that weak ties bridged between individuals in different structural positions, whilst strong ties could lead to the formation of cliques. Clearly Granovetter saw weak ties as an asset, in opposition to strong ties: "weak ties, often denounced as generative of alienation are here seen as indispensable to individuals' opportunities and to their integration into 
communities; strong ties, breeding local cohesion, lead to overall fragmentation" (Granovetter 1973: 1378).

Gittell and Vidal then adapted this definition to specify links between those "like each other" and "unlike each other" (1998). At the same time, and also drawing on the same work by Granovetter, Michael Woolcock was developing the parallel notion of integration and linkage, which he later renamed bonding and bridging (Woolcock 1998; 1999). Woolcock also introduced a third categorization of social capital which identified ties across power and status differentials, coining it as linking social capital (Woolcock 2001). Developing this concept further in an important article, Szreter and Woolcock defined it as a subset of bridging social capital that can be particularly useful in creating productive relationships between formal institutions and local communities (Szreter and Woolcock 2004: 655).

However, whilst bonding, bridging and linking social capital have contributed to a better definition of the concept as a whole, I would argue that they still entail considerable problems and contradictions. The first problem is that these typologies amalgamate a variety of contradictory aspects of both networks and norms into single categories, creating methodological blind spots that decrease the use-value of the concept. The bonding v. bridging distinction, for instance, has from the start rested on an overstated commonality between degrees of social identification and strength of ties within networks. Granovetter suggested that stronger ties were more likely to be found between individuals who saw themselves as similar in some way (Granovetter 1973: 1362). While evidence shows that this is often the case, (cf. the review in McPherson, SmithLovin, and Cook 2001), it does not follow that it is always the case. Clearly, there must be a distinction between degree of social identification and strength of tie. Similarly, discussions of linking social capital unite in the same category the question of power differentials with questions of identity: linking social capital is a subset of bridging social capital, and therefore a tie between individuals who are "unlike" each other.

To illustrate these objections and how they create methodological problems, imagine studying the collective action capacity of a kin group, an example often used to illustrate bonding social capital. The bonding social capital assumption that family ties will be both strong and between individuals close in social identity, may make us blind to processes that can pull these two elements apart, such as exogenously determined declines of patriarchal authority that reduce the strength of the tie, or the development of youth subcultures that create identity cleavages within the kin group. Furthermore, there is often an assumption that bonding social capital naturally encompasses horizontal relationships, a statement that has drawn gender-informed criticism, as will be discussed below. 
Contrary to the bonding social capital assumption, the strength of the tie is not necessarily related to the degree of identification between the individuals so connected (although this often co-varies), but rather to the strength of the norm that rules that relationship. Equally power differentials characterize all types of relationships, not just those that are weak, or between those who are not alike.

A second problem with this characterization of types of social capital concerns the juxtaposition of the access and cooperative action aspects of social capital it entails. It assumes a complete overlap of effects and structures between networks used to access and channel resources, and those used for collective action purposes. Granovetter and the network theorists claim that weak ties or structural bridges are of greater value to individuals in accessing important resources than strong ties because those unlike us are more likely to possess goods we, and those like us, lack (Granovetter 1973: 1366; Burt 2000; Lin 2001). By contrast, bonding relations were at best seen as those that help you "get by", through the close support of those nearest to each other (as in a clan group, for instance), while bridging relations were those that really helped you "get ahead", by allowing individuals and groups access to those resources that would allow them to leverage themselves to another - presumably better position (Woolcock 1999). Groups can be seen both as channels, recipients, and as agents, and these aspects can be mutually reinforcing. Nevertheless, these elements need to be conceptually separate, analysed independently, and in relation to each other.

In addition, the simple distinction that sees bonding ties as having little added value in comparison to bridging ties might not be so clear in collective action terms: the elements of social capital that may be functional in the context of accessing resources, may not be functional for collective action. In order to achieve some kinds of collective goals, the "getting by" functions of social capital may be exactly those that help you get ahead: for riskier acts, close identities and strong mutual bonds are essential, as studies of terrorist groups have shown (Della Porta 1995: 202-6). There is tension, then, between seeing groups as channels or as agents, between exchange and action.

The contention here is that the types of networks that are functional for accessing resources may be different from those that facilitate collective action. As such, it may not take us very far to simply transpose the conceptual tools of economic sociology to the realm of collective action. To better understand social capital we must construct a typology of networks and norms that can be applied to the study of collective action. The challenge is to find a comprehensive yet parsimonious typology of elements of social capital where these can be combined in order to compare different groups in relation to their capacity to act collectively. At the same time, such a definition must acknowledge that combinations of the elements of social capital will differ in the extent to which 
they are functional in regards to facilitating different types of collective acts. Furthermore, a redefinition must untangle issues of access and collective action, and create a set of propositions based on combinations of elements of social capital that can be more easily tested and verified.

To this end, I propose a categorisation of the two central elements of social capital (networks and norms) that separates the important insights relating to issues of social identity, power relations and strength of ties into separate measures, and adds the dimension of norms that organise collective efforts in groups. These four categories are grouped into two sides of the social capital issue. On one hand, the questions of social identity and power differentials refer to the ascribed characteristics of group members, or whom the networks connect; on the other, the quality of the relationships between them, encompassing the strength of that tie, and the rules that direct such relationship, or the norms of that group's social capital. This typology is presented in Figure 4.1.

Figure 4.1 Typology of Networks and Norms

\section{Ascribed Characteristics:}

- Degree of social identification:

- From Bonding to Bridging.

- Relative power position:

○ From Horizontal to Vertical.

\section{Quality of Relationship:}

- Degree of Norm Enforcement:

o From Weak to Strong.

- Degree of symmetry of inputs and outputs:

o From Equal (Conjoint) to Unequal (Disjoint). 


\section{Ascribed Characteristics}

The ascribed characteristics typology of the networks composing social capital relies on descriptors of the individuals that constitute them: whom networks connect. The first distinction focuses on social identity, or how close do network members see each other according to a relevant social identity. Social ties can be varied, and each individual carries a variety of identities, any of which can be called upon to characterize a relationship. We can talk of our work colleagues, our family, the members of our political party or fellow supporters of a sport club, and in doing so we are attributing a particular identity tag to the relationship. Individuals engage in social relations with a large variety of individuals they see as very, fairly or not at all like themselves. The bonding and bridging distinction reviewed above often fails to recognize this by imposing an either/or framework when it comes to describing these types of social capital. The typology being proposed here focuses on degrees of social identification between network members, preferring to see bonding and bridging relations as two ends of a scale, rather than mutually exclusive conditions.

A second but no less important relational characteristic of group members which affects their collective action capacity is the extent to which there are power differentials within the same group. Power differentials within networks (or vertical networks) are said to have a negative influence on capacities for collective action, Putnam claimed that "a vertical network, no matter how dense and no matter how important to its participants, cannot sustain social trust and cooperation" (Putnam, Leonardi, and Nanetti 1993: 174). However, not all social capital theorists see all vertical networks as having necessarily negative implications. For Woolcock, links forged across the large power gap between citizens and governments can create "cooperation, accountability [and] flexibility", if combined with organizational integrity, or the presence of government agencies with a Weberian professional ethos and efficient administration (Woolcock 1998: 175; Woolcock 1999). Clearly, the difference lies in how the degree of "verticality" of a relationship intersects with other elements of social capital, such as norms and identities, a question to which I will return below. For the moment, it will be enough to note that while vertical relations have the potential to link between different strata and create synergy, they can also facilitate relations of dependence and subjugation.

Whilst the structural aspects of networks, such as whom they connect in terms of identity and power, are crucial to understanding the relationship between social capital and collective action, they need to be complemented with a more rigorous attention to norms, or the qualitative element of group relations. Norms can be said to influence collective action within networks in one of two ways, which will be our two further dimensions of the components of social 
capital. Firstly, they exert this influence through the strength of their endogenous incentives for cooperation. Secondly, and assuming a broadly defined perspective of rationality, norms alter the ratio of input and returns to collective action, making it more or less attractive to individuals. The following section examines these two aspects of norms.

\section{Norms embedded in networks}

Work on social norms is an expanding field, and definitions are varied (Opp 2000; Fehr and Fischbacher 2004). Hechter and Opp distinguish social norms from legal norms, seeing the former as more likely to be spontaneous, unwritten and informally enforced, as opposed to the latter, which tend be designed, formalized through writing and enforced by a specialized bureaucracy (Hechter and Opp 2004a). Legal norms can certainly influence the creation of certain types of networks exogenously, for instance by outlawing certain types of interaction between social groups, as in societies with caste systems or which prevent women from participating in civic life. Also, through the threat of external sanction, they can make cooperation more likely regardless of other factors (Dasgupta 2000). However, rather than pack such elements into this definition of social capital it is better to see them as contextual factors. It is important, for the sake of parsimony and of rigorous analysis, to separate external influences from internal mechanisms. Therefore, the norms that are part of social capital are those that are intrinsic to particular groups, to the extent that we can compare their capacity for collective action with other groups in similar and wider contexts. The question is which norms, specific to a given network, facilitate certain types of collective action in that particular case, beyond contextual factors.

The first key way in which norms bounded by networks influence the capacity for collective action is through their prescription of behaviour and through its enforcement. In their first element, the prescriptive sense, not all norms matter for collective action in a direct sense (dietary norms, for instance) rather only those that do tend to prescribe an element of reciprocity in cooperation. In their prescriptive element, they tell individuals they ought to keep their end of a bargain. The second element of norms, the prescription of enforcement, presses group members to sanction those that do not follow its prescription. In this way, norms work to reduce the uncertainty of cooperative dilemmas and reduce the costs of cooperation, by increasing the degree of certainty as to the behaviour of others we know subscribe to the same norm.

The "strength" of the norm relates to how deeply the prescription of behaviour is ingrained in individuals' mentality, how strong the "oughtness" drive is in ruling their behaviour; it also relates to how likely it is that other 
group members will sanction defection and how much effort they are willing to expend in doing so. In Coleman's words:

Norms which have been internalized through socialization directly modify the utilities of certain actions, while norms that depend on external sanctions modify utilities only to the degree that the actor believes that external sanctions will be applied (Coleman 1987: 135).

The stronger these elements are, the more likely is the norm to be followed. If this norm is one that bears on collective action, then it follows that it will be easier for a group sharing a strong norm to act towards a common goal.

The final element of social capital relates to an aspect of collective action and norms often neglected by the relevant scholarship. This is the question of the distribution of inputs and rewards to collective action within networks. The critique of the "negative" externalities of social capital, i.e. of the fact that groups act to acquire resources to the exclusion of outsiders has often been made, as by Portes and more recently and very persuasively by Ogilvie (Portes 1998; Ogilvie 2004). However, the point that particular norms ruling networks can buttress inequalities within groups has not been made often. In a recent review of social capital, Radcliffe cited evidence that certain types of norms fail to benefit women who join cooperative efforts by prescribing a division of labour and rewards that is not symmetrical. For instance, norms can ask women to contribute disproportionately to a collective effort whilst being omitted from most of its benefits (Radcliffe 2004: 520).

This insight is also a neglected aspect of James Coleman's important work on social norms, which the social capital literature would do well to revisit. Coleman defined norms as being characterized on a continuum from conjoint where the benefits and obligations of the norm are contained within the same actor - to disjoint, where the benefits of the norm do not accrue to those that are obliged to follow it (Coleman 1990a: 247). In between we have situations where conflict and cooperation go hand in hand, buttressed by power inequalities (Coleman 1990a: 262). A parallel debate and illustration of this point can be found in the study of household decision-making. According to Amartya Sen, members of households simultaneously face two types of problems, one of cooperation - adding to the total production of the household - and one of conflict, relating to the distribution of the goods thus produced: "Social arrangements regarding who does what, who gets to consume what, and who takes what decisions can be seen as responses to this combined problem of cooperation and conflict" (Sen 1990: 129). These social arrangements (norms) can, and often do, mean that women contribute disproportionately to the household in relation to their entitlement share of the total output, leading to reduced life-span, higher morbidity, and deprivation. 
The household is just one of the many settings in which individuals face the characteristic dilemmas of cooperation and conflict, investment of resources, and distribution of rewards which are always required in cooperative actions. In order to solve these dilemmas, norms ruling cooperative acts can develop, and sometimes create with them unequal distributions of effort and reward (Hechter and Opp 2004b). For social capital research to ignore this important insight would be to create a blind-spot and leave it once again vulnerable to the criticism of assuming that cooperation can only have "positive" outcomes. Having already accepted that the positive externalities of social capital are contingent rather than necessary, so now we must also accept that even for "insiders", the fruits of cooperation are not necessarily distributed equitably ${ }^{2}$. The norms that determine this distribution must therefore be one of the objects of social capital research.

It must be accepted that these four dimensions of a typology of social networks and norms, although conceptually distinct, have likely (though not necessary) relationships between them. For instance, stronger norms are likely to be associated with closer social identity. This results from the weight of social identity in individual's self-conception. Breaking the accepted pattern of behaviour amongst those close in identity terms could jeopardize an individual's membership of a cherished source of social identity, and as such it supports the norm of cooperation (McPherson, Smith-Lovin, and Cook 2001). Equally, the more vertical a relationship, the more likely it is to be bridging between different social identities due to the stratification observed in most societies. It can also be expected that vertical power relations will be correlated with more asymmetric norms of distribution of effort and reward to the benefit of those controlling more power.

Nevertheless, the four elements are distinct and can appear in combinations that alter these usual relationships. Whilst one of the elements may work to make collective action easier for a group, another aspect of their relationship may curtail such potential and vice-versa. The aim of a four-part model is to allow an analysis of how the elements of social capital interact with each other to produce differing capacities for collective action.

\section{From Social Capital to Collective Action}

There are two mechanisms through which the four elements of social capital influence collective action. Firstly, each of them individually may make collective action more or less likely. Secondly, different combinations of the elements are functional for both the likelihood of collective action in general, and for different types of collective action. 
How each of the elements of social capital affects collective action on its own is relatively straightforward. The structural elements of social capital influence cooperation in a number of ways. The degree to which close social identities characterize the group can make cooperation more likely. As Hirschman noted, the prospect of loss of identity through defection may be a strong incentive for loyalty (Hirschman 1970). The closer the identity, the more restricted the numbers involved are likely to be, as the larger the group, the more likely it is that diverse identities are present. As for the extent to which networks link across power positions, the stratification of a given society can mean that the more horizontal a group is, the more restricted it is likely to be, depending on context.

The normative dimensions of social capital also influence capacity for collective action. In the first place, they alter the preference ordering of players: if the norm is strong (either through internalization or group enforcement) it may be more difficult to defect, which provides reassurance about other group members' trustworthiness. The distributive element of norms of cooperation also affects individuals' interest in participation in the cooperative effort. Assuming the reasoning process regarding cooperation is limited to a calculation of input and reward, the higher the first is in relation to the second, the less likely an individual will be to cooperate.

However, decisions regarding cooperation are never limited to one of these elements alone: all combine, and pull in different directions to influence collective action ${ }^{3}$. For instance, close identities may predispose individuals for cooperation in group action, while on the other hand, weak norms of cooperation and a disadvantageous distribution of effort and reward may work in the opposite direction. Asymmetric or disjoint norms can be sustained in collective action by strong norms, the exercise of power within the group, and the extent to which the particular norms become bound up with group identity. As such, inequality or even inefficiencies in collective action can persist in groups, limiting or modifying their ability to cooperate even where other elements of their social capital are conducive to certain types of collective action. For instance, the close social identity and strong traditions of reciprocity that sustain the systems of mutual help in rural societies also means that new types of collective action that involve altering power relations and distribution of benefits are very difficult to introduce, even if in the long run they would be of benefit to the entire community (Eggertsson 2004). As such, the social capital of those communities is conducive to one type of cooperation, but not for others, a situation that highlights the need to understand the relationship between elements of social capital.

Certain combinations of elements of social capital can also increase capacities for collective action by undercutting the negative influence of some 
of the elements. Overarching identities can be constructed or mobilized in order to link groups with different identities or in very different positions of power structures, a phenomenon observable in a variety of situations, from nationalist conservative alliances between the poor and traditional elites, to appeals to religious or ethnic identities that encompass class differences. Charles Tilly and his colleagues have highlighted the importance of such coalitions for democratization, citing the example of Switzerland and France (McAdam, Tarrow, and Tilly 2001; Tilly 2004). In nineteenth-century France, middle-class Republicanism and popular Radicalism were often united under the banner of Populism with important consequences for the fortunes of the left (Ansell 2001). In these cases, a relationship that relies on strong identification with others can go hand in hand with power stratification.

Cooperation in unequal power relationships can also be achieved if there are strong and conjoint norms that prevent those with more power from exploiting their position to benefit from collective action. The norm of duty developed by Weber's understanding of bureaucracy - more recently termed organisational integrity - is one such example, allowing productive relations between state agencies and grassroots (Weber 1978; Evans 1996; Woolcock 1998). However, due to the enforcement problem - those with less power find it too costly to sanction those above them - it is likely that this combination will only work if the strength of the norm comes from its internalisation (a moral obligation), since the likelihood of punishment for defection is reduced.

Table 4.1 outlines a few hypothetical examples of where different combinations of the dimensions social capital could be found and of their possible implications for the characteristics of collective action. 
Table 4.1 Some potential combinations of elements of social capital and their impact on Collective Action.

\begin{tabular}{|c|c|c|c|c|c|}
\hline $\begin{array}{c}\text { Social } \\
\text { Identity }\end{array}$ & $\begin{array}{l}\text { Power } \\
\text { Position }\end{array}$ & $\begin{array}{c}\text { Norm } \\
\text { Strength }\end{array}$ & Symmetry & Example & $\begin{array}{c}\text { Characteristics } \\
\text { of Collective } \\
\text { Action }\end{array}$ \\
\hline Strong & Horizontal & Strong & Equal & $\begin{array}{c}\text { The } \\
\text { Communitarian } \\
\text { Dream }\end{array}$ & $\begin{array}{l}\text { Solid, durable, } \\
\text { defensive, } \\
\text { isolated }\end{array}$ \\
\hline Strong & Horizontal & Weak & Unequal & $\begin{array}{l}\text { Disintegrating } \\
\text { Communities }\end{array}$ & $\begin{array}{l}\text { Little incentive } \\
\text { for cooperation }\end{array}$ \\
\hline Strong & Vertical & Strong & Unequal & $\begin{array}{l}\text { The Patriarchal } \\
\text { Family Unit }\end{array}$ & $\begin{array}{l}\text { Solid, durable, } \\
\text { defensive, } \\
\text { exploitative }\end{array}$ \\
\hline Weak & Vertical & Strong & $\begin{array}{l}\text { Unequal } \\
\text { (benefiting } \\
\text { powerless) }\end{array}$ & $\begin{array}{l}\text { Benevolent } \\
\text { Bureaucracy }\end{array}$ & $\begin{array}{l}\text { Extensive, } \\
\text { dependent on } \\
\text { norm of duty } \\
\text { towards others }\end{array}$ \\
\hline Weak & Vertical & Strong & $\begin{array}{l}\text { Unequal } \\
\text { (benefiting } \\
\text { powerful) }\end{array}$ & Conscript Army & $\begin{array}{l}\text { Cohesion by } \\
\text { strength: solid } \\
\text { as long as } \\
\text { coercion } \\
\text { effective, able } \\
\text { to organise } \\
\text { different social } \\
\text { identities. }\end{array}$ \\
\hline Weak & Vertical & Weak & Equal & $\begin{array}{l}\text { The Inter-class } \\
\text { Alliance }\end{array}$ & $\begin{array}{l}\text { Contingent, } \\
\text { re-negotiable, } \\
\text { extensive }\end{array}$ \\
\hline Weak & Horizontal & Weak & Equal & $\begin{array}{c}\text { Diffuse } \\
\text { cooperation }\end{array}$ & $\begin{array}{l}\text { Rational-based, } \\
\text { Gemeinschaft } \\
\text { types of } \\
\text { enlightened } \\
\text { self-interest } \\
\text { cooperation }\end{array}$ \\
\hline
\end{tabular}


All but the second example - "Disintegrating Communities" - contain, with different combinations of the elements of social capital, a capacity for collective action, but are likely to be more efficient for different kinds of cooperation. "Diffuse Cooperation" is perhaps closest to the workings of a rational homos economicus, but how solid and risky can we expect cooperation to be in such a context? Although we may rely on such a type of social capital for everyday low-cost and low-risk interactions, we would expect to see other types of social capital behind more complex types of cooperation. Power is used in the "Patriarchal Family" and the "Conscript Army" examples to support collective action, but the latter is able integrate wider identities as long as its coercive capacity is intact. While in the conscript army the norm is strong because power inequalities make sanction credible, in the "Benevolent Bureaucracy" scenario the exercise of power is nullified by the internalization of a strong norm of duty.

The "Communitarian Dream" example is often invoked as an ideal type basis for cooperation. It is certainly extremely functional for the most challenging types of collective action as all elements work towards integrating individuals' preferences into the group. Consequently it is at the heart of some of the most durable, and resilient types of collective action, including those where members face the ultimate cost on behalf of the group. Nevertheless, as identities become bound up with the norms practiced by the group, it is also very resistant to change. The danger is that as its norms, through lack of adaptation, become obsolete to the extent that they collapse and the groups' egalitarianism ebbs away, they loose their ability for cooperation, becoming disintegrating communities.

To finalize, there are two caveats that must be made in relation to the concept as presented here. The first is the question of tipping points: to what extent do each of the elements counterbalance the others? It is unlikely this question will ever be answered with mathematical accuracy, as these elements do not show perfect proportional relations to each other, and the weight of each certainly varies between individuals and in different circumstances. The power of identity is likely to be stronger in someone whose self-view is bound up in a restricted number of categories than with someone can access a wider number of identity vectors. Outside factors can at different times put constraints on the exercise of power within the group, or on the possibility of enforcing norms. The second caveat is that the relationship between social capital and collective action is not a one-way street. There is a feedback loop through which collective action can generate, transform, or destroy social capital, as noted by Diani (2001). Going through the experience of collective action can generate closer identities (Gould 2003); expending or gaining resources through collective action can change the relations of power between the actors, and norms can change if they prove inadequate to meet the collective challenges faced by 
groups. As an example, participation in micro-credit associations along with other members of their family leads women to have a greater role in household decision-making, and to a change in male attitudes to the capacities of women (Pitt, Khanker, and Cartwright 2003).

\section{Conclusion}

This proposed typology of elements of social capital represents a small adaptation of the norms and networks school in order to present a model of social capital that attempts to shed light on its black box, providing a set of claims to be falsified. These are the following. Social capital is a combination of networks of individuals and sets of collective norms embedded in those networks. Networks connect individuals within and across power and identity structures. The norms ruling those relationships prescribe how individuals should relate to other group members in varying degrees of strength, and prescribing different roles in social exchange. Finally, a group's social capital is therefore the combination of these elements to the extent that they influence its capacity for cooperative behaviour, both positively or negatively, and in relation to different types of collective action.

\footnotetext{
${ }^{1}$ I would like to register my thanks to a number of people for their comments and support in the preparation of this chapter, in particular Simon Szreter, Rosie Vaughan, Adam P. Coutts, S. V. Subramanian and the editors of this volume.

${ }^{2}$ The asymmetries I am presenting here refer only to the organisation of inputs and rewards to collective action. Russell Hardin has identified other types of asymmetries in collective action, relating to the qualities of the goods produced (i.e. the aim of the action), that can also affect the distribution of rewards and as such have a bearing on the emergence of collective action. However these factors are external to the relationship between potential partners, which is the focus of this article (Hardin 1984).

${ }^{3} \mathrm{We}$ should of course bear in mind that social capital as described here is not claiming to be the only influence on collective action. Implicit to this discussion is that there are contextual variables (threat, opportunity, legal norms, wider cultural frames), as well as individual variables (life-history and experience, as well as individual resources) which also affect group capacity for collective action.
} 


\title{
CHAPTER FIVE
}

\section{RETHINKING THE POLITICS OF SOCIAL CAPITAL: Challenging TOCQUeVILlian PERSPECTIVES}

\author{
Mike Savage, Yaojun Li \\ AND GINDO TAMPUBOLON
}

Over the past decade there has been considerable concern about accelerating social fragmentation in many democratic nations. Key indicators such as declining electoral turnout, falling party membership and associational involvement, increased public cynicism and falling levels of inter-personal trust have been identified as indicative of the loss of social cohesion. Much interest has centered on the arguments of Robert Putnam that these trends are related to a wide-ranging collapse in social capital (Putnam 1995; 1996a\&b; 2000), often summarised as the "social capital lost" argument (e.g. Edwards 2003). His work has generated interest in the role of voluntary association membership both as a key indicator of the stock of social capital, and as an important vehicle in which individuals learn to relate to each other so that the beneficial effects of social capital can be realized (Putnam et al. 1993; Paxton 1999; 2002; Li et al 2005; Hooghe and Stolle 2003).

In this paper we draw on recent collaborative research projects to offer an alternative interpretation of trends in social capital to that elaborated upon by Robert Putnam ${ }^{1}$. Our main concerns are threefold. First, we argue that the theoretical debate on social capital has been unhelpfully polarised between supporters and critics, whereby Pierre Bourdieu's approach to social capital is held up as offering the most useful critical approach. However, we argue that Bourdieu deliberately played down the importance of social capital in his work, and that we should not look to him to provide the best counter to the arguments developed by Putnam and Coleman. Instead, we argue that we are better off yoking interests in social capital to broader debates about stratification and inequality.

Second, we pursue this argument by emphasising the importance of social network analysis as providing a better way of grasping the dynamics and 
mechanisms of social capital. Despite the fact that the concept of social capital refers to the significance of social networks, famously in Putnam's definition of social capital as "features of social organization such as networks, norms, and social trust that facilitate coordination and cooperation for mutual benefit" (1995: 67), the potential of network approaches has not been fully realized. Alluding to case study research on voluntary associations in the North West of England, we show how trust and collective activity is - counter-intuitively related to internal tensions within associations. This reveals that we need to recognise how effective social capital requires stakes and contestation.

In the third part of the paper we draw together theoretical and methodological arguments to present a brief interpretation of trends in social capital in Britain since the 1970s. Here we argue that we can best understand developments not as the decline of social capital in general, but rather as a crisis of white, male working class social capital, the ramifications of which are very significant for understanding the contours of social change in Britain.

\section{Theoretical issues}

It is commonplace in the now vast literature on social capital to refer to three key theorists - James Coleman, Robert Putnam and Pierre Bourdieu - each with a distinctive "take" on the nature and significance of social capital (e.g. Portes 1998; Fine 2003; Field 2003). They are, however, strange bedfellows. James Coleman is seen as the pioneer of the concept in recent debates. In his work, social capital arises from his rendering of rational choice theory to provide a means of accounting for the familiar "prisoner's dilemma": how to generate collective goods from individuals pursuing their rational, egoistic interests. $\mathrm{He}$ thus construes social capital as a resource, seeing it as "some aspect of social structures, (which) facilitate certain actions of actors - whether persons or corporate actors - within the structure" (Coleman 1988: 98). Coleman's studies of educational attainment indicate how ethnic minorities were able to utilise their social capital - even in the absence of marked economic capital - to advance their social position in American society. Many empirical studies have followed this approach, addressing variations of the influence of social capital and the wider environment on their well-being and school attainment (Coleman 1988: S109-119, Modood 2004).

Robert Putnam refers admiringly to Coleman's work but actually works from a very different intellectual tradition, associated with Ronald Inglehart's political culture (e.g. 1990) perspective, which is critical of the value of rational choice perspectives such as those used by Coleman. Putnam's original use of the concept, in his work on Italian politics (Putnam 1993), is couched within this tradition, but departs from Inglehart in seeking proximate reasons for explaining 
the greater democratic cultures of Northern rather than Southern Italy. This interest in exploring the specific supports for collective and democratic cultures has led him towards a more sociological interest in recognising the social relations conducive to social capital, and it is here that he has drawn on Coleman. Yet this intellectual move has also caused theoretical problems. In his earlier work he championed a clear Tocquevillian perspective, which saw the culture linked to formal associations as vital for generating trust and the ability to work together:

Participation in civic organizations inculcates skills of co-operation as well as a shared sense of shared responsibility for collective endeavors.... Taking part in a choral society or a bird watching club can teach self discipline and appreciation for the joys of a successful collaboration (Putnam 1993: 90).

Hence "good government is a by-product of singing groups and soccer clubs" (1993: 176). His argument is underscored by research indicating a relationship between interpersonal trust and associational membership (Anheier and Kendall 2002), though this association is increasingly contested by recent research and is no longer substantiated by survey evidence ${ }^{2}$. In his most influential work, on Bowling Alone, which charts the decline of social capital in the US since the 1960s, he broadens his concerns to include an interest in the social capital relating to informal social relations. In part this is related to his recognition that informal socialising is much more important in terms of the time spent than that in formal associations. Yet the problem is that it is no longer clear why informal social relations necessarily create the kinds of ties that promote social capital. Whereas involvement in formal associations, it can be argued, involves dealing with strangers and learning to accommodate difference, informal socialising, if it is simply with one's own kin or friends ("people like us"), may be conducive to the promotion of self interest or factionalism. Putnam hence broadens out his definition of social capital at considerable theoretical expense.

Within the work both of Coleman and Putnam, we can therefore see how the concept of social capital is a means of claiming stakes over the "social", though from different directions. For Coleman, the concept is a means of recognising how egoism may be overcome; for Putnam it is a means of grounding political cultures. Coleman comes from a micro perspective and Putnam from a macro one, and the concept gestures towards an uneasy middle ground where formal and informal social relationships and ties are attributed with great significance. Both writers, however, lack a developed account of the kind of relationships and processes that define the social itself. This is one reason why critics of the concept of social capital see the debate as being a form of disciplinary imperialism: the concept of capital operates as a kind of Trojan horse which 
allows economistic assumptions to be smuggled into the city of the social from where they can then subjugate these very champions.

Our account so far covers familiar ground. However, we now want to dispute a common step in the arguments. Those who are sceptical of the concept of social capital because of its inadequate grounding in social relations often seize on Pierre Bourdieu's theoretical framework as the most viable critical alternative. Bourdieu is, after all, a bona fide sociologist, and his concept of social capital appeals to those wanting to recognise the exclusive and divisive qualities of social capital. For Bourdieu, social capital is "the aggregate of the actual or potential resources which are linked to possession of a durable network of more or less institutionalised relationships of mutual acquaintance and recognition" (Bourdieu, 1997: 51), and he draws attention to the way that elites use this to shore up their own position.

However, this appeal plucks the concept out of its context in Bourdieu's thinking. The important point, for Bourdieu, is that social capital is actually relatively unimportant in explaining elite privilege, and should only be seen as operating at the margins of power, a kind of residual resource which is only occasionally important. Bourdieu is clear that the two most important forms of capital which operate in contemporary capitalist nations are economic and cultural capital, and that it is these which are central to any account of contemporary social relations. In both cases, systematic processes allow the privileged to pass on their privileges, through the routine operations of property and money inheritance and transmission, and through the way that cultural capital allows those from privileged backgrounds to perform well in the educational system without needing to rely on the kind of personal networks or contacts which might be seen as part of an "old boys club". His theoretical emphasis on capital being operative in particular "fields", so that individuals come to have "a feel for the game", is precisely designed to explain why upper class people can feel they fit into elite institutions even if they do not have any personal contacts or connections with them. Similarly, his advocacy of correspondence analysis allows him to argue that people who are otherwise unconnected may nonetheless share similar positions in social space. These points all explain why Bourdieu hardly mentions social capital in his most important book, Distinction (1984).

The point here is that we need to recognise that Bourdieu is concerned to place the concept of social capital in a broad frame where its relative unimportance vis-a-vis other forms of capital should be recognised. A satisfactory approach requires that social capital be placed within a more developed sociological perspective, in which we see it as tied up with processes of boundary maintenance which define social categories. Effectively, this means 
placing the study of social capital within an emphasis on social stratification of race, class, gender, and so forth - as fundamental features of the social fabric.

There is a further reason why we should not rely on Bourdieu's approach to social capital. In emphasising its link to informal elite ties, he passes too quickly over the potential for disadvantaged groups to mobilise around both formal and informal ties. It is a well-known weakness of his social theory that he tends towards a functionalist emphasis on the reproduction of inequality, rather than its contestation. Here we might usefully retain an aspect of Putnam's original argument, that the formation of formal association allows the potential to mobilise previously unconnected groups, and hence that formal associational involvement is of sociological interest. However, we need to recognise the myriad kinds of association, their different dynamics and constituencies, to develop a more nuanced and adequate account of their importance, rather than think in terms of their abstract formal properties as in Tocquevillian perspectives ${ }^{3}$. This involves seeing how associations are implicated in the routine social relations of neighbourhoods, workplaces, leisure and activity more generally. Here, there is in fact a rich tradition of research - nearly entirely ignored by most of those who have studied social capital - which explores the role of associations and organisations in social life from an anthropological, sociological and historical perspective, and which allows us to develop a distinctive kind of account which recognises the significance of formal associations, but as devices implicated in the constitution of social boundaries and divisions.

Three traditions can be mentioned here. First, dating back to the early part of the century, and especially strong in the $1950 \mathrm{~s}$ and $1960 \mathrm{~s}$, there is anthropological and sociological research on community relations (see e.g. Frankenberg 1957; 1966; Crow and Allan 1994), which show how associational involvements are implicated in divisions between "insiders" and "outsiders". Frankenberg (1957), Pahl (1970), Strathern (1981), Edwards (2000) and Crow and Summers (2002) all show how people claim moral rights to a place by virtue of their activity in associations. In many cases, this allows middle class incomers who might otherwise be deemed as outsiders, to claim some kind of moral rights. Thus Pahl (1970: 93) reports the words of one middle class incomer (living in the "Wood"):

I expect you have heard of the difficulties between here and the village.... The Wood people are energetic and run things and the village people complain; but they do nothing by themselves, so what is one to do?

However, as Frankenberg (1957) also noted, locals also used the involvement of outsiders in voluntary associations as a means of giving them responsibility for difficult decisions. Hence, rather than any simple bridging 
process, associational involvement reproduces tensions and conflicts even in those situations where different groups do actually belong.

A second tradition of research is in social history. It was a central claim of Edward Thompson, in his path-breaking work on The Making of the English Working Class (1966) that the formation of the London Corresponding Society in 1793, with its advocacy of "members unlimited" was a key moment in the formation of modern class relations. This tradition of seeing associational forms as devices for class mobilisation was developed within Labour history through numerous studies of how trade union organisations were rooted in the social relations of work and community. It is also possible to find some accounts of how professional associations were related to the formation of the modern middle classes. This body of work takes associations not as devices for meeting diverse others, but as means by which sectional interests can be effectively mobilised, and hence presents a very different picture to that painted by Putnam (see Szreter 2002).

Developing from this body of work, a final tradition is associated with social movement studies, which has also explored how associations mobilise individuals through people's attachment to a range of social networks, which may explain whether an individual is available for participation (McAdam and Snow, 1997: 120-1). A key feature of "structural availability" was an individual's position within pre-existing personal or organisational networks that facilitates their recruitment into activism (Snow et al, 1980; Diani and McAdam, 2003; McAdam and Paulsen, 1993). This literature has become increasingly sophisticated as it engages with more technical network literature (eg McAdam, 2003; Gould, 1995; 2003). In this respect membership flows out of prior commitments and should not be seen as allowing relative strangers to come to trust each other.

This brief account should be enough to demonstrate the rich tradition of research on formal associations that reveals how they are interwoven into the social fabric and play important roles in the reproduction and contestation of prevailing social relations. The fate of associations is therefore important, as Putnam argues, but in ways which are more complex and contradictory than he indicates. Let us build on this point in the rest of the paper, first by considering the role of social networks in associations, leading into an account of trends in social capital in Britain.

\section{Networks and Associations}

Within the existing literature on social capital, there is little discussion of how the internal networks between members of organizations help to facilitate or reduce - civic engagement from their members. We currently have no clear 
account of mechanisms by which associations generate trust, activism, and civic engagement with the result that associations are "empty boxes" which are deemed to produce particular outcomes with little understanding of what actual processes might generate them. Instead, most research relies on survey data on individuals to examine trends in participation in voluntary associations, levels of trust and their correlates with various other socio-demographic characteristics (Hall 1999; Paxton 1999; 2002).

The tradition of anthropological and sociological research mentioned above, however, emphasises how associational involvement is implicated in divisive social networks. In a recent project with Brian Longhurst, Kath Ray, Gindo Tampubolon and Alan Warde, Savage examined the internal network structures of two different social movement organizations ${ }^{4}$. First, a local Labour Party branch was chosen, as exemplar of one of the two main political parties in Britain since 1918, with a long history of local organization pursuing campaigning political projects. The case study branch, situated within an affluent area of Cheshire (a predominantly suburban and rural county located to the south of Manchester), is relatively active, and comprises a number of adjacent wards (neighbourhoods), which operate together organizationally because of low membership levels in any one ward. The size of the branch membership at the time of the survey was 128 .

The other case study is an independent Conservation group in metropolitan Manchester. This nature protection association engages in "pressure politics", mainly by lobbying local and central government to protect wildlife and natural environments. It began as a group of local wildlife gardeners in the 1980s, and later broadened its concerns to the conservation of wildlife within the city as a whole. The group participates in a national network of similar groups, but operates structurally as an autonomous local group. Like many local environmental groups (see Lowe and Goyder, 1983), it seeks to influence the local authority in safeguarding particular sites, as well as influencing general policies on conservation and development. The Conservation group was in a quieter phase of a "protest cycle" at the time of the research, but still had 121 members 5 .

Using the membership lists made available to us by the organizations, we sent a postal questionnaire to all members, asking for information on their socioeconomic position, the means by which they were recruited, and the extent and nature of their participation and commitment. We also asked people to name anyone in the organization with whom they "discuss things to do with the organisation (for example, activities, issues, strategy)". We sent up to three reminders, and obtained a very high response rate of $79 \%$ for the Conservation group and $80 \%$ for the Labour Party branch. These three phases of fieldwork were conducted between 1999 and 2001. 
Figures 5.1 and 5.2 reveal the people with whom the members reported discussing organisational matters (during phase one of the study). Figure 5.1 reveals that two-thirds of Labour Party branch members did not discuss organizational matters with anyone else. The core of the Labour Party branch network, defined as those who discussed issues with five or more other members, consists of nine people ( $9 \%$ of the total membership). Ties between these core members are well developed, as are their links to more peripheral members who have between one and four ties to other members. Figure 5.2 shows that just over half of the members of the Conservation group are isolates. The core of the group, however, is much smaller, containing only five members (5\% of the total membership), with members of the periphery communicating primarily with only two members of the core. Beyond their ties to these two dominant individuals, there are very few other ties between members of the periphery. This is a very sparse network with a small core. 
Figure 5.1 Communication networks within the Labour Party

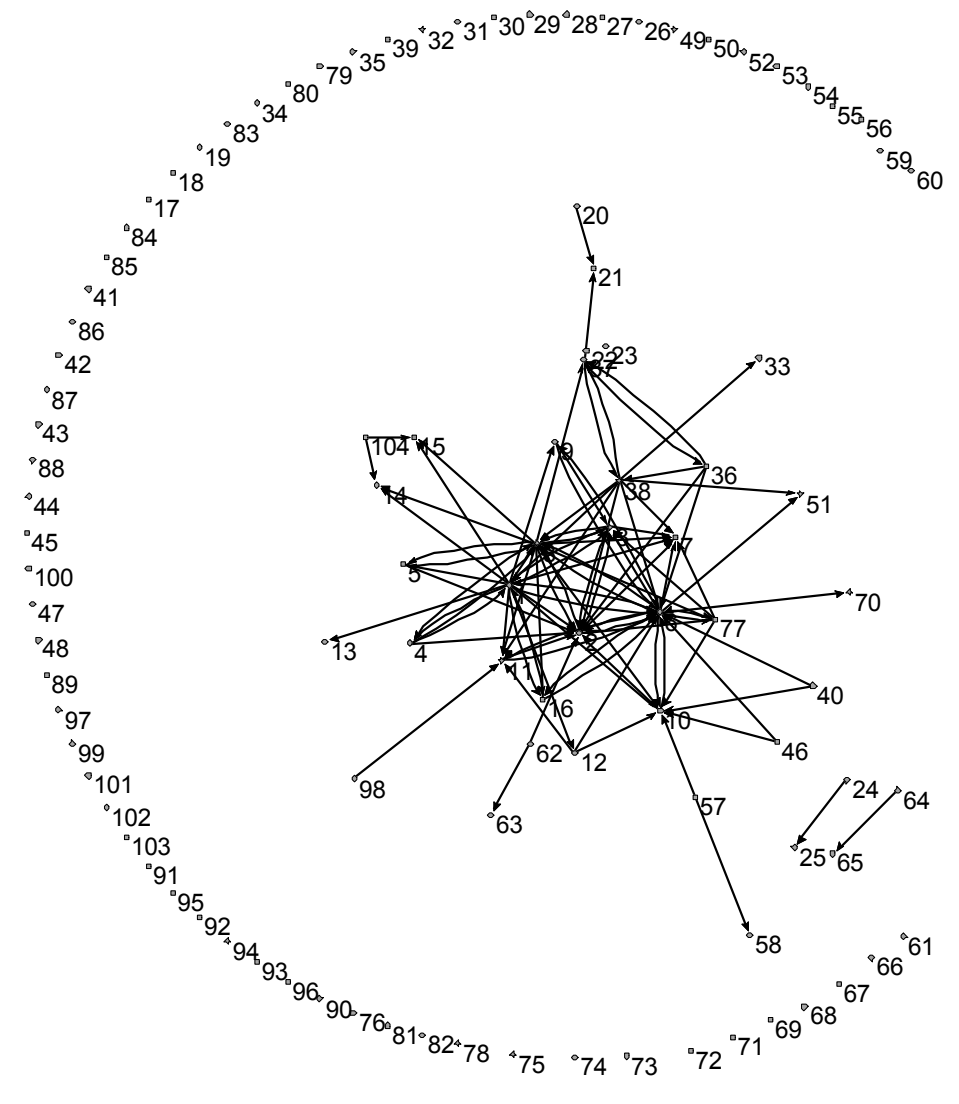

Note: Respondents were asked "with whom do you discuss things to do with the organisation (for example, activities, issues, strategy)". 
Figure 5.2 Communication networks within the conservation group

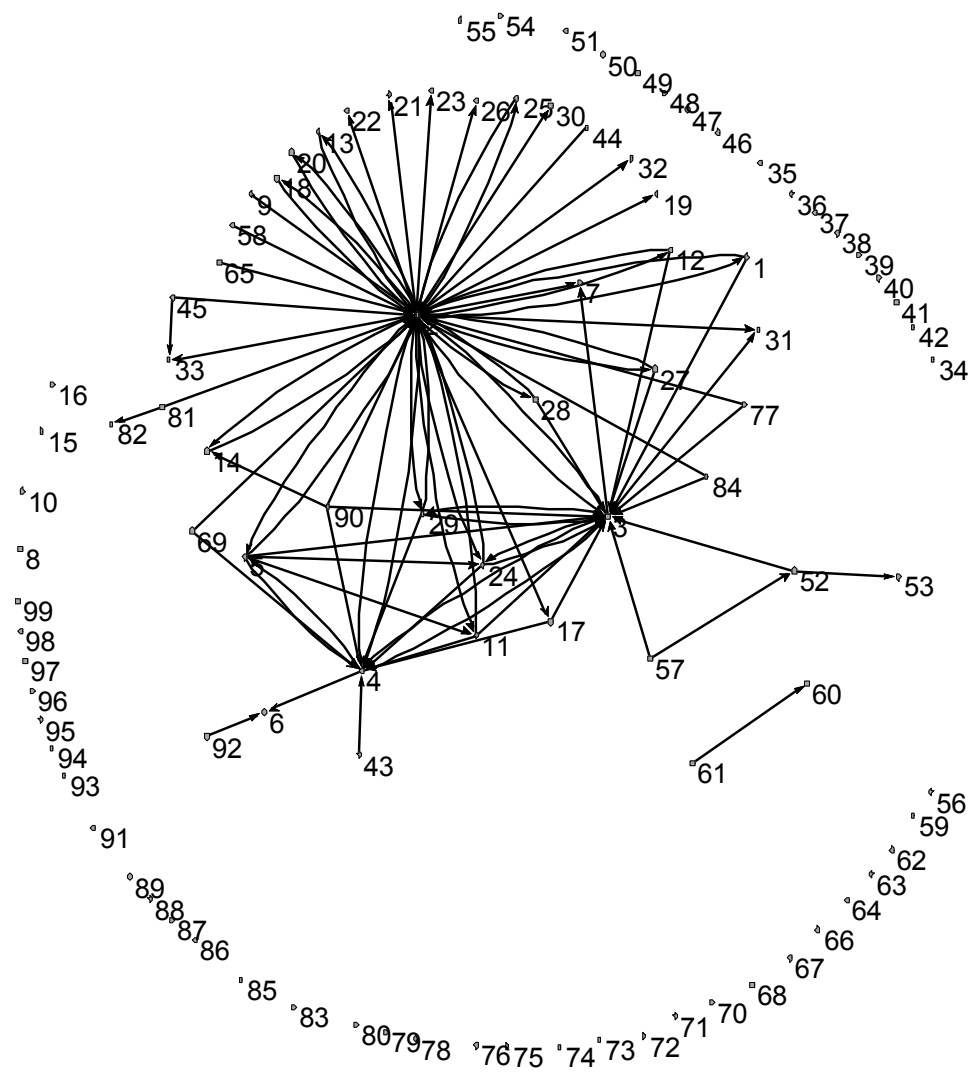

\section{露}

Note: Respondents were asked "with whom do you discuss things to do with the organisation (for example, activities, issues, strategy)".

Figures 5.1 and 5.2 thus indicate that the core group within the Labour Party branch comprises an "inner circle", with a significant body of "networked" members, and a dense structure of ties with other core members, then stretching out to peripheral members, but also detached completely from a large proportion of the membership. In the Conservation group, by contrast, there is more of a 
bicycle wheel, "hub and spoke", structure with a small central group communicating with a larger number of peripheral members, but fewer crosscutting ties between other members.

Table 5.1 uses information from the first phase postal questionnaire to show that nearly all members were active, but that this was very uneven between activities. Nearly everyone read the newsletters, but less than half went to meetings, donated money, or attended social events. It is also apparent that there is a significant difference between the Labour Party branch and the Conservation group. Activism in the latter was lower overall and involved less effort. Only one activity, reading the newsletter, was reported by more than a quarter of its members, and it is striking that this is largely a passive and private activity. Less than a quarter of the membership attended meetings or wrote letters of protest. By contrast, Labour Party branch members were more likely to attend meetings, donate money, sign petitions, and get involved in fund raising. They were also considerably more sociable with each other.

Table 5.1 Members engaging in particular activities at least once a year (percentages)

\begin{tabular}{lcc}
\hline Activity & Labour Party & Conservation \\
\hline Reading newsletter & 83 & 98 \\
Donating money & 42 & 11 \\
Writing letter of protest & 19 & 23 \\
Signing petition & 33 & 11 \\
Purchasing merchandise & 4 & 4 \\
Attending meetings & 40 & 23 \\
Attending demonstrations & 8 & 5 \\
Awareness or fund raising & 23 & 9 \\
Organising social event & 6 & 0 \\
Attending social event & 28 & 2 \\
Administrative work & 17 & 9 \\
Research or writing & 8 & 11 \\
Presentations to outside organisation & 4 & 4 \\
Liaising with media & 6 & 7 \\
Consultation & 7 & 11 \\
Representation on committees & 12 & 7 \\
Direct action & 0 & 4 \\
\hline
\end{tabular}


Table 5.2 Correlates of activism

\begin{tabular}{|c|c|c|c|}
\hline & Coef. & Std. Err. & $\bar{P}>|\mathrm{z}|$ \\
\hline \multicolumn{4}{|l|}{ Position } \\
\hline Periphery & 2.114323 & .5206909 & 0.000 \\
\hline Core & 3.557143 & .6125678 & 0.000 \\
\hline Female & .0934872 & .3965229 & 0.814 \\
\hline \multicolumn{4}{|l|}{ Education } \\
\hline GCSE & -.2103913 & 1.402453 & 0.881 \\
\hline A-Level & .2414416 & 1.260147 & 0.848 \\
\hline Technical & -1.353706 & 1.520022 & 0.373 \\
\hline Nursing & -1.180605 & 1.410506 & 0.403 \\
\hline Degree & -.5758848 & 1.252017 & 0.646 \\
\hline Postgraduate & .0428669 & 1.255319 & 0.973 \\
\hline \multicolumn{4}{|c|}{ Age: Reference : less than 25} \\
\hline $25-34$ & 10.91914 & 1025.995 & 0.992 \\
\hline $35-44$ & 11.59448 & 1025.995 & 0.991 \\
\hline $45-54$ & 11.35755 & 1025.995 & 0.991 \\
\hline $55-64$ & 11.87535 & 1025.995 & 0.991 \\
\hline $65+$ & 10.00271 & 1025.995 & 0.992 \\
\hline Personal income & -.002062 & .0712501 & 0.977 \\
\hline \multicolumn{4}{|c|}{ Class (Goldthorpe 5 class scheme) } \\
\hline Petty bourgeoisie & -37.58004 & $1.72 \mathrm{e}+08$ & 1.000 \\
\hline Farm workers & 1.289327 & 1.135849 & 0.256 \\
\hline Skilled workers & 1.268142 & 1.228581 & 0.302 \\
\hline Non-skilled work & -32.54105 & $1.01 \mathrm{e}+07$ & 1.000 \\
\hline Constant & -13.75636 & 1025.995 & 0.989 \\
\hline
\end{tabular}

Notes: definition of position: periphery $=$ knows between 1 and 4 other organisation members, core $=$ knows five or more (reference group $=$ outsiders, who know nobody)

Table 5.2 examines the variables that correlate with levels of activism in the two organizations - defined here as the amount of time spent on organizational activities $^{6}$. Table 5.2 shows that network position is the only significant variable that accounts for different levels of activism amongst members. Core members (especially) and peripheral members are significantly more likely than isolates to be active. This is not surprising: we would normally expect that those in core positions are most active simply by virtue of their being in such positions, but it 
is striking that no other factor, including the individual social class position, age and gender of the members, makes any difference. It is important to note that there are no differences between the two organizations. Hence, if we want to know why the Labour Party branch reports more aggregate activism than the Conservation group, the answer is not to do with the fact that it has different types of members, but that its "inner circle" network structure with a larger core tends to generate higher levels of involvement.

Clearly, these are only two case studies, but they nonetheless have interesting implications. They suggest that involvement and activism is most intense when linked to disputatious stakes and contests. In the Labour Party branch there were acrimonious debates about the shift to New Labour politics, about who should be the local leaders, and about the most effective forms of activism. In these situations factions developed, arguing different views, but this nonetheless generated higher levels of activism. Associations are hence important when stakes are involved, and when its causes matter. This observation helps explain the golden age of social capital depicted by Putnam as being in the 1960s in the US (see also Szreter 2002). This was not only the period when membership of associations peaked, but it was also a period of major conflict, linked to the civil rights movement, the anti-Vietnam war protests, second wave feminism, and so forth. The lesson for those who want to promote social capital through encouraging associations is that unless the associations have stakes and real issues which motivate members, they are unlikely to be effective in generating involvement. One cannot have "controlled" social capital, with people active in associations but in ways decreed by policy makers and governments: in short one cannot have one's cake and eat it.

\section{A crisis of white male working class social capital}

Let us conclude by using our theoretical and methodological observations to reflect on the debate about the stock of social capital in contemporary Britain. Peter Hall's (1999) influential interpretation of trends in social capital argues that in the UK, unlike the US, there is no simple and unequivocal decline in associational membership, but that membership of particular kinds of association, especially trade unions, have fallen. Collaborative research we have conducted with Andrew Pickles ${ }^{7}$, Gindo Tampubolon and Alan Warde supports this interpretation for the more recent periods (see Li et al. 2003; Warde et al. 2002). Table 5.3 considers how associational membership is related to these trends. Near the bottom of Table 5.3 are shown the mean number of organisations that respondents belong to, allowing us to reveal broad trends in stocks of social capital. The findings, based on the Social Mobility Inquiry 
(SMI) of 1972 and the British Household Panel Survey (BHPS) of 1992 and 1999, are reported in three ways to deal with differences in the types of associations that respondents could claim membership of in the three surveys. First, the figures for all listed organisations are 1.42 in 1972 and 1.17 in 1999 for men, which are broadly consistent with but actually show less decline than those offered by Hall. However, this figure is misleading since respondents were offered a different range of associational types of which they could claim membership in 1972 and 1999. Therefore, if we only consider the seven organisations that were asked about specifically in both the SMI and BHPS, we see a fall from 1.16 in 1972 to 0.86 in 1999, suggesting a significant fall in social capital. However, most of this decline in male participation occurred primarily in trade unions and working-men's clubs. If we exclude memberships in these two organisations, the mean number in the remaining five common organisations shows considerable stability from the early 1970s to the late 1990s (0.50 and 0.46). Women's participation was on the whole lower than that of men but was somewhat on the increase no matter how one views the results: in terms of all listed, or seven or five common, organisations. 
Table 5.3 Participation in voluntary associations in England (1972-1999)

\begin{tabular}{|c|c|c|c|c|c|}
\hline \multirow[b]{3}{*}{ Membership in organizations (\%) } & \multicolumn{3}{|c|}{ Men } & \multicolumn{2}{|c|}{ Women } \\
\hline & 1972 & 1992 & 1999 & 1992 & 1999 \\
\hline & & & & & \\
\hline Trade unions & 38.7 & 26.1 & 21.7 & 15.5 & 16.1 \\
\hline Sports/Hobby Clubs & 25.0 & 25.6 & 26.5 & 11.3 & 14.3 \\
\hline Working men's or Social Clubs & 27.2 & 20.6 & 17.7 & 7.4 & 6.9 \\
\hline Professional associations & 11.4 & - & 14.1 & - & 7.8 \\
\hline Church or religious groups & 9.0 & 8.1 & 7.0 & 12.4 & 11.1 \\
\hline Tenants'/Residents' groups & 3.6 & 7.1 & 7.3 & 8.4 & 9.1 \\
\hline Parent-Teacher Associations & 5.6 & 3.6 & 2.4 & 7.3 & 6.4 \\
\hline Political party & 7.1 & 3.5 & 3.1 & 2.7 & 2.1 \\
\hline Voluntary services groups & - & 4.6 & 3.8 & 4.2 & 3.3 \\
\hline Environmental group & - & 3.2 & 2.4 & 5.3 & 4.3 \\
\hline Other community/civic groups & - & 2.9 & 1.6 & 3.2 & 1.9 \\
\hline Women's institutes/groups & - & - & - & 4.4 & 3.7 \\
\hline Scouts/Guides organizations & - & - & 1.2 & - & 1.8 \\
\hline Pensioners' group & - & - & 0.7 & - & 0.4 \\
\hline Other & 14.8 & 12.3 & 7.9 & 9.2 & 7.2 \\
\hline \multicolumn{6}{|l|}{ Mean number of organizations } \\
\hline All listed organisations & 1.42 & 1.17 & 1.17 & 0.91 & 0.96 \\
\hline Seven common organisations & 1.16 & 0.94 & 0.86 & 0.65 & 0.66 \\
\hline Five common organisations & 0.50 & 0.48 & 0.46 & 0.42 & 0.43 \\
\hline $\mathrm{N}$ & 9,857 & 2,981 & 2,673 & 3,145 & 2,826 \\
\hline
\end{tabular}

Note:

1. For respondents aged 20-64 and resident in England at the time of interview.

2. The seven common organisations are trade unions, sports/hobby clubs, working men's or social clubs, church or religious groups, tenants/residents groups, parent-teacher associations and political party. The five common organisations are sports/hobby clubs, church or religious groups, tenants/residents groups, parent-teacher associations and political party.

3. Cross-sectional weights are used for each of the data sets.

Source: The Social Mobility Inquiry (SMI) of 1972 and the British Household Panel Survey (BHPS) of 1992 and 1999 (the same for Tables 5.4 and 5.5 below). 
The apparent decline in social capital is therefore accounted for almost entirely by two types of organisations. In 1972 trade unions were by some distance the most popular associations for men, yet by 1999 they had lost 44 per cent of their members and had been overtaken by sports/hobby clubs. Workingmen's or social clubs were the second most popular organisations for men in 1972, but also lost 35 per cent of their members in this period. (We cannot easily identify the comparable trends for women, as we do not have data on female membership in 1972.) However, there was actually rising membership in groups such as tenants' groups and professional organizations (3.7 and 2.7 points respectively). There was also a remarkable decline in memberships of political parties, a drop of 4.0 points. Comparing women's membership profiles with those of men in the 1990 s, we see that the former are less likely to be in trade unions, sports clubs, working-men's clubs and professional associations at the corresponding time points. Women are, however, more likely than men to join religious groups, tenants' groups, parent-teacher associations, voluntary or civic organizations. Table 5.3 indicates that the electoral success of New Labour coincided with a remorseless decline in the kinds of associations that helped support the Party in previous years.

In some ways of more concern than this is that the social composition of associations has changed substantially, so that increasingly all kinds of association are the province of professional, managerial and white-collar workers (see Table 5.4). Table 5.4 looks at the odds ratios of various groups for belonging to associations. In 1972, the male service class and the intermediate class have negative odds ratios compared to the working class: in other words they were less likely to be in associations (though in the case of the service class, the odds ratio is not statistically significant). By 1999, however, the service class has a significant positive odds ratio, indicating they are considerably more likely to be members. The odds ratios for women indicate that service class women are even more disproportionately likely to be members compared to working class women than is the case for men. It is also more likely for the well educated to be members, though for men this odds ratio falls somewhat. 
Table 5.4 Logit models for associational involvement (joiners versus nonjoiners) (1972-1999)

\begin{tabular}{ccccc} 
& Men & \multicolumn{2}{c}{ Women } \\
1972 & 1992 & 1999 & $1992^{2}$ & 1999 \\
\hline & & & & \\
-.331 & .513 & $.623^{*}$ & $1.174^{* * *}$ & $1.626^{* * *}$ \\
$-.253^{* *}$ & -.152 & $-.427^{*}$ & $.307^{*}$ & $.566^{* * *}$
\end{tabular}

\section{Education}

Degree/professional

$\begin{array}{lclll}.948^{* * *} & .705^{* * *} & .518^{* *} & .686^{* * *} & .770^{* * *} \\ .203 & .335^{*} & .127 & .382^{* *} & .238\end{array}$

A/O Levels

Intergenerational mobility

Up into service

Down from service

$\begin{array}{rrrrr}.321 & .061 & -.323 & -.271 & -.128 \\ -.054 & -.095 & -.053 & .380^{*} & .380^{*}\end{array}$

Work-life mobility

Up into service

Down from service

$\begin{array}{lllll}-.048 & -.401 & -.233 & -.358 & -.673^{*} \\ .146 & -.511 & .116 & -.007 & .366\end{array}$

Friendship homogamy

Having SV friends

$.181 \quad .310^{*} \quad .116 \quad .376^{* *} \quad .316^{*}$

Constant

$1.510^{* * *} \quad .329^{* *} \quad .485^{* *} \quad-.533^{* * *}-.783^{* * *}$

$\mathrm{N}$
Pseudo $\mathrm{R}^{2}$

5,024
.012

1,485

1,193

1,741

1,426

Pseudo R ${ }^{2}$

.042

.031

.060

.079

Note:

$1{ }^{*} \mathrm{p}<0.05,{ }^{* *} \mathrm{p}<0.01$, and ${ }^{* * *} \mathrm{p}<0.001$ with robust standard errors used in the models (the same for Table 5.5 below). 
It is important to recognise, therefore, that Table 5.4 is testimony to an important historical reversal. It was E.P. Thompson's point that the manual working class invented the modern formal association which anyone could join, and the powerful presence of the working class in British society was dependent on their remarkable institutional strength in trade unions, friendly societies, cooperative societies, building clubs, health clubs, and working men's clubs. Whereas the kinds of organisations populated by the middle classes tended to be autonomous civic associations, the working class tended towards the branch form, whereby they belonged to local branches of larger organisations which could hence connect otherwise disparate locales. This kind of tradition of organisation persisted well into the post-war years: when Brian Jackson (1968) reported his study of his native Huddersfield in the early 1960s, he portrayed it as a working class town brimful of formal associations: working men's clubs, brass bands, bowling clubs, trades unions. He noted that it was difficult to find any area of the town that did not have some kind of social club located in it, and he observed the central role of these clubs for local sociability and neighbouring. Indeed, in this period, working class men were more likely to belong to associations than were middle class men, if only because they were more likely to be in trades unions. One account of working men's clubs in Nottingham and Leicester noted that

On Saturday evening, if one stands in the centre of the town, it can be with the thought that there are about 10,000 people enjoying club activity, all within a few minutes walk. They are not producing anything and nobody is making a profit (except for the employed artistes and waiters), but all these people are associating spontaneously and democratically (Qualidata, Jackson collection, box $\mathrm{C} 2$ ).

Of course we should not assume that these organisations mobilised all working class people. Far from it: they too were organised on the basis of insiders and outsiders - since we have argued that all effective organisations depend on creating a group of outsiders against whom one distinguishes oneself and thus gains collective identity. In the case of these working class associations, the gender divide was of primary significance. Women were formally debarred from full membership of most working-men's clubs and social clubs - though on the weekends as many as $40 \%$ of visitors might be women admitted as guests. This, however, confirmed their honorific and dependent status. There was also a marked racial division, with black and ethnic minorities mainly being excluded, and marked factionalism along ethnic and religious lines. Furthermore, as Jackson also emphasises, involvement in these associations was contested in that the middle class patrons were often treated with some distrust. One Huddersfield man asked how it was that we had only $£ 4$ 
$14 \mathrm{~s}$ and $6 \mathrm{~d}$ from all these vice- presidents. "We give them the honour, and they do nothing back". The secretary explained

it's not just donations that we get, its services in kind, and they don't all go down on the accounts. Generally speaking you find that it's the people you never see who send a donation..... the others do other things. Councillor Harold Haigh (presidents of Lockwood, a business owner) you don't see him so oft, but he's printed programmes for us twice free of charge. He's a very valuable man to have. Somebody else remembered that Cllr Haigh had put a pound in the collection at the band contest. The Barretts of Manchester were the people who'd been invited to the dinner. (Qualidata archive, Jackson collection, box C4).

This kind of associational culture has atrophied with remarkable speed since the 1960s. Today, the kinds of associations that predominate are sporting clubs organised on commercial lines that appeal very largely to a middle class audience. At one extreme are consumerist gyms and sports complexes - some with swimming pools, squash courts, restaurants, golf courses, and saunas which now proliferate in out of town locations and charge a high fee. Such associations slot into particular kinds of executive lifestyle. During research Mike Savage conducted with Gaynor Bagnall and Brian Longhurst on people's sense of local belonging in and around Manchester (Savage et al. 2005), it was striking that the area with the most members of associations was the executive suburb of Wilmslow, and that many men were attracted to these kinds of complexes. The "Pond" was a particularly lavish example, located close to Manchester airport in semi rural Cheshire. Stuart, one affluent respondent responded to a question about who belonged by noting that

I would say that there are many entrepreneurs and private business owners, I think there are many other people that join there because it's good for their business they believe, people like bankers, accountants, lawyers, who believe they can network and meet people. You get a lot of young children who are introduced by their parents who are members there, because it's got a very active gymnasium area there's a lot of young people go and mothers go during the day, especially in school holidays. But generally you're talking about higher income people, I don't think it's expensive but an average working man would think that fifteen hundred pounds a year for an annual fee might be expensive. I think it's very inexpensive when you compare its facilities to other places in the world, somewhere like that in America would cost ten times that.

This point was amplified by another member

It's convenient. Because it's a private club and I can typically have people show up off a train or a plane, it's the kind of place that happens to have dining facilities from eight in the morning till eleven at night, and sixteen years ago when I joined you still had restrictions on licensing laws so you would go along 
somewhere, nothing to do with that, but a pub or a hotel would close and somebody would turn up in the middle of the afternoon and you couldn't get a drink or a snack. Things have changed drastically and a private club like that had all of those facilities, I believe that's why they've been very successful, so that was the reason I joined it, plus I was getting very interested in golf and it's a good course.

There is then a close congruence between these kinds of associations and the habitus of the affluent middle classes (see further, Savage 2004). Surprisingly, campaigning and pressure groups, which generally appeal to different kinds of people, also exemplify some similar features. Just as in the two case studies we examined above, these are now overwhelmingly composed of the affluent middle classes. We also found, during our studies of belonging in Manchester, that the kinds of involvements these generated were also minimal: the "good purpose" that was evinced in joining an organisation need not lead to fuller engagement. Sometimes this was for pragmatic reasons: for one member "we do keep meaning to go to all the meetings, but they are on Monday evening and we tend to be busy then". For another "I'm a member of Amnesty and Friends of the Earth, but I just pay a subscription, I don't do anything". A third was "not active at all" in Amnesty and Greenpeace, and when asked if he attended meetings he replied bluntly, "No, I'm lazy". The following participant expressed this syndrome especially well

I mean I tend to belong to things, you know, like I'm a member of Amnesty International, but my social life isn't bound up with them, I'm very much the sort of "here's my annual fee", and I might write some letters and join in a campaign, but I do it very much under my own steam, so I wouldn't really count things like that..... (When asked if she ever attended meetings) I've tended not to. I have done in the past and at the moment quite honestly I'm what I'd call a sleeping member... I completely believe in what they're doing, and I suppose it is a convenient way for me, as someone who is not going to run about and do anything about it myself, to actually support what they're doing. It's very much that sort of thing.

What we see here is a kind of individualised expressive commitment to an organisation as a badge of visible commitment, which need not involve practical activity within the association. It seems that once the badge of concern is earned through membership, little more needs to be done. There is no real concern to develop social contacts because there is little direct instrumental gain in such organisations, when an individual changes their values or time commitments, so their membership wanes. A further example is a participant who had recently joined the Labour Party branch because 
I had the feeling the need to be more politically active and understand more about politics and I supposed I've always felt that I've never been taught anything about politics, its quite difficult to find out about politics, and I'd been reading a few books and deduced that Blair's version of socialism was more akin to what my view of politics was.... so I thought I'd give them my moral support....

\section{But you didn't want to get involved?}

I think maybe I would have done, but the meetings are always on a Monday night and I teach on a Monday night so it clashes with that.

Increasingly there is an alignment between associational involvement and particular forms of middle class habitus. In part, this is due to the way that some organisations deliberately seek to recruit the kinds of people who have the skills and aptitudes that are useful to them: as experienced chairs, public speakers, secretaries and the like (see Savage 2005 for an elaboration of this argument).

The observations above support one of Bourdieu's (1987) contentions that a fundamental divide in contemporary societies is between those who are involved, and are able to have a point of view, and those who are disconnected and detached, who do not feel able to have stakes. Evidence is accumulating that it is especially the white, young, working class who fall into this position, to the extent that we can see associational social capital as involving a vicious circle: associations increasingly come to be populated by well educated middle class groups, so that those from other social positions feel they do not belong and tend to drop out. This confirms the need on the part of the organisations to look to the kinds of people who can be relied upon to be recruited into the organisation, so reproducing the exclusive character of the group itself. This reduces the kinds of stakes - the kinds of contests and different opinions - that may be found within these organisations, which as we have seen above in Section 2 reduces activism and involvement from members.

\section{Conclusions}

The account above is in some respects a bleak one, at least insofar as associational social capital is concerned. Associational social capital is important, as Putnam argues. It does convey benefits: those who belong to associations are more trusting and more publicly involved. However, there has been a fundamental remaking of the social relationships of associational memberships. Previously based on the public role which primarily distinguished active men from private women, they now do include women, but are marked by a striking class divide. Yet, because these associations serve as apparently open to everyone, their sectional nature is opaque, and the lack of involvement 
of particular social groups can be identified as their problem, rather than as a result of the associations themselves. This is central to contemporary class relationships: fundamental inequalities are registered as the product of individual taste, skill or decision (see Savage 2000).

As Putnam would expect, we can see that those who are not in any organization are less likely to identify with a political party. Indeed, this becomes more pronounced over time. In 1972 male non-members were 54 per cent more likely not to identify with a party than those in both civic and labour organizations. By 1999 male non-members were 82 per cent more likely not to identify. By 1999, 42 per cent of all respondents who were not in any kind of organization showed no support for any of the main political parties, and these respondents were typically found in disadvantaged social positions and were poorly educated. ${ }^{8}$ By the 1990 s there therefore appears to be a distinctive group who are not involved in associations and do not politically identify.

One indication of the significance of this point is to note the importance of associations in generating sectional loyalties. Table 5.5 presents one example, the case of political identification, in this case with the Labour Party. It is now a staple argument that over the past thirty years there has been a process of class dealignment as voters become more discriminating and less likely to vote on the basis of habit or their social location. Table 5.5 does indeed show that the class gradient does decline between 1972 and 1999: in 1972 service class men were three times less likely to support Labour compared to working class men, but by 1999 this ratio had fallen to half. If, however, we look at the top rows, which indicate how membership of labour or civic associations affects membership, we can see that membership of civic associations continues to depress Labour identification, and there is no sign that this relationship has changed.

\section{Table 5.5 Logistic regression models on Labour support}

\begin{tabular}{lllll} 
& Men & \multicolumn{3}{c}{ Women } \\
\hline 1972 & 1992 & 1999 & 1992 & 1999 \\
\hline
\end{tabular}

Associational involvement

$\begin{array}{lcllll}\text { Both } & 1.40^{* * *} & 1.44^{*} & 0.94 & 1.59^{*} & 1.06 \\ \text { Civic only } & 0.72^{* *} & 0.61^{* *} & 0.56^{* *} & 0.58^{* * *} & 0.58^{* * *} \\ \text { Labour only } & 1.70^{* * *} & 1.71^{* *} & 1.14 & 2.07^{* * *} & 1.33 \\ & & & & & \\ \text { Neither (base) } & 1.00 & 1.00 & 1.00 & 1.00 & 1.00\end{array}$


Class

Service class

Petty bourgeoisie

$0.31^{\text {*** }}$
$0.24^{\text {*** }}$
$0.49^{\text {*** }}$

$0.36^{* * *}$

$0.51^{* * *}$

$0.66^{*}$

0.81

Intermediate class

$0.36^{*}$

$0.51^{* *}$

$0.44^{*}$

$0.30^{* *}$

$0.56^{* *}$

$0.45^{* * *}$

$0.61^{* *}$

$0.59^{* *}$

Working class (base)

1.00

1.00

1.00

1.00

1.00

Education

Degree

Professional

$1.78^{* *}$

$1.93^{* *}$

1.39

$1.87^{*}$

$2.26^{* *}$

A/O Levels

1.07

0.90

0.81

1.15

1.14

$0.66^{* * *}$

0.79

1.06

1.05

0.75

Voc/None (base)

1.00

1.00

1.00

1.00

1.00

Parental class

Service class

$0.42^{* * * *}$

$0.66^{*}$

$0.53^{* * *}$

$0.41^{* * *}$

$0.50^{* * *}$

Petty bourgeoisie

$0.38^{* * *}$

$0.46^{* * *}$

$0.39^{* * *}$

$0.35^{* * *}$

$0.47^{* * *}$

Intermediate class

$0.73^{* * *}$

$0.70^{*}$

0.82

$0.54^{* * *}$

$0.61^{* *}$

Working class (base)

1.00

1.00

1.00

1.00

1.00

Friendship homogamy

Having service

$0.68^{* * *} \quad 1.04$

0.85

0.87

$0.66^{* *}$

class friends

No service

class friends (base)

1.00

1.00

1.00

1.00

1.00

Marital status

Married

$0.76^{* *}$

0.88

0.92

$0.67^{* *}$

$0.67^{*}$

Other (base)

1.00

1.00

1.00

1.00

1.00

Employment status

Unemployed

$1.73^{* *}$

$3.77^{* * *}$

0.87

1.52

2.17

Other (base)

1.00

1.00

1.00

1.00

1.00 


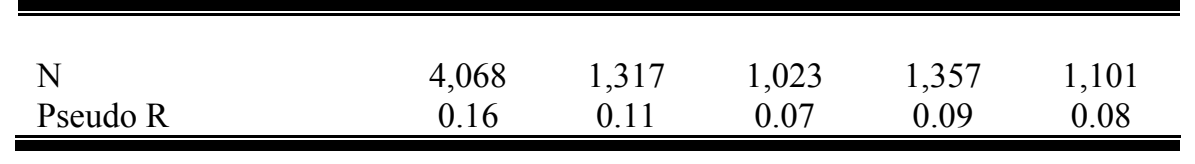

In this paper we have therefore argued that the research agenda on social capital has opened up important issues for investigation. In order to do justice to these issues we need to avoid conflating the concept of social capital with informal social relationships, and remain sensitive to the particular kinds of networks and connections which can be made in diverse ways. Using this framework we have drawn attention to the intimate connection between connection and disconnection. Creating effective ties between people (defining "insiders") also involves distinguishing boundaries from others ("outsiders"). Where social capital is important it generates stakes, tensions, and factions, both inside associations, and in social relationships more generally. With this argument in mind, we have shown how we can agree with Putnam that there are important trends occurring in the contemporary distribution of social capital. However, rather than these marking a straightforward decline of social capital, it is more accurate to see this as representing the end of white, male, working class social capital, which had previously played an important role in British society. The result, we have speculated, is to create a new kind of division around the axis of involvement, but this is an axis which is opaque because it can be rendered as one which is produced by individual tastes, rather than by more systematic social process.

\footnotetext{
${ }^{1}$ The arguments developed in this paper owe a great deal to our research collaborators, and although we refer to their specific contributions at appropriate points, we want to mention here the contributions of Gaynor Bagnall, Brian Longhurst, Kath Ray, and Alan Warde.

${ }^{2} \mathrm{Li}$ et al. (2005) show that in the UK, the apparent association between associational membership and interpersonal trust disappears once the social attributes of individuals are controlled for (since well-educated professionals and managers are likely both to belong to associations and be relatively more trusting). Hall (1999) in the UK and Paxton $(1999 ; 2002)$ in the US show that falling levels of reported trust can co-exist with stable levels of associational membership.

${ }^{3}$ See Li et al. 2005 on how it is possible to distinguish social capital arising out of associational membership from that resting on neighbourhood attachment and social network support.

4 'Social capital and social networks: the careers of political activists', funded by the ESRC under its 'Democracy and Participation' Initiative (ref L215252045).

${ }^{5}$ We also had a third case study, an environmental group. Because it was much smaller than the other two organisations (it had only 31 members), we have omitted it from most
} 
of our analysis so that we can focus on the pair-wise comparison between the two larger organisations.

${ }^{6}$ We have used factor analysis to examine the relationship between different types of activism. This reveals three different factors, one linking those who were collectively active, another linking those who were financially active, and a third linking those who were active in individual activities. However, since there are no obvious differences in the factors pre-disposing individuals to these three types of activism, we focus here on an aggregate measure of activism in general.

${ }^{7} \mathrm{Li}$, Pickles and Savage, 'Social capital: developing a measure and assessing its value in social research' (R000223671).

${ }^{8}$ Further analysis shows that while $24 \%$ of the working-class men were in the 'Neither' group in 1972, the figure was $40 \%$ in 1999 . A full $60 \%$ of the working-class women showed no political support in 1999. For further details of class differences in associational involvement, see Li et al. 2002b. 


\section{CHAPTER SIX}

\section{BANKING ON FAMILIES: How FAMILIES GENERATE AND DisTRIBUTE SOCIAL CAPITAL ${ }^{1}$}

FRANK F. FURSTENBERG

\section{Banking on Families: How Families Generate and Distribute Social Capital}

It is hard to find a recent concept in the social sciences that has been greeted with more enthusiasm than the notion of social capital. (A recent Google count produced 98,000,000 hits.) The construct combines long-standing and fundamental ideas in sociology and political theory that are applicable to a wide range of issues. Yet, as is true of many broad theoretical concepts, consensus on its meaning and measurement is elusive. This chapter identifies a set of theoretical and methodological concerns that must be addressed if we are to put this construct to good use in empirical research.

In an earlier essay on family-based social capital I traced the history of the term and pointed out several ambiguities and gaps in its use (Furstenberg \& Kaplan, 2004). The term seemingly brings together ideas from two distinct theoretical traditions: Emile Durkheim's (1951) writings on social norms and the integration of society, and Alexis de Tocqueville's (1969) seminal work on mediating institutions and social trust. In fact, however, these different lines of scholarly work have produced somewhat dissimilar understandings of social capital, strategies for examining it, and its implications for social policy.

Although I do not review this history in any detail, I begin with a capsule statement of these traditions, which provides a rationale for the relevance of social capital to the sociology of family and kinship, the topic of this chapter. Then, I discuss a set of interrelated theoretical questions that social capital theory raises for researchers. This discussion inevitably leads to the thorny issue of measurement; how we know whether family arrangements have high or low social capital and are themselves embedded in larger communities that possess 
various levels of social capital. The problem of measurement must be solved before we can determine whether the idea of social capital is merely decorative or truly fruitful.

\section{Social Capital: What Is It?}

Durkheim (1951) argued forcefully that social life is not irreducible to individuals. Individuals are embedded in a social system of common expectations and obligations - a normative structure - that regulates social life and, hence, represents an entity that is more than the sum of its individual parts. Where high consensus and a strong sense of obligation to the collectivity exist, individuals feel a sense of integration, belonging, and commitment to the larger society. The opposite state, which Durkheim referred to as anomie, leads to disintegration and deviant behaviour.

James Coleman (1988), who is principally responsible for introducing the idea of social capital to sociology, owes much to Durkheim's ideas. For Coleman, possessing social capital ultimately means that individuals are embedded in a system of normative obligations created by social consensus. Individuals can draw on this type of system for help and support, but they are also obligated to respond to others. Coleman's ideas apply equally to families, schools, and larger communities, although his work is centered on micro rather than macro structures. The sense of obligations and reciprocity figure prominently in his discussions of social capital in families and schools, which, he believed, engendered academic success. His writing has stimulated work on social networks, connectedness, and the flow of information (Burt, 2000; Lin et al., 2001).

Pierre Bourdieu (1973), whose work preceded Coleman's, offered a variation on Durkheim's ideas in his theory of social reproduction. According to Bourdieu, families possess different amounts of symbolic and material resources, which enable them to gain advantages for their members. How families generate and mobilise these resources ultimately affects the success of their members, an idea that closely resembles and antedates Coleman's general hypothesis.

Others, especially political scientists and political sociologists draw from Tocqueville (1969) in conceiving social capital, who explores the relationship of the individual to the state and how political systems gain popular legitimacy and create political participation. Robert Putnam $(1995,2000)$ has been the chief proponent of this line of inquiry. His interest has focused on national and local systems that generate high social trust (legitimacy) and high civic involvement. Although social capital is conceived of as a social property, its manifestations 
have largely been measured at an individual level. This line of work has been more macro than micro and rarely extends to family and kinship.

I attempt to blend these two (or three) traditions in this chapter, given that they both contain important ingredients for exploring family-based social capital, although it is clear that my ideas more closely follow those of Durkheim, Coleman, and Bourdieu (see also, Portes [2000b], who has followed a similar strategy). I define social capital as the stock of social goodwill created through shared social norms and a sense of common membership from which individuals may draw in their efforts to achieve collective or personal objectives. By membership or affiliation, actors (in this case, members of a family or kinship system) may derive benefits through sharing objectives, sponsorship, connections, and support from others inside and outside that family. Thus, social capital, like human capital, presumably enhances life chances by mobilising social rewards, reinforcing commonly shared standards, and creating connections to and help in achieving economic, political, and social ends.

Note that this definition is morally neutral: High social capital can reside in the Mafia, religious sects, or military families alike. It is a property of a social system to which individuals residing in that system potentially have access. As will become evident, however, it does not automatically follow that individuals will benefit from their social circumstances simply because they are embedded in a family (or community) with high social capital. My definition of "family" includes membership related by blood, legal ties, adoption, and informal ties including fictive or socially agreed upon kinship.

I propose a set of questions that must be answered before we as a field can make serious headway in understanding how social capital operates within family and kinship systems and whether it evokes the types of consequences that were predicted by Coleman (1988) and Bourdieu (1986; Bourdieu \& Passeron, 1977).

1. How is social capital generated and accumulated in families and larger kinship structures?

2. How do families mobilise and deploy the social capital that they possess?

3. What are the effects of the successful deployment of social capital on their members' behalf?

4. How does the use of social capital translate into the achievement of family objectives?

In answering these questions, it is useful to remember the macro and micro divide. Namely, is the ability of kinship systems to garner social capital related 
to features of the larger social structure in which the family systems are embedded? This raises the issue of how family-based social capital is distributed in the larger society. Here we might consider minority populations in countries where they are denied citizenship; for example, Jews in Medieval Europe, Turks in Germany, or non-citizens in the United States. Can social capital created in kinship systems be leveraged beyond family boundaries or the ethnic community in which kinship systems may be overlapping?

To answer these questions requires a method to accurately measure social capital. This is especially difficult because the construct refers to a collective property whereas existing measures rely on reports of individuals. Moreover, social scientists have been unable to agree on a common procedure for measuring social capital. I will return to this vexing problem after first explaining what is at stake in answering the questions posed above.

\section{Generating Social Capital}

According to my definition of social capital, families and kinship networks will differ in their capacity to invoke common norms and levels of trust, commitment, attachment, and exchange that produce a sense of mutual obligations among their members. Independent of, but probably correlated with, this ability to create common beliefs and obligations is a family's ability to connect to outside communities with similar attributes, whether those communities be neighbourhoods, local institutions, or less immediate connections through work or affiliations. In fact, we know little about how such processes operate both within families and between families and their surrounding communities (Bott, 1957; Furstenberg, 1993; Leventhal \& BrooksGunn, 2000; Burton \& Jarrett, 2000). Since Bott's classic study, a series of studies have examined the process by which families adapt to and make use of local ties, though few of these have explicitly addressed how families build social networks of extended kin and neighbours (see, e.g., Bott's 1971 review in the revised edition of her book, and Micheli, 2000; Unger \& Sussman 1990; Wellman \& Wortley, 1990).

\section{Within Families}

We can speculate on some of the sources of differences in creating social capital within families. No doubt, individual differences are an important part of the story of how families operate as a tiny social system. A long tradition of research dating back to Burgess (1948), Blood and Wolfe (1960), and Winch (1958), among others, postulates that the success of courtship (what economists refer to as "the search process") varies according to both information and the 
ability to make good choices. The predominantly free market system of marriage selection in the West assumes that individuals will select like-minded partners, although probably not nearly so like-minded as parents would select for them. Judging from the relatively high rates of divorce, personal choice has its limits and calls into question the ability of a system based on romantic love to create unions of high consensus and compatibility.

As family sociologists observed a half-century ago, the success of marriages depends to some degree on the level of class, ethnic, and age similarity between the partners. Educational systems, neighbourhoods, and workplaces are breeding grounds for assortative mating, in which individuals of similar status meet and mate. Presumably, such status congruity is linked to greater consensus, or what Bourdieu referred to as a solidarity of interests. Partners who share views have a head start in the process of generating high social capital. Moreover, their extended families and surrounding communities ought to be more likely to share common goals, creating the basis of a high social capital, kinship network.

Yet, as Durkheim (1933) proposed, individuals build ties based more on complementary than compatible skills and attributes, and marital stability is grounded in an agreed-on gender-based division of labour (Parsons, 1942). Individuals in these unions are left to bargain on their own apart from family and community, although prevailing ideas of marital roles shape the nature of the bargain.

Marriage has certainly changed over time, as historian Stephanie Coontz (2005) has observed. The prevailing model in the 1950s regarded marriage as a single unity. The companionate model was built on the assumption that $1+1=$ 1 (you and I become a single us.) The current model, at least in a growing number of couples, is modified to $1+1=3$ (you, me, and us). In the simplest terms, the assumption of unity has been altered to permit for more separateness within the relationship.

Therefore, contemporary families are formed under conditions that do not necessarily confer high social capital (a congruence of beliefs, shared meanings, and common expectations). At the atomic level, the union is formed often without much outside pressure to build a common nomos, an internal congruity based on common statuses, or even a shared sense of complementary, though we might expect that this would vary considerably among immigrant versus native born and presumably be higher when both partners share common educational, religious, and political values (Berger \& Kellner, 1975). In short, family formation relies first on a successful search and then on personal attributes that lead to consensus between partners and a symmetrical exchange, where partners voluntarily trade affection, support, skills, and the like to achieve an equitable bargain. Thus, the Western model of marriages relies on an exchange of 
interests rather than an imposition of common interests such as may exist in marriage systems in Asia or Africa (Goode, 1964; Kalmijn, 1998).

This is not to say that similarities in class, ethnic, age, and even religious affiliations are unimportant in a couple's ability to achieve consensus or a common perspective, and family demographers might want to ask whether endogamous unions are more or less likely to create stability than they did in the past (see, e.g., Kalmijn, 1998; Mare, 1991.) And qualitative researchers could explore the ways that common culture is imported from family experience, religion, mass media, and the like.

Thus, at a microlevel, couples must, themselves, generate the stock and trade of high social capital, through sustained interaction. The creation of these smallest societies, however, has not been fully explored, although recent studies of marital dyads by clinical researchers are adding greatly to our understanding of how couples manage to forge lasting bonds. (See, e.g., Bradbury \& Karney, 2004; Huston, 2000.) We know, for example, that divorce is generationally linked to some degree, but we know little about the basis for this correlation. Is it the result of genetic and temperamental differences that influence a couple's ability to manage a relationship, or skills and capacities that are learned and passed on, or material circumstances that have little to do with a couple's ability to sustain a relationship? Can we assume that high-quality marriages, in which consensus and trust prevail, are correlated as well across generations and that possession of social capital in the form of shared expectations is an ongoing intergenerational process?

Family sociologists and psychologists also have not done enough longitudinal work on families as social systems to pursue this problem, although a growing body of research on continuities and discontinuities in family functioning is likely to provide some insights (Huston, 2000; Gottman \& Krokoff, 1989; Markman, 1981; Rossi \& Rossi, 1990). The ideas and skills among new couples are simultaneously shaped by received wisdom from earlier generations, but also from a couple's capacity to learn from peers through education, employment, and civic life. Partnership roles are based, in part, on anticipatory socialisation and, in part, on socialisation that takes place once roles are acquired. In contemporary society, however, couples are likely to have a series of relationships that can offer "on the job" learning that can either refine or undermine their ability to sustain a relationship. It is an interesting, but largely unanswered, question whether individuals improve their abilities to sustain a relationship through practice in previous relationships, perhaps through a series of cohabitations or marriages. The conventional wisdom is that they do not, but the evidence has not been carefully reviewed to rule out methodological problems related to selection. 


\section{The Impact of Children on Building Social Capital}

Children introduce a new element into the system, requiring partners to collaborate more actively in child-rearing activities. This process provides a critical ingredient in a family's ability to generate a shared system of norms, values, and practices. It is widely assumed that two parents are better for children than one, but this assumption rests, in large part, on the idea that parents help correct, compensate, support, and reinforce each other's parenting abilities (Edwards, 2004; Holland et al., 2003; Morrow, 1999). Although many argue that this ability is grounded in evolutionary biology, skilful parenting is hardly a "natural" human capacity. Poor nurturance (rejection or disengagement) occurs among primates, attributable, in part, to their own upbringing (Soumi, 1991). With the exception of work by clinical and family systems and developmental researchers, remarkably few studies have examined how families "do parenting" together (see, e.g., Dunn \& Brown, 1994; Eisenberg, 1992; Parke \& Bhavnagri, 1989; Sroufe et. al., 1999). Therefore, it is difficult to show how social capital is generated when parents work together or how it is potentially undermined when they do not (Cowan \& Cowan, 1999).

In part, the gap in our knowledge is methodological. Relatively few studies gather data from both (or, perhaps, I should say all) parents and their children, that is, whole family systems even within households much less across households. Therefore, it is difficult to know with certainty whether parents' mutual expectations and investment create a sense of obligation among their children. Elder's research (2000) on farm families suggests that high levels of social capital are created when couples work together and involve their children in a common enterprise. The same might be accomplished in families that operate small businesses or in immigrant enterprises. In such family systems, where cooperation is required, children may be expected and allowed to participate, creating a sense of lasting obligations.

Thus far, I have concentrated on building social capital through union formation and parenting. I would be remiss, however, to ignore children's role in this process. By their expressions of affection and connection, children create or discourage parental investment (Dunn \& Brown, 1994; Dunn \& Plomin, 1990; Eisenberg, 1992). As such, children quickly become full players in a family system. In addition to these face-to-face encounters, children become involved in the outside world, which becomes a source of connection to school, religious organisations, and community life, what Portes (2000b) calls "bridging social capital." Lacking data on how parents and children build ties to the larger community, we can only assume that the presence of children requires parents to reach out to potential connections in the larger kinship system, the neighbourhood, and by involvement in local community institutions. But it is 
clear that in many families, children do a lot of the "work" in making these connections and provide parents with a strong rationale to establish links outside the household (Furstenberg et al., 1999).

\section{Connecting With Kin and Community}

The starting point for building such connections often begins with strengthening bonds with the extended family, which typically have a strong stake in rendering support and sponsorship. As grandparents and other extended kin become more involved, the child (and parents) becomes embedded in a web of obligations and affiliations. Placing the child in social enclosures also occurs through religious involvement. Families generally become more involved in a religious institution when their children are young as a way of incorporating them into a religious community. Similarly connections are made through visits to the park, child care, and the like that increase the indirect links that parents have to information and resources, the stuff of social capital. Children, therefore, provide critical links to the community, although they may do so differently, depending on social class, ethnicity, age, and gender.

We know that generating capital differs greatly by social location and family demography. The distribution of social capital surely varies by religious involvement, a potent source of commonality and connectivity. We know less about how social class influences social capital, but these are some clues suggesting that social capital may operate quite differently across social strata (Furstenberg, 2003). At the bottom of the social strata, families are inclined to rely on close and direct ties for support, limiting the reach of information and resources. Working-class families may be more integrated into the surrounding community, using both kinship and neighbourhood connections (Bott, 1957; Gans, 1962). More affluent and better educated families have more extensive reach, which is perhaps less community and kinship based (Lareau, 2001). Lareau, among other researchers, shows how social class operates to narrow or broaden the scope of community contacts (see also Burton \& Jarrett, 2000). Without the capacity to adequately measure social capital, however, we can only speculate on how it is distributed across social classes.

With the recent waves of immigration, many social scientists have been interested in how the process of social capital accumulation differs among groups with different cultural expectations and practices. Many researchers have noted that family-based social capital is closely connected to the structure of immigrant communities (Portes, 1996; Portes \& Rumbaut, 1996; Waters, 1996). Religious, cultural, and political organisations prevalent in new immigrant communities can help to foster common expectations within families and connections between them. Again, children may play a role in providing 
links within communities and, among more isolated immigrant groups, they can help to create ties to mainstream social worlds. The level of social capital across different immigrant groups offers a natural experiment for examining the effect of social capital on patterns of social mobility, a topic to which I will return.

\section{Mobilising Social Capital in Families}

Earlier, I emphasised that social capital is not an individual property. Individuals have access to different levels of social capital, however, by virtue of their place in a high or low social capital system. Yet, I argue that all members of a system might not enjoy these benefits equally. So it is with families, as Conley (2004) has recently argued.

The skill in accessing or deploying social capital has only recently been recognised as an important component of parenting. How parents manage risk and opportunity by channelling resources to their children may be related to, but is certainly not identical to, their ability to socialise in face-to-face encounters. Whether they reside in high or low social capital settings, such as kinship networks, communities, or work situations, parents must recognise and use the resources at their disposal. Their skill at mobilising and using available social capital is, itself, a resource that should be ultimately linked to their children's success (Burton \& Jarrett, 2000).

In previous work, I have suggested that parents may hoard or misspend social capital, depending on their investment strategies (Furstenberg \& Kaplan, 2004). In her classic ethnographic account of low-income Black families, Stack (1974) observed that members of the "flats" displayed a range of capacities for making and using social connections when rearing children. Some members overdrew on their accounts, exploiting their kin and neighbours, whereas others were more equitable in their exchange. The accumulation of social capital ultimately relies on "the norm of reciprocity," a phrase Gouldner (1960) coined for the principle of social exchange in socially integrated systems.

No doubt, individuals with limited access to social capital must be more skilful and industrious in garnering it, whereas those more favourably situated can draw more freely on the resources at their disposal. Regardless of their circumstances, family members, especially within larger kinship contexts, cannot afford to squander the social capital at their command lest they be accused by kin of taking more than they give in return (Furstenberg et al., 1999).

Children, too, must acquire skills at striking a balance in the supply and demand of social capital. Undeniably, children's capacity to strike this balance depends on both social learning and temperamental differences. To my knowledge, however, there is little research among developmental scientists on how children in different settings learn to manage social capital. A noteworthy 
exception is the comparative study of Italian and American school children by Corsaro (1994) in which he shows how school children learn to manage peer and teacher relationships. (See also Barrie Thorne, 1993.) Similarly, Laureau's (2003) recent study of working-class and affluent families offers a wealth of information about how children are trained to manage social relationships, both inside and outside their families.

The burgeoning research on immigrant families also may help us understand how social capital is deployed. As I noted earlier, different immigrant groups have varying beliefs and practices, as well as resources, for building and accumulating social capital. Accordingly, children learn quite different obligations, which influence how they perceive and use social capital (Bankston \& Zhou, 1995, 2002; Caplan, Choy, \& Whitmore, 1991; Kao, 2002). Comparative work underway in the United States and Europe promises to yield important insights on how family members manage social capital in ways that balance individual and social interests differently in ethnic subcultures (Stone, 2001).

Oddly missing from our accounts of family-based social capital are contemporary studies of religious communities, which may be rich in social capital. A classic study of the Hutterite community conducted decades ago revealed the strains that young people experienced in balancing individual and collective interests (Eaton \& Weil, 1955). This strain may be felt even more profoundly today as communities find it more difficult to isolate themselves from the surrounding world amid today's pervasive spread of information. Thus, an intriguing question is how such religious communities contain and enforce culturally specific obligations through socialisation and social control.

Using class, ethnic, and religious groups to understand how social capital is perceived, managed, and deployed should be attractive to researchers because this topic promises to reveal some of the fundamental benefits for individuals and the collective of investing wisely among families, kinship groups, and communities. It helps to integrate the study of family members at a microlevel and a mesolevel, to borrow the language of the great developmentalist, Uri Brofenbrenner (1979). How families relate to and exchange with the context in which they are embedded is central to understanding how social advantage and disadvantage are perpetuated. Research on social stratification, however, has placed too much emphasis on the individual and not enough on the settings such as kinship, ethnic and religious affiliations, and social class placement that influence how the individuals come to think of themselves in relation to others (Crosnoe \& Elder, 2004, provide an exception). This, of course, reflects our Anglo-American perspective treating the individual as the primary unit of analysis. This almost exclusive attention to individual development may be gradually tempered as social science increasingly reflects the perspectives of 
recent immigrant populations involving cultures in which families and kinship are irreducible entities.

\section{Social Capital and Its Consequences for the Welfare of Families}

Social capital would have little importance were it not believed to be a potent resource for social groups and their members. Because social capital, unlike human capital, however, is not, strictly speaking, a property of individuals, examining its consequences must thus extend beyond the individual. This is easy to understand when we consider that not all individuals may benefit from being in high capital systems because they may be called on to sacrifice their own interests for the good of the collective. Similarly, community bonds instil a sense of obligation that often leads members to override immediate individual interests.

Except in the most general sense, social scientists have not yet fully explored most of these propositions in families (Bengtson \& Harootyan, 1994; Rossi \& Rossi, 1990). There is a long tradition in America of bemoaning the loss of family and community bonds (Berger \& Berger, 1983; Nisbet, 1953; Popenoe, 1989; Putnam, 1995). As far as I know, however, there is no evidence that today's parents are less willing than those in the past to make sacrifices for their progeny. Indeed, the flow of resources from parents to children over the course of their lives is quite substantial and has become more extended and more onedirectional; that is, children today provide less for their parents than their parents provide for them. This pattern may also indicate, however, a higher level of trust by parents that their offspring will do the same for the next generation. In this respect, the principle behind kinship exchange may have changed, but this change does not necessarily indicate a weakening of intergenerational bonds. The fact that we have so little empirical data on kinship practices reveals a cultural inattention to how the extended family system operates and its consequences for the welfare of its members. (A good starting point would be to investigate the history of family bequests.)

No doubt, some of the ongoing studies of comparative family bonds among immigrant and non-immigrant populations will redress this research gap. We need careful examinations, however, of reciprocity with family systems that go beyond the counting of time and money, the elements of economic exchange. The exchange of symbolic goods, such as affection, esteem, expressions of respect and deference, even if less tangible, are surely no less important as consequences of investment. Immigrant children, disadvantaged minorities, and even more advantaged youth frequently report that achievement is, in part, an expression of paying back parental investment and support. Zelizer's (1985) 
marvelous historical account of how children became "priceless" in the $20^{\text {th }}$ century helps to explain the shift to a view that makes children more symbolically than materially valuable and suggests why the flow of resources has become one-directional and intergenerational.

Although an unduly large amount of the research has been directed at the consequences of social capital for education, there is no reason to believe that systems with high social capital affect only education. Such systems should also be more efficient in instilling religious, political, civic, or family objectives when they have attributes that generate consensus, commitment, and enduring obligation. Yet, relatively little headway has been made in demonstrating this idea. Consider, for example, the growing body of research that has explored this proposition using neighbourhoods as the unit of social capital (Brooks-Gunn \& Duncan, 1997). When they exist at all, effect sizes are small and inconsistent, a disheartening finding for sociologists who believe that systemic properties should have powerful effects on individual behaviours. The problem, as some researchers have observed, may be in the difficulty of measuring systemic properties well and finding the statistical methods capable of distinguishing social from individual effects and cumulative from short-term effects (Cook et al., 2002). It is also possible that the effect sizes are indeed very small, on average, and conditional on particular constellations of contexts or on producing certain types of outcomes.

Applying the lessons from family-based social capital studies may make the problems both easier and more difficult to solve. As I noted earlier, we have not yet carefully examined social capital in the smallest element of families, conjugal unions, or partnerships. Consensus, trust, mutual obligations, and shared networks result in higher stability and greater happiness in families over time, for example (Amato \& Booth, 1997).

There is even less information on how larger family systems including children, much less three-generation families, operate at particular life-cycle stages to produce particular outcomes for various members. This problem becomes more complicated when we try to account for the degree to which families and kinship networks are embedded in larger social systems that either support or undermine the normative consensus within a family or kinship unit. This is the methodological challenge to which I now turn.

\section{Measuring the Social Capital of Families}

The explosion of interest in social capital has been accompanied by what one observer has referred to as a "measurement rush." This rush has resulted in a plethora of items and scales based more on convenience than conceptual rigor (Stone, 2001). The all too unreflective quality of measurement occurs, in part, 
because no general agreement exists on what is meant by social capital, and because many researchers (myself included) have relied on makeshift measures crafted from secondary data sources rather than tailored measures intended strictly for social capital. Finally, measures employed to assess the macro-, meso-, and microlevel manifestations of social capital might well differ. There is a formidable challenge ahead in designing robust and reliable scales to tap the various dimensions of social capital.

In this same vein, one might also think of perceived and observed social capital that might be collected from different sources or from using different research strategies (e.g., qualitative or quantitative, surveys or observations, direct or indirect sources). It is unclear whether the measures used to gauge social capital at the national level are appropriate for community-based, much less family-based, social capital studies. I restrict the discussion that follows to microlevel measures that are appropriate for measuring social capital in families, kinship groups, and small communities.

Researchers have sometimes confused measures of social capital with presumed consequences of access to social capital, creating something of a tautology and confounding attempts to test whether social capital has presumed consequences for individuals or collectives (Paxton, 1999; Stone, 2001). Again, though, at a very minimum, we must establish whether individuals reside in systems with varying levels of social capital (the twin issues of availability and access) and the consequences of being in such settings (individual outcomes). Alternatively, we might examine such consequences for the collective's maintenance (social outcomes). Any proper demonstration of the "effects" of social capital requires longitudinal research — or better yet, social experimentsto establish a causal link between access to social capital and its consequences. Although we cannot expect to carry out such experiments at a family or kinship level, it is surely possible to conduct such experiments in schools or community programs.

To summarise, we need separate measures of (a) the level of social capital that exists in families and kinship units, (b) the access or use of available capital, and (c) separate and lagged outcomes that might be theoretically related to the possession of such capital for individuals or collectives.

My task here is not to define, much less measure, the potential outcomes of social capital but only to mention some of the problems involved in linking levels of social capital, the process of employing it, and consequences for individual and social well-being. One complication in measuring the outcomes should be reiterated: the benefits might not be always apparent because residing in a high social capital system not only confers benefits, but also entails obligations. Thus, social capital can promote some actions and restrict others, and theories must take into account the norms of exchange and reciprocity that 
are inherent in the notion of social capital. To think that outcomes will be uniformly positive is naïve.

A broad array of measures of what might be called normative embeddedness is probably a reasonable starting point for examining social capital within families and kinship systems. This involves measuring both normative consensus and a family member's sense of obligation to comply with expectations of other family members and kin. Do individuals feel compelled to show up at family events, do they feel they must comply with family standards, or are they committed to assist and support other members in the system?

It is possible to map the degree to which consensus and commitment extend among members of a larger family system; that is, the boundaries of normative embeddedness? Conceivably, strong marital ties could exist in a family where children feel little or no part of the marital system, or nuclear families could feel little part of extended families, or extended families could have only limited association with their surrounding communities. The degree to which these networks overlap is an important element of the potential level of social capital. The dimensions of network boundaries, density, and extensiveness are related ideas that embody slightly different features of family structure. Note how different they are, however, from our customary and simplistic idea of family structure.

Finally, we must ask whether individuals buy into such systems of obligations or how they make use of the available stock of social capital. It is possible that some family members prefer not to use the resources available to them or they have them but do not need to call upon them. As noted, some members hoard social capital whereas others spend it too freely; these dimensions of entitlement involve assessing how members perceive the availability of social capital and lay claim to it.

It is not at all obvious that family members are equally able to report accurately on the social capital available to them. Clearly, younger children probably cannot, but it is quite possible that most individuals within a family cannot provide investigators with reliable accounts of their social resources, the reach of their networks, or even the degree to which their parents' expectations are in accord. We need to think more about how to chart and measure the demographic, social, and normative properties of kinship networks by sampling kinship networks directly in which smaller family units are nested.

Complicating this problem is the growing complexity of family and kinship networks created by divorce, remarriage, cohabitation, and non-marital childbearing (Johnson, 1988). In prior research, I discovered that when asked, "whom do you consider to be part of your family?" adults and children in the same family did not always agree. A significant minority excluded their stepparents or stepchildren as family members. If we were to try to find 
agreement on the boundaries of a kinship group, the task would be even more challenging. Eliciting reliable responses about such subtle features of family functioning as value consensus, expectations, exchange, and perceived obligations is a significant obstacle standing in the way of developing a reliable measures of family-based social capital.

Relatively few studies contain information from more than a single parent and a single child. Until we collect information from both parents and all children, we cannot measure system properties of families that tap consensus, and we will not know whether family members correctly perceive their accord. Creative work on measuring the intensity of family obligations that draws on qualitative fieldwork may help to identify appropriate ways of gaining information on obligations and exchange as well as the use of novel quantitative approaches to sample broader kinship network.

Few researchers are patient enough to engage in the programme of measurement that I have suggested. Yet, we should be cautious about reaching conclusions on the consequences of social capital until we have good measures in place. Shortcut approaches may very well reach erroneous conclusions about the value of social capital theory.

\section{Conclusion}

This chapter is by no means a systematic account of social capital theory, although I hope it stimulates other researchers to expand on my observations of what is needed to construct such a theory. My more modest goal was to put forth a series of considerations that deserve attention as we build on the work of Coleman, Bourdieu, Portes, and others. I have argued that we must work on several fronts at once: (a) how families generate and accumulate social capital, (b) how family-based capital is managed and deployed, (c) the relation between family-based and community-based social capital, and (d) the consequences of social capital for the welfare of families as collectives and for their individual members (two different consequences).

Throughout, I have posed methodological challenges for researchers who hope to test the hypotheses that social capital has important consequences for family systems and their members. The measures of social capital have been simultaneously crude and promiscuous. Different definitions of social capital abound and have been put into use in far-fetched ways that are not subtle or searching enough to do justice to a more general theory about the role of social capital in families and kinship networks. Before we can make real headway, we must agree on what social capital is and how it can be measured reliably. The possession of social capital within family systems is not tantamount to its accessibility, at least for all members to the same extent. Without better 
qualitative studies, I fear we may go astray and reach unwarranted conclusions about the utility of this theory before we can give it due consideration.

Unfortunately, the shelf life of interesting theories in sociology is sometimes all too brief. One of the attractive features of social capital is that it is deeply rooted in classical theory and may, therefore, survive its current wave of popularity before it is discarded in the scrap heap of wasted ideas. If that plight is to be avoided, we must give equal attention to theoretical elaboration and careful measurement.

${ }^{1}$ This paper is a slightly revised and shortened version of an article published in the Journal of Marriage and Family 67(November 2005):809-821. 


\title{
CHAPTER SEVEN
}

\section{THE PROSPECTS OF SOCIAL CAPITAL: NETWORKS IN BOSNIA AND HERZEGOVINA}

\author{
IVA BoŽOVIĆ ${ }^{1}$
}

\section{Introduction}

Discovering grand truths about the way our social and economic worlds function and specifying systemic theories and explanations for this depends on efforts to open the "black box" that links the phenomena we observe with whatever we suspect are their causes. In attempting to improve economic models in this regard, scholars in the 1980s struggled to understand economic growth by discussing the issues of human knowledge and investment in human capital. The goal today, as Granovetter (2005) has pointed out, is to make "networks, norms, and institutions, history and culture fully endogenous to economic models" (p.47). The field of social capital is actively and wholeheartedly attempting to contribute to this goal. Periodically, however, it is necessary to reflect on the strengths and weakness of these contributions in order to set the path ahead and steer efforts in the most productive direction.

Research so far has elucidated the multifaceted nature of social capital by showing that its elements exist both at the level of the individual and of the structure in which those individuals are enmeshed. As a result, it is difficult to disentangle the elements of social capital that are strictly operational as a property of an individual, and the properties of the social structure comprised by individuals. The complex relationship between its various elements prevents us from aggregating social capital and incorporating it into economic models as an endogenous variable or as a shift factor in the production function. However, such endeavours should not be the ultimate validation of the usefulness of the concept.

The metaphor of social capital has gone far in indicating the need for an analysis that delves deeper into the various elements that are included in social capital, and the social mechanisms that explain how these elements affect individual actions and their aggregate outcomes. Rather than identifying the 
correlation between elements of social capital and economic success at the individual and aggregate levels, social mechanisms outline the causal relationship and specify the conditions for which it holds (Hedström and Swedberg, 1998). This analytic approach is essential for opening up the black box that relates norms, relations, trust and culture to economic development and growth. It is also an approach through which the social capital literature will move beyond the metaphor to contribute studies that specify clear and concise determinants, distinct relationships with particular outcomes, and differentiate macro-to-micro and micro-to-macro mechanisms.

This chapter evaluates the utility of the commonly used social capital discourse in an empirical analysis. In particular, the chapter addresses the way that generalised trust, and the distinction between bridging and bonding social capital fall short of becoming useful tools for analysing intra-group and intergroup relations. An alternative approach to social capital is discussed which is founded upon social networks and explains inter- and intra-group behaviour based on individual actors' incentives to establish network relations. To illustrate the implications of the bridging-bonding distinction for empirical analysis, as well as the strengths of the alternative social networks approach, the chapter examines quantitative and qualitative evidence from Bosnia and Herzegovina. Thus, the chapter has a dual purpose: to illustrate the efficacy of the social networks approach to social capital; and to describe the nature of social capital in Bosnia and Herzegovina.

\section{The function of social capital}

Social capital is a metaphor that has been evoked to suggest the potential benefits of norms, relationships, networks, trust, and other identifiable components to economic and political advancement. ${ }^{2}$ As any other form of capital, though less tangible, social capital is thought to comprise an asset that individuals can use to their own advantage (Coleman 1988: S98). For example, when in a financial bind, an individual can receive assistance from close family members, friends, and co-workers. The fewer and more restricted relations a person possesses, the more limited his or her social capital, and therefore the lower the opportunity to resolve the problem successfully. Overall, social capital literature accepts that some individuals are economically advantaged because they are more trustworthy and trusting of others, have more resourceful relationships, belong to better networks, and join various civic organisations. At the aggregate level, these advantages can translate into better economic performance manifested in a better standard of living, higher economic growth, and a happier society. Overall, this approach defines social capital strictly by its function in assisting individuals to achieve individual or collective goals. 
Dense networks of individuals who share similar beliefs about what constitutes accepted behaviour and who trust one another to abide by the same norms are at the heart of groups that are successful at coping with risk and providing for the security of its most vulnerable members (Woolcock, 1998). At the same time, such tightly-knit communities can exclude outsiders, limit upward mobility of its members, ${ }^{3}$ and can be exploited for the advancement of parochial objectives (Woolcock and Narayan, 2000). Hence, social ties that connect closed communities are thought to produce a more cohesive society and better economic performance (Sobel, 2002; Putnam et al., 1993). A distinction is thus born between intra-group and inter-group behaviour and the notion that intra-community ties may segregate the broader society to which such a community belongs. A cohesive and economically advanced society balances intra-community and inter-community ties. The former is captured by the notion of bonding social capital, which holds a community together, and the latter is defined as bridging social capital, which brings different communities closer together. The aim of an analysis that adopts this distinction is to evaluate the extent to which both types of social capital are available to a particular group under study. The next section introduces the World Bank Study of Bosnia and Herzegovina (hereafter Bosnia) in order to illustrate the limitations of this approach in an empirical analysis.

\section{Social capital in Bosnia and Herzegovina}

In 2001, the World Bank conducted a comprehensive study of Bosnia to evaluate social capital and local level institutions. The study offered a rich collection of qualitative and quantitative data from an environment that was subject to horrific destruction of human life and economic resources. While the civil conflict produced a difficult problem for the creation of political institutions that would integrate various ethnic groups into a system with comprehensive representation, the economic destruction resulting from the war compounded the problem of the economic transition initiated throughout SouthEast Europe at the beginning of the 1990s. The Bosnian case provides a unique opportunity to observe the importance of social capital in political re-integration and economic restructuring, as well as its interaction with formal institutions that were built since the war.

Based on the survey results that explore the degree of socialisation among different groups in the society and the willingness to assist individuals with material resources, the World Bank (2002) reports that the level of social capital has declined in Bosnia. In particular, socialisation has decreased more among colleagues and neighbours than among family relatives and close friends (shown in Table 7.1). Neighbours of different nationalities have lowered their 
socialisation rates to the greatest extent. In terms of the distinction between bonding and bridging capital, the report notes that the lower socialisation for all groups included in the survey indicates a general loss of both kinds of social capital. However, the greater loss of socialisation among neighbours of different nationalities relative to neighbours of the same nationality is indicative of a relatively larger loss of bridging capital (ibid, p.9). Invitations to visit one's home and offers of material assistance are more common among new neighbours of the same nationality than among old neighbours of different nationalities indicating that new relationships are formed along ethnic lines (ibid, p.12). This is particularly true for internally displaced people (IDPs) who report the largest loss in terms of bridging social capital (ibid, p.13). ${ }^{4}$

Table 7.1 Socialisation Levels in Bosnia

Question: Do you socialise with those people to the same degree as before, more than before, or less than before? If you socialise less than before, what is the main reason?

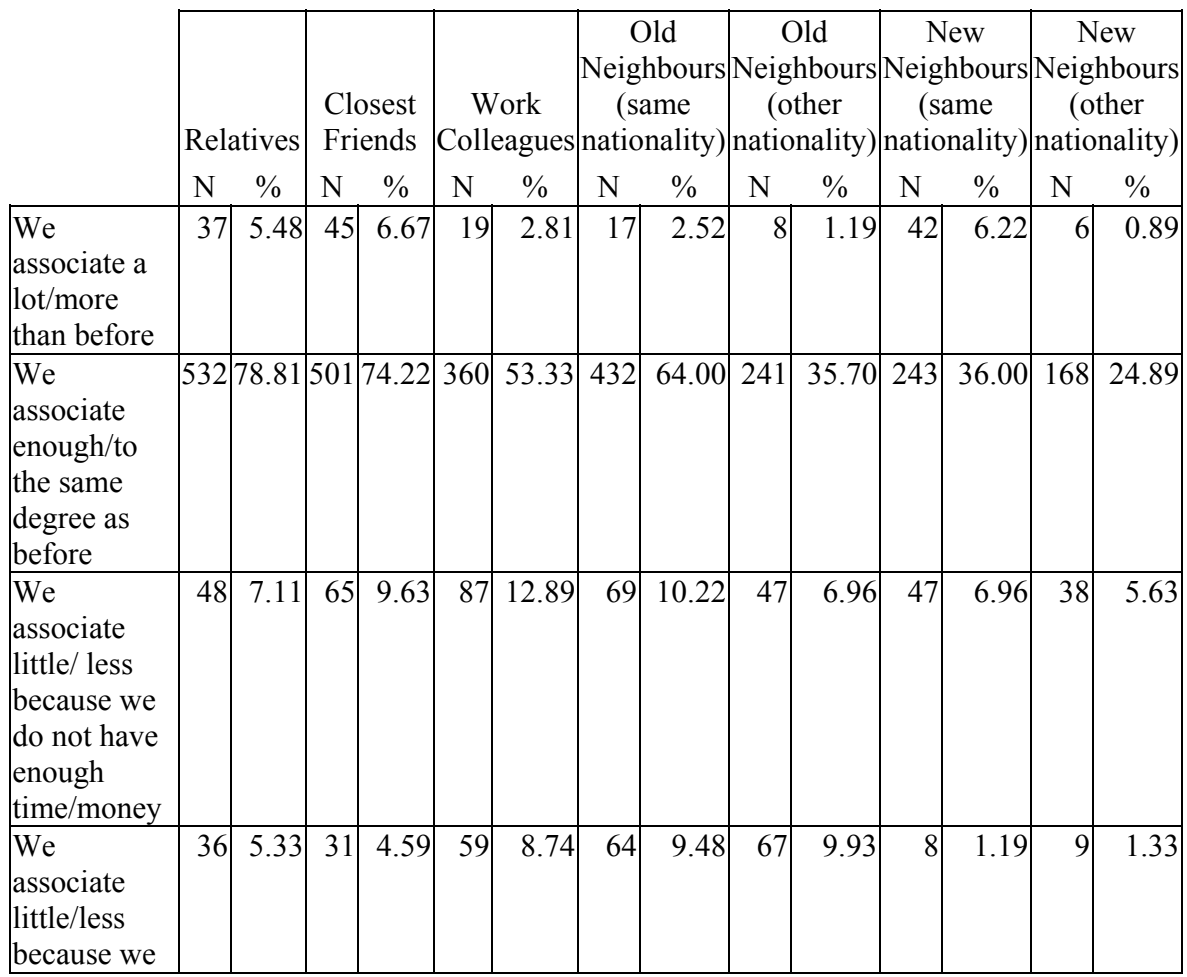




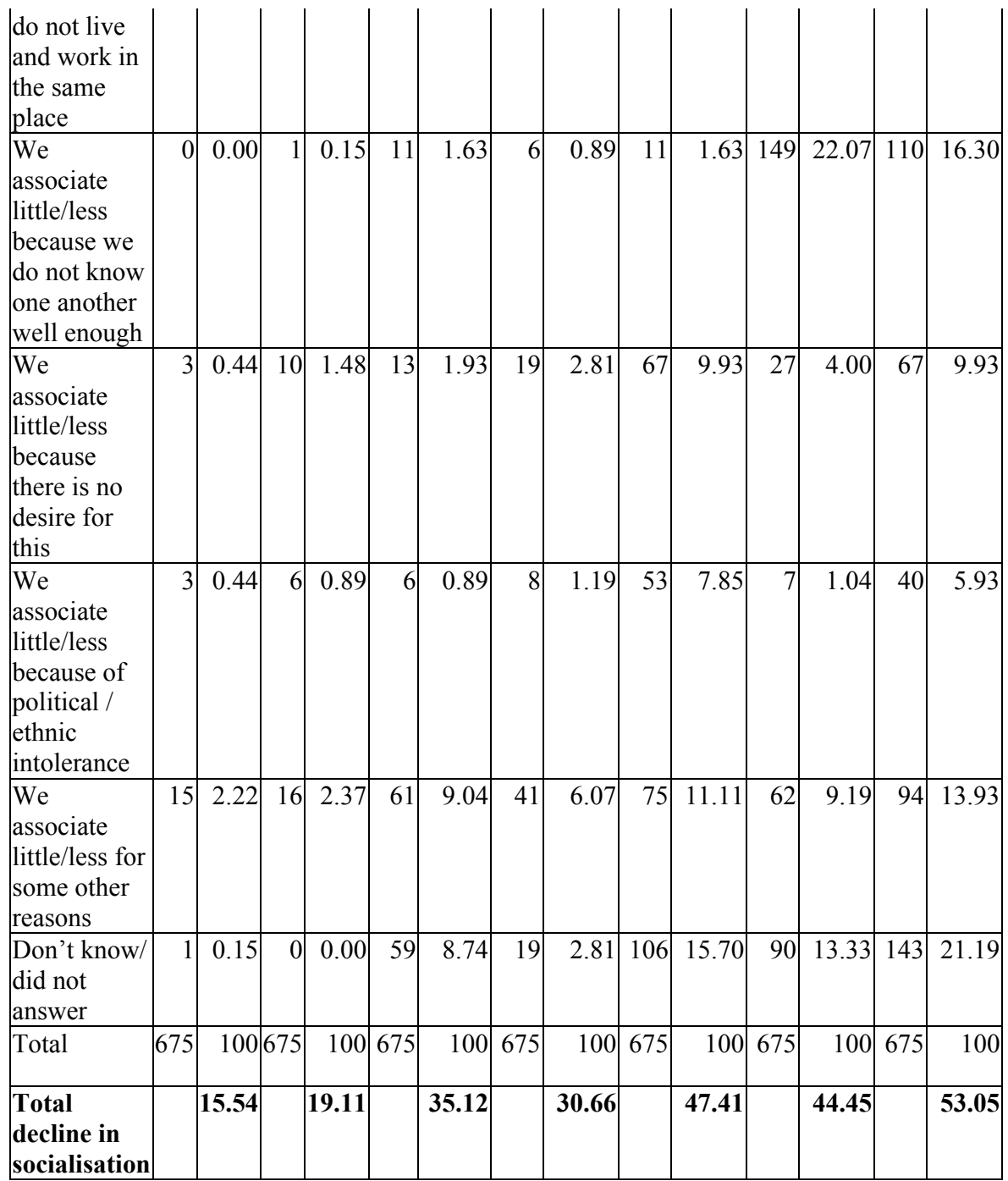

Source: World Bank 2002, Annex 7, Table 1.

The application of the concepts of bridging and bonding capital embodies several weaknesses of the approach that defines social capital solely by its function. The problem with the notion of bridging social capital is that the boundaries between groups are not defined in terms of different types of 
bonding capital providing the centripetal force that brings the particular community together. Instead, socio-demographic differences such as ethnicity, race, gender, and various indicators of social distance are used to define the community boundaries. Hence, the demarcation lines are artificially instituted before the presence or absence of bridging social capital is ascertained. In other words, we use socio-demographic differences to divide the society into various groups and then test for the presence or absence of inter-group relations based on the imposed categories. If in the study we observe relationships between individuals belonging to different ethnic groups, as in the case of Bosnia, then we infer the presence of bridging social capital.

An obvious problem with this type of analysis is that depending on the context under observation, some group distinctions will be more analytically appealing than others. If we are studying post-civil war Bosnia, we wish to examine the presence of inter-ethnic relations as an indicator of bridging social capital, and we chose to ignore the importance of relationships that bridge gender differences in employment practices, for example. Or, more importantly, focusing on the ethnic delineation of various groups and the level of inter-ethnic cooperation can prevent us from observing the lack of relations between the local inhabitants and IDPs of the same ethnic orientation. Hence, the categories that define the group boundaries are imposed by the researcher and can potentially lead one to ignore more prevalent and consequential group differences.

A problem related to the analysis that employs the distinction between bridging and bonding social capital is the unavoidable identification of positive outcomes with the presence of social capital. When we detect the occurrence of inter-ethnic relations we document the presence of bridging social capital linking ethnic communities into a cohesive society. When such relations are not present we note the absence of social capital. For example, the World Bank study notes an exception to the decline of inter-ethnic relations in Krizevci, where the Muslim minority was supported by the Serb majority in rebuilding and reopening a local school (p.17). The report states that in this case the common interest overcame ethnic cleavages producing positive collective action, which resulted in bridging social capital. Collective action theories, however, achieve their success by determining conditions, or changes in actors' incentives, that will result in the provision of positive cooperative outcomes even among self-interested, rationalistic actors who have to act without knowledge of each others' dispositions (Sandler, 1992). In this case, identifying instances of collective action as indicative of bridging social capital equals imputing positive outcomes to social capital. Determinants of bridging social capital and the role of bridging social capital in producing cooperative relations are not specified. This indeed should be the more exceptional contribution of 
social capital studies. The lacuna emphasises the need for social capital analysis to employ an analytic approach with social mechanisms in order establish a theoretical link between observed inter-group relations and some positive determinants of such outcomes without simply equating the two.

To explain declining social capital the report points to the increase in generalised mistrust. The concept of generalised trust has been introduced in the social capital literature to describe a form of trust that is not based upon information about actors but on an inherent and socially conditioned predisposition to trust anonymous individuals. In small communities, trust is based on familiarity with individuals' personal characteristics and dispositions. In a complex social setting, a more indirect form of trust is needed and preferred. Generalised trust allows one to move beyond ties with family members, friends, and acquaintances, to forge relationships with complete strangers and thereby participate in anonymous exchange.

The causal link between generalised trust and social capital, however, has never been established, nor have the components been identified. First, it has been suggested that generalised trust can be created through an expansion of existing social relations (Raiser, 1999). This explanation, unfortunately, does not specify how the trust formed among individuals who are familiar with each others' disposition, can be used to form relationships with complete strangers. Second, the availability of third-party enforcement has also been suggested as a factor promoting the growth of generalised trust (ibid.). However, if third-party enforcement is effective, we cannot automatically conclude that generalised trust is high, only that the costs of cheating are significant and therefore function as an effective deterrent. Individuals themselves are not innately more trusting simply because formal institutions are effective. Third, membership in civic associations has also been identified as a determinant of generalised trust. The proposed causal mechanism suggests that membership in civic groups fosters the spread of trust and norms of reciprocity to non-members (Putnam et al., 1993). Unfortunately, neither micro-level theory nor empirical evidence show how and why associational membership translates into norms of reciprocity and generalised trust (Rothstein and Stolle, 2001; Rose-Ackerman, 2001). Nor does this explanation establish successfully how trust and norms of reciprocity spread to non-members. Finally, optimism about one's long-term prospects has also been identified as a significant determinant of generalised trust (e.g. Uslaner 2003). The explanation is that optimists share a sense that they have a degree of control over their long-term future that makes them more inclined to trust strangers. This argument, however, does not resolve the problem of endogeneity. We cannot dismiss the possibility that individuals who are inherently more trusting are also optimistic about their long-term future. 
The report on Bosnia, nevertheless, employs the notion of generalised trust both as an indication and a cause of lower bridging social capital (World Bank 2002: 10). The Bosnian civil war has severely depleted the trust levels between different ethnic groups and has reinforced trust among the members of the same ethnic group. This has resulted in lower socialisation among Bosnians of different ethnicities, or, in other words, lower bridging social capital. This type of analysis, unfortunately, does not give us profound insights into the determinants of bridging social capital. First, some scholars would argue that the mistrust among different ethnic groups preceded the war and therefore the exogenous decline in generalised trust used to explain the resulting decline in bridging social capital is subject to debate. Second, animosities enhanced by the war cannot explain why socialisation would decline among colleagues and neighbours belonging to the same ethnic group. For example, the total decrease in socialisation with work colleagues recorded in the report is $35.12 \%$ (Column 3 , Table 7.1 ). However, $21.36 \%$, or $61 \%$ of that decline in socialisation, is due to the fact that people's economic means have declined or they no longer work together (Rows 3 and 4, Table 7.1). This evidence does not offer any support for the argument that the decline has been caused by the rise in generalised mistrust.

The concept of generalised trust also cannot adequately account for the greater decline in socialisation among new neighbours, as opposed to old neighbours within the same ethnic group. If individuals in the same ethnic group possessed an inherent motivation to trust their co-ethnics, we should have observed a similar decline in relations among old and new neighbours. Also, the decline in generalised trust among different ethnicities does not sufficiently explain the particularly high decline in bridging social capital of IDPs. Hence, a more nuanced explanation of the reduction in inter-ethnic relations is required. A phenomenon whose results are being observed is obviously closely related to ethnicity and the overarching presence of war memories, but other mechanisms are also interacting with these factors, whose results are not fully accounted for by simply noting the absence of trust.

Using the example of inter-ethnic relations in Bosnia, this section has illustrated that the metaphor of social capital that points to the distinction of bridging and bonding social capital is not sufficient for understanding the observed changes in empirical evidence. The approach falls short of differentiating causes and outcomes, and also tracing the social mechanisms that help us explain the underlying relationship between the elements emphasised in the analysis. As a result, this type of social capital approach must resort to an exogenous factor for explanations of changes. The concept used is that of generalised trust whose theoretical underpinnings and empirical evidence are weak or at best incomplete. An alternative approach that adheres to the fundamental ideas behind the notion of social capital, but addresses the above 
issues to a significant extent, is one that involves the concept of the social network. The next section elucidates this approach before it is applied to the case of Bosnia.

\section{Network approach to social capital}

The central premise of the network approach is that individual actors do not make decisions isolated from others. Instead, the actors are embedded in a system of social relations they build in every day encounters with other individuals. ${ }^{5}$ They form and maintain relationships in order to take advantage of the available resources necessary for their economic advancement, such as capital and information. The resulting structure formed by a set of relationships among individual actors is known as the network. In turn, networks of social relations have an impact on preferences, expectations, and constraints that affect the actions of the individuals that comprise them.

A strong definition of a social network recognises only those social ties that are backed by enduring, reciprocated exchange relations (Rauch, 2001). A weaker definition includes short and long-term relationships without regard to reciprocation. For example, affect-based ties between actors linked though familiar or emotional relationships can represent the social ties at the basis of a network. The weaker definition of a network essentially includes all linkages based on relationships that can provide access to economic resources. This definition thus subsumes the common distinction between social and economic ties. In reality, it is difficult to disassociate a business owners' trade agreement from any underlying social ties among them, such as friendships or familial connections. All relationships, no matter how established, that can be used to take advantage of resources are considered equally relevant for the definition of a social network.

Social networks have two essential contributions: the formation of interpersonal trust and the provision of access to information and resources. In the absence of highly efficient institutions, or when contracts must be enforced only with non-insignificant costs, individuals would be reluctant to enter into exchange with strangers since they have no assurances that the other person would abide by the terms of an agreement. However, the exchange would take place if the actors had access to some information that would lead them to trust the other person to uphold the contract. An existing relationship, or perhaps a guarantee of sound reputation offered by a friend, relative, or other trading partners, can serve to reduce the expected probability that the other person will renege on the agreement. Social networks facilitate the spread of such information that members can access to identify and verify the reputability of potential partners. Actors that trade repeatedly within the network build the 
economic and social relationships that are the basis of interpersonal trust. ${ }^{6}$ Defecting on an agreement results in the breakdown of trust and loss of reputation. Since networks disseminate information about actors, no one will choose to enter into agreements with individuals who have a questionable reputation. Loss of reputation thus serves as an informal, network specific, sanctioning mechanism against defection because it can result in the termination of all future relations.

Networks also assist actors by providing access to valuable information and resources. A plethora of information, which can generate economic value, can be accessed through ones' immediate social relationships. For example, one can obtain information about availability of goods in short supply, business and employment opportunities, and the names of good candidates for specific jobs offered. Also, one can learn about the procedures for starting a business venture, instructions for obtaining necessary legal documents in the shortest time and at the lowest cost, and also the names of particular bureaucrats who may be trusted not to jeopardise a license application for personal gain. Overcoming problems associated with frequent changes in formal laws and procedures, or with discretion in the bureaucratic enforcement of rules, is frequently achieved though connections available in social networks. Together, the use of networks for contract enforcement, as well as provision of information and resources, shapes individuals' incentives to pursue productive economic activities and thereby affect aggregate economic performance.

The network approach to social capital also permits the analysis of negative consequences of network relations that goes beyond merely noting the absence or presence of bridging social capital. Essentially, trust formed within relationships breeds distrust in individuals who are not known to network members. What makes networks viable is that they connect individuals who, while distrustful of others in general, rely on established relationships to reduce the risk of misconduct on the part of other individuals with whom they interact. In exchange theory, the decision to continue to trade with specific partners to the exclusion of others is known as commitment (Cook, Rice and Gerbasi, 2004). However, commitments can be costly for the individuals involved. Forgoing better offers from alternative, yet unfamiliar partners, translates into an opportunity cost of paying higher prices for goods and services in the committed relationship (Johnson, McMillan and Woodruff, 2002). Working within dense overlapping relations can block individuals from accessing new information, resources and technologies, which places limits on the economic potential of existing network configurations. Limiting the number of outside contacts can result in lower productivity and limited learning (Sedaitis, 1997; see also Uzzi, 1996 and Perry, 1999). 
Traders who find themselves without ties to a specific network are at a disadvantage since they cannot enjoy the benefits of cheaper or more efficient contract enforcement, as well as access to information and resources. For example, a more productive firm without network ties may be prevented from gaining access to customers who are locked in relationships with its competitors. The transaction costs of operating outside the network can be significantly larger than those of firms with network ties, forcing outsiders to charge higher prices. A similar price differential can occur if networked firms benefited from access to cheaper resources that outsiders have to obtain at higher prices. If established networks of suppliers and consumers are so strong as to be impenetrable by new firms, many entrepreneurs will decide not to initiate a particular venture, thereby lowering competition and the welfare benefit that it entails for consumers.

Because of the beneficial role networks play in fostering interpersonal trust and providing access to valuable resources, the omnipresence of social networks does not pose a threat in itself. Closed and tightly knit networks, however, can create significant problems for insiders and outsiders alike. Hence, the main factor affecting overall economic welfare is the degree to which networks are exclusive in terms of their membership. The network approach to social capital, therefore, does not distinguish between bridging and bonding social capital, but analyses differences in inter-group and intra-group behaviour in terms of the incentives that individuals have for forming relationships and the way the resulting network structure shapes their incentives for action. The following section applies this approach to the evidence collected in the World Bank study and offers a more intricate mechanism to explain the decline in inter-ethnic relations and its relationship with social capital in Bosnia.

\section{Social networks in Bosnia and Herzegovina}

The social networks approach explains the decline in inter-ethnic relations without introducing the notion of generalised trust and without equating the same to the loss of bridging social capital. Inter-ethnic divisions, in this approach, are not a result of some exogenous shock to social capital as a whole, but a result of changes in individuals' incentives to form new relationships and maintain existing ones. In other words, evidenced decline in inter-ethnic relations is related to the distinction between inter-group and intra-group exchange. While networks are particularly beneficial for fostering the formation of trust and exchange of information and resources within the group, incentives to go outside the network are more limited, depending on the characteristics of the network under scrutiny. What needs to be explained then is why social networks in Bosnia are impenetrable and tightly knit, preventing outsiders from 
forming ties with network members. More importantly, we need to explain why ethnicity demarcates the boundaries of these networks such that there is a lack of incentives for individuals to form ties outside their own ethnic group.

Ethnicity is a critical part of Bosnia's history and cultural richness. Even after its incorporation into the Ottoman and Hapsburg Empires, and most recently the Yugoslav Socialist experiment, Bosnian society preserved communitarian structures despite the fluidity of community boundaries. For example, Bougarel (1996) notes that "the informal institution of komsiluk (good neighbourliness) certainly continue[d] to be the rule in everyday dealings between the communities; but it was based on a constant reaffirmation of community identities and codes, and not on their effacement. Komsiluk never developed into intimateness (p.88)." In other words, Bosnian society has always been cognisant of communitarian divisions, which have allowed ethnicity to exist as a key identifying mark in Bosnia more so than in other republics of former Yugoslavia. Given that communitarian structures based on ethnicity persisted in Bosnia throughout history, most of the neighbours in a specific community are likely to share ethnic identifications. Therefore, when individuals choose first to approach family members and close friends before they reach out to more distant friends, business acquaintances or members of the broader community, they are effectively turning to their co-ethnics for help.

Civil war destroyed the social fabric of Bosnia. During the war, ethnic differences were reaffirmed and animosities fostered by war demagogues. Interethnic relations that existed in Bosnia prior to the war were destroyed when people were displaced and moved to areas that were populated by others of the same ethnic orientation, since their security was best protected there. In the places where IDPs settled, they did not have friends and neighbours with whom they could interact to better their security and economic condition so they had to form ties with strangers. Naturally, they turned to co-ethnics who were in a similar position and who could, at the very minimum, be trusted to not jeopardise their security (World Bank, 2002). Ethnicity thus became a proxy for trustworthiness among IDPs. IDPs are strangers to one another and also to the local population, which explains why the World Bank (2002) report demonstrated the lowest levels of socialisation among IDPs, not only with friends and relatives, but also with neighbours of all ethnic identities (p.12). But in the case where population displacements have been less intense, qualitative evidence shows that pre-war networks have been preserved with higher levels of inter-ethnic relations (Ibid, p.14).

Even for those who stayed where they built their homes, inter-ethnic relations declined. The war reinforced the distinctions between ethnic groups by encouraging expressions of ethnicity such as putting flags in windows, wearing special clothes and symbols, and openly denigrating the "other." In an 
environment of emotional and psychological arousal such as one engulfed in a civil conflict, those who do not demonstrate their ethnic identifications are considered less worthy members of an ethnic group. Therefore, a member of a Serbian majority, who wants to share barter goods with a Muslim friend she knew since childhood cannot show this preference in public because others will criticise her, and may even punish her for betraying her co-ethnics by wanting to assist the Muslim "enemy." For fear of punishment and loss of reputation in her relationships with other Serbs, the woman must decide not to help her Muslim friend. Her private preference is to continue her relationships with the Serb, but her public preference is to ignore her. ${ }^{7}$ Those who did not change personal beliefs nevertheless had to falsify their preferences and signal distrust toward other ethnic groups in public, which adversely affected inter-ethnic relations. Evidence from Bosnia does show that relations between members of different ethnic groups broke down more frequently than relations among members of the same ethnic group. Interaction between old neighbours of different ethnic groups, with respect to invitations to visit homes and material assistance ( $22.21 \%$ and $8.6 \%$ respectively) was significantly less frequent than interactions among old neighbours of the same ethnicity (45.1\% and $18.1 \%$ respectively) (World Bank, 2002, Tables 3 and 4). The least frequent was the formation of ties with new neighbours of different ethnic identity, namely $11.56 \%$ of individuals extended invitations to this group on some sort of regular basis, and only $5.48 \%$ offered material assistance (ibid, Tables 3 and 4).

Ethnic divisions have also been built into Bosnian formal institutions and organisations. ${ }^{8}$ The division of Bosnia into cantons and entities was imposed by the international community, but ethnic delineation of institutions was allowed to extend all the way down to the local level. The comprehensive social safety net provided by the pre-war Yugoslavia has now been replaced with a broad spectrum of municipal institutions in charge of supplying social services, education and financial assistance. However, municipalities shrank in size and grew in number since the beginning of the war in order to produce more ethnically homogenous units (World Bank, 2002: 41). Mjesna Zajednica (MZs), types of local administrative organisations, were also divided along ethnic lines and continued to offer services to their own communities even though they are no longer formally recognised. Duplication and fragmentation of MZs along ethnic lines produces waste in terms of rent-seeking activities undergone to secure limited funds. More importantly, such a divided social safety net reinforces ethnic divisions in the population because individuals find that relationships with their co-ethnics provide them with greater access to goods and services designated for that specific ethnic group. If all of the social services were equally available to all groups regardless of their ethnicity, then forming relationships with non-co-ethnics who happen to have greater access to 
a needed resource would prove to be an efficient strategy for anyone. Otherwise, turning to relationships with other ethnicities would not be as productive.

Together, the historical significance of ethnicity in Bosnian society, internal displacement and severing of ties, "preference falsification," and ethnification of formal institutions, help produce social networks whose boundaries align significantly with ethnic divisions (see footnote 6). Overall, we observe a declining number of relationships spanning network, or ethnic boundaries. None of the explanations offered, however, depend on some exogenous decline in trust that individuals have toward others. Instead, individuals' incentives to maintain and form relationships, combined with the above forces, cause them to stay within their own group.

A related issue for Bosnia is the degree to which networks are based on close friends and relatives and the degree to which they are closed to new members. Friends and family provide the greatest security in terms of contract enforcement but lowest potential in terms of access to resources and information. This idea is captured in social networks theory with the concept of the strength of ties. Strong ties have low informational benefits because they tend to offer information that the individual in question already knows. More distant contacts such as work colleagues and business acquaintances offer lower contract enforcement benefits but higher informational benefits. If networks consist mostly of connections with family and friends, their benefits for dynamically efficient economic activity would be very limited. Therefore, more open, or less dense, networks are preferred because they have the greatest potential for introducing contacts with better informational resources at their disposal, and also for lowering ethnic homogeneity. In Bosnia, unfortunately, the war has severed business relations and ties among work colleagues, forcing individuals to rely mostly on family and friendships as sources of security. The utility of using connections within ones' network and the resulting perpetuation of closed ethnically based networks is discussed next.

\section{The demand for connections}

The problem of social networks that form along ethnic lines is exacerbated by the great need for networked relationships in order to get something done. Within the two broad roles of providing for contract enforcement and access to resources, informal networks provide connections for obtaining bureaucratic favours, loans, admission into schools and universities, legal favours, and recommendations from others (Lomnitz and Sheinbaum, 2004). A respondent in the World Bank (2002) report described the role of social networks in Bosnia in general: "If you have connections, you will get the job done. If you don't, 
then you have to bribe someone (p.57)." Individuals in Bosnia frequently discuss the need for "veze" or "stele" (connections) to obtain access to resources administered at the local level (Ibid; Pickering, 2003). The following quote is especially illustrative of the instrumental nature of network formation that was alluded to in the theoretical discussion:

If I am to resolve a problem, I look for where I know someone who can do something. If I am not close to the president I will look for someone I know who is close to him, someone who has influence over him, and get that person to help me finish what I need to get done. That is the way it is, because directly as an individual it is extremely difficult to get any problem resolved (World Bank, 2002: 68).

The system of network relations is essential for coping with failures of socio-economic institutions. One of the most noted complaints among the respondents in Bosnia was the poor performance of local bureaucracies and lack of access to their services (World Bank, 2002). Interviewees indicated that bureaucratic units turn a deaf ear to petitions, delegations, and street protests, and only make false promises if forced to react (Ibid, pp.103-104). As a result, individuals viewed bureaucratic offices as "zatvorena vrata," or the closed door, inaccessible and unavailable for support. Moreover, individuals lacked information about the breakdown of responsibilities in specific situations and rely on bureaucrats and local officials to point them in the right direction. Officials, on the other hand, used the lack of information to mask their own irresponsibility and abuse of formal positions. Individuals in Bosnia described access to bureaucratic organisations as "zatvoreni krug" (closed circle) because they were shuffled from one office to another until they give up (p.64).

Virtually all studies of social relations in post-war Bosnia have concluded that individuals are extremely distrustful of their institutions and organisations (Pickering, 2003; World Bank, 2002; Djipa et al., 1999). Focus group participants revealed deep distrust in their elected politicians. They believed that officials lose sight of the common agenda as soon as they secure a "fotelja" (arm chair) - an influential position that allows them to pursue narrow selfinterest. Even when such individuals were caught embezzling money, they were not held accountable for their actions. Accountability of politicians is so low that local IDP leaders urge their constituents to return to their pre-war residences while they retain plots and residences obtained since they have been displaced. Naturally, IDPs feel neglected by their leaders as well as municipal organisations that assist the locals and minority returnees first and turn the administration of IDPs over to international organisations.

Such negative experiences in seeking access to local services have contributed to the general mistrust of formal institutions, especially the 
judiciary. Most Bosnians will not approach the judicial system because they "fear reprisal, consider justice itself to be an inefficient and corrupt institution, and cannot afford to hire a lawyer or feel that they could not win the case without one (World Bank, 2002: 66)." Most respondents are discouraged from taking their grievances with organisations and institutions to the courts because they expect the proceedings to be too costly and extremely lengthy. Similar assessments of the judiciary are reported in the Business Environment and Enterprise Performance Survey (Fries et al., 2002) where around $75 \%$ of respondents negatively assessed the courts on three different dimensions: fairness and impartiality, honesty and corruption, and ability to enforce decisions. $^{9}$

The above evidence shows that one of the significant problems for social integration and economic transition, with implications for inter-ethnic relations, is the low confidence in public institutions in terms of their effectiveness and credibility. As a result, Bosnians have strong incentives to seek out private connections and to form dense networks for provision of services and assistance in contract enforcement. The inability to rely on formal institutions and organisations results in the perpetuation of closed social networks. When institutions improve in terms of their ability to enforce contracts, individuals no longer have to turn only to those with whom they have traded before and who have an established reputation. Inter-network exchange, or exchange with strangers, becomes feasible because individuals can benefit from the rule of law and effective courts to enforce the terms of contracts.

Given the low level of institutional trust currently present in Bosnia, examples showing a positive correlation between higher institutional trust and more open and cross-cutting networks of exchange are only suggested in theory. However, we have evidence that low levels of institutional trust do indeed encourage "closure" of networks. Many Bosnian citizens have indicated in their responses that the only possibility they have for resolving their problems is to turn their villages and communities into MZs or a separate municipality (World Bank, 2002: 48). This presents a greater chance of receiving representation at a higher level of local administration that has decision-making authority with respect to financial resources and distribution of foreign aid. The fragmentation of MZs along ethnic lines indicates that Bosnians would rather resort to their own ethnicity-based networks than rely on formally mandated authorities they do not trust. IDPs and minority returnees have also created "parallel municipal institutions of some kind - departments in the ministries in charge of IDPs, state-subsidised IDP associations, or informal networks of municipal councillors with the same ethnic background (Ibid, p.42)." Instead of the state serving as a medium for the resolution of inter-group rivalries and for fostering ties across 
ethnic divisions, the distrust in state institutions discourages citizens from accessing them, resulting in greater closure of networks within ethnic groups.

\section{Conclusion}

Network approach to social capital exhibits several key advantages over the approach that defines social capital solely by its function. The network approach clearly specifies the link between the underlying elements of social capital and the mechanism though which they produce positive and negative outcomes. This eliminates the problem of equating causes with instances of positive outcomes. The categories that differentiate inter-group from intragroup behaviour are built into the concept of the network itself and are therefore unfettered by researcher's perspective and goals. Most importantly, the approach avoids altogether the use of the fragile concept of generalised trust.

The network approach can be quite useful for analysing social capital as was demonstrated in the case of Bosnia. The analysis showed that one of the significant factors blocking political and economic integration in Bosnia is the prevalence of closed and ethnicity based social networks. The same mechanism used to explain the formation of networks that align with ethnic boundaries also explained the lower socialisation among neighbours of same ethnicity, and between local majority and the IDPS. The analysis using the social network approach has also pointed out that the lack of institutional trust observed in Bosnia encourages individuals to rely on closed networks, which further diminishes their incentives for inter-network or inter-ethnic exchange. Thus, it can be concluded that improving efficiency and accountability of formal institutions may be a way to encourage inter-network exchange regardless of the level of trust that Bosnians have in strangers.

1 The author is grateful to Timur Kuran for insightful discussion and comments, and to the editors for their helpful suggestions. The author also wishes to acknowledge the support of the University of Southern California.

${ }^{2}$ For an overview, see the key work of Putnam et al. (1993), Woolcock (1998), and Foley and Edwards (1999).

${ }^{3}$ A well noted case is that of communities based on strong egalitarian norms, which demand that members support their own close relatives at the expense of the individual (Dasgupta 2002; Platteau 2001, Ch.5).

${ }^{4}$ Three groups of people are differentiated for the purpose of this study: the majority, minority returnees and internally displaced people (IDPs). Minority returnees are individuals who temporarily abandoned their place of residence during the war to escape the threat from the majority. IDPs are individuals who abandoned their place of residence but have not returned since the end of the war and have instead taken up residence in areas of similar ethnic make-up. The relationship between minority returnees and IDPs is strained because some IDPs moved into the residences abandoned 
by the minorities that are now trying to return and repossess their property. IDPs are also in conflict with the members of the ethnic majority because the latter are outsiders not familiar with the needs and goals of the community to which they relocated.

${ }^{5}$ This concept of embeddedness used here originated with Granovetter (1985).

${ }^{6}$ The term interpersonal trust is used here to denote the trust that exists among trading partners or individuals who belong to the same social network. It is not meant to indicate the trust toward any individual in general irrespective of the context in which the individuals met.

7 The theory of "preference falsification" that has inspired the above discussion was developed by Kuran (1995). In that analysis, an actor's public preference is a function of the society's revealed decision, rewards and punishments associated with an actor's particular private preference, and the rewards associated with self-expression.

${ }^{8}$ The distinction between institutions and organisations can be found in North (1991).

9 Negative assessment is a total of responses in the categories Never, Seldom and Sometimes. Source: World Bank and EBRD (2002). 


\title{
CHAPTER EIGHT
}

\section{THE WEAKEST LINK?: SOCIAL CAPITAL IN AUSTRALIAN REGIONAL DEVELOPMENT}

\author{
KERI CHIVERALLS
}

\section{Introduction}

This paper takes a critical approach to debates around the concept "social capital". Over the last decade, there has been a veritable explosion of academic and political interest in social capital theory. While Bourdieu understood social capital as a tool for the explanation of social stratification, in recent years the term has more frequently been employed as a normative concept for addressing perceived social problems. Of particular interest to policy makers has been the argument that there is a link between social capital and economic development. These arguments are highly problematic, as indeed is the concept "social capital" itself. This paper suggests that the popularity of the concept may be due more to the academic and political environment in which it was spawned, than its ability to tackle issues of inequality in regional economic development. The neo-liberal project of economic "globalisation" carried out over the last few decades has served to exacerbate existing inequalities both within and between regions. In turn, this has led to a renewed academic and political focus on regional economic development and a call for the re-introduction of social issues into the political agenda. The perceived "crisis of the welfare state" and the more recent failures of free market policies in addressing issues of social and economic disadvantage have led to governments in the UK and Australia adopting "Third Way" policies aimed at bridging the gap between the market and the state. Through a brief analysis of the operation of social capital in the Australian policy context this paper explores the concept as an ideological tool of Third Way governance and considers the implications of this for the future of "social capital" in both policy and social theory. 


\section{Forging the "Missing Link"}

Whilst the term "social capital" has received extensive attention only in the last two decades, the ideas expressed through it are by no means new. Put simply, social capital is another expression of the old adage "It's not what you know [that counts]- it's who you know!" (cited in Harriss, 2002: 2). One of the first references to social capital occurs in Das Kapital (1862), where Marx employs the term in a discussion of social solidarity amongst the different classes. While a number of social theorists made reference to "social capital" in the century to come, the concept did not receive extensive theoretical attention until the 1980's when Pierre Bourdieu (1986) published his Many Forms of Capital (Hanifan 1916; Jacobs 1961). In Bourdieu's work, social capital was situated within a tightly theorised framework of the different forms of capital, which he understood as the forces through which privilege, class and status were produced and reproduced through social structures and processes. For Bourdieu, theorizing capital was an exercise in theorising power, for capital "is what makes the games of society - not least, the economic game - something other than simple games of chance offering at every moment the possibility of a miracle" (Bourdieu 1986: 241). Bourdieu argued that, depending on the field in which it functions, and at a higher or lower cost of transformation, capital can present itself in four different forms: cultural capital, social capital, economic capital and symbolic capital. Bourdieu defined social capital as

[T]he aggregate of the actual or potential resources which are linked to possession of a durable network of more or less institutionalized relationships of mutual acquaintance and recognition - or in other words, to membership of a group - which provides each of its members with the backing of the collectivelyowned capital, a "credential" which entitles them to credit, in the various senses of the word. (Bourdieu 1986: 248)

Thus, social capital, through the "possession" of particular social relationships, provides for differential access to resources and as such is not an attribute of society as a whole but an aspect of the differentiation of classes (Harriss 2002: 4).

Bourdieu's understanding of social capital was transformed by James Coleman (1988; 1990a), who applied one of the first instrumental economic analyses to the concept. Putnam argues that it was Coleman who "put the term firmly and finally on the intellectual agenda" using the concept in a similar manner to Hanifan, in his discussion of the "social context of education" (Putnam 1995: 20). As a "rational choice" theorist, Coleman advocates the idea that social theory can be developed through the aggregation of models of individual behaviour which contend that individuals are motivated primarily (if not solely) by a desire to maximize their own interests. While anthropologists 
and other sociologists would question whether it is possible to define these interests outside of social, cultural, historical and political contexts, this model of human behaviour is one shared by neo-classical economics, perhaps the most potent force in the most powerful economic and social research institutions today: The IMF and World Bank. Using a number of examples, like traders in Cairo markets who share information about customers, Coleman argues that social relations have economic value in that reciprocity and trust help reduce transaction costs through increasing the communication of information and providing forms of insurance through the recognition and enforcement of obligations. Due to his grounding in rational action theory, Coleman's understanding of social capital is instrumental, as exemplified by his statement that social capital is "defined by its function" (Coleman 1990a). Thus, while Bourdieu understood social capital as an explanation of social stratification ("power over"), Coleman saw social capital in terms of its benefits to individuals or groups ("power to"). This discrepancy, between an understanding of social capital as a normative quality which should be increased in communities, and as an analytical tool for the explanation of social stratification, is ongoing in the social capital debate.

The link between social capital and economic development was developed and popularised through the work of American social capitalist extraordinaire Robert Putnam (1993, 2000) in his studies, Making Democracy Work and Bowling Alone. In Making Democracy Work: Civic Traditions in Modern Italy, Putnam defines social capital as the "features of social organisation such as trust, norms and networks that can improve the efficiency of society by facilitating coordinated actions" (Putnam, Leonardi et al. 1993: 167). In this oftcited text, Putnam argued that there was a link between social capital (embedded in norms and networks of civic engagement) and economic development, which he believed could account for the differences between the rates of economic development in Northern and Southern regions of Italy. Putnam argues that north central Italy had a large "stock" of social capital dating back to the middle ages, which has produced a virtuous cycle resulting in higher levels of civic engagement, economic development and better governance today than in Southern Italy, which has been locked into a vicious cycle of negative social relations for most of the same period. While Putnam acknowledges the role of institutions, landholding structures and the politics of patronage and clientalism with which they are associated, he concludes that it was not these structural conditions that caused the Italian South to remain locked into a process of "underdevelopment", but its lack of social capital (Harriss 2002: 6). Putnam argues that social capital, embedded in the norms and networks of civic engagement, is a precondition for economic development. "These communities did not become civic because they were rich. The historical record suggests 
precisely the opposite: They have become rich because they were civic" (Putnam 1993: 37). Thus, Putnam's work suggests that in order to attain economic growth, community development initiatives must consider the importance of civic groups that may seem to have little to do with either politics or economics. Putnam suggests that governments should direct efforts at encouraging civic engagement and self-help in poor regions, effectively ignoring the possibility that redistributional policy might play a much more significant role in alleviating the plight of socio-economically disadvantaged regions (Harriss 2002: 6).

In his later work Bowling Alone, Putnam presents extensive data from a variety of sources to argue that America's social capital has declined drastically over the last few decades. This contrasts markedly with his previous argument that the rise and decline of social capital in Italy resulted from historically embedded patterns of path dependence spanning centuries. In Bowling Alone social capital was not only removed from a tightly theorised framework of the different forms of capital, but also from the extensive social and historical context in which he had placed the concept in his Italian study. Thus, social capital became the ahistorical and apolitical property of regions and even nations and it became possible to argue that these geographically defined areas have a "stock" of social capital which affects their development. This transition, from a concept residing in the networks of individuals, to the property of regions and even nations, was never explicitly theorised and has created much confusion over the meaning of the term "social capital".

Nevertheless, Putnam's argument proved highly popular and was taken up by academics and policy bodies around the world. Social theorists such as Francis Fukuyama (1995), Michael Woolcock (1998) and Christian Grootaert (1998), extended the work of Coleman and Putnam clarifying the argument that social capital contributes to economic development by enhancing systems of reciprocity, improving collective decision making and co-operation between groups; facilitating co-ordinated actions; increasing information transfer; and enhancing trust thereby reducing transaction costs and minimising the need for formal contracts and the enforcement of norms. World Bank theorists lauded social capital as the "missing link" in development and argued the plight of regions and even nations with high levels of socio-economic disadvantage could be tackled through policies and programs that encouraged the development of social capital (Grootaert 1998: 1).

\section{"Missing Links" Remain}

The link between social capital and economic development is highly contested. The literature is contentious over whether social capital is a cause or 
consequence or both of high levels of social and economic well-being. As Putnam himself admits in Bowling Alone, "the causal arrows... are as tangled as well-tossed spaghetti" (1995: 137). As social capital often functions in studies as both an explanation and the object being explained, the concept has been dismissed as a tautology, with studies finding frequent statistical correlations to back up their claims because their dependent and independent variables are measuring the same thing (Mayer 2003). Portes (2000a; Portes and Landolt 1996) argues that this trend is due to a lack of theoretical distinction between correlation and causation in social capital research. Where high levels of community solidarity are found in regions displaying patterns of sustained economic growth or other positive outcomes, researchers often conclude "that one causes the other without consideration of the possibility that both are determined by common external causes" (Portes 2000a: 4). A distinction must also be drawn between social networks, the ability to command resources through social networks and the level or quality of such resources (Kilpatrick, Loechel et al. 2002). As Portes and Landolt argue, "When social capital and the benefits derived from it are confused, the term merely says that the successful succeed" (Portes and Landolt 1996: 2). As Portes (2000a; Portes and Landolt 1996) points out, actors may have trustworthy and reliable networks and social ties yet still remain unable to access high quality resources. Some studies have found that many regions with a low socio-economic status are actually characterised by high degrees of social capital (Arthurson 2002). This is especially true for remote or rural regions where "everyone knows everyone" (Kilpatrick, Loechel et al. 2002). Apparently high levels of social capital in socio-economically disadvantaged regions may be accounted for by the relationship between unpaid work and social capital (Cox 1995). Research has also shown that the level of inclusiveness of social networks in a given region may affect the link between social capital and economic growth (Annen 2001). As Coleman (1990a) suggests, different types of social capital may be more fungible than others. Many of the links are still missing, as the exact nature of the relationship between social capital and economic development in regional development remains unclear.

The dominant understanding of social capital as a normative concept is challenged by studies exploring the more negative aspects of social capital. Even Putnam acknowledges in Bowling Alone (however briefly), that social capital also has its "dark side". Citing Bagehot, Putnam recognises that social capital can "exact obedience to itself" and encourage conformity and group mentalities (Putnam 2000: 352). Coleman also drew attention to the "dark side" of social capital arguing that "[a] given form of social capital that is valuable in facilitating certain actions may be useless or even harmful for others" (Coleman 1990a: 302). In a study investigating the effects of international "micro finance" 
schemes promoted by the World Bank, Rankin (2002) found that social capital development initiatives can serve to re-enforce existing power structures and inequalities. As part of this scheme, the Grameen Bank of India provided individuals with loans against social capital. The result of which, Rankin claims, demonstrate the instrumental role associational and collective norms and values can play in producing and maintaining disparities based on gender, class and other social divisions. Portes (2000a; Portes and Landolt 1996) highlights three main "downsides" or "pitfalls" associated with social capital including: conspiracies against the public; restrictions on individual freedom and business initiative; and downward levelling pressures. By "conspiracies against the public" Portes is referring to the negative aspect of social capital highlighted by both Putnam (2000) and Coleman (1990a), whereby members of a group may benefit from their ties at the expense of the broader public. Portes uses the term "downward levelling pressures" to refer to the situation where social capital may have adverse effects on group members. For example, in ghetto communities, not only are social links often unlikely to ensure greater access to resources, but members of these communities may be ostracised or punished for achieving success beyond that of their peers. Portes argues that social capital may also lead to "restrictions on individual freedom and entrepreneurship" due to pressures that may be placed on groups or individuals in a community to abide by particular behavioural norms and standards of reciprocity.

Accordingly, the recent trend of tackling inequalities in regional development through policies and programs aimed at developing or increasing social capital is also a cause of contention in the social capital literature. A study of regional communities in New South Wales found that "social capital" was indeed a key factor in the ability of the communities studied to cope with social problems (Hase et al. 2004). The study found that "social capital" in the form of "extended family networks" and strong community ties enabled social problems to be addressed through innovative and imaginative projects, especially where those communities had a poor economic base and highly visible social disadvantage. However, despite these efforts, the underlying causes of these problems and the general level of disadvantage in the community did not disappear. As Portes (2000a; Portes and Landolt 1996) points out, while social capital can play an important role in the success of economic or political development initiatives in a given community, the bonds are difficult to establish, take time to develop and may not be created by outside forces. As social capital initiatives are often applied to communities by external development bodies, the lived experiences and voices of those being developed are often neglected (Rankin, 2002). Furthermore, unexpected and negative consequences may also emerge in the process of attempting to establish the required preconditions for their creation (Portes 2000a). Concern has also arisen 
that due to their relatively inexpensive nature, government bodies may view social capital initiatives as an alternative to the provision of funding for services or infrastructure in socio-economically disadvantaged regions. Ultimately, this equates to "expecting the most disadvantaged people to pull themselves up by their own bootstraps, in a way which is remarkably convenient for those who wish to implement large-scale public expenditure cuts" (Harriss 2002: 7). As Portes argues, "contrary to the expectations of some policy makers, social capital is not a substitute for the provision of credit, material infrastructure, and education" (Portes 2000a: 8). While, it may be possible that social capital development initiatives can "increase the "yield' of such resources" the economic benefits of social capital are of a limited nature, for example, "all the social capital in the world will be of no value if there are no jobs at all" (Portes 2000a: 8; Hase et al. 2004: 8). Thus, social capital development initiatives have been criticised as policies developed by the rich and powerful "to improve the lot of the poor" by promoting self-help and co-operation which has been "unproblematically raised from the individual to the community level without adequate theorisation" and "without questioning the sources of their economic disadvantage" (Fine 2003: 199). Particularly in relation to Australian regional development, it seems reasonable to suggest that rather than blaming regions for a supposed deficit in "social capital" policy makers and social scientists would be wise to consider that "the real problem underpinning social disadvantage lies in the culture of neo-liberalism that colours the political, economic, and social landscape" (Hase et al. 2004: 4).

Criticisms such as these have led to the concept receiving extensive theoretical attention in the years following Putnam's study. It has become increasingly ambiguous acquiring new dimensions as it stretches to incorporate the various criticisms. While Granovetter was discerning enough never to have used the term himself, his "strength of weak ties" theory contributed markedly to developments in social capital theory. Granovetter's (1973) argument that one is more likely to gain employment through a friend of a friend than a close acquaintance like a family member, formed the basis of the distinction between "bonding" and "bridging" social capital. Burt (1992) expanded on Granovetter's work with his "structural holes" theory, arguing that one could benefit more from a few contacts to unconnected groups than from a multitude of contacts to people who knew one another. Burt (1992) argued that maintaining contacts with disparate groups enabled individuals to span "structural holes", or gaps between unconnected groups, thus gaining access to a number of different information flows, rather than accessing information from one source and benefiting along with other group members. Michael Woolcock (1999) of the World Bank built on Putnam's (2000) distinction between bonding and bridging social capital, introducing the idea of linking social capital. According to 
Putnam (2000), bonding social capital is exclusive among groups, while bridging social capital is inclusive and occurs between groups. Woolcock (1999) uses the term linking social capital to refer to interactions which link groups or individuals with more powerful individuals, structural or institutional bodies. This three fold distinction appears in the World Bank World Development Report 2000/2001. The idea of linking social capital was developed in response to the criticism that "A theory of social capital that focuses only on relationships within [bonding] and between [bridging] communities opens itself to the criticism that it ignores power" (Harriss 2002: 10). Whilst acknowledging the existence of external forces that contribute to exclusion and poverty, the suggestion is that linking social capital enables people to overcome these barriers. However, there is little evidence to suggest that "linking social capital" contributes to the reduction of poverty and oppression and in some cases it may even serve to reinforce oppressive power structures (consider for example, client-patron relationships in Southern Italy) (Harriss 2002). Uphoff (2000) added new dimensions to social capital theory with his distinction between the structural and cognitive dimensions of social capital. Structural social capital refers to external, objective social structures such as networks, associations, community groups and institutions; whereas cognitive social capital includes the more subjective intangible elements, like trust, shared values and norms of behaviour and reciprocity. Grootaert and Bastelaer (2002) added yet more dimensions, arguing that social capital could be found at the macro, meso and micro levels. The macro level refers to the institutional and political environment of a particular region in which social capital is developed. The meso level covers both horizontal and vertical relations among groups. At the micro level social capital can be found in the relations between individuals and households (Grootaert and Bastelaer 2002). As Harriss (2002) quotes repeatedly from the World Bank website on social capital: "Social capital while not all things to all people, is many things to many people" (Narayan and Pritchett 1997). And Ben Fine argues, "[t]he process of excising Bourdieu from social capital has had the effect of endowing social capital with an unlimited scope of application both in terms of what it is and what effects it has" (Fine 2003: 97).

\section{Rational Choice Trojan Horse or Third Way Weasel?}

An ardent observer may wonder why a concept that is so heavily criticised and so inherently problematic has become one of the most popular and prolific in the history of social science. In order to address this question I turn to the academic and political environment in which the concept has taken hold. During the 1980s and 90s, neo-liberalism was ceaselessly presented and packaged as "the end of history" (Fukuyama, 1990: 75). The demise of the Soviet Union and 
the Eastern bloc in the 1980's strengthened the argument of neo-liberal ideologists that the free market provided the only viable path to development. Margaret Thatcher justified the neo-liberal revolution in Britain with a single word TINA, short for There Is No Alternative (George 1999: 3). Neo-liberal ideology is driven by the pivotal idea that the unregulated capitalist economy has an inherent tendency towards equilibrium. Neo-liberal approaches to development argue that when markets are left to themselves, economic development and thus poverty and its associated problems, take care of themselves. The key goals of neo-liberalism are growth (measured by gross domestic product or GDP), and efficiency (entailing a maximisation of profits and minimisation of costs). Unfettered market forces are believed to be the key to achieving both. As Bourdieu argues, the dominant discourse of neo-liberalism presents the economic world as a pure and perfect order, where the market is seen as infallible (1998: 94). The drive towards what Bourdieu calls a "Utopia of Unlimited Exploitation" is made possible by policies of financial deregulation and privatisation and through the emergence of new policies and institutions that challenge or dissolve "all the collective structures capable of obstructing the logic of the pure market" (Bourdieu, 1998: 94; 1998: 96). Neoliberalism generates a particular belief which Bourdieu refers to as "free trade faith", a deification of the power of the market in the name of economic efficiency (Bourdieu 1998: 100). As Bourdieu (1998) argues, neo-liberalism or economic rationalism is a scientific programme, a giant mathematical abstraction pursuing a political programme to create the conditions for the operation of the theory. Of primary relevance are "assumptions concerning the nature of producers' and consumers' rationality in the form of profit and utility maximization...assumed to have universal validity", and "incorporated into deductive analytical frameworks that are static, ahistorical and claimed to be value-free" (Lefeber 2000: 526). This "rule of the market" does not take into account social costs. It favours instead a separation between the abstract economy and social realities, which results in the construction of an economic system corresponding to theoretical description.

The asocial nature of neo-liberal theory combined with the increasing inequality produced by neo-liberal policy over the last few decades, created extensive opposition to the neo-liberal paradigm (Bourdieu 1998; George 1999; Weller, Scott et al. 2001). The popularity of social capital lies, largely, in its compatibility with Third Way ideology. A reaction to both the perceived "crisis of the welfare state" and the policies of government withdrawal which this inspired, the Third Way seeks a balance between liberal free market policies and welfare statism (Giddens 1998; 2000; 2001). In response to Thatcher's TINA, social capital can be viewed as a desperate attempt on the part of both academics and primarily social democratic policy makers to find an alternative that is 
acceptable to both critics of neo-liberal capitalism and the establishment. Critics of neo-liberal policies saw social capital theory as a means of re-introducing a focus on the social into the predominantly market-orientated economic rationalist perspectives on development (Cox 1995; Lyons 1997; Onyx and Bullen 1997; Woolcock 1998; 1999). Social capital's role in regional development was emphasised as part of an agenda for "a new development economics", led by Joseph Stiglitz, who recently resigned from his position as chief economist at the World Bank after much encouragement from those within the institution who were less than pleased with his ongoing critique of the neoliberal policies (Fine 2003: 173). Unfortunately however, the post-Washington consensus does not leave its rational choice origins behind. It is still based on methodological individualism and understands "society" through the aggregation of mathematical models of the behaviour of individuals, models, which assume the primary motivation for human behaviour is self-interest expressed through utility maximisation. Furthermore, it is "reductionist", in that complex historical and social processes are explained away within the premise of rational choice theory (Fine 2003: 144).

Where previously the Washington consensus painted a picture of the economy as unduly obstructed by the intrusion of the non-economic, the post-Washington consensus construes the market and non-market as inextricably attached to one another through greater or lesser efficiency in handling market imperfections. However, the result is one in which the social remains extraneous non-economic facilitator to the economy (Fine 2003: 153).

As Fine argues, the dominant tendency in both policy and social theory is for social capital theorists to bypass important political and economic issues as though the social and the economic are separate domains. The absence of a proper understanding of political economy "precludes a proper consideration of how economic powers, structures, and processes impinge upon, constrain and condition their social counterparts" (Fine 2003: 196). As in both policy and theory social capital essentially leaves economic issues alone, it functions as "a major plank in Third Wayism" essentially acknowledging and tackling social issues only in so far as they do not interfere with or challenge neo-liberal approaches to the economy (Fine 2003: 196). Thus, in its current form, it seems far more likely that social capital will function as a rational choice "Trojan Horse". While the concept may appear to re-introduce the social into economic agendas, ultimately social capital is unlikely to deliver while it remains embedded in a rational choice framework which denies the inherent complexity and contingency of social life and the power struggles with which it is imbued (Tarrow 1996; Harriss 2002; Spies-Butcher 2002; Fine 2003). 
The ideological implications of social capital theory become evident through a simple examination of the concept itself. The term "social" is juxtaposed with the term "capital", contrasting the values of collaboration and interdependence inherent in "social", with the values of independence and self-reliance implicit "capital" (Smith and Kulynych 2002). The concept is also an oxymoron, since while it suggests both social and capital it is in fact neither. The inescapable origins of social capital in rational choice deny the concept's ability to address the social except through aggregation of models of individual behaviour narrowly motivated by self-interest, and its understanding of capital is limited to "a prior physicalist notion of capital as resource" (Fine 2003: 199). This "cascade of perverse oppositions has important implication in terms of the "politics of language" (Smith and Kulynych 2002: 168). Former speechwriter to Paul Keating, Don Watson $(2003$; 2004) writes of the increasing dominance of "weasel words" in public language. Just as the weasel cunningly sucks the contents from bird's eggs, leaving behind only an empty shell, so the weasel word is employed to deprive a statement of its force or evade direct commitments. Social capital is a weasel word par excellence, enabling policy makers to address the concerns of both sides of the political spectrum, while in effect committing to nothing. As pointed out by Smith and Kulynych, the term "calls to mind Marcuse's discussion in One-Dimensional Man of how certain types of language integrate their conceptual opposites, thus smoothing over the tension between the contradictory concepts" (2002: 168; 1964). Thus, while the term appears to put "people before profit", this Orwellian juxtaposition often serves to subsume the social and political within economic discourse, effectively depoliticising political and economic processes. Pairing "capital" with "social", suggests that capital is otherwise not social, denying the way in which "capital" is itself a social construct. Thus, critics have argued that this terminology further serves to neutralise, naturalise, depoliticise and mystify the current global neoliberal project suggesting that the contemporary form of capitalism is the "natural" state of affairs (Harriss 2002; Fine 2003).

The term could also be seen as evidence of what Stilwell refers to as the "commodification of social life": the encroachment of free-market ideology into more and more aspects of our life, as more and more things become subject to "monetary values and the "rule of capital"" (Stilwell 1996: 46). Coronil (2000) writes of a relatively new trend by financial institutions like the World Bank to directly define both natural and human resources, along with produced assets, as capital. Social capital can be seen as part of a proliferation of a number of new forms of "capital" to have emerged over recent decades, as "homo-economicus" encroaches on more and more aspects of our lives: human, political, social, creative, and even emotional capital (Florida 2003; Reay 2000). The emergence of a whole number of new "capitals" is described by Fine as "a sort of capital- 
and capitalism-fetishism", whereby "The failure to specify capital, properly allows it to roam freely over any number of non-economic or social characteristics, whether attached to capitalism or not" (Fine 2003: 16). This redefinition of people and nature means all are in danger of being similarly treated as capital, valued only in so far as they can be used and exploited as sources of profit. Furthermore, it subsumes difference under the application of a single category, reflecting the neo-liberal tendency to make one thing out of many, "illocutionary force out of illusion", forging "the impression of consonance amidst contrast" and "the existence of universal standards" (Comaroff and Comaroff 2000: 329).

\section{Social Capital in the Australian Context}

Despite or perhaps due to, the numerous theoretical problems with the concept social capital, it remains extremely popular in the contemporary Australian policy environment. In recent years, it has come to play a starring role in Australian development policy. Indeed, use of the term is so widespread as to promote arguments for the concept as "doxa" - a taken-for-granted belief or assumption that escapes critical scrutiny (Smith and Kulynych 2002). Social capital has been constructed as a panacea for all social ills and is said to influence everything from health, wealth, and education to governance and crime rates. The term continues to appear in most of the development policies recommended by both Australian Labor and Liberal Governments and in recent years, has emerged in almost every Australian government plan (federal, state, and local) that makes reference to community (Genoff 1999; FACS 2004; Government of South Australia 2004). The importation of the term into Australian development contexts is evident in Australian Commonwealth Government initiatives such as the Community Networks Initiative and the Stronger Families and Communities Program, designed to foster the development of social capital in disadvantaged communities assumed to have deficits in this area (FACS 2004). While the main advocate and theorist of social capital in Australian politics, Mark Latham resigned from his position as Federal Opposition Leader in 2005 due to ill health, the concept has champions on both sides of the political spectrum. Prime Minister John Howard has described social capital as vital in ensuring that both international and local communities are able to "respond constructively to the challenges of change" and Federal Opposition Leader Kim Beazley has delivered a speech decrying unemployment, substance abuse and crime as "symptoms of Australia's declining social capital" (Howard 1998; Beazley, 2001). Federal Treasurer Peter Costello, the man tipped to become Prime Minister when Howard retires, has also delivered a number of speeches on the benefits of social capital (Costello 
$2003 \mathrm{a} ; 2003 \mathrm{~b} ; 2003 \mathrm{c})$. Thus, it seems likely that social capital will play a starring role in Australian development discourse for some time to come.

The social capital approach to regional development in Australia takes place within the context of an importation of Third Way agendas from overseas. Australian advocates of the Third Way have used the concept to distance themselves both from extremist economic rationalists and leftist critiques of the free-market agenda (Latham 1996; 2000; Botsman and Latham 2001). The Third Way is characterised by a whole of government, whole of community, social partnerships approach to human service provision, and a focus on the "devolution" of government. It encourages "social capital" building programs, which aim to foster social inclusion and economic development in underdeveloped regions through regional development programs. Social capital initiatives are compatible with the trend in recent years towards the minimisation of government intervention and the devolution of responsibility for social problems to the local level. As argued by Hase et al., "As government attempts to reduce its expenditure on human services, it shifts responsibility to the local level through community programs at a much lower cost through virtue of volunteers and low paid community workers" (2004: 9). Social capital is thus a useful rhetorical device for governments hoping to minimise financial involvement and evade responsibility for regions experiencing high levels of socio-economic disadvantage.

Neo-liberal policy came to dominate Australian policy making in the 1980s in response to the perceived "crisis of the welfare state" and the changing nature of the economy and its hold over Canberra has not since been relinquished (Pusey 1991; Beeson \& Firth 1998; Stilwell 2000; O'Neill and Moore 2005). Australia, was drawn into the neo-liberal project "in conscious pursuit of the enhanced competitive advantage that was commended to nations by Michael Porter (1990)" as the 80s and 90s saw both sides of politics dominated by the belief that neo-liberal policies "represented the only workable response to the forces of "globalisation"” (Badcock 1997: 252). While neo-liberal economic policy continues to dominate in Canberra, the contemporary federal Australian policy stance may be better summarised as neoconservative, as increasingly the propagation of neo-liberal economic policies is complemented by a focus on issues of morality and community.

In this context, social capital serves as a major tool in what Jayasuriya, borrowing a term from Jeffrey Herf (1984), describes as "the new reactionary modernism", a new form of governance that seeks to depoliticise social and economic life. The Howard government shares a common political logic with Blair's New Labour, which Jayasuriya describes as "a strategic mix of enthusiastic commitment to the value and processes of economic liberalism with an equally assiduous propagation of illiberal policies that draw on reactionary 
and nostalgic understandings of community and culture" (Jayasuriya 2003: 1). Jayasuriya argues that the declining capacity of governments to deliver social goods in the contemporary economic and political climate has been met with "the intensification of a form of communitarian politics geared around issues of morality and culture" (Jayasuriya 2003: 3). While social democratic elements may have seen social capital as an effective tool for arguing against Thatcher's claim that "there is no such thing as society", social capital continues to function in the contemporary Australian policy environment in a way relatively compatible with elements of Thatcherism (Thatcher 1987). One of the Howard government's main strategies aimed at building social capital in Australia is "mutual obligation", exemplified through programs like "Work for the Dole", which fits nicely with Thatcher's assertion made in completion to the previous quote, "There's no such thing as entitlement unless someone has first met an obligation" (Howard 1998; Thatcher 1987).This sentiment is echoed in Latham's (1996; 2000) catch phrase, borrowed from Third Way academic Anthony Giddens (1998), "No rights without responsibilities". In this context, Third Way terms such as "social capital" and "social inclusion" simply mean the "inculcation of certain standards of responsible social conduct", as exemplified in such policy documents as the McClure Report, and a passing off of moral responsibility from the state to the disadvantaged (McClure 2000; Jayasuriya 2003: 3). As Smith and Kulynych argue, social capital theory is often employed by policy makers and pundits to represent the poor and marginalised "as in need of traditional individualist values and largely to blame for their lack of 'stock' of social power" (Smith and Kulynych 2002: 172). Thus the current function of social capital in Australian public policy frequently equates to "blaming the collective as opposed to individual victim" (Smith and Kulynych 2002: 92). According to Jayasuriya, this "cultural turn" effectively marginalises the social and distributional issues associated with neo-liberal processes of economic restructuring (Jayasuriya 2003: 3).

In an article in The Australian, Howard lauded the development of a "social coalition" which would involve partnerships between government, business and welfare organisations in tackling social disadvantage (Howard 2000). Howard's agenda for "strengthening Australia's civic culture" includes a focus on drug and gun control, combined with a focus on partnerships between government, business and community sectors and "recognition of the important role of nongovernment community organisations" (Howard 1998). However, in light of the Howard government's hostile attitude towards unions and the constant push towards the dismantling of Australian industrial relations policy, it seems clear that Howard is intent on strengthening "social capital" for select groups, namely business and industry at expense of unions and the wider Australian community. While the Howard government may be more than happy to voice support for 
community volunteer organisations in partnership with government and business, it seems the same support will not be extended to community organisations likely to express opposition to the neo-liberal policies of the Howard government.

The 2004 federal election brought Howard's Coalition Government majority control of the senate which has enabled the Coalition to pass law through parliament with almost no opposition. There was little opportunity for debate within parliament as the Howard Government pushed major legislation through the senate in a matter of months before the close of parliament in 2005 (Murray 2005). In the first week of December, the Senate passed the Howard Government's Welfare to Work package (Commonwealth of Australia 2005c). This radical welfare reform package does not seek to address the causes of unemployment, through for example job creation, long-term workforce planning or investment in skills development, education and training. Instead these changes "place an unfair burden of responsibility on groups that are particularly disadvantaged in the labour market" (Spoehr 2005a). The bill includes punitive measures to encourage recipients of the Single Parenting Payment (SPP) and the Disability Support Pension (DSP) back into the workforce, such as the threat of having payments cut for a period of up to eight weeks (SVDPS 2005). In the context of the industrial relations reforms, these workers will enter "a more minimalist, individualistic system with significant care responsibilities and weak bargaining power" (Pocock 2005: 3). In the recent Senate Inquiry into the Welfare to Work Legislation, Australian charity organisation the St. Vincent De Paul Society concluded that "The welfare to work legislation combined with the industrial relations legislation will see an increase in poverty levels in Australia, with a significant growth in the number of working poor" (SVDPS 2005: 1).

According to the Howard Government, the Work Choices Bill 2005 replaces the current Industrial Relations system with "A simpler, fairer, national Workplace Relations System for Australia" (Commonwealth of Australia 2005d; Commonwealth of Australia 2005e). The new system is about as fair as it is simple; introducing close to 700 pages of new legislation and severely compromising the rights of Australian workers by shifting the balance of power between employer and employees (King and Stilwell, 2005; Spoehr 2005b). The bill effectively abolishes the award safety net, replacing the previous 20 conditions with just five protected by law, provides an exemption from unfair dismissal laws for businesses with 100 employees or less; and replaces the Australian Industrial Relations Commission (AIRC) with the so-called "Fair Pay Commission" which lacks the independence from government of the AIRC and has a mandate to reduce real wages over time in order to encourage employment (King and Stilwell 2005; Spoehr 2005b). The legislation also undermines the power of Australian Unions and the labour movement by introducing additional 
obstructions to collective bargaining and promoting use of the more individualist Australian Workplace Agreements (AWA's) (Pocock, 2005; Spoehr 2005b). In the last session of parliament for 2005 the senate further undermined the Australian labour movement by passing a bill to abolish compulsory student unionism in Australian Universities in the name of freedom of association (Commonwealth of Australia 2005b). While the industrial relations reforms have obvious benefits for small business, they contradict Howard's stated agenda of strengthening "social capital" and creating "Stronger Families and Communities" (Murray 2005). With worker's rights undermined and pay days, weekends, penalty rates, annual leave and leave loading under threat it will become more difficult for the average Australian to find time to spend with their family and friends, let alone to network their own way out of poverty (Pocock 2005).

As nationwide protests broke out over the Work Choices legislation, protest organisers and participants began to joke that they may soon be charged with sedition under the new Anti-Terrorism Bill 2005, which was passed just days later (Commonwealth of Australia 2005a). As pointed out by the Civil Rights Network, this bill has serious implications for human rights, free speech and collective action in Australia (Agnes et al. 2005). For example, concern has arisen over new "sedition" laws under which those voicing opposition to government policy could potentially be charged with "urging disaffection" against the government and imprisoned for up to seven years, and community organisations supporting these sentiments could be branded "unlawful associations" (ABC, 2005; Law Council of Australia 2005; Socialist Equity Party 2005; Welch 2006).

In the contemporary Australian political environment it seems that the "social capital" of government in partnership with business and industry is being promoted at the expense of families, workers, unions, non-government organisations and the Australian community at large. In other words, what social capital really means is that the "social" remains subordinate to the interests of "capital". The defeat of Latham's Labor party in the 2004 Australian federal election has made it even more likely that in the hands of Howard's neoconservative government, social capital will operate as a rhetorical device enabling politicians and policy makers to pay "lip service" to social issues without impeding the completion of Howard's neo-liberal economic vision for Australia. The statements of leading politicians in the Labor party following the 2004 election, who argued the results demonstrated a need for the party to align itself with a more conservative neo-liberal agenda, leave little hope that a dramatically different ideological construction of social capital will be employed by the Labor party in coming years (Bramble 2004). 


\section{Conclusion}

Recent years have seen a rapid expansion of interest in social capital by academics and policy makers alike. Of particular interest to policy makers has been the suggestion that there is a link between social capital and economic development. This paper contends that arguments linking social capital to the economic development of regions are highly problematic. In the transition from Bourdieu to Putnam social capital transformed from an analytical tool for the explanation of social stratification, to a normative concept that policy makers and social theorists suggested could be used to combat socio-economic disadvantage. As this paper and many others before it suggest, social capital is an inherently problematic concept and its current popularity may well have more to do with the academic and political environment in which it was spawned, than the concept's ability to address issues of socio-economic inequality in regional development. Following the "crisis of the Welfare State" and the failure of free market policy to deliver equitable social outcomes, social capital theory has been championed as a means of restoring social issues to the policy agenda. However, this paper argues that in the current Australian political environment, the concept functions as a neo-conservative rhetorical or ideological tool of Third Way governance, which allows governments to continue neo-liberal agendas for economic reform while paying "lip service" to the social and divesting responsibility for social problems to lower levels of government, or worse, to the disadvantaged communities themselves. The question remains as to whether the social democratic elements of social capital can be salvaged through approaches to regional development which address the historical and contextual nature of the social, the impact of political and economic processes on regional development, and restore issues of power, class and structural inequality to the development dialogue. If not, as seems likely in the contemporary Australian policy context, I suggest that the term "social capital" should be abandoned altogether and alternative approaches which emphasise the value of social life above and beyond economics be considered. As the well-known Australian feminist academic Eva Cox wrote a decade ago in her treatise on the same topic:

If we are social beings rather than economic beings, then society is threatened by the presence of Economically Rational Man in public policy...If he takes over, he will destroy society because social connections have no place in a world full of self interested, competing individuals. (Cox 1995: 2) 


\title{
CHAPTER NINE
}

\section{WHAT ARE WE PLAYING AT? SOCIAL CAPITAL AND MUSIC THERAPY}

\author{
SIMON PROCTER
}

\section{Introduction}

It's a Thursday afternoon. In an inner London psychiatric hospital, three inpatients (all in acute phases of psychotic illnesses) are sitting with me (a music therapist) in a large room, surrounded by musical instruments. Yusuf, a quiet man in his 30s diagnosed with thought disorder, is sitting at the top end of the electric keyboard, his fingers wandering distractedly. Raymond, who's about 40, is strumming the guitar aimlessly and talking loudly, often rather denigratingly about Yusuf, whom he knows from the ward. A psychiatrist would describe Raymond as manic. Corina, who is barely in her 20s, doesn't speak English but seems attentive.

Suddenly Yusuf's fingers find a fragment of a tune - it's a little melodic motif that repeats over and over. I start to support him harmonically at the bottom of the keyboard and his pulse begins to structure the group. Raymond seems resistant to this - he talks even more loudly across the tune about cigarettes and karaoke. I hum a bit, partly to counter Raymond and partly to encourage Yusuf. Raymond keeps talking and coughing, until Yusuf takes us all by surprise by launching into a vocal phrase with the words "Stars in her eyes". Once he has finished, I wait a moment, then recap it, without the words, extending it a little. I notice that Raymond has stopped talking now and is strumming the guitar sensitively and in time. Corina takes her lead from me, it seems, and takes a turn at singing Yusuf's phrase, extending it her own way. Then suddenly Raymond is doing the same, adopting Yusuf's phrase and giving it back to him. Shortly afterwards we find ourselves all swept up together in a wave of free singing of the phrase, at the same time but all in our different ways - it sounds extraordinarily harmonic and lifts the four of us into quite a different place ...

A few minutes later, when this improvisation eventually subsides, there is silence. Even Raymond is quiet. Then Yusuf says "That was good!" He's surprised - by himself, I think, as well as by what has happened between us. So 
are we all. Unexpectedly, we feel together - linked in some way. And this new atmosphere, with Raymond listening and Yusuf seeming more confident, affects the way we relate together both musically and non-musically for the rest of the session.

Later that day, I visit the ward where Raymond and Yusuf are confined in order to document the session. The nurses want to know what happened "down there": they too have noticed something changed, both in the relationship between these two men, and in the way that Yusuf is carrying himself.

The above is a description of a fragment of my work as a music therapist. I am paid to make music (usually improvised) with patients in a psychiatric hospital with the aim of contributing in some tangible way to their well-being. Within the highly medicalised context of the hospital, and indeed of the National Health Service as a whole, this is most often couched in paramedical terms (i.e. in terms of its impact on their symptomology). However, many patients tell me that the value of music therapy to them (and the reason they choose to attend it) has much more to do with the opportunities it offers them to experience healthiness. This is expressed primarily as the enjoyment of music making. And when I observe people enjoying music making together, I am struck by the capacity of this music making to offer them opportunities for the kind of collaboration and social interaction that their diagnoses would suggest are unlikely to be available to them. I can see this in sessions, I can hear it in the music we make, and, like the nurses on the ward in the example above, I can see its impact on people beyond the sessions. This reminds me of discussion in the social capital literature of how (to put it at its very simplest) doing things together impacts on people's well-being and can indeed benefit not only them but the community of which they are part. Thus I am intrigued by the possibilities that social capital as a concept might have to offer my discipline.

\section{The arts and social capital}

Robert Putnam consistently cites active involvement in the arts (rather than passive consumption of the arts) as a means of growing social capital. For example:

Art is especially useful in transcending social barriers. Moreover, social capital is often a valuable by-product of cultural activities whose main purpose is purely artistic. (Putnam 2000: 411)

Indeed, Bowling Alone is littered with references to music making as a means of generating social capital. Putnam correlates the decline of informal social connections with the fall in the number of people learning to play 
instruments, or playing socially with others (2000: 114-115). He points out repeatedly that our engagement with music has become increasingly passive (we are all listening to our iPods) and decreasingly active (we get together in each others' houses to make music of whatever variety, or sing in choral societies, or play in brass bands, far less often than we used to).

This theme is continued by the Saguaro Seminar on Civic Engagement in America:

The arts can nurture social capital by strengthening friendships, helping communities to understand and celebrate their heritage, and providing a safe way to discuss and solve difficult social problems....

Whether visual, musical, dramatic, or literary, the arts allow us to "create together" and to discover shared understandings. The creation and presentation of art often inspires a raft of civically valuable dispositions - trust, openness, honesty, cooperativeness, tolerance, and respect. From museums to open-air amphitheaters to dance studios, arts spaces are, at root, civic spaces. The arts are a superb means of building social capital....

(Saguaro Seminar on Civic Engagement in America 2000)

And of course one of the supposed benefits of social capital lies in the arena of health and well-being. A more specific reference to this potential as far as music is concerned comes from a little outside the social capital canon - this time from the anthropology of social psychiatry. Estroff (1995) tells of how, having spent two years observing a psychiatric patient as part of an ethnographic project, her entire understanding of her social situation was transformed when she eventually accepted an invitation to attend church with her:

.... I had had no way of knowing what she was missing when she had mentioned that she missed going to church and singing in the choir. Now it was evident that she was retrieving lost social roles and contacts, reconstructing her self and her life in all the ways rehabilitation professionals hope for. It was clear that the research instruments I had used and the interviews I had conducted fell far short of capturing the nature and significance of what I had witnessed at the church .....(Estroff 1995)

Thus Estroff suddenly realises the connectedness of musical and social participation. Somehow her research instruments, although presumably finely tuned to all the foci of psychiatric rehabilitation, had failed to recognise the value of the musical.

A final example of the lauding of arts comes from the recently published report from the Social Exclusion Unit on Mental Health and Social Exclusion (2004): 
Arts are believed to have a therapeutic role as well as helping people reintegrate into wider society by increasing self-esteem, confidence and social networks.... (Social Exclusion Unit 2004)

But is there anything special about the arts in this respect? Do they simply constitute an attractive way of generating social capital, much as any other activity might? Or is there something specific about the generation of social capital in an arts context? If so, that would be of considerable interest not only to social capital scholars, but also to me as a music therapist.

\section{Music and social contexts}

To learn more, we perhaps need to take in the view from the opposite perspective. People concerned with the generation of social capital may see the arts, such as music-making, as an attractive means of doing so. But what about those whose primary interest is in the art form itself? Is there, for example in musicology (the critical study of music), a concern for - or even a recognition of - the social dimension of music making? And if so, can this convincingly be extended to the generation of social capital? Furthermore, how does this link with the traditional practice of making music for healing or well-being which has been documented throughout history (Hordern 2000) and in many disparate cultures (Gouk 2000)? And can this link be regarded as manifested in the regulated professional practice of professional music therapy?

Musicology is in its own right a rich and diverse field - and in recent years it seems very quickly to have become richer and more diverse still. Williams (2001) ascribes this expansion of focus both to the growing role played in every field by theory (and the consequent possibilities for overlap between fields), and to the broader range of activities generally described as "music" that musicology has come to regard as worth studying. However, it is worth asking why this range has grown so much of late.

As a distinct academic discipline, modern musicology is generally reckoned to be not much more than a century old, with the publication by Guido Adler of a guide to the discipline (1885) often considered some sort of inauguration. Nevertheless, its origins certainly owe much to the age-old practice of learning composition from existing compositions. Thus in its early days, musicology was an inescapably canonical discipline, founded on the identification of "great" works and the propagation of the "great" musical values they were believed to demonstrate. In Bourdieu's terms, it was the gatekeeper of distinction. And inherent in this role is the exclusion of works - indeed whole musics, and with them entire cultures - deemed not to be great.

In a sense, then, musicologists can historically be seen as the curators of a "museum of music", their role being to identify works worthy of preservation, 
and then to exhibit them in ways which demonstrated their greatness (for example by developing techniques of analysis such as that pioneered by Heinrich Schenker which privileges structure in such a way as to demonstrate the superiority of the values of the Austrian-German tradition - see, for example, Schenker 1971). In this role musicology could be seen as acting on behalf of society, ensuring that the great works of the past were preserved, and that contemporary and future composers would be exposed only to the most wholesome and productive works of the past. Thus might progress be assured. This image of the museum is still a potent one - as recently as 1992, Lydia Goehr saw the need to entitle a book "The Imaginary Museum of Musical Works: An Essay in the Philosophy of Music."

And indeed, the changes to this internal view of musicology - its internal discourse - are relatively recent. Commentators frequently identify the contribution of Joseph Kerman (1985) as a turning point in this regard. Essentially he asked both editors of musical editions (who sought to be as "faithful" to the composer's "original intentions" as possible - itself a museumsanctioned project fraught with all sorts of difficulties and contradictions) and the historians of music (known in the USA, where Kerman was writing, as "musicologists") the big question - "So what?". What was the point of refining increasingly "accurate editions", or of building up bodies of knowledge about musical "objects", unless these scholars were prepared to go that bit further and use this garnered information to cast light on the music as music? He called for critical engagement with the music itself, both on an aesthetic level and in an attempt to cast light on our broader human understanding of its social, historical and political contexts. He dismissed the museum approach as "positivist" and argued for a broader, more humanistic musicology that was capable of contributing to human understanding of humanity: i.e. a musicology that understood its role as part of the wider world of the humanities.

In a sense, Kerman's call was for a revolution that was already underway. Cook (1998) describes the experience of being a postgraduate musicologist in universities around 1970, spending days looking at music in a vacuum and the evenings listening to or participating in music with a clear social and political context. This bred a generation of younger musicologists who were ready to answer Kerman's call, perhaps even in ways he could not have imagined.

And so it is that a survey of contemporary musicological writing reveals a much more socially situated interpretation of the discipline. Music is no longer simply an object (although something of this approach does still live on) - rather it is a human activity, to be considered along with its culture. And its consideration is seen as contributing to perspectives on that culture. Contemporary musicologists - even those who in many ways are still rooted in 
the scores of the old canon - are explicitly addressing issues such as gender, sexuality, identity and so on.

And no longer is the written score the only form of music worth considering. Increasingly there is focus on how people use music, how music is produced, performed, listened to, appropriated. At the same time the range of musics considered worthy of study has exploded out of the old Bach/ Beethoven/ Brahms canon and now includes rock, rap, indie, house and so on - all seen as valuable aspects of the ways we live and use music together. At the same time the geographical net has been spread much wider - of which more in a moment.

Perhaps the clearest expression of this new integrated stance is Christopher Small's concept of "musicking" (1998) which starts from the position that "there is no such thing as music" (p. 2). Instead Small posits "musicking" as an intrinsically human activity which, he argues, is a fundamentally (and inescapably) social and hence also political practice. It is something that people DO together, rather than dots on a page or sounds in a hall. And people's involvement in it is varied and not always foreseeable.

It might therefore be argued that musicology has in a sense "pulled itself up by its own bootstraps" - that the recent internal revolution staged by the new musicologists at the behest of Kerman (and others) has led to a new perestroika and climate of engagement with the outside world. But this would be at best a half-truth, and here it is important to point out how social thinking and cultural contexts have exerted influence on the profession for some years, even if with minimal response at first. There are many possible examples of this, but two will suffice here.

Firstly, it would be impossible to chart the development of musicology without mentioning the influence of Theodor Adorno. It is hard to describe accurately either where he came from in professional terms, or what his contribution was since his work is so complex and multi-faceted and still the subject of considerable debate and controversy today. Best known perhaps as a critical theorist and founding member of the Frankfurt Institute of Social Research, Adorno was also a musician who studied composition with Alban Berg (member of the Second Viennese School and himself a pupil of Arnold Schoenberg, the towering figure of $20^{\text {th }}$-century Central European music). Adorno is often remembered for his dismissive attitude to popular forms of music, such as jazz, and he certainly demonstrated little interest in nonEuropean musics. In this way he might be accused of continuing the Viennesecentredness of old musicology at its most extreme. Yet, at the same time, Adorno brought critical theory thinking to bear on musicology in a rigorous, if highly complex, fashion, thus encouraging musicologists to consider music as "encrypted subjectivity" (Williams 2001). According to Adorno, music is a form of social practice in which people's energies are put together (Paddison 
1995). Ironically, given Adorno's expressed and implied tastes, this is frequently most apparent in the very musics of which Adorno seems to have been most dismissive - the popular and the non-European. Its relevance in the traditional canon needs a bit more un-encrypting, and this has led to our tendency to focus on the scores as things as and in themselves. Yet there can be no doubt that even this music is performed, managed, listened to, bought, consumed and used in various ways and thus socially situated. In this way Adorno can be considered to have issued a challenge to musicology which ultimately demanded the reabsorption of ethnomusicology.

The great museums of the European capitals achieved their status as repositories of greatness in the nineteenth century, and the (virtual) musicological museum was no exception. Like the real museums, the musicological museum saw fit to expand its collections with oddities from the empires. Adler's (1885) vision of musicology certainly viewed what would now be termed ethnomusicology as part of musicology (Nettl 1999). Ethnomusicologists travelled all over the world, particularly within their countries' empires, plundering their various musics for the museum - to add artefacts to the collection. But these travellers discovered that the musics they found lost something when transported as the music seemed inseparable from its social context in a way that Western music had largely ceased to be. This preoccupation with social context was met with some distaste amongst scorecentred, "objective" mainstream musicologists and for a long time ethnomusicology was a sort of radical drop-out relation of musicology. But in recent years, for a variety of reasons perhaps including Adorno's intervention and certainly also because of the changing role of musics in society, this concern has been absorbed back into the mainstream and, as has already been described above, "new musicology" (as it has been dubbed) is profoundly concerned with music's social meanings and contexts.

So musicology has not simply evolved internally. It has been influenced by changes in society as well as in academic thinking and musical practice. And now it finds itself in a position to engage with neighbouring disciplines - among them sociology, social psychology and economics. For example, Small's formulation of musicking as something that people do together enables musicology to focus on people's involvement in it. This leads on to DeNora's (2003) description of how music offers both appropriation and affordance. That is to say that the traditional notion of performers as active and audience as passive is misleading. On an individual level, people make use of music to construct their identities. On a social level, we use music to create, manage and regulate our relationships. And societally, we use music to create and understand our role in relation to the world. 
Clearly, then, musicology has arrived at a place where the concept of social capital is one with much to offer. Furthermore, musicking in Small's sense is a rich sphere of social activity which may offer scholars of social capital rich opportunities for observation of its generation and deployment.

\section{Musicking and social capital}

As noted above, Robert Putnam and others have noted the potential for active engagement in music making for the generation (whether intended or not) of social capital. And, as also already noted, musicology has moved from a historical position of objectivity in the sense of text-centredness to subjectivity in the sense of social-centredness. How do these two things fit together?

Little has been written directly about social capital in the musicological literature. There is much more reference to the related concept of cultural capital, most of which acknowledges Bourdieu as its point of reference. This is particularly evident in the field of music education (e.g. Green 2003).

However lately, writers examining particular specific forms of musicking, especially in an ethnographic manner, have begun to draw explicitly on the concept of social capital as a way of conceptualising and describing the benefits that people experience as part of the musicking they engage in. For example, Mattsson \& Stenbacka (2003) compare male and female engagement in music and sports activities in two specific localities in terms of the social capital benefit. They critique the existing literature for its failure to discriminate with regard to gender, but equally it could be argued that it fails to discriminate in terms of means of social capital generation. How do sports and music differ in their potential for generating social capital? And do they simply generate the same thing differently, or is there something specific about the kind of social capital generated by music?

Rankin (2001) examines marimba music making in terms of its contribution to the generation of both social and cultural capital. Richter (2004) focuses on the social capital generated in the process of music-making amongst street workers in a city in Indonesia and attempts to reconcile Putnam's "bonding" and "bridging" forms of social capital (2000) with Bourdieu's focus on power and inequality (1986).

It is notable that these studies which draw on social capital thinking in relation to musicking are very specific in their situatedness. This enables the researcher to examine the minute details of what is actually happening and to observe the possibilities for social capital generation. Music therapy might be considered to offer a comparable scenario: music therapy happens within particular places and involve particular people. Furthermore, they are often recorded and documented in ways which offer access to considerable 
phenomenological detail. Might this too then be regarded as a potential laboratory for the observation of the generation of social capital in practice? Indeed, might the generation of social capital be considered a legitimate goal of music therapy? And what implications might this have for the professional practice of music therapy and its role in the medical-social care complex within which it is conventionally situated?

\section{The profession of music therapy and social capital}

As Hordern and Gouk might both point out, people everywhere have been using music and musicking for therapeutic purposes for years. But only in the last few decades have musicians been able to undertake a postgraduate training as a "professional" music therapist. In the early days, music therapists were often radical musicians who didn't see why someone should lose out on the experience of music making just because they were ill or locked away in an asylum. As the profession sought to establish itself in psychologically-minded environments, it needed to make alliances with the dominant treatment models of the day - at first, behaviourism, and later psychoanalysis. In addition it bought significantly into medicalism. These alliances necessitated the adoption of some language and ways of thinking but the central practice - musicking continued more or less unaffected despite its non-indigeneity to the adopted model. Recently, however, there is a sense that music therapy might be once again focusing on the practice of musicking and its potential for connecting people to music and people to people (see, for example, Ansdell 2002 and Pavlicevic \& Ansdell 2004). This has arisen in particular because of an increased concern for working with relevance to the specific places and communities within which music therapy takes place: whereas this can be significantly obstructed by adherence to a one-size-fits-all imported theoretical model, musicking is an intrinsically socially-situated activity. Thus music therapists are asking questions like "What are the inherent benefits of musicking and for whom? What skills do we need to offer these benefits to those who may otherwise have most difficulty in accessing them?" And some of the answers are being sought in the connection between the experience of music therapy practice and the insights in offer from new musicology (e.g. Ansdell 1997, 2001).

But others are asking questions too. In a healthcare environment which will always be apportioning limited resources, all interventions are under constant pressure to demonstrate their clinical effectiveness - and arts-based interventions such as the arts therapies are no exceptions (e.g. Geddes 2004). The problem arises because at present only certain kinds of evidence of effectiveness are regarded as acceptable. These are ordered into a hierarchy (see, for example, SIGN Methodology Review Group 1999), the most acceptable 
being experimental data gathered in large-scale replicable randomised controlled trials (RCTs) - the methodology used in most drug trials. Along with colleagues, I have argued elsewhere (Ansdell, Pavlicevic \& Procter 2004) that this precipitates a two-pronged response: on the one hand, it is incumbent upon us (often on pain of losing our employment) to be seen to engage with this demand as constructively as possible, even though the realistic chances of meeting any of its requirements are minimal, given that music is not a pill and simply does not work as a pill does. On the other hand, we also need to argue for the relevance of other, different, kinds of evidence. People who come to music therapy tell me that they keep coming because they enjoy it, because of the nature of the contact they experience with me and with others, because of the way in which music becomes something alive and powerful for them again (in some cases after many years of absence). Rarely does anyone mention reductions in their symptomology. Could it be that social capital has an explanatory role to play here?

The exaltation of the RCT is a consequence of a medicalised, privatised view of health. It is privatised in the sense that each patient is seen as a discrete bundle of symptoms and processes, to be cured separately from any other. Given the social and relational nature of musicking, it is therefore not surprising that music therapy has lately been exploring what has been termed a "turn to culture", wherein health too is considered relational. In this view, health is no longer simply the property of the individual but to some extent at least also social and societal. This enables music therapy to be seen less as a medicalmodel-derived "absolute" practice and more as a culturally situated practice. It also frees music therapy to consider the development of cultural identity and social change as legitimate goals (see Stige \& Kenny 2002). And as the profession wrestles with this, could the notion of social capital, with its burgeoning scholarship, be a useful means of conceptualising this?

\section{But what about the micro-level of musical phenomena?}

At first glance, some practitioners might fear that such a discussion, focusing on big issues such as cultural identity and social change, neglects the essence of what they do. However, a concern for the essential phenomena of musicking characterises much of the practice of those advocating a cultural turn. At the heart of most music therapy practice is an acute listening to people, a trained hearing of what people offer as music, and a honed skill in responding in ways which people can experience effectively. To this end, therapists often record their sessions with patients and listen back to them afterwards. This serves the dual purpose of heightening their awareness of what has been going on in the musicking at the same time as developing their ongoing skills in following 
threads of interaction in their work. Whilst listening back, they may compile what is known as an index sheet. In Figure 9.1 I reproduce a pared down index sheet for the example outlined at the start of this chapter. (Usually this would be much more detailed and would include fragments of musical notation, but for clarity here it is reduced to its barest bones in order to highlight simply the evolution of the vocal theme: there are in fact several things going on at once.)

Figure 9.1 An index for the example, including timings

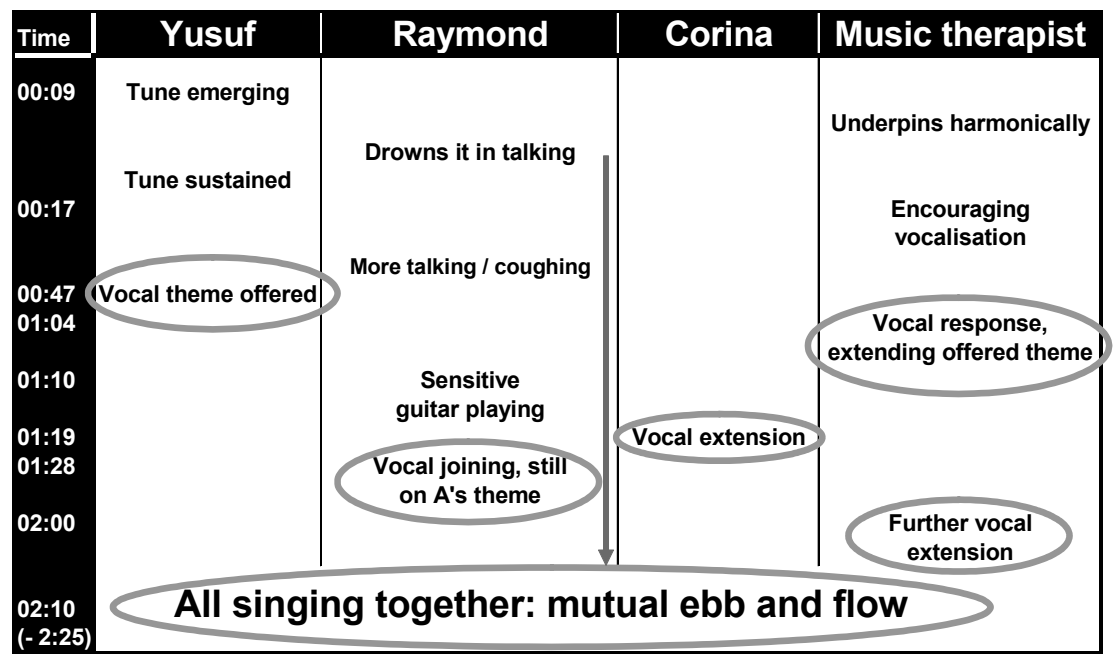

The circles in Figure 9.1 highlight the appearances of the vocal theme, from its introduction by Yusuf, through its adoption by each member of the group in turn, to our coming together in free vocal harmony. The arrow indicates Raymond's journey from resistiveness (to the extent of being deeply undermining with his comments at first) to his fully engaged participation in the give and take.

So, on this phenomenal level, is there a role for a level of description drawing on social capital theory? I would suggest that there is. To continue with the somewhat artificial isolation of Yusuf's vocal theme, it is consistent with experience, and with music therapy discourse, to describe Yusuf as exhibiting trust in the group (despite Raymond's comments) in order to launch this new vocal phrase. It is a bit of him presented to the group without regard to reward. $\mathrm{He}$ is taking a risk which is simultaneously both aesthetic and personal. The rest of us take this up and give it back to him. This doesn't happen on its own, however: I model it first, imitating and then extending the phrase (a conscious 
intervention on my part), but the others key into this and eventually we are all sharing it. This is a prime example of musical reciprocity. Thus trust and reciprocity - features of interpersonal relations closely associated with social capital (Field 2003: 62-65) - are happening in the musicking, audible in the musicking and experienced in the musicking.

What lessons can be learned from this very simple (and admittedly rather reductionist) collision of music therapy phenomena and social capital theory? Well, I would suggest three points here:

1. The trust and reciprocity do not arise simply from the four of us attending the group: they arise rather from our experience of what happens in the group and of being heard musically by each other and responded to musically by each other. I am clearly facilitating this, both by providing an appropriate musical context for the music that the group members bring, and also by modelling listening and response in ways that can be taken up by others if they wish.

2. In this example, musical norms and structure are aiding "successful" participation and experience. This is not simply a case of people doing what they normally do translated into music. Rather the way music works - using tonality, metre, phrasing, cadences etc - gives people a way of jumping into participation and even offers semi-structured opportunities to experiment with small-scale acts of trust and reciprocity. People often express surprise at their success in such interaction, as though it were beyond their own resources. (A crude analogy might be of someone swimming with armbands - they are not swimming any less, but they are benefiting from the buoyancy the armbands afford.) And indeed, in psychiatric terms, people do seem in this kind of facilitated musical interaction to be able to rise above the limitations on social interaction usually associated with their diagnoses. There is an interesting, and I think compelling, comparison to be made here with the role of societal norms and structure in models of social capital generation.

3. This kind of musicking changes how people are, even outside the music. Different patterns of non-musical interaction are observable in the group after the musicking. Likewise, the nurses on the ward (who had not been present in the group) noticed the changes in the interaction between Raymond and Yusuf and in Yusuf's own way of being as a result of the musicking. This could perhaps be couched in 
terms of increased readiness for the sort of social interaction more normally recognised as generative of social capital. On returning to the ward, Yusuf and Raymond didn't launch into collaborative activity, but each in his own way was more prepared for positive social interaction: Raymond by his increased ability to listen rather than bully, Yusuf by his increased self-assurance and experience of his own creative ability.

\section{But is this social capital?}

So is the musicking in music therapy generating social capital? I think it could be argued that it is: it has the capacity to do so, just like any other social activity, and I also think that this is a desirable outcome, particularly for people whose psychiatric illnesses may impede their ability to build and maintain links with others. But perhaps what this example demonstrates is something before social capital. It's all essentially musical, it all arises out of musical interaction and as such I feel that it might be better regarded as a sort of pre-social, "musical capital" (Procter 2004), as shown in Figure 9.2. 
Figure 9.2 The generation of musical and social capital

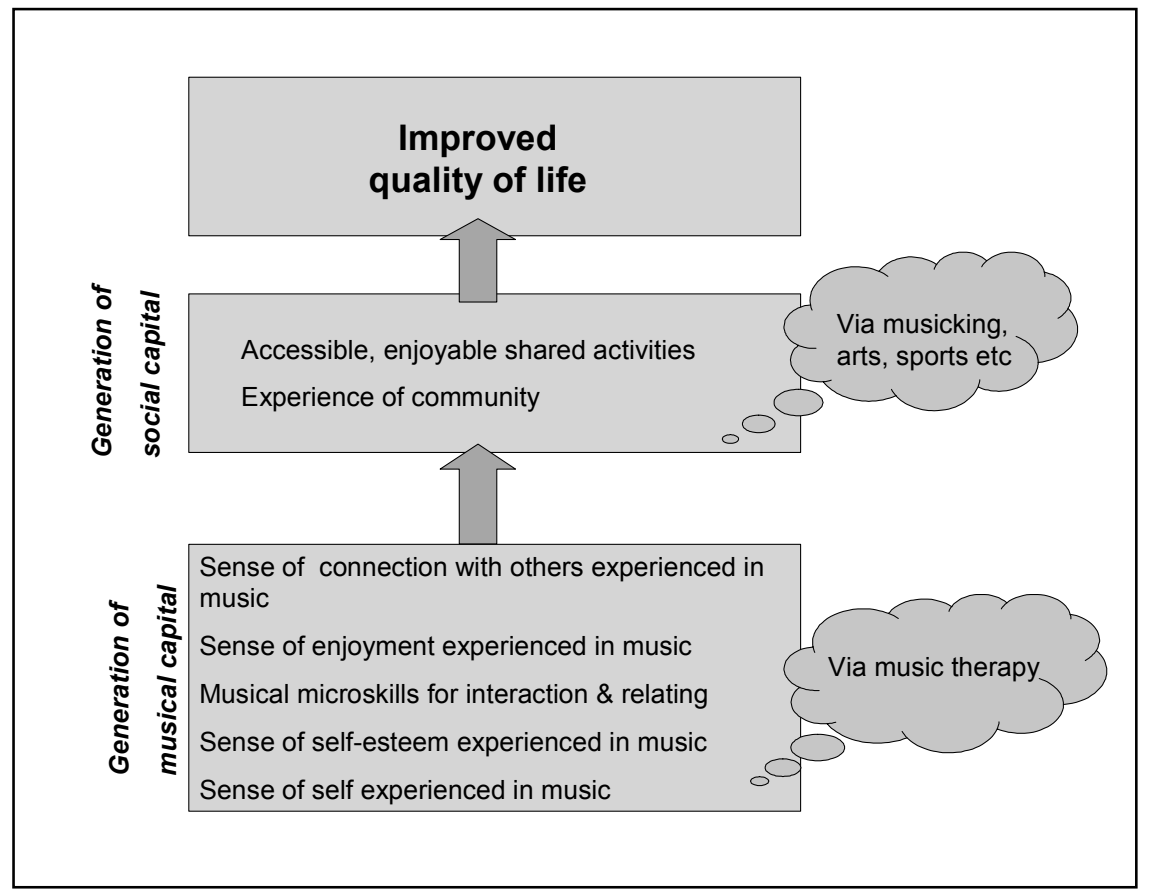

Figure 9.2 is purely a diagrammatic means of representing the notion: I do not wish to suggest that musical and social capital are actually entirely discrete. But perhaps experiences gained in musicking can equip people for the kind of participation which certainly does lead to the generation of social capital, whether this occurs in musicking (perhaps also within music therapy, although not necessarily) or elsewhere. I would also suggest that the experiences I have listed in the musical capital box in Figure 9.2 are preparatory for success in more general interaction. They mirror our developmental experiences (the mother-infant interaction literature being couched in almost wholly musical terms). They also act as tools in a manner reminiscent of DeNora's notion (derived from cultural repertoire theory) of culture as a "toolkit" which enables us to perform ourselves and to engage in meaningful social relationships:

We draw upon and use the cultural tools that stand within our reach, and these tools may be afforded from habit, proximity, serendipity, or chance, as well as 
due to often arduous or heroic forms of appropriation and creation. (DeNora 2003:150)

For some people - for a variety of reasons, including mental illness as well as the way mental illness is treated - these tools are simply not within reach. Despite their "arduous or heroic forms of appropriation and creation", additional help is needed. As a music therapist then, my role is perhaps to help people to appropriate and create - which takes the form of accessing, mobilising and keeping going with the therapy offered by musicking with others, thus building up the toolkit with which they can then go on to access social capital in the ways that society as a whole has to offer.

\section{Implications}

So what is the outcome of all this wondering? I suggest four areas of implication:

\section{(i) For music therapy}

Social capital is a useful concept for thinking about the practice of music therapy. It is equally applicable to an examination of the micro-phenomena of musicking in music therapy as to consideration of the broader patterns of interaction between group members. It provides a conceptual bridge to a consideration of health and well-being as relational, and taken with DeNora's concept of cultural toolkits, fulfils the aspiration of Stige \& Kenny (2002) that cultural identity development and social change should be regarded as legitimate goals of music therapy.

\section{(ii) For health and social care planning}

It is well established that social capital can lead to health benefits, for individuals as well as for society as a whole (e.g. Halpern 2005). What seems to be a less well understood implication of this is that in many cases (such as those of people with mental illness) an enhanced ability to accrue social capital is in and of itself a health benefit. Interventions such as music therapy which render this a practical possibility therefore have a particular role to play. However, this is currently unacknowledged in the hierarchies of evidence demanded by the medical system. Is it possible that social capital could acquire validity as evidence of effectiveness? Given the current state of measurement of social capital, this is likely to be some way off - but it may be something worth 
working towards, and something towards which music therapy may be able to contribute evidence.

\section{(iii) For community development}

The notion that arts activities in and of themselves produce social capital leading to community development may be simplistic. As in the example given, it may be that the intervention of a skilled person is required to facilitate this in some situations. Consideration needs to be given to which skills are important in which contexts.

\section{(iv) For the relationship between arts and health}

Via social capital, the arts and health are linked in a manner that current funding, authority and governance structures do not recognise. In the UK at least, these are entirely separate at central government, local government and quango level, with a consequent lack of joined-up thinking. (There have lately been some attempts in UK public policy to portray the two as linked in government thinking, but these seem to be rather simplistic and tokenistic, without much grounding in evidence or skill bases - e.g. Arts Council England 2004). A more coherent and firmly grounded approach could yield significant benefits in both fields. This linkage is at least partly connected with a view of health as social and relational, rather than entirely individual as dictated by the medical model. Social capital theory has considerable value in its potential to challenge this assumption, thus rendering a closer relationship between arts and health policy more achievable.

\section{Limitations}

It is evident that social capital offers useful perspectives on the practice of music therapy and arts therapies in general as well as ways of conceptualising the link between musicking and well-being. However, social capital is not sufficient to describe these interventions on its own. In particular, it seems to have little to say as yet about experience of self, which clearly has a huge impact on our experience of, and ability to participate with, others. It also seems not to address aesthetics, emotional experience or expression, all of which are significant areas of discourse in and around the arts therapies. 


\section{Conclusion}

Social capital seems to have considerable potential as an informing concept in the provision of arts and arts therapies in health and community development. In particular, it validates a relational view of health and suggests alternative means of providing "evidence" of effectiveness by linking what we do in terms of artistic phenomena with broader patterns of interaction within music therapy and beyond. As a young field, social capital is still developing and producing considerable new thinking - music therapy would benefit from tapping into this, but equally the musicking that occurs within music therapy might offer social capital theorists a sort of laboratory within which to observe the emergence of social capital as well as nascent pre-social or musical capital. 


\title{
CHAPTER TEN
}

\section{FRAGMENTED YOUTH: SOCIAL CAPITAL IN BIOGRAPHICAL CONTEXT IN YOUNG PEOPLE'S LIVES}

\author{
JANET HOLLAND
}

\section{Introduction}

Social capital has become a popular concept for policy in a range of countries in recent years. In the UK it underpins much government policymaking. Building and enhancing social capital is seen as a magic bullet for difficult policy issues including the consequences of individualisation and globalisation, changes in family forms, declining, alienated and socially excluded communities, and a lack of political and civic involvement (Edwards et al. 2003). This policy reliance on social capital, stemming largely from Putnam's approach, contains the seeds of conflict at community and individual levels. The policy focus on building social capital as a route to community and social cohesion, stands in sharp contrast to a policy discourse of social mobility and individual success in which educational achievement is central, particularly in the lives of young people. It also ignores many problems of definition, use and meaning, and the concept's motley heritage across a range of social sciences.

Social science uses and definitions of social capital fall largely into two traditions of social theorising: it is seen as a concept dealing with the dilemma of collective action and integration, or as one dealing with the dilemma of social injustice and inequality (Kovalainen 2004, Adkins 2005a). Coleman, Putnam and Fukuyama are in the integration camp, stressing collective goods of reciprocity, trust and co-operation, as Putnam puts it "features of social organisation, such as networks, norms and trust, that facilitate action and cooperation for mutual benefit" (Putnam et al. 1993: 35). Many studies have emanated from this perspective, but it has also been heavily criticised, and the 
work of Bourdieu, in the social injustice and inequality camp has been employed as a corrective.

Bourdieu's contribution is a typology of different forms of capital (economic, social, cultural and symbolic) and his concern is with how social and cultural capital are linked with economic capital, the fundamental resource in capitalist societies. He developed this extended metaphor to describe and understand the production and reproduction of privilege (Allatt 1993) but these terms have increasingly been used to explore the absence of resources in the production and reproduction of inequality (Reay et al. 2001, Skeggs 1997).

There has been a growing recent interest in the applicability of the concept to the lives of children and young people, with much of the research involving a critique of mainstream approaches for their omissions in this regard. Following developments in the sociology of childhood which focuses on children and young people as actors in their own right (James and Prout 1997 [1990]), this research grapples with questions about the extent to which they access and/or generate social capital and exhibit agency in its acquisition and deployment. The work encompasses a range of definitions, operationalisations and contexts of potential generation of social capital for children and young people - families, educational institutions, friends and peer groups, communities, political and civic activity (Morrow 1999, Schaefer-McDaniel 2004, Egerton 2002, Whiting and Harper 2003).

In this chapter I draw on a qualitative longitudinal study of young people moving into adulthood to examine processes of social capital generation and use.

\section{From values to adulthood to social capital: a qualitative longitudinal study}

The qualitative, longitudinal study ${ }^{1}$ followed a sample of young people from five sites in England and Northern Ireland. These vary in socio-economic profile - a leafy commuter town (middle class and white ${ }^{2}$ ); an inner city site (working class and ethnically diverse); a disadvantaged estate in the north west (working class and white); an isolated rural area (mixed social class - professionals, rural labourers, farmers) and a city in Northern Ireland (communities mixed re social class and religion) (Thomson and Holland 2003). We have investigated agency and the "reflexive project of self"; values and the construction of adult identity; and how the social and material environment in which young people grow up acts to shape the values and identities that they adopt.

The first study, Youth Values, employed questionnaires (1800) across the sites, followed by focus groups (56) and individual interviews (54), with volunteers from the questionnaire sample (Holland et al. 2000, McGrellis et al. 
2000). In the second, Inventing Adulthoods, we selected 120 young people across the samples and sites, using a range of methods over two and a half years to investigate their understandings of and strategies for transitions towards adulthood. These included repeat biographical interviews, memory books and lifelines (Thomson and Holland 2002, Thomson and Holland 2005). The third component, Youth Transitions, continued the biographical interviews with a focus on families, communities and social capital. The young people were between 11 and 18 years at the start and are currently 19-26.

Our empirical material lends some support to theories pointing to a progressive decline in the influence of tradition and social institutions in the formation of values and identities, a process variously described as "detraditionalisation" (Heelas et al. 1996), "individualization" (Beck 1992) and "disembedding" (Giddens 1991). Many of the fears and anxieties generated by this type of change have focused on the beliefs and behaviours of young people, constituting in some respects a moral panic. Others have seen this generation of young people as the first to live the postmodern shift, plunged into the risk society to make their own decisions and choices in a reflexive project of self, and as such a suitable object of study (Wyn and Dwyer 1999, Chisholm et al. 1990). This generation is moving into what has been called the new economy, argued to be becoming increasingly more virtual, reflexive, flexible and networked, and characterised by data, knowledge and service intensity (Adkins 2005b, Castells 1996, Lury 2003, Thrift 1998) through a process of economic postmodernisation (Hardt 1999).

A blurring of the public/private division has developed, and Adkins (2002) and McDowell (1997) for example have suggested that resources once attributed to the personal, private and domestic sphere are increasingly demanded by employers. We can link this line of argument back to social capital, since most social capital theorists assume that the family is a crucial site for transmitting, reproducing and accumulating social capital. Whilst social capital theorists, like other social theorists tend not to include women in the analysis, the notion is based on the assumption of the gendered division of labour, with women as the bearers and creators of social capital and producers of collective goods through their kin, family and community work.

The broad social shifts outlined here have wrought havoc on what could be seen as traditional classed and gendered youth transitions, from school to work or education, from youth to adulthood. This process has been shaken, fragmented and stretched (Goodwin and O'Connor 2005).

Here I draw on these theoretical strands to examine the accounts the participants in our study render in relation to some of the key components of social capital, and our interpretations of both this concept and their accounts. As a research team, we place ourselves in the social justice and inequality strand of 
social capital work, drawing on Bourdieu. For Bourdieu social capital is something which must be worked for on an ongoing basis, "the product of investment strategies, individual or collective, consciously or unconsciously aimed at establishing or reproducing social relationships that are directly useable in the short or long term" (Bourdieu 1986: 251). And "the sum of the resources, actual or virtual, that accrue to an individual or a group by virtue of possessing a durable network of more or less institutionalized relationships of mutual acquaintance and recognition" (Bourdieu and Wacquant 1992: 119).

In this context we regard social capital as a resource available to the young people in the study, along with economic and cultural capital. Access to these resources, and agency in recognising and deploying them, play through the biographies of the young people, entwined with personal, family and community factors, and subject to individual, social and policy contingencies.

\section{Analysis and interpretation}

Immediately after each interview, the interviewer made an analysis incorporating related and background information from the context and situation. At each interview more information and interpretation became available and incorporated in the analysis, constituting a changing and developing case profile of the individual young person. From this, the researcher assessed their levels of social, economic and cultural capital. These capitals as resources could vary with the young person's structural context, including class, gender, ethnicity and location, but also in relation to their biological trajectory and historical and social time. Social capital included networks of association and support upon which they could draw, economic capital included the types of material and financial support they had access to, through their own labour and the wealth and property or otherwise of their parents, and cultural capital was based on a broad interpretation of cultural goods, including those associated with youth and class culture, and the knowledge and information society. This cumulative information, analysis and interpretation constitutes both data and background for this chapter.

\section{Young people and social capital at moment in time}

In the fourth interview the young people (aged 17 to 24) were asked questions about social capital: about communities and belonging, networks of association they were part of and the benefits that might accrue from those contacts, who they could turn to if they need various types of support (economic/practical, social, emotional), and about feelings of inclusion and exclusion. Their responses on networks and communities are considered here. 
The major source of support for the young people at that point in their lives was their family, in particular parents who provided emotional, financial and social support and resources. They also provided networks of contacts through which their children could secure information and help with educational choices, and work. Clearly young people without this backdrop of support for whatever reason could face considerable difficulty. Others in their social networks who provided support and resources in various ways included friends, people in their workplaces and communities, college and university teachers, and members of the social services. They could also gain support, networks and social capital through relationships, youth culture, the gay scene, sport and the internet.

\section{Networks of association and support}

For some of the young people the idea of networking, building and using contacts was totally familiar, and they were usually well networked. Others had little idea about what it meant, and often minimal networks and contacts. Yet others rejected the idea of networking, preferring to go it alone or deploring the idea of using their friends or family in an instrumental way.

Shirleen recognises that from her background (African-Caribbean, respectable working class, inner city site, aged 17) she probably does not have the contacts that she needs to get work in her chosen area, law. When asked about opportunities and career possibilities she comments:

Shirleen: Well that's the problem I'm having at the moment.

Int: Is it?

Shirleen: Yeah, cos I don't know many barristers, on a good level, and I need those kind of connections if I'm gonna really get through, but erm, I do know a few solicitors, well my aunt knows a few solicitors, my aunt's friends, she's got two friends that are solicitors, so that can help me to get my foot in the door really. But erm, just to er really, just to really go to university and learn it all first.

Shirleen's cultural capital is drawn from her strong identity as a black woman. She has considerable support from her family, including financial from her mother, all of which is critical and motivates and enables her to pursue her ambition to become a barrister. It is a family (and generational) affair, and the wider, extended family for her is community (Thomson 2004). In an earlier interview she had commented:

I try and work hard because like I wanna be something that, cause like when people in my family, they just, they don't get to be that prestigious, have lots of money, not rich or anything, so I just wanna kind of turn it around. ... I really do 
wanna get somewhere, I really do cause like some people in my family they just end up in jobs they don't like.

Francis, from a comfortable middle-class background (leafy commuter town, aged 21), thought he was not well networked particularly in relation to his chosen field, finance, but quite liked that:

Int: Do you feel that you're well networked yourself?

Francis: Um well for getting a job in London I feel I'm completely useless. I spoke to a few of the other interns and they spoke to their dad who phoned their friend who spoke to this person or whatever. So I suppose in finance and things like that I don't know anybody at all. ... I suppose it would be quite nice to have a network, but at the same time I quite like the idea that I'm almost going in blind or whatever, and it makes it a bit more interesting. I prefer to be a bit more independent where it concerns getting a job. The idea that, I suppose, that daddy gets you the job or whatever, I suppose all the stigma attached to not fending for yourself - I suppose I probably wouldn't be at all upset if I was found a job by my Dad - but (laughs) I am quite keen on doing it myself. Yeah so I'm not too worried about the lack of networks.

Maeve (middle class and feeling at home and easily included in the community in her university town at this point, Northern Ireland, aged 19) more clearly rejects the idea of using her family networks to gain work or advancement, preferring to take an independent line:

Maeve: I'd say that I'd form my own networks gradually over time and I already feel that (the town) is my place do you know what I mean, so I'd like it if I had, see if went out and got myself a job then whatever, form networks from that, my own that I made myself I'd be even more proud of that. You're not living in anyone's shadow at all, not that I am here but, you know, the way it's not like I'm working with people who know your mammy and daddy, there's none of that, it's nice to be your own person.

Judy (upper middle class, commuter town, aged 17) is networked through her parents, gaining different benefits from each, work experience and information about education from her father's contacts, social contacts through her mother:

$J u d y$ : I think so because Dad's line of business, if I - he knows a lot of people who know a lot of people. So if I wanted to get work experience I think it would be possible in most places, which is very good. And he's been getting advice from people he's worked with as to where they think would be a good place for me to go to Art College. ... Um Mum knows everybody - even when we're walking round (hometown) she knows most people in most shops - "Hello, hello, hello." So networking through her is very good for social things. 
Like Francis, Judy regards herself as responsible for her own decisions, but values the advice, information and contacts she can glean from these sources. The thread of independence, self-reliance and agency runs through these comments.

A few of our young people have developed their leisure time activities into work, and generated useful networks in the process, sometimes incorporating members of their family. Patrick for example (lower middle class, aged 18) is very well networked in the music business, and has supportive uncles who are in the same business living in different towns. He obtains all manner of practical and other support from his wide networks, and like others in the sample operates with a principle of reciprocity, since through his contacts he provides help for his brother. He observes:

Patrick: When I first started off, like, I didn't know as many people as I know now and there would have been a lot more effort, like, a real determination. Now it's kind of, like I can sit back and just, like it can all happen when I want it to.

Int: So did you put in the effort I mean it's paying off now.

Patrick: Yeah, that's what I mean like I really put in the effort making friends with people, getting to know people and now it's like everything is far easier it's great, it really is.

Samuel (middle class, commuter town, aged 20) regards networking as his main skill, and gave up university after a year because "It's about who you know not what you've done". By that time he had developed the skills and contacts he needed for his planned future in the entertainment world and he highlights here the instrumental nature of networking. He distinguished between his true friends and networking friends:

Int: So do you confide in them?

Samuel: Hmm completely and utterly, I'm very, very honest with my friends my true friends anyway, not like the connections. It's not the networking friends, it's my proper friends ...

Int: And aspects of opportunities and ideas for careers, things like that - are there certain people you'd go to for that?

Samuel: Friends again - I'd say more my networking friends than my close friends, because all my networking are usually friends for reasons. And there are a lot of people for a certain reason - not because I don't - not because I'm using them - but just because it helps to have friends in - not so much high places, just in places.

The people that he knows in the music and entertainment business are also his community:

Int: And is there any other community that you feel part of? 
Samuel: Well it's just mainly the - there's a real underground scene to (hometown). ... And that's how I'm really known. It's just the people who run all the (hometown) things really that I'm friends with. It gives me a lot of confidence actually, knowing that all of my friends are prominent people in (hometown).... It's kind of an ego boost.

Int: So it's a really good network?

Samuel: A very good network, especially for what I'm going into, I know everyone there is to know.

Int: And are they all different sort of things they do and age groups and things like that?

Samuel: All different age groups, all different styles, which is really cool.

Int: Hmm yeah, so you could say - would you say you were really well networked?

Samuel: Yeah very. It's what I've always wanted to do, it's the only skill I really have is networking.

These examples of the well networked in our sample have tended to be middle class young people, albeit in a range of circumstances, and with both themselves and their families exhibiting some of the fluidity of identity associated with postmodern times. They also tended to be flexible and their networks span different age groups and communities - local, family, educational, work, leisure - and a range of activities, from bell-ringing to volunteering. They are often well resourced by their family. Although some of the working class young people in the sample are well networked, keen to be socially mobile upward often through education, and are resourced by their families, many of them have networks that tend to link them into family, community and locality, rather than providing broader opportunities for contacts, education and work.

\section{Communities}

Sectarian communities in Northern Ireland could exert a strong hold, and generate an equally strong desire to get out. A large proportion of the Northern Irish group in our sample have left their homes and communities for education or work in other parts of the UK or further afield. Unusually, Allan's (embedded working class, Northern Ireland, 16-20 over the interviews ${ }^{3}$ ) parents acted to change their son's networks. They invested financially to get him interested in sport, and the sport and leisure networks he developed were instrumental in moving him away from earlier strong ties in the local sectarian youth culture. Others such as Stuart (embedded working class, Northern Ireland, 16-18) in contrast were totally embedded in that sectarian youth culture, and all their social capital came from those associations and networks. There were also strong family and other networks in our other very localised community in the 
disadvantaged estate, leading to a similar, insular, bonding type of social capital that would enable people in Putnam's words to "get by", but could generate the conviction that to get on you had to get out, with education as the means for this escape from "the bubble". Putnam, following Gittell and Vidal (1998), distinguishes between bonding social capital "inward looking and tend[ing] to reinforce exclusive identities and homogeneous groups" and bridging social capital "outward looking and encompass[ing] people across diverse social cleavages" (Putnam, 2000: 22-3) Louise (embedded working class, disadvantaged estate aged 14-15) and Sandra (respectable working class, disadvantaged estate, aged 14-18) were embedded in the community. Louise drew increasingly on local networks of disenchanted young people, spending time drinking with older lads and mixing with "mad heads", in the context of very few other resources. And Sandra explains the pull of family and community:

Int: And is there - I mean, there must be a reason why you think it's more important to stay in (local community).

Sandra: That's where I was brought up.

Int: Yeah.

Sandra: Yeah, this is me.

Int: This is where you belong?

Sandra: Yeah - my home, around here.

Int: You would never even contemplate leaving it?

Sandra: If me Mum weren't here.

But some young people separated themselves from the values, norms and ties of the local community to pursue education as their route out (Thomson, Henderson and Holland 2003), and Maisie for example (embedded working class, disadvantaged estate, aged 17-22) pursued a lonely path through education, unsupported by her family, generating her own social capital and networks (see also below).

In some instances community was more clearly related to place and space, particularly as we have seen in the case of Northern Ireland, and the disadvantaged estate. Other sites might be characterised by multiple communities, across which the young people moved, or indeed did not move, for example the inner city site, the rural area, and the leafy commuter town. For a span of time, some young people might draw on a notion of community and belonging whilst at college or university, and for many this also provided the momentum to leave their home community behind them. Most of those going to university saw it as an opportunity to meet new and different people and make friends. For others the community might float free of space, a diasporic 
association based on family or ethnicity, religious affiliation, a gay community, the music scene, local variants of global youth culture.

As we have seen, for many, particularly the working class members of the sample, family networks linked them into community networks. Tamsin (lower middle class, rural area, aged 15-19) had wider links, her ease with the variation in her social worlds, her strong family and community base, her continued emphasis upon the value of work and reciprocity, and a quiet sense of self reliance all contribute to considerable social capital in her locality. But she has wider links beyond her village through a predominantly heterosexual couples pub culture, with gay and international connections. At her last interview her interviewer commented: "Her coming year of travel will play a key role in determining how transferable this social, cultural and economic capital really is. It may prove the bridging capital that currently seems required for a life beyond the local stage".

It seems in our sample that it is the predominantly working class sites that generate bonding, and possibly negative social capital. But there are other forms of networking and association for the working-class young people that can support them in their activities in education, as entrepreneurs, and in terms of work and travel opportunities. These often have a diasporic element, with contacts amongst those in our sample in the USA, West Indies, Australia and elsewhere. Young people in such settings can also develop networks of support and concomitant social capital that enable their lives in the community (Raffo and Reeves 2000, Leonard 2004).

Similarly to Leonard, we have found in Northern Ireland that bonding within communities as a result of community and political activism could generate networks that made links out of the community, or initiate broader changes within that could create progress for the whole community. Along with Leonard we would argue that the move from bonding to bridging social capital is more complex than envisaged by Putnam.

Drawing now on individual case studies in longitudinal perspective, I will illustrate how resources, community, networks, and agency can play out in individual biographies.

\section{Young people and social capital in biographical context}

Two young women, both surrounded by poverty, ill health, crime and low aspirations in their very localised community on the disadvantaged estate, pursue different pathways to educational achievement. At her first individual interview (aged 17-22) Maisie (embedded working class) expressed a desire to go to university to do a degree in the creative arts, a seemingly unrealistic desire given her resources. Against the odds and with a turbulent trajectory, she has 
achieved a degree. With only an initially highly abstract vision to aim for and few resources to draw on, her path has been precarious. She has faltered in her education and changed the detail of her desired career; and her strong bonds with her demanding, crisis-ridden family have consistently pulled her in the opposite direction. She continued to live in the community whilst at university, and took financial, practical and emotional responsibility for her ailing mother and the family. She needed at least 25 hours a week paid work to maintain her precarious arrangements, usually involving at least two jobs. Much of her paid labour has been in service industries where she also diligently provides emotional labour, and is a good worker (Hochschild 1983). She has held down multiple jobs whilst gradually building her education, through several educational institutions. She recognises the value of social capital built in networks of association, and has used her multiple jobs to generate such networks:

Int: Well do you think you've got more networks than people you know?

Maisie: I think it's just because I've got so many jobs, and I've had so many jobs, you know.

Int: Yeah.

Maisie: Because I've got friends at (sports club where she works part-time), I've got friends at my new job, I've got friends that I know from the (hotel where she worked), I've got friends from College, from school, from uni-

She spends most time with university friends:

Maisie: Yeah because I'm there at university. But people have always said to me, "When you go to university you'll meet friends who will be your friends for your life," and they probably are true.

Both the sports club job and her course at university, which involves foreign travel to fashion and design shows, have opened up new worlds and provided new contacts for her desired future. Maisie sees herself as independent and adult:

Maisie: I think like going to university I think has like made me grow up. 'Cos like you've just got up and you're in like a different environment and stuff, aren't you? And meeting new people has like made me grown up.

Maisie demonstrates considerable agency and energy in her drive to her desired future, and clearly knows what she wants and does not want. She does not want to stay in the community, although in loyalty she comments that it is not 'that bad', and responsibility for and duty towards her family wove through her later interviews. But she does want: 
Maisie: At the end of the day when I grow up I want to have like a nice job, you know, and have a nice house and like a nice family with children and a husband and a nice car and like, you know, just to have a nice life.

Maureen (respectable working class, aged 15-20) was academically able, but quiet and seemingly lacking in self-confidence. Over three interviews, however, the centrality of a quiet commitment to social mobility came increasingly to light, and by the third interview she was firmly set on course for university. Her family was crucial as support. Maureen lived with her mother and mother's boyfriend on a new housing development and had a room in her father's house. She saw her two-site family as a positive resource and it seemed to enable her to situate herself (physically and in terms of horizons) outside the locality more easily than most. Exceptionally on the estate she took advantage of opportunities made available to her by policy interventions targeted at disadvantaged communities. Maureen valued the support of a school based mentor, and her participation in a summer residential scheme aimed at giving working class young people a taste of university life played a role in confirming university as her path to the future. She also benefited from a scheme aimed at low wage families to provide financial support for young people in further education.

Family support and withdrawal from the local community were key elements here; Maureen illustrates the necessity of getting out to get on for young people in areas of social exclusion, and the need to defer the pleasures of youth, indeed of active heterosexuality and womanhood until they held less of a threat to the chosen future. At 17, she talked of "having to wait to do anything with me life beyond education", and of having little space in her life for fun, boys, pubs and clubs. The knowledge that she had to separate herself from the local culture and leave it behind seemed to come from both of her parents, but she made it her own, and demonstrates agency in pursuing this strategy with quiet persistence. We missed a fourth interview with Maureen, but contacted her on the fifth round two and a half years later. She was in the second year at university, seeming more adult and confident than earlier. She had taken control of her life and moved out of home, although her father still provided some financial support. University had provided her with new contacts and friends.

Two young men illustrate the variability of the potentially smooth middle class passage from school to higher education to work. Each has had the experience at university of being surrounded by wealthier middle class young people, stimulating them into networking and socialising. Danny (aged 17-21) comes from a mixed class family living in a middle class area in Northern Ireland. It was clear from his first interview that he was set for a successful academic career, a top student, regarded as a bit of an eccentric through his intellectual interests (a "mad scientist type"), and predicted to move from 
Northern Ireland to mainland UK to go to university. He was well resourced in terms of family and school support. Once at university in England he found his niche among other like-minded people in an environment that suited him well and made many contacts. His parents always provided considerable support of all types, financial, emotional, and social. He enjoys education for its own sake, not just as a means to an end:

Danny: I don't see it as a means to an end I just see it as, well also to me it's all that I've known since I was four years old. It's just I've been in education since four years old so it's just I don't really know life outside of education.

Int: So you're not in a hurry to get out there and get money or start a career or anything like that.

He was shocked at friends who could not wait to get out of university and get a job:

Danny: .... I was shocked at that really because, I don't know, the student life is just brilliant I don't know how anybody could want to be anything else.

In an old university in England, Danny rapidly became aware that his fellow students come from much wealthier, privileged backgrounds, and he is learning from them, seeing them networking for personal gain, and regarding university as an opportunity to party and socialise.

Keith's family were incomers to the rural area when he was two (Henderson, 2005), mixed class in essentially a working class village. They have been a source of cultural capital for him, encouraging him to be mentally and socially active and independent in his ideas, social life and worldview ${ }^{4}$. We have known him from age 15-21 so far. He demonstrates agency in taking charge of his life, but is subject to the vagaries of fate - his mother's acute and cumulative ill health has resulted in her traumatic hospitalisation at crucial moments in his life, and whilst enjoying relationships with young women, he met "the one" at the unexpectedly early age of 17 , disrupting his plans for extensive travel. Caring for his mother with the rest of his family gave him early responsibility and an adult outlook on life, as did his definition of himself as cosmopolitan "other" in the village.

Keith has a strong sense of self-sufficiency and draws on all resources available to him - work (while both at school and university), school (and later university), local neighbourhood - for material and social purposes. The family is a crucial network, including his girl friend's family who have increased his cultural and social capital. He has also developed other networks across the age range, gaining support and contacts, and maintains a balance between a number of different social worlds and the identities he inhabits within them. He gained a more acute sense of class when he realised that the majority of his fellow 
students at university were more middle-class than he, and expected to slip into daddy's company on leaving. Keith's university course has provided him with key resources for building his future, not the degree since he says they are "two a penny", but key contacts, which he has mobilised to shape a career in his chosen field of the creative arts.

These four young people all managed to get to university by varied routes with access to varying degrees of support and social and other capitals. Just one, from a lower middle class background, with parents dedicated to education and social mobility, has had a relatively smooth ride. Variability and contingency characterise the rest, but access to social capital, networks of support provided by families, educational institutions, and friends, in the past, present, and from their accounts potentially in the future, has played an important part in their trajectories.

\section{Conclusion}

We have taken a flexible approach to Bourdieu's concept of social capital in the context of empirical research, following both his own injunction on the usefulness of concepts being in their use, and the supple use of his approach by many other researchers located in the inequality and justice strand both of social capital research, and research more generally (Reay 1998, 2004; Allatt 1993, 1996; Connolly 1998). We have found social capital as "the product of investment strategies, individual or collective, consciously or unconsciously aimed at establishing or reproducing social relationships that are directly useable in the short or long term" (Bourdieu 1986: 251) in the accounts of the young people in the study. We have also found an association between social class location and social capital, although it is complex and variable. We have taken a similar flexible stance towards Putnam's notions of bonding and bridging social capital. Here I have identified the kind of bonding social capital Putnam suggests in some of the communities our participants have been part of, particularly in the examples given here, and the need for a break from those communities to "get ahead". But, like others (Raffo and Reeves 2000; Leonard 2004), we have also found networks of support and social capital that enhance and facilitate the young people's lives in the community, and can offer potential links out of the community, calling therefore for a far more nuanced understanding of bonding and bridging social capital and the relationship between community, society and polity.

1 The three studies were: Youth Values: A study of identity, diversity and social change, ESRC funded (L129251020), Inventing Adulthoods: Young people's strategies for transition, ESRC (L134251008); Youth Transitions, part of the Families \& Social 
Capital ESRC Research Group at London South Bank University. The core research team are Sheila Henderson, Janet Holland, Sheena McGrellis, Sue Sharpe and Rachel Thomson.

2 The dense information provided by our long-term contact with the young people gave multiple sources of assessing class location, and the picture has become complex. Based on this knowledge researchers attached a social class location to each, using the categories: embedded working class (ewc), respectable wc (rwc), lower, middle and upper middle class (lmc, mc, umc). We do however stress the variability in the sample, including changing circumstances of work, economic situation and family form.

${ }^{3}$ The age range across the interviews that we had contact with the young people are given here.

${ }^{4}$ Keith's father was working class and relatively local; his middle class social and cultural capital come from his mother and her family, economic application and work ethic from his father. 


\title{
CHAPTER ELEVEN
}

\section{CHILDREN'S GEOGRAPHIC MOVEMENTS AND SOCIAL CAPITAL: DOES SPACE MATTER?}

\author{
NICOLE SCHAEFER-MCDANIEL ${ }^{1}$
}

Social capital has recently evolved to a "hot" topic across the social sciences leading some to call it the "most popular export of sociology into everyday language" (Portes, 1998: 2). While Bourdieu (1986) was one of the first to formally discuss social capital in relation to other forms such as cultural and economic capital, I draw mostly on Coleman's (1988; 1990b) and Putnam's discussions (2000) of the construct. Explaining that "capital" is defined as "an asset that a person or persons can use as a resource," Coleman's social capital refers to "any kind of social relationship that is a resource to the person" (American Federation of Teachers, 1990: 35). More concretely, Coleman (1990b) defines social capital by its function as "a variety of different entities having two characteristics in common: They all consist of some aspect of the social structure, and they facilitate certain actions of individuals" (p. 302).

Unlike other forms of capital, Coleman (1990b) notes that social capital lies in social relationships between people. Social capital is not as tangible as human capital (that lies in our heads such as education) or physical capital (that lies in our bank accounts). Coleman's examples of social capital include the case of the woman who moved her family from Detroit to Jerusalem. The woman moved because she felt more comfortable letting her children play outside in Israel where she thought that neighbours would have a watchful eye over her children. This was not the case in her neighbourhood in Detroit, which lacked social capital. This example also illustrates Coleman's discussion of "intergenerational closure," which exists when parents have friendly and social relationships to other parents. These relationships enable and create shared social norms, values, and behaviours such as keeping an eye on a neighbour's children and thus build social capital. 
Social capital also found a home in political science where Putnam (2000) builds on the fact that social networks have value. He redefines social capital as a key characteristic of communities noting "social capital refers to the connections among individuals - networks and norms of reciprocity and trustworthiness that arise from them" (p. 19). By applying the term to communities, Putnam introduces two forms: 1) bridging or the inclusive form that draws different people together and 2) bonding or the exclusive form present in cohesive groups. Putnam notes that bonding social capital produces strong "in-group" and "out-group" behaviours and can lead to narrow identities despite the fact that it is good for mobilising solidarity and notions of trust and reciprocity. The bridging form, on the other hand, is better for linking to "external assets and for information diffusion" (p. 22). So, one might consider one form of social capital good for "getting by" (bonding) and the other good for "getting ahead" (bridging).

Putnam (2000) also discusses social capital in different types of neighbourhoods. For example, he suggests that a neighbourhood in which there is high residential turn-over contains poor social capital, since residential mobility dissolves the roots of social ties among neighbours and thus compromises the shared values and norms that govern the neighbourhood. In Coleman's (1990b) language, residential mobility disrupts the neighbourhood's intergenerational closure and subsequently negatively affects social capital. Putnam further notes that the same holds true for neighbourhoods where social capital rich families move away and leave social capital depleted families behind.

Despite the numerous theories, social capital remains a somewhat abstract concept. Although Coleman, and to a lesser extent Putnam, incorporate a reference to place, for example neighbourhoods, and attempt to ground the construct, the discussion of place and social capital remains underdeveloped. Furthermore, mainstream social capital theory fails to consider gender and ethnic differences. The theorists do not discuss how women experience social capital differently from men or how different ethnic groups may build social capital. Furthermore, children and youth have been excluded from social capital theory since Coleman's theory views children as mere benefactors of parental social capital. This has led to a growing body of research where young people have been neglected and not recognised as active social agents with notable exceptions such as work by Morrow $(2001,2004)$.

Since children have been excluded from this theory as active in building their own social capital, I developed a framework of how social capital may be applicable to them (Schaefer-McDaniel, 2004). Building on Coleman's and Putnam's focus on place, I include children's sense of belonging to their neighbourhood as a component. I understand social capital to consist of the 
three following dimensions: social networks and interactions, trust and reciprocity, and sense of belonging or place attachment. The first component refers to young people's social networks and relationships and whether they possess the skill to utilise these networks and recognise them as resources. Secondly, trust and reciprocity were first introduced by Coleman (1988) but over time have become more or less the key ingredients for Putnam's (2000) conceptualisation. Here, this dimension refers to young people's quality of relationships and can be understood as acts of authentic fairness and overall trustworthiness. The last component, place attachment or sense of belonging, links the abstract concept to young people's perceptions of places. Place attachment is generally defined as the enduring, positive bonds between people and their environment or places (Altman \& Low, 1992; Brown \& Perkins, 1992). This term is similar to sense of belonging, a concept that has gained recognition in the school psychology literature (Goodenow, 1993). While some recognise the importance of sense of belonging and social capital (Morrow, 2001; Narayan \& Cassidy, 2001), it is a new way of formally conceptualising and thinking about the construct.

Studying social capital with children is important as research in this area remains scarce. Examining social capital with minority ethnic children in poor neighbourhoods, as done here, is especially imperative since previous research with adults has connected social capital with improvements in well-being and other aspects of positive development (James, Schulz, \& van Olphen, 2001; Lochner, Kawachi, Brennan, \& Buka, 2003). So, social capital has the potential of serving as a stress buffer with adults, but we need to explore whether the same is true for children. If social capital is relevant for children, then future work with children and young people can build on connecting social capital to outcomes previously examined with adults.

The aim of this study was to explore whether social capital is a relevant concept for children and youth. I also explored children's geographic movements from the home in order to determine whether children's spatial movements is related to their ability to build social capital. After introducing the neighbourhood and children, I discuss the methods of my study. The following section describes how social capital applies to three groups of children categorised by their levels of spatial movement in their neighbourhood. I conclude by offering new directions for future social capital research and theory with children.

\section{Neighbourhood and Participants}

All the children taking part in my research lived in the same neighbourhood in New York City, which I will refer to as Seaside (Figure 11.1). Seaside is 
located in a borough outside of Manhattan and borders water on its south and east sides. The area is also bounded by two parks on the south-east and west and is separated from another neighbourhood by a major highway in the north. Seaside is primarily a lower-income neighbourhood, comprised mainly of Hispanic/Latino and African American residents. In 2000, residents' median annual income was $\$ 27,733$ compared to $\$ 41,994$ for U.S. residents overall, and one in four families falls below the poverty level (U.S. Census Bureau, 2000).

Seaside's poor socioeconomic structure is further reflected by the presence of many public housing developments along with a general lack of social service agencies and resources for residents. While the map suggests an unusual high number of parks for an urban neighbourhood, it is important to note that these parks as well as the neighbourhood in general were troubled by abandonment, gang activity, and violence. As mentioned earlier, Seaside would constitute a social capital depleted neighbourhood in Putnam's terms, in which shared community norms or values and tight social relationships are absent.

Figure 11.1 Seaside neighbourhood

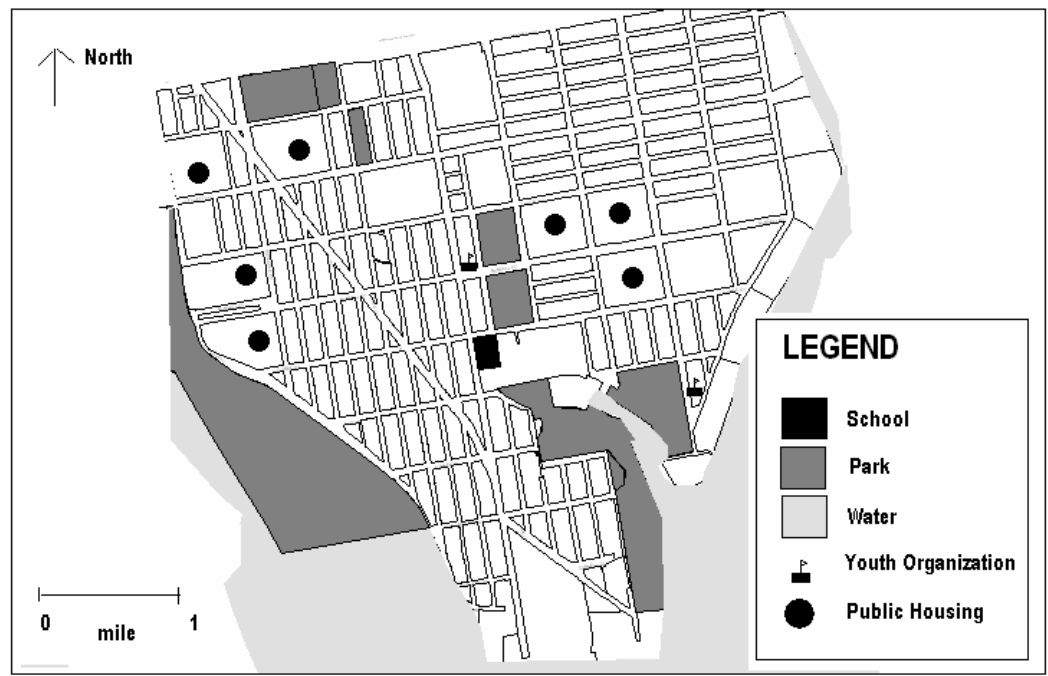

Since the goal of my project was to explore children's lives through a social capital perspective and since this literature has predominantly focused on adolescents, I chose to work with younger children. The 15 children participating in the project ranged in age from nine to 13 years. Most were in the 10-to-12 year age group while one boy was nine years old and another boy was 
13. Most of the children had always lived in Seaside but some had recently moved to the neighbourhood.

As this project began towards the end of the 2003-2004 school year, I recruited children through two neighbourhood programmes sponsored by the YMCA of Greater New York. Seven children participated in an after-school basketball programme and eight were enrolled in a summer day programme. All identified as minorities either as Hispanic/Latino or African American. The majority - 10 out of the 15 - were boys, an unsurprising fact considering the nature of the after-school programme.

All but one of the children attended or were going to attend the same school in the coming school year. At the end of the 2003-2004 school year, this middle school served over 1,500 students ranging from $5^{\text {th }}$ through $8^{\text {th }}$ grade, while employing only 86 teachers (New York State Education Department, 2004). The vast majority of the students are eligible for the free lunch programme. In 2003, the average expenditure per student at this school was $\$ 9,403$ compared to $\$ 11,247$ in similar New York City schools; this funding inequality in poor, urban schools has been thoroughly documented by Kozol (1992). The remaining child was enrolled in a different but nearby school with almost identical characteristics.

\section{Methods}

After obtaining their parents' and their own consent, I invited the children to individual interview sessions which consisted of open-ended, semi-structured interviews and a mapping exercise lasting about twenty minutes. First, I asked them to describe their neighbourhoods and discuss what they liked, disliked, and what they would like to change. Then, I presented the children with an enlarged map of their neighbourhood listing schools, streets, and parks as reference points. Their ability to read the map was assessed by asking them to locate their homes and schools. All but two children demonstrated great comfort with the map. For those who were not so comfortable with the maps, I mapped their responses as they answered the questions.

Building on previous research (Conn, 2000; Percy-Smith, 1999), I used the map to guide the conversation as I asked the children to colour different areas such as places they are allowed to go to by themselves and with their friends. I also asked them about their sense of belonging to the neighbourhood, for example whether they felt they were a part of their neighbourhood (based on Goodenow, 1993) or if they would be sad if they had to move away (Brown, Perkins, \& Brown, 2003).

I also talked with the children about their perceptions of their schools including what they liked, disliked, and their social support systems. 
Incorporating Morrow's (2001, 2004) and Bryant's (1985) research on young people's lives, I asked the children to describe what makes a person a friend and a best friend, to whom they can talk if something is bothering them, and how these people would help them. I also discussed the element of trust within those relationships with the children.

\section{Children's Spatial Movements}

Overall, the children enjoyed being a part of a research project and were excited to use maps. Some were thrilled to learn that they could read the map and that it helped them locate new areas in Seaside. One girl even asked for her own map to help her find the way to a neighbourhood organisation she had always wanted to go to but never knew where it was.

Since the nature of this research was theory-driven, I had predetermined expectations of responses. For example, I expected the children to discuss the presence of friends and the notion of friendship in relation to feelings of belonging to their school and neighbourhood. I did not expect them to discuss Seaside's physical environment, yet some expressed great dislike of the physical space and deterioration of their neighbourhood. For instance, Levonn ${ }^{2}$, an 11year-old boy, said he would change the grass to make it "look nicer so people [from far away] could come and say the block looks nice." The fact that children had such detailed perceptions and opinions of the neighbourhood environment led to my current focus on children's perceptions of their neighbourhoods.

From the children's accounts about their everyday geographies (i.e. types of places they visit, frequency) and their maps, I identified three categories of geographic range: spatially restricted, spatially active, and middle range. I discuss these in turn below, drawing attention to the social capital dimensions of their accounts: social interactions and friendships, trust and reciprocity, and sense of belonging.

\section{Spatially Restricted Children}

All but one of the children whose movements were spatially restricted was female; an unsurprising discovery considering that previous research found that girls are more limited in their everyday geography than boys (Hart, 1979; Matthews, 1992; O'Brien, Jones, Sloan, \& Rustin, 2000). Most of the restricted children had lived in the neighbourhood for the majority of their lives. While some were allowed to go to places in their neighbourhoods with friends such as stores, parks, and friends' homes, they did not engage in these activities very often. One girl stated that "there's nowhere to go," suggesting that her neighbourhood is a boring place. 
A major theme among this group of children was that their parents influenced much of their activities. Specifically, some of the girls reported that "my parents don't let me go anywhere by myself" and one girl was only allowed to attend a neighbourhood organisation after school until she was picked up by a parent. The influence of parents was again a prevailing theme when the children were asked if there were any places they would like to go to but cannot:

“...my friends' house but I can't go cause my mom doesn't know their parents...cause my mom don't know what's going on" (Natasha, 11 years).

Most of the children in this group spent the rest of the day after school at home. Common activities included playing board or videogames and watching TV. Some reported visiting or hosting friends. During these social encounters, however, most of the activities took place in close proximity to their home either indoors or in backyards. Nonetheless, these children knew the locations of various neighbourhood organisations they could attend, and all but one girl did belong to one such organisation. While another girl regularly attended the organisation just up the road from her school, others attended rather irregularly or stopped going because "it got boring", as Donna (12 years) explained.

In addition to friendships, the children discussed themes such as play and authority figures when asked what they liked about school:

“...'cause we don't just do work, we sometimes play or do games" (Jennifer, 10 years)

"I guess it's the principal ... I like him and the teachers" (Donna, 12 years)

Losing friends and being alone, as would be the case if children had to move from the neighbourhood, was a major concern:

“...'cause I already moved once and I started crying and I had to start school and I didn't have friends. I didn't know anybody" (Natasha, 11 years)

“... 'cause I wouldn't wanna loose my friends I made at [school] and then I am not a people person and I wouldn't wanna make new friends" (Donna, 12 years)

Feeling included and having friends was also important for this group of children in feeling that they belonged in their schools: "so you don't feel left out or that no one cares about you" as 10-year old Jennifer stated. Generally, friends and best friends were very important to this group and described as being loyal, honest, and trustworthy.

“[A friend] is someone who won't betray you" (Rob, 12 years) 
"A best friend you spend a lot of time with, they're more honest, more trustworthy 'cause you know them" (Natasha, 11 years)

"The best friend is someone you can trust...well you can trust all friends, but they can keep a secret and you feel comfortable with them" (Jennifer, 10 years)

When asked to whom they would be able to talk when something was bothering them, all of the children in this group mentioned their mothers. Some listed people at school like a teacher or staff person as well as a sibling.

\section{Spatially Active Children}

The children who fell into the spatially active group were quite different from those children whose movements were restricted. All but one had lived in Seaside for more than five years, and only one was a girl. These children listed a number of places they were able to go to by themselves such as parks, stores, neighbourhood organisations, friends' houses, and other places around their neighbourhood. Common afternoon activities included riding bikes and going to parks. The children in this group were also quite involved with neighbourhood organisations; that is they regularly attended them and most knew of one or more such organisation in their close proximity. Overall, they felt that there was always something to do in their neighbourhood and were rarely bored. This is of course in opposition to the restricted group who, as we saw earlier, perceived their neighbourhood as somewhat boring where there was nothing to do. However, similar to the children who were spatially restricted, friendship was a dominant theme in discussing liking the neighbourhood and feelings of belonging.

"[I belong here] 'cause I've been living there for eight years and I know everyone" (Chris, 9 years)

Like their more restricted peers, some of these children anticipated feeling sad if they had to move away from their neighbourhood because they would leave friends behind. Interestingly, however, one boy said he would be moving to another neighbourhood in the next month and - in the face of reality rather than speculation - was looking forward to moving and making new friends. Additionally, 12-year old Latisha suggested that she would not feel sad if she had to move from Seaside: "I wanna move...I want to start over, I want to meet new people."

While friendship was an important and recurring theme for liking school for the children who were spatially restricted, the spatially active children did not mention friends. Rather, they indicated that they enjoyed school because they liked classes and the variety of after-school programmes. 
"[I like school] 'cause it's learnable and educational" (Louis, 10 years)

It appears then, that while these children valued going to school for academic reasons, the children whose movements were more restricted embraced the social aspects of school life or the ability to interact and build social capital. Spatially active children had more opportunities for building social capital outside of the school and thus reported not going to school for meeting and interacting with peers. However, children with restricted movement valued the friendships and interactions they have at school and subsequently consider the school as an important context for building social capital.

When asked to define a friend, the children had readily available definitions and suggested that loyalty and trust make a friend:

"It's a person that you can trust and someone that you know can have your back"

(Glen, 10 years)

"Somebody that treats you right" (Marc, 13 years)

Furthermore, they described a best friend in terms of greater level of trust and as someone that was extremely loyal:

"He never betray me, he always be with me" (Chris, 9 years)

"...like you really, really trust and if you need something they will be there for you" (Latisha, 12 years)

"It is someone who like if you have something that you like, they tell you like truthful that they like it" (Louis, 10 years)

Similar to the children with restricted movements, spatially active children also mentioned family members such as parents and siblings as people they would be able to talk to if something was bothering them. Only the girl indicated being able to talk to her friend.

\section{Geographic Middle Range}

All of the children who described a "middle range" of movement about their neighbourhood were boys, most of whom had lived in the neighbourhood for less than two years. Similar to the children who were spatially active, these children indicated that they were allowed to go to several places alone including around their block, to friends' and relatives' homes, and to parks. Unlike the more active children, however, they did not engage in outdoor activities on a regular basis. While their movements on their own were not as limited as the children in the restricted group, the children who fell into the middle range 
group also highlighted the fact that their parents had somewhat of an influence over their afternoon activities. For example, one boy said that his mother would not let him go out, even though he would like to spend more time with his friends after school. Also 11-year old Levonn said that his parents "don't want me in the projects," yet he still spoke about going there every weekend to play with his friends.

As with the other two groups of children, friendship was the dominant theme for feeling that children belong to the neighbourhood:

"[I belong] 'cause there's good people there and I make a lot of friends" (Martin, 10 years)

“...'cause we all get along and we all know each other” (Levonn, 11 years)

One 11-year old boy, though, pointed out that he did not feel he belonged to the neighbourhood “...'cause I don't got that much friends." Similar to the children who were spatially active, the children who had a middle geographic range had a mix of feelings about moving out of their neighbourhood:

"[I would feel sad] because then I have to make new friends and meet new people" (Chris 11 years)

"Not sad...it's good to make new friends and meet other people so you won't feel lonely in the world" (Dominic, 10 years)

They were also similar to the other groups of children in defining a friend as someone who was honest and loyal. Again, a best friend was someone in whom the child had greater trust:

"A friend is a person who is honest and every time I have a secret they won't share it" (Dominic, 10 years)

"You can trust your best friend more than your friend" (José, 11 years)

"A best friend is a person that's always there and that you can trust the most" (Jamal, 11 years)

Compared with the other groups, however, the children with a middle range of movement listed the most types of people they could talk to when something is bothering them, citing teachers, friends, family members, and counsellors as people they could count on for support. This would suggest that these children had stronger social capital in terms of the greatest ability to draw on others for support. 


\section{Children and Social Capital}

The aim of my research was to explore whether social capital is a relevant and applicable concept for children. My discussion above of some of the findings from my work would suggest that, in contrast to the lack of attention to this issue by mainstream theorists such as Coleman and Putnam, it is relevant since the themes of friendships, trust and reciprocity, and sense of belonging that form the elements of social capital are such prominent themes in the children's accounts of their everyday lives in their neighbourhoods. In terms of the cornerstone of social capital, social relationships and interactions, all the children, regardless of their spatial movement, were able define a friend and best friend, and reported having at least one person with whom they could talk when something was bothering them. Whatever their level of mobility around their neighbourhood, there was no apparent difference in the way the children defined a friend. A friend was generally considered as someone who was loyal, kind, and honest. This suggests that in addition to Coleman's and Putnam's emphasis on trust and reciprocity, the notion of loyalty should also be recognised in children's discussion of social capital.

Furthermore, within my findings, it is evident that children whose movements in their local area are more restricted have the greatest attachments to their school and neighbourhoods in building their own supportive social capital, in contrast to their more mobile peers. So, children's level of spatial movements seems related to their ability to build social capital. In the sections above we saw that spatially active children were open to building social capital and friendships in the neighbourhood and did not fear the possibility of moving house. Spatially restricted children, on the other hand, showed great attachments to their neighbourhoods and demonstrated the more cohesive form. This difference in children's discourse brings Putnam's (2000) different levels of social capital to light. Bonding social capital is evident with the spatially restricted children who anticipated feeling extremely sad if they had to move from their neighbourhoods. They appeared anxious of meeting and making new friends but seemed happy with their small, cohesive group of friends. Spatially active and middle range children, however, predicted feeling less anxious and generally welcomed the idea of making new friends, or "bridging" to other groups of people. These children thus seemed more flexible in building social capital when faced with the possibility of residential mobility.

It is also possible that this finding is a function of gender as most of the spatially restricted children consisted of girls compared with spatially active children who were dominantly boys. It is probable that girls in general have stronger feelings of belonging to their neighbourhoods and schools. When thinking about gender differences, it is also important to consider the amount of 
autonomous movement that parents think is best for their children. For example, some of the spatially restricted children felt that they did not spend enough time with their friends. A common restriction for not being able to visit more friends was the fact that children's parents did not know the parents of the friend their child wanted to visit. This has an important implication for their children's ability to build social capital. Connecting children's parents through informal social events at schools or in the neighbourhood could enhance existing parentparent relationships as well as create new ones. Simple interventions such as these would be beneficial in increasing the existing social networks and supports within a community and create social capital among adults and children. So, while my findings suggest that girls have less opportunity to build social capital, this may be due to the spatial movement restrictions imposed by their parents and not a function of girls not being able to build social capital.

As we saw earlier, my findings also suggest that the school context plays an important role for building social capital. Spatially restricted children mentioned liking school because they can meet friends there. The school, along with the neighbourhood, therefore appears to be an important context in which social capital with young people should be explored. Future research and theoretical work on social capital and children should consider schools and neighbourhoods as places where social capital is built. It is essential to connect children's physical and social worlds if we are to understand social capital for children. While I incorporated a transactional approach by studying children in their everyday context, future research should pay closer attention to the types of places where children build social capital. Gibson's (1979) theory of environmental affordances, in which he recognised the functional properties of the physical environment, might provide a valuable theoretical foundation for such endeavours, as could previous work by Heft (1988) and Kyttä (2004) on affordances in children's everyday environments. Social capital research should thus build on this body of literature and recognise the intersections of children's physical and social environments.

Interestingly, my findings also suggest that length of residency in the neighbourhood is related to children's residential mobility. Both spatially restricted and active children had lived in Seaside for a long time, while middle range children had only lived there for about two years. Due to the gender difference in the group composition, it seems then, that the longer a boy had lived in Seaside, the farther he was allowed to explore the neighbourhood. The opposite was true for girls.

On a less obvious note, my findings also suggest that social capital might be class related. While middle class children generally demonstrate the same types of social supports as the children described here (Markward, McMillan and Markward, 2003), there were some hints in the children's discourse regarding 
their social class status. For example, Levonn's wish to change the physical appearance in his neighbourhood to attract people from far away demonstrates his sensitivity to how other people from the outside view him and his surroundings.

While my study confirms that social capital is relevant for children and young people, a potential problem in this project as well as in future studies on social capital is the fact that the construct relies heavily on studying behaviours in and perceptions of actors' everyday neighbourhoods. But, exactly, what does "neighbourhood" mean? This term is largely subjective, and meanings can change depending on the question, particularly in work with children. While I overcame this problem by using maps and asking children visually to define their neighbourhood, future research should utilize more exact definitions of the concept "neighbourhood" and explore what children mean by this expression.

\section{Conclusion}

In conclusion, I believe that my study adds to our understanding of social capital and how it works. As I have shown, friendships and feelings of belonging are central to children's everyday lives. I would also argue that Coleman's and Putnam's theories seem appropriate as a starting point, with a few modifications: researchers should incorporate the idea of loyalty to the notion of trust and focus on sense of belonging to children's schools and neighbourhoods. Aside from suggesting that the school and neighbourhood are important contexts for examining social capital, I also found that children's geographic movement is related to their ability to build social capital, and is gendered. As I have said, work on social capital with children should thus concentrate on connecting children's social and physical worlds, taking these issues further to explore whether children's social capital is linked to the same sorts of outcomes as research with adults has suggested (for example, acting as a stress buffer). Such work needs to pay close attention to gender and ethnic differences, and explore whether and how social capital is a relevant concept to children living in more affluent neighbourhoods.

${ }^{1}$ I am grateful to the children who participated in this study and to Gary Winkel and Roger Hart for their help with this project. I would also like to thank Rosalind Edwards for her insightful comments and assistance.

${ }^{2}$ All of the children's names have been changed. 


\section{CHAPTER TWELVE}

\section{THE ROLE OF FAMILY BACKGROUND AND SOCIAL CAPITAL IN THE SOCIAL MOBILITY OF MigRANT ETHNIC MINORITIES}

LUCINDA PLATT AND PAUL THOMPSON

\section{Introduction}

Equal opportunity is an underlying principle of citizenship in a multicultural society. It is regularly expounded as central to the current government's agenda (Aldridge, 2001; Blair, 2001). How far ethnic minorities in Britain enjoy opportunities for social mobility on a par with the majority is an important issue for both social equality and cohesion. Striking differences between Britain's ethnic groups in terms of occupation, educational levels and wealth or poverty have been regularly noted (Modood, Berthoud et al. 1997; Platt, 2002). Thus, for example, Indians appear to be achieving ever higher levels of qualifications and occupational success, while Caribbeans appear to lag behind. How much these differential outcomes depend upon unequal opportunities and how much they result from unequal starting points is the subject of extensive debate and policy interest. ${ }^{1}$

Migrants are acknowledged to experience potential barriers in the labour market, whether through lack of contacts, failure of employers to recognise qualifications gained in other countries, and racism (Daniel, 1968; Smith, 1977), or as a result of lack of relevant skills and lack of English language fluency (Shields and Wheatley Price, 2002). The paradigm against which the outcomes of the second generation are measured are, however, that such difficulties, being associated with the migration process itself, should disappear over time (Park, 1950). The "second generation" should experience life chances comparable to those of the "host" community. Obstacles to migrants' labour market 
participation appear to diminish over time (Clark and Lindley, 2004), but they do not disappear in the second generation. Heath and McMahon's study of the 1991 Census concluded that "being born in Britain is not associated with any improvement in competitive chances" (Heath and McMahon, 1997). Instead they presented evidence of an ongoing "ethnic penalty" afflicting minority groups into the second generation. A number of studies have identified this ethnic penalty directly with discrimination (Blackaby et al., 1999, 2005). However, critics have countered both that there may be other factors within the "ethnic penalty" that we need to take account of (Hatton and Wheatley Price, 2005) and that we need to understand why discrimination should affect some groups more than others.

To understand more about ethnic penalties, it is crucial to understand the extent to which they can be related to different family origins (Heath and McMahon, 1997; Heath and McMahon, 2005; Heath and Yu, 2005) That is, we need to be able to describe and explain patterns of intergenerational social mobility and the processes and characteristics enabling or hindering such mobility. It is in this spirit of seeking an analysis that does justice to the different opportunities and experiences of minority ethnic groups that we focus on comparison across groups (Goulbourne and Solomos, 2003) and on complementary quantitative and qualitative approaches (Thompson 2004). In this exploratory paper our intention is to show the potential fruitfulness of our comparative and mixed methodological approach for further research.

First, using secondary analysis of nationally representative survey data for England and Wales, the ONS Longitudinal Study, the paper describes patterns of intergenerational mobility from the migrant to the second generation for two of Britain's main minority ethnic groups: Indians and Caribbeans, both of which experienced their main period of migration relatively early in the post-war period. It examines the extent to which those mobility patterns can be explained in terms of family background characteristics, such as social class background, parents' educational achievements and family economic resources following migration to England or Wales. These aspects of parental background are relatively susceptible to quantification. Results reveal that family background plays apparently only a small part in Caribbeans' class mobility. This part of the paper also explores the role of educational attainment for the second generation and how it appears to determine chances of occupational success for the children of migrants.

We then use one set of qualitative in-depth life story interviews, with 50 first generation migrants from transnational Jamaican families to investigate the extent to which understanding the role of family social capital can illuminate our earlier findings. We take a broad definition of family social capital, including occupational traditions and know-how, attitudes to education, social networks, 
and family structures and attitudes to gender. While this may seem to include areas that, from a strictly Bourdieuian perspective are more closely associated with cultural capital (Bourdieu, 1997; see also Portes, 2000a), we consider that the broader conception is crucial to thinking across widely differing social, economic and educational contexts. Our concept of family social capital also overlaps with notions of ethnic capital, in terms of the cultural, educational, linguistic and associational resources specifically available to particular groups on account of their geographic origins and migration histories (Borjas, 1992; Esser, 2004). While these aspects of family social capital interact with more tangible forms of capital such as educational qualifications and economic resources, they are inherently less susceptible to quantitative measurement, which is why we are drawn to this complementary qualitative and quantitative approach. $^{2}$

It is important to pay attention to the role of family social capital, partly because of the role attributed to it in achieving and maintaining occupational and social class success, and partly because of the way it and related concepts have been found helpful in accounting for diverse and sometimes counterintuitive patterns of success among immigrant groups. We discuss these two elements further below. Moreover, in his joint work with Daniel Bertaux, Thompson argued that social change could not be understood solely in terms of the economy and politics: major elements such as population growth/decline or migration could only be explained in terms of individual and familial decisions (Thompson, 1980, 1984).

On the other hand, we are aware of the dangers of overuse of ideas of social capital (Portes, 1998). Alongside the caveats about attempting to use social capital as a catch-all for policy (Aldridge et al., 2002), there are specific concerns that, for minority ethnic groups in particular, over-emphasis on social capital risks on the one hand "blaming the victim" or idealizing ethnic minority communities, and on the other ignoring more fundamental structural issues (Halpern, 2005; Fine, 2005). Nevertheless, we consider that in this study, where we are specifically concerned with understanding social mobility, its utility outweighs its disadvantages.

As we shall see, the use of family social capital as an analytic concept within the qualitative analysis offers three insights into mobility patterns observed in the quantitative data. First, that to understand different groups' social class outcomes and mobility patterns it is important to be sensitive to different ideas of what constitutes "success" in earlier, migrant and pre-migrant generations. Second, we draw attention to the fact that values and family patterns that may be adaptive in some contexts may be disadvantageous in others. And third, aggregate patterns may disguise much within-group variation. We also stress the importance of gender to understanding ethnically differentiated mobility 
patterns. Before we demonstrate these points, we consider further the ideas on which we draw in our use of social capital.

Much British discussion of social capital revolves around the work of Putnam $(1995,2000)$, despite substantial criticism of his claims and methods (Portes, 1998). However, Putnam conceived of social capital as primarily a community-level resource (Portes, 2000a), emphasising "networks, norms and trust", and has relatively little to say about the role of the family in the creation or maintenance of social capital. While Putnam has responded to criticisms that he ignored the way social capital could be used for socially destructive aims (Schuller et al., 2000), the ideas most closely associated with him remain those of the strength of homogeneous communities creating social capital as a public good. While our notion of family social capital acknowledges the importance of community and family norms, which have been important in Putnam's work, our stress on the family leads us to draw more on Coleman and Bourdieu, who have both paid attention to the role of the family in social capital formation.

Bourdieu (1997) links social capital with other forms of capital (cultural and economic) as the means by which privileged families maintain their advantage. Thus, his work, though helpful in illuminating the way classes reproduce themselves is less well-suited to understanding the upward mobility of disadvantaged groups. Nevertheless, his focus on the instrumental creation and utilization of social capital is important in understanding how it can operate or fail to operate for relatively advantaged immigrants. Moreover, Bourdieu stresses the need for constant maintenance of social capital: but if an individual is divorced from the networks within which it was formed such maintenance may not be possible. We also draw on Bourdieu's analysis of education systems and credentialism (Bourdieu, 1977; Bourdieu and Passeron, 1979).

Coleman has emphasized the role of family social capital in the production of human capital (Coleman, 1988). His work, despite extensive criticism for its underlying conservatism, is thus considered especially relevant to those concerned with the relationship between family social capital and educational outcomes (Schuller et al., 2000). Moreover, his conception of social capital indicates that it can provide a resource precisely where other forms of advantage are lacking, rather than, as with Bourdieu, the forms being mutually selfsupporting.

Nevertheless, despite proffering examples from a range of different countries, Coleman's theory is highly context specific. For example, his utilisation of "single motherhood" as a proxy for lack of adult contacts is not appropriate to a context in which fathers may not be co-resident but may be one of a number of adults with whom the child has contact (Coleman, 1988). In Jamaican families for at least two centuries, mothers have been key workers, and children have been brought up within extended families so that terms such 
as "single mother" have little useful meaning. Moreover the extolling of closed networks reveals an underlying nostalgia for a former, idealised society (Edwards et al., 2003). Indeed, Coleman subsequently identified some of the virtues of these idealised former communities with certain tight-knit migrant communities (Schuller et al., 2000).

This emphasis on closure also highlights a further issue in considering the effectiveness of family social capital in promoting social mobility. If social capital is to be utilised as a resource for success, not only are "weak" ties likely to be of more benefit, as Granovetter (1973) argued (see also Lin, 2001, and Putnam's (2000) distinction between "bridging" and "bonding" social capital), but closed networks may, in fact, become disrupted in achieving success, thus diminishing their future potential. For example, if success means not only social but also geographic mobility then the very resource (the social capital derived from the family or network) that enabled that mobility may be inaccessible in the future. Conversely, where closed networks and tight family ties are unproductive of upward mobility - and thus their own disruption - they may serve to reproduce close-knit but marginalised communities. The situation of British Bangladeshi families, who are argued to remain highly embedded in close local relationships (Eade et al., 1996), but who do not have the consequent material success that Coleman would predict could perhaps be understood in this light. Nevertheless, we acknowledge that close ties may in certain circumstances facilitate the bridging not just of social sectors but also of continents.

Thus, while we would qualify, we would not reject Coleman's insights into some of the ways in which the family can be found at the heart of social capital formation and maintenance. In what follows, we draw attention to the ways in which family social capital draws on norms, networks and expectations that are highly context specific. In a new context, retaining such norms and expectations may be counter-productive. On the other hand, we need to remain sensitive to different points of reference for notions of success fostered by the operation of family social capital.

\section{The Evidence of the ONS Longitudinal Study Data}

For the study of mobility patterns we use the ONS Longitudinal Study (LS). The LS is a one per cent sample of the population of England and Wales that is followed over time. It was initially obtained by taking a sample of the 1971 Census, based on those born on one of four birth dates (day and month). Information from samples taken at each subsequent Census has been added to the study. Members are also added to the study by linking information on births and immigrations using the same selection criteria. No more information is 
linked where study members have records indicating that they have died or left England and Wales; though study members who leave England and Wales and then return will be re-incorporated into the study at the subsequent Census.

These data from the ONS LS have a particular advantage in terms of the aims of this paper: they enable the direct comparison of parent to child class transitions, which is crucial if we are to draw conclusions about the role of family processes. And they measure transitions where family origins (parent's class, economic status and educational achievement) as well as destinations are measured in England or Wales and at the same time point for both groups. Previous studies have tended to infer mobility patterns (such as the upward mobility of the Indian group) from comparison of cross-sections at different time points (e.g. Modood, 1997; Robinson, 1990). However, this cannot inform us about direct family processes in mobility processes. Alternatively, a small number of studies (Heath and Ridge, 1983; Heath and McMahon, 2005) have directly measured parent to child mobility but have not distinguished whether parental class is measured pre-or post migration. For the purposes of this study it is important to measure quantitatively the mobility patterns of minority ethnic group members in relation to their parent's situation in Britain. The complementary qualitative material then makes the connections with premigration circumstances.

We pooled two cohorts of LS members, those who were children aged 4-15 in 1971 and those who were aged 4-15 in 1981. Their outcomes are measured at 2001 (when they were aged between 24 and 45). Social class of origin was based on the CASMIN scale (Erikson and Goldthorpe, 1993) with four possible values: service (the highest social class), intermediate, working, and other (where respondents did not fit one of the former classes). Parents' higher education qualifications at 1971/1981 were also measured, as were economic status indicators for the household of origin (car ownership and tenure). In addition, ethnic minority concentration in the area of residence was included to capture something of the geographical factors that have been shown to be important in mediating outcomes. ${ }^{3}$

The study members' own class (based on their and their (co-habiting) partner's occupation and economic status) was measured at 2001. This destination social class is based on the NS-SeC social class classification (Rose and Pevalin, 2003). We concentrate here on the attainment of professional or managerial class position compared to any other outcome. Other characteristics of the study members, such as education (as one of four categories) and partnership status were also measured at 2001. 

of Migrant Ethnic Minorities

\section{Mobility Patterns}

Table 12.1 shows the overall mobility patterns for all respondents in the study sample with Tables 12.2 and 12.3 illustrating the transitions for Caribbeans and Indians. If we look first at the class distributions at 2001 we see that about half of the whole cohort held a professional or managerial position, while around a fifth and a quarter were in the intermediate and the routine/manual classes, respectively (Table 12.1). By contrast, only 45 per cent of second generation Caribbeans (Table 12.2) but nearly 60 percent of second generation Indians (Table 12.3) of the same cohort were in the professional managerial positions at this point. How much of these different relative positions can be explained by the class position of parents?

Looking at parent to child class transitions, we can see that for the cohort as a whole there is a clear effect of expanding "room at the top" (Goldthorpe, 1987). That is, upward mobility is a function at least in part of changes in the occupational structure resulting in more professional / managerial class jobs and fewer working class ones. Table 12.1 shows that the proportion of available working class positions halved (from 51.5 per cent to 24.6 per cent) over the period and a high proportion of those with working class origins (44 per cent) ended up in the professional managerial classes. Nevertheless the impact of social reproduction is clearly visible: nearly 70 per cent of those with service class origins ended up in the managerial and professional classes; and 32 per cent of those with working class origins ended up in the routine/manual classes compared to only 13 per cent of those with service class origins. Privileged origins were also protective against unemployment. 
Table 12.1 Social class destinations 2001 according to social class origins 1971/81 (row percentages)

\begin{tabular}{|c|c|c|c|c|c|c|}
\hline & & \multicolumn{4}{|c|}{ Destinations (2001) } & \multirow{2}{*}{$\begin{array}{r}\text { Total } \\
(\mathrm{N}) \\
\text { (column } \\
\%)\end{array}$} \\
\hline & & $\begin{array}{r}\text { Managerial } \\
/ \\
\text { Profession } \\
\text { al } \\
\end{array}$ & Intermediate & $\begin{array}{r}\text { Routine } \\
\text { Manual }\end{array}$ & $\begin{array}{r}\text { Un- } \\
\text { employed }\end{array}$ & \\
\hline \multirow{4}{*}{$\begin{array}{l}\text { Origins } \\
(1971 / \\
1981)\end{array}$} & Service & 68.9 & 16.6 & 12.6 & 1.8 & $\begin{array}{l}34777 \\
(29.0)\end{array}$ \\
\hline & Intermediate & 49.2 & 24.5 & 23.8 & 2.5 & $\begin{array}{l}23353 \\
(19.5)\end{array}$ \\
\hline & Working & 43.9 & 21.0 & 31.6 & 3.5 & $\begin{array}{r}61728 \\
(51.5)\end{array}$ \\
\hline & Total & 52.2 & 20.4 & 24.6 & 2.8 & $\begin{array}{r}119858 \\
(100)\end{array}$ \\
\hline
\end{tabular}

Source: ONS Longitudinal Study, author's analysis.

Table 12.2 Social class destinations 2001 according to social class origins (row percentages): Caribbeans

\begin{tabular}{|c|c|c|c|c|c|c|}
\hline & & \multicolumn{4}{|c|}{ Destinations (2001) } & \multirow{2}{*}{$\begin{array}{r}\text { Total } \\
(\mathrm{N}) \\
\text { (column } \\
\%)\end{array}$} \\
\hline & & $\begin{array}{r}\text { Managerial } \\
\text { Profession } \\
\text { al }\end{array}$ & Intermediate & $\begin{array}{r}\text { Routine } \\
\text { Manual }\end{array}$ & $\begin{array}{r}\text { Un- } \\
\text { employed }\end{array}$ & \\
\hline \multirow{4}{*}{$\begin{array}{l}\text { Origins } \\
(1971 / \\
\text { 1981) }\end{array}$} & Service & 52.5 & 21.2 & 17.5 & 8.8 & $\begin{array}{r}137 \\
(12.8)\end{array}$ \\
\hline & Intermediate & 38.5 & 28.1 & 29.2 & 4.2 & $\begin{array}{r}96 \\
(9.0)\end{array}$ \\
\hline & Working & 44.6 & 24.0 & 22.9 & 8.5 & $\begin{array}{r}836 \\
(78.2) \\
\end{array}$ \\
\hline & Total & 45.1 & 24.0 & 22.7 & 8.1 & $\begin{array}{r}1069 \\
(100)\end{array}$ \\
\hline
\end{tabular}

Source: ONS Longitudinal Study, author's analysis 

of Migrant Ethnic Minorities

Table 12.3 Social class destinations 2001 according to social class origins (row percentages): Indians

\begin{tabular}{|c|c|c|c|c|c|c|}
\hline & & \multicolumn{4}{|c|}{ Destinations (2001) } & \multirow{2}{*}{$\begin{array}{r}\text { Total } \\
(\mathrm{N}) \\
\text { (column } \\
\%)\end{array}$} \\
\hline & & $\begin{array}{r}\text { Managerial } \\
\text { / } \\
\text { Profession } \\
\text { al } \\
\end{array}$ & Intermediate & $\begin{array}{r}\text { Routine } \\
\text { / } \\
\text { Manual }\end{array}$ & $\begin{array}{r}\text { Un- } \\
\text { employed }\end{array}$ & \\
\hline \multirow{4}{*}{$\begin{array}{l}\text { Origins } \\
(1971 / \\
1981)\end{array}$} & Service & 75.9 & 11.8 & 9.6 & 2.7 & $\begin{array}{r}187 \\
(13.6)\end{array}$ \\
\hline & Intermediate & 59.6 & 27.9 & 10.4 & 2.2 & $\begin{array}{r}183 \\
(13.3)\end{array}$ \\
\hline & Working & 55.6 & 19.2 & 21.6 & 3.6 & $\begin{array}{r}1008 \\
(73.1) \\
\end{array}$ \\
\hline & Total & 58.8 & 19.4 & 18.5 & 3.3 & $\begin{array}{r}1378 \\
(100)\end{array}$ \\
\hline
\end{tabular}

Source: ONS Longitudinal Study, author's analysis

Turning to the Caribbeans (Table 12.2) we see that the migrant generation were overwhelmingly concentrated in the working class (78.2) and that a slightly higher proportion from such backgrounds moved up to the professional and managerial classes than for the cohort as a whole (44.6 per cent compared to 43.9 per cent). The apparently poor outcomes of Caribbeans appear congruent with their class background and, in fact show some advantage relative to their white working-class-origin peers. This is consistent with a number of studies which show that the disadvantage of the children of immigrants disappears or even turns to a slight advantage once social class background is taken into account (see, for example, Vallet, 2005). On the other hand, there is no indication that the small proportion of the migrant generation who made it into the service class were able to transmit that advantage to their children.

By contrast, the Indians, who also started with a massive over-representation in the working class, showed much more dramatic upward mobility from the working class. Over 55 per cent of those from such origins made it into professional or managerial class positions. Moreover, this group also demonstrates the ability of those from the migrant generation who achieved service class positions to transmit this advantage to the next generation: over three quarters of those with service class origins moved into professional or managerial positions. We see here both a high level of social reproduction of privilege, consistent with social reproduction theory, combined with a high level of upward mobility from the working class, consistent with a number of studies on the position of children of immigrants (Lauglo, 2000; Card, 2005). 
How then do we understand these very different mobility patterns of Indians and Caribbeans? The greater extent of upward mobility from the working class among the Indians is congruent with the thesis that they had suffered downward mobility on migration (Daniel, 1968; Heath and Ridge, 1983). Was this less the case for Caribbeans? And, if education is the route by which migrants retain advantage, is there any evidence that privileged Indians are more likely to channel that advantage through education than privileged Caribbeans?

We explore these questions by moving to multivariate analysis. If differences in upward mobility across groups can be partly explained by differences in enforced downward mobility on migration, then we might expect to see this reflected in the impact of other background characteristics, notably parental education and parents' economic resources. Those migrants who end up in the "wrong" social class on migration are likely still to be more highly qualified and have more economic resources than those for whom a working class destination on migration does not constitute a downward move. Therefore, in our first model we control for these characteristics of parental background. Moreover, if class advantage is channelled through education, we would expect to see background effects disappear once education is included. We therefore include education in our second model. In both models, we control additionally for sex, age group, whether parents characteristics were measured in 1971 or 1981, respondent's partnership status, area effects (the concentration of minorities in the ward of origin), and ethnic group. Table 12.4 provides the estimates from these two models for the whole cohort.

Table 12.4, Model 1 shows that, controlling for background, both Caribbeans and Indians have higher chances of ending up in professional or managerial class positions relative to their white peers, though the effect is much bigger for the Indians. Second generation Caribbeans are doing relatively well in relation to their starting positions, though not as well as Indians. We can also conclude that these relatively good chances of higher class outcomes cannot be attributed to enforced downward mobility on migration. Model 2 shows us that the effect of ethnic group for both Indians and Caribbeans becomes very small and non-significant once education is included in the model. This implies that these greater relative levels of upward mobility are achieved through educational qualifications. This may reflect the particular motivation of immigrants to achieve success through educating their children and, as posited by Lauglo (2000), migrants' ability effectively to exploit social capital for educational achievement and class progression. 

of Migrant Ethnic Minorities

Table 12.4: Logistic regressions of probability of professional/ managerial destination in 2001, controlling for individual and background characteristics

\begin{tabular}{|c|c|c|c|}
\hline & $\begin{array}{r}\text { Model } 1 \\
\text { Coefficient } \\
(\mathrm{SE})\end{array}$ & $\begin{array}{r}\text { Model } 2 \\
\text { Coefficient } \\
(\mathrm{SE})\end{array}$ & $\begin{array}{r}\text { Model } 3 \\
\text { Coefficient } \\
(\mathrm{SE})\end{array}$ \\
\hline Cohort (base is 1971 cohort) & $\begin{array}{r}-.081 \\
(.012)^{* * *}\end{array}$ & $\begin{array}{r}-.077 \\
(.012)^{* * *}\end{array}$ & $\begin{array}{r}-.236 \\
(.013)^{* * *}\end{array}$ \\
\hline \multicolumn{4}{|l|}{ Age (base is 12-15) } \\
\hline Agegroup 1 & $.011(.013)$ & $.013(.013)$ & $\begin{array}{r}-.192 \\
(.014)^{* * *}\end{array}$ \\
\hline Agegroup 2 & $\begin{array}{r}.041 \\
(.014)^{* *}\end{array}$ & $\begin{array}{r}.041 \\
(.014)^{* *}\end{array}$ & $\begin{array}{r}-.049 \\
(.015)^{* * *}\end{array}$ \\
\hline Male & $.015(.013)$ & $.015(.012)$ & $\begin{array}{r}.076 \\
(.014)^{* * *}\end{array}$ \\
\hline Partnered & $\begin{array}{r}1.017 \\
(.014)^{* * *}\end{array}$ & $\begin{array}{r}1.026 \\
(.014)^{* * * *}\end{array}$ & $\begin{array}{r}1.135 \\
(.016)^{* * *}\end{array}$ \\
\hline \multicolumn{4}{|l|}{$\begin{array}{l}\text { Area } \% \text { of minorities (base is } \\
0 \% \text { ) }\end{array}$} \\
\hline Up to $1 \%$ & $\begin{array}{r}.197 \\
(.021)^{* * *}\end{array}$ & $\begin{array}{r}.192 \\
(.021)^{* * *}\end{array}$ & $\begin{array}{r}.191 \\
(.023)^{* * *}\end{array}$ \\
\hline 1 to $5 \%$ & $\begin{array}{r}.326 \\
(.024)^{* * *}\end{array}$ & $\begin{array}{r}.301 \\
(.024)^{* * *}\end{array}$ & $\begin{array}{r}.349 \\
(.026)^{* * *}\end{array}$ \\
\hline $5-10 \%$ & $\begin{array}{r}.241 \\
(.034)^{* * *}\end{array}$ & $\begin{array}{r}.189 \\
(.034)^{* * *}\end{array}$ & $\begin{array}{r}.268 \\
(.037)^{* * *}\end{array}$ \\
\hline More than $10 \%$ & $\begin{array}{r}.240 \\
(.032)^{* * * *}\end{array}$ & $\begin{array}{r}.154 \\
(.035)^{* * *}\end{array}$ & $\begin{array}{r}.266 \\
(.038)^{* * *}\end{array}$ \\
\hline \multicolumn{4}{|l|}{ Origin class: base is working } \\
\hline Service class & $\begin{array}{r}.534 \\
(.017)^{* * *}\end{array}$ & $\begin{array}{r}.539 \\
(.017)^{* * *}\end{array}$ & $\begin{array}{r}.322 \\
(.019)^{* * *}\end{array}$ \\
\hline Intermediate & $\begin{array}{r}.060 \\
(.017)^{* * *}\end{array}$ & $\begin{array}{r}.061 \\
(.017)^{* * *}\end{array}$ & $.019(.018)$ \\
\hline Other & $\begin{array}{r}-.205 \\
(.033)^{* * *}\end{array}$ & $\begin{array}{r}-.203 \\
(.033)^{* * *}\end{array}$ & $\begin{array}{r}-.096 \\
(.036)^{* *}\end{array}$ \\
\hline \multicolumn{4}{|l|}{$\begin{array}{l}\text { Mother's education (base is } \\
\text { no higher qualifications) }\end{array}$} \\
\hline No co-resident mother & $\begin{array}{r}-.216 \\
(.045)^{* * *}\end{array}$ & $\begin{array}{r}-.208 \\
(.045)^{* * *}\end{array}$ & $-.123(.050)^{*}$ \\
\hline Mother with qualifications & $\begin{array}{r}.432 \\
(.025)^{* * *}\end{array}$ & $\begin{array}{r}.420 \\
(.025)^{* * *}\end{array}$ & $\begin{array}{r}.115 \\
(.027)^{* * *}\end{array}$ \\
\hline $\begin{array}{l}\text { Father's qualifications (base is } \\
\text { no higher qualifications) }\end{array}$ & & & \\
\hline
\end{tabular}


No co-resident father

Father with qualifications

Tenure at origin (base is owner occupation)

Local authority

Private rented

Cars at origin (base is none)

1 car

2 or more cars

Ethnic group (base is white

British) $\dagger$

Caribbean

Indian

Sample member's

qualifications (base is none)

Lower

Middle

Further
.224 $(.028)^{* * *}$

.535

$(.022)^{* * *}$

$-.575$

$(.015)^{* * *}$

$-.306$

$(.021)^{* * *}$

.265
$(.015)^{* * *}$

.399

$(.021)^{* * *}$
.226

$(.028)^{* * *}$

.529

$(.022)^{* * *}$

$(.023)^{* * *}$

.135

$(.031)^{* * *}$

.215 

of Migrant Ethnic Minorities

Table 12.5 shows estimates from the same models run separately for the Caribbean and Indian samples. We see that for Indians, as for the cohort as a whole, service class origins, a highly qualified mother and car ownership (standing in for economic resources) all had positive and significant effects on achievement of a professional or managerial class position. Background matters for this group. Once educational qualifications were added in (Model 2), these origin effects became much smaller and statistically insignificant. That is, these sources of advantage were all channelled through the education of the second generation. Where the majority could use privileged origins to help achieve success over and above education such an option was either unavailable to or was unnecessary to the Indians (once they had achieve sufficiently high qualifications levels).

By contrast, Table 12.5 shows that for the Caribbeans, there were no statistically significant effects of origin (whether social class, economic status or parental qualifications). Advantaged parental background does not help this group. Why should this be? Introducing education (Model 2) showed that educational qualifications are relevant in achieving upward mobility for this group (consistent with results from Table 12.4). However, the size of the coefficients appears to be smaller than for the Indians.

Table 12.5 Logistic regressions of probability of professional/ managerial destination in 2001, controlling for individual and background characteristics, separate models for Indians and Caribbeans

\begin{tabular}{lrrrr}
\hline & \multicolumn{2}{c}{ Indians } & \multicolumn{2}{c}{ Caribbeans } \\
\hline & $\begin{array}{l}\text { Model 1 } \\
\text { Coefficients }\end{array}$ & $\begin{array}{r}\text { Model 2 } \\
\text { Coefficients }\end{array}$ & $\begin{array}{r}\text { Model 1 } \\
\text { Coefficients }\end{array}$ & $\begin{array}{r}\text { Model 2 } \\
\text { Coefficients }\end{array}$ \\
& $(\mathrm{SE})$ & $(\mathrm{SE})$ & $(\mathrm{SE})$ & $(\mathrm{SE})$ \\
Cohort (base is & $.119(.124)$ & -.313 & $-.264(.138)$ & -.492 \\
1971 cohort) & & $(.145)^{*}$ & & $(.148)^{* *}$ \\
Age & & & & \\
(base is 12-15) & & & & -.322 \\
Agegroup 1 & $.186(.128)$ & -.317 & $-.146(.145)$ & $(.155)^{*}$ \\
& & $(.147)^{*}$ & & $-.055(.160)$ \\
Agegroup 2 & $.219(.128)$ & $-.169(.148)$ & $.021(.151)$ & $-112(.138)$ \\
Male & $.040(.111)$ & $-.103(.127)$ & $-.098(.129)$ & .1127 \\
Partnered & .532 & .948 & 1.043 & 1.127 \\
Area \% of & $(.129)^{* * *}$ & $(.150)^{* * *}$ & $(.132)^{* * *}$ & $(.141)^{* * *}$ \\
minorities (base is & & & & \\
\hline
\end{tabular}




\begin{tabular}{|c|c|c|c|c|}
\hline $0 \%)$ & & & & \\
\hline $\begin{array}{l}\text { More than } 0 \% \\
\text { Origin class: base } \\
\text { is working }\end{array}$ & $-.259(.299)$ & $-.267(.325)$ & $-.356(.256)$ & $-.274(.268)$ \\
\hline Service class & $.468(.212)^{*}$ & $.301(.234)$ & $-.017(.189)$ & $-.164(.199)$ \\
\hline Intermediate & $-.033(.176)$ & $-.113(.208)$ & $-.411(.233)$ & $-.302(.235)$ \\
\hline Other & $-.136(.235)$ & $.013(.284)$ & $.110(.219)$ & $.085(.243)$ \\
\hline $\begin{array}{l}\text { Mother's } \\
\text { qualifications } \\
\text { (base is no higher } \\
\text { qualifications) }\end{array}$ & & & & \\
\hline $\begin{array}{l}\text { No co-resident } \\
\text { mother }\end{array}$ & $-.503(.440)$ & $-.078(.417)$ & $.163(.311)$ & $.261(.363)$ \\
\hline $\begin{array}{l}\text { Mother with } \\
\text { qualifications }\end{array}$ & $.833(.372)^{*}$ & $.592(.380)$ & $.440(.246)$ & $.252(.250)$ \\
\hline $\begin{array}{l}\text { Father's } \\
\text { qualifications } \\
\text { (base is no higher } \\
\text { qualifications) }\end{array}$ & & & & \\
\hline $\begin{array}{l}\text { No co-resident } \\
\text { father }\end{array}$ & $.362(.296)$ & $.252(.346)$ & $.104(.198)$ & $.108(.206)$ \\
\hline $\begin{array}{l}\text { Father with } \\
\text { qualifications }\end{array}$ & $.321(.226)$ & $.052(.247)$ & $.465(.320)$ & $.331(.315)$ \\
\hline $\begin{array}{l}\text { Tenure at origin } \\
\text { (base is owner } \\
\text { occupation) }\end{array}$ & & & & \\
\hline Local authority & $\begin{array}{r}.765 \\
(.209)^{* * *}\end{array}$ & $\begin{array}{r}.915 \\
(.242)^{* * *}\end{array}$ & $-.202(.146)$ & $-.054(.154)$ \\
\hline $\begin{array}{l}\text { Private rented } \\
\text { Car ownership at } \\
\text { origin (baseline is } \\
\text { no cars) }\end{array}$ & $.502(.225)^{*}$ & $.386(.249)$ & $-.155(.229)$ & $-.095(.242)$ \\
\hline 1 car & $\begin{array}{r}.468 \\
(.121)^{* * *}\end{array}$ & $.235(.139)$ & $.088(.139)$ & $.101(.149)$ \\
\hline $\begin{array}{l}2 \text { or more cars } \\
\text { Sample member's } \\
\text { qualifications } \\
\text { (base is none) }\end{array}$ & $.515(.223)^{*}$ & $.197(.245)$ & $.553(.288)$ & $.564(.289)^{*}$ \\
\hline Lower & & $\begin{array}{r}1.827 \\
(.329)^{* * *}\end{array}$ & & $\begin{array}{r}1.547 \\
(.342)^{* * *}\end{array}$ \\
\hline Middle & & 2.343 & & 1.970 \\
\hline
\end{tabular}



of Migrant Ethnic Minorities

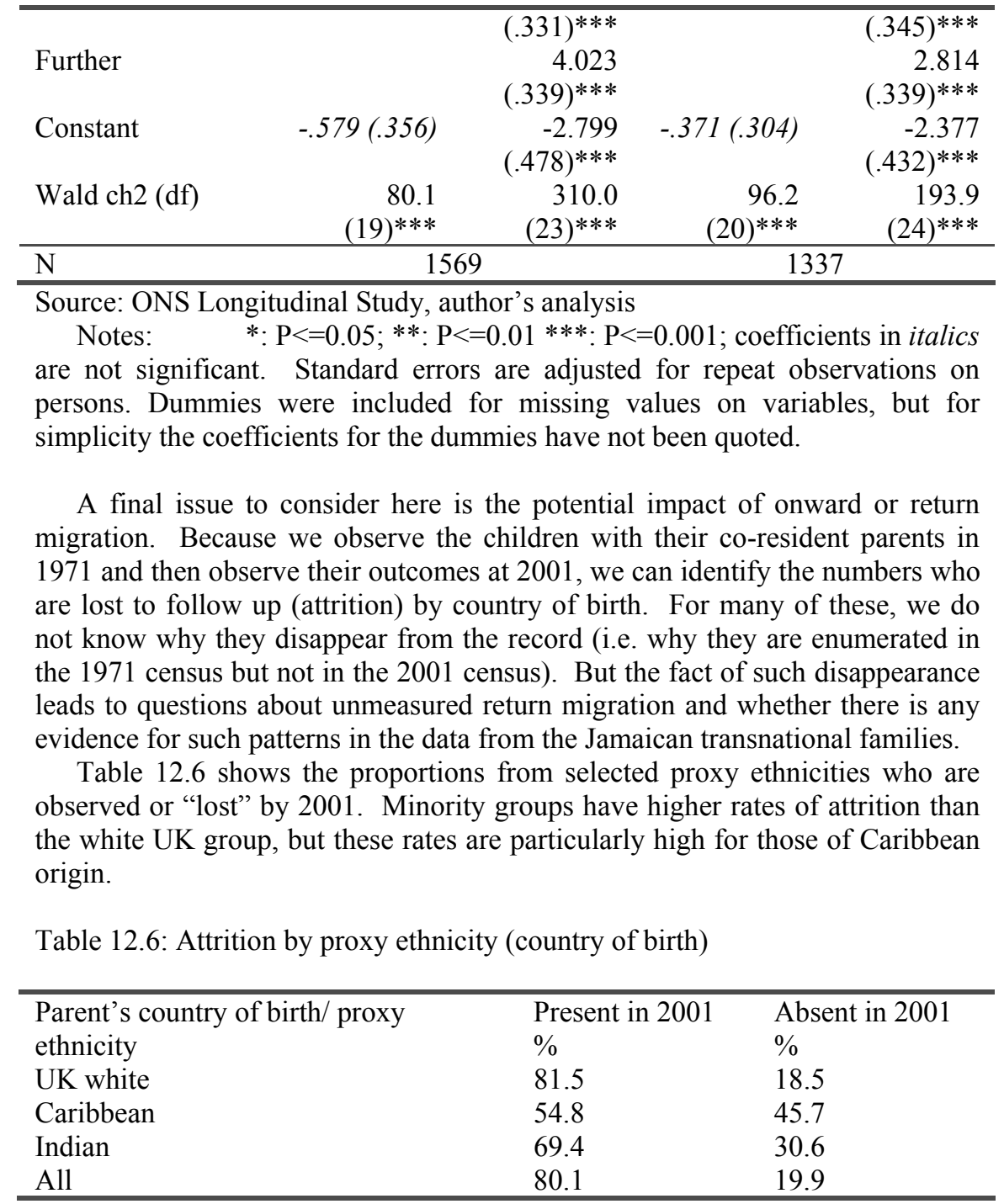

Source: ONS Longitudinal Study, author's analysis

Note: The proportions for "All" in this are based on all those for whom a proxy ethnicity could be created (i.e. for whom there was country of birth information). 
These findings raise a number of distinct issues that we attempt to consider further by examining the qualitative data on Jamaican migrants. For Caribbeans, why does privilege not appear to be retained across generations? What are attitudes to and uses of education: while it plays an important role for those who succeed, why is it not a greater emphasis for this group? What explains both the upward mobility of some Caribbeans and the working class retention of a large number of others, relative to the Indian group? And to what extent are our impressions influenced by differential patterns of emigration? Do the most successful leave: is the "myth of return" all myth (Anwar, 1979; Byron, 1999)?

\section{The Evidence of the Jamaican Migrant Life Stories}

\section{The Data}

The 50 migrants' life stories are drawn from over a hundred interviews recorded for Elaine Bauer and Paul Thompson's "Transnational Jamaican Families Project", a study of families with members in Jamaica, Britain and North America (Thompson and Bauer 2000, 2003, 2004). (The other interviews include those who never migrated, returnees, and second generation family members.) Interviewees were chosen in relation to a rough quota sample in order to give a cross-section of experience, so that of the 50 migrants half are women and half are men; and half were in manual occupations or unemployed, and half in non-manual occupations, based on their last main occupation. The oldest left Jamaica in the 1940s, the most recent in the 1990s. Table 12.7 breaks down the sample by the decade of emigration and by their main destination.

Table 12.7 Migrants' Main Destination by Decade

\begin{tabular}{ccccc}
\hline & UK & Canada & USA & All countries \\
\hline $1940 \mathrm{~s}$ & 1 & 0 & 0 & 1 \\
$1950 \mathrm{~s}$ & 6 & 0 & 0 & 6 \\
$1960 \mathrm{~s}$ & 8 & 2 & 3 & 13 \\
$1970 \mathrm{~s}$ & 0 & 7 & 3 & 10 \\
$1980 \mathrm{~s}$ & 1 & 2 & 9 & 12 \\
$1990 \mathrm{~s}$ & 2 & 0 & 6 & 8 \\
\hline Total & 18 & 11 & 21 & 50 \\
\hline
\end{tabular}

Source: Transnational Jamaican Families Project, author's analysis

The most obvious importance of the qualitative interviews is that, unlike the survey data which deals only with their British experience, they allow us to 
compare the migrants' social position both before and after migration. And a second point immediately follows from this. While it is usually easy to categorise the migrants in terms of their occupations once settled in Britain and North America, this is not so in relation to their "class" in Jamaica, particularly when they came from the countryside, for two reasons. Firstly, many of them combined working their own land or running their own shop with paid work as employees. There was also normally more than one earner in the household, often with occupations at very different levels. Secondly, having land of their own, or family land, was crucial to their social position, even though the typical plot size was only around five acres, because this enabled the families to grow their own food and to raise some additional cash too. Bearing these points in mind, we have divided the 50 interviews into four groups, which are illustrated in Table 12.8 .

Table 12.8 Gender and Social Mobility

\begin{tabular}{lccc}
\hline Transition type & Men & Women & Both \\
\hline Middle class "stayers" & 6 & 6 & 12 \\
"Risers" into non-manual & 6 & 7 & 13 \\
$\begin{array}{l}\text { occupations } \\
\text { "Fallers" into manual occupations }\end{array}$ & 0 & 5 & 5 \\
Working class "stayers" & 15 & 5 & 20 \\
\hline Total & 27 & 23 & 50 \\
\hline
\end{tabular}

Source: Transnational Jamaican Families Project, author's analysis

First, there are twelve migrants who started from an advantaged position in Jamaica and ended abroad in non-manual occupations. Second, at the other end of the spectrum there are twenty migrants who began poor and ended in manual work. Third, in between there are the more mobile migrants: thirteen who rose from poorer backgrounds into non-manual work, and five who have fallen into manual jobs. These do not include those who dropped in social class position within the working class, moving from skilled to semi- or unskilled occupations. These get counted among the working class "stayers". Other migrants who "fell" initially, but who subsequently recovered their class position get included among the middle class "stayers". Overall there are only 5 "fallers" but all of these are women. However, 15 of the 20 working class "stayers" are men. The middle class "stayers" and "risers" are much more evenly divided between the sexes. So what can be learnt from their life stories? 


\section{Family Social and Cultural Backgrounds}

In the first group who were later in non-manual occupations, all came from families with material and cultural advantage in Jamaica. Most were rural families who had land, some extensive, farmed by family members, and they combined this advantage with administrative jobs, such as in the fire or water services, or in one family a big liquor store. Such administrative roles, or owning a substantial shop, also brought social capital in the form of networks and access to information. Thus we see the fungibility of economic and social capital that is stressed by Bourdieu (1997). Two other families were different, but each with a particularly strong model. In Roy York's family it was a very successful entrepreneurial grandfather, who "used to deal in lobster, and supply the hotels and various tourist boats... He's always busy because of his business... He was a JP, he was the mayor, his own business. When he wasn't doing that, he had his little farm going". The connection of the Jamaican middle class on a range of levels and the importance of entrepreneurial models of activities within the wider kinship networks stands out here. Finally there were two families from Kingston. One had recently shifted from farming to political administration. The last family came from the city, urban professionals from the colonial era, including influential lawyer uncles, and the father a distinguished doctor.

The backgrounds of those who rose into non-manual work were much more mixed. While half of them had grandfathers who were small farmers, the rest had little or no land. One migrant's father was a butcher active in local politics. Also, in both this group and the first group, one of the mothers ran the local post office. This brought a very specific type of social capital, supplying the families with information as well as some means to finance migration. One postmistress mother was moreover recognised as the active planner of the family migration strategy: "She set the direction".

These groups of middle-class stayers and risers, and the relative lack of fallers represents the ability of Jamaican middle-class families to reproduce their class advantage across time and space and their apparent utilization of all three forms of "capital" to do so (Bourdieu, 1997), alongside the ability of the riser's families to translate different forms of capital into attainment in the migrant generation. The inability of the migrant generation to maintain this advantage into the second, British-born generation that we observed in the previous section cannot, therefore, be attributed to a general lack of class structure or class retention in the countries of origin. However, the brief discussion of these stayers and risers also reveals how it was the mix of activities and the role of an extended kinship network from which to draw models that was important for the majority. This would seem to give some support to Coleman's emphasis on 
closure in achieving "success". But it also reveals the potential weakness of such closure in that its benefits are, by definition, hard to maintain across generations.

Twenty migrants had unprivileged starts and ended abroad in manual occupations. They were brought up in poor manual working families, and ended in manual occupations themselves. Typically they are older men, but three are older women. Nearly all came from the countryside, only two from urban families. Some of their families had smallholdings, but most little or no land. Fathers were very small farmers, fishermen or skilled artisans, and mothers, domestics or shop assistants. The poorest mother was a field worker and stone breaker. It is also interesting that their lack of upward mobility was a feature of their families as a whole: almost all their siblings also became manual workers. It looks as if their childhood family culture had a strong shaping effect. Interestingly, we did not find this pattern repeated in the second post-migration generation, whose destinies were much more scattered.

Here we can see again apparent strong class retention within the working class. However, in our quantitative data such origins did not unequivocally shape the destinations of the second generation. Class retention appears to be weaker within the new country, despite England and Wales' high levels of stratification overall, than across national boundaries. We go on to explore how we might understand this greater diversity in outcomes by looking at the role of family, attitudes to education and use of housing.

\section{Family Structures}

The life stories demonstrate the relevance of family, but in a different manner from that which might be assumed from a British perspective. With most of these migrants, whether staying poor or comfortable or rising between the two, family played an important supportive role, particularly in the migration process, but also through the exchange of help afterwards, both financial and with caring for children. In this respect it is interesting that when we compared the occupations of our migrants with those of their brothers and sisters, both those who migrated and those who did not, we found that they had followed similar paths: two thirds shared the same pattern with their sibling group. This was less marked with those who rose, but it was most marked of all with the more privileged first non-manual group, whose siblings almost entirely also went into non-manual occupations.

The family background was not, however, normally one of upbringing in nuclear family households, but rather in a variety of forms. Jamaican family culture is typically flexible and pragmatic, and indeed needs to be in order to care for children in a context in which most men and women have children from 
more than one partner, young mothers are encouraged to work, and parents frequently migrated leaving children at least temporarily behind. Thus, nearly all of these migrants grew up in extended families, or solely with grandparents, or in stepfamilies. Interestingly the only group of interviewees who lived their childhoods in nuclear households were those who came from relatively prosperous backgrounds in Jamaica but fell to manual occupations abroad.

The importance of family norms being reinforced at the local level, is reminiscent of Coleman's arguments about the enabling power of social capital. However, if these norms and expectations are carried through into a context in which they are seen as dysfunctional and cannot operate to mobilise support, given less dense networks, we can see how they could then serve to undermine prosperity and chances of success.

There is also an interesting contrast among the manual workers as a whole between their childhoods and their own family lives as adults, which suggests that for them the Jamaican family system worked much less well after migration. Their stories begin with childhoods in households and villages full of people, but as they age in their new countries their lives have become increasingly solitary. There are just three men in this group in lasting marriages. Of the remainder, seven have had more than two broken marriages and four of these men and women are now living alone, two men have remained single, and one man is out of contact with all but one of some dozen children whom he has fathered. Thus while these interviews do not suggest that conventional British distinctions between intact families and stepfamilies are very helpful in explaining mobility or occupational status among migrant Jamaicans, it may be important to look in a broader perspective at changes in kin support systems following migration, and their impact on the careers of both men and women and on subsequent generations.

\section{Attitudes to Education}

Jamaicans come from a country in which there is a widespread belief in education as the key to self-betterment, and also in which the voluntary Basic School system provided most children with the chance of an early start. Nevertheless, the interviews show that there was a marked social class variation in attitudes and experience.

Thus most of those twenty migrants from poorer families who were to remain manual workers had finished school as early as they could and felt they owed little to education. Even if a child had ambition, in many cases the sheer poverty of these rural Jamaican families meant that they needed their children to be earning as soon as possible. This was particularly true of the older children, who were finishing school just when their parents had the largest number of 
children still to feed and clothe. The vision that drove most of this older generation of migrant men and women was not hope of achieving through education. It was much more one of earning well abroad from steady manual work. Thus a strong attachment to investment in education, that is commonly associated with migrants, as discussed above, is not evident for this group. Instead we see that there is potentially a different conception of what it means to succeed than that associated with the credentialism of educational qualifications. Such notions of success in manual work, may be hard to sustain in the face of de-industrialisation; but, on the other hand, having practical skills may bring other advantages and shape migrants' and second generation destinies in other ways, as we discuss further below.

With those twelve families from more privileged backgrounds who were in non-manual work, belief in education is recounted as an assumed value. The middle-class identification with education was evident in the pre-migration experience of these respondents. Typically in this group the parents found their children good schools in Jamaica, paying school fees and sometimes also sending them out of the area in the search for better schools. The children did well and two went on to graduate level.

With those who rose from poorer families into non-manual occupations, in contrast to those from better-off families, it seemed that the key influences came through school and college. With the exception of one boy who did badly at school in England, all of these migrants stayed on at school to the age of 18, one becoming head boy, and over half of them went on to further college education, two qualifying in Jamaica as accountants. Three had become teachers before migrating. Two other boys who came to Britain at school age were rescued from the lower streams and given confidence in their talents by committed comprehensive school teachers. They demonstrate the ability to use education to achieve upward mobility, illustrated in the quantitative data.

We see here the diversity of backgrounds and experience that can lead to a range of attitudes to and uses of education. But the ability to utilize education for and within the second generation is also dependent on the receptiveness of the education system in the country of migration and the extent to which alternative strategies for obtaining education are available.

Successful, professional Jamaicans have tended, partly because of their commitment to the state welfare and education system and partly because of the gendering of professions, to go into less well-paid work in health and social work and teaching. Fewer of them have gone into business, law or accounting. This makes it very difficult for them, despite being professionals, to accumulate sufficient savings capital to employ the strategy of using alternative private schools when their children needed this, as they most likely would have done in Jamaica. And in Britain, the need for alternative strategies is likely to be that 
much greater given the role of the education system in credentialising the dominant classes (Bourdieu, 1977; Bourdieu and Passeron, 1979) and the evidence on the channelling of children of Caribbean migrants into less academic routes (Coard, 1971; Stone, 1981). With education the prime path to occupational success, this lack of means to buy their children out when they are in difficulty may be one reason why for Caribbeans in Britain, to have middle class parents does not give their children markedly better chances.

There are also interesting hints in these life stories of a special favouring of girls' education. Thus Ted Oliver felt it was reasonable that he should go to fieldwork while his sister stayed on at school. He felt a man did not need education in order to get work. "You would have to sacrifice some way, for her to go sometimes, because what can she do [to earn after school]? So the girl will go to school more than the guys would go. I do go to school, but, like, I would stop for a month or two months." While the open expression of such attitudes is uncommon in the life stories, there are many instances of families in which the sibling boys went into farming or other forms of manual jobs, while the girls got clerical or professional work. This gender pattern has continued after migration. In Britain the second generation girls have much higher educational and occupational success rates than the boys. The same is also true in the Caribbean, where, for example, women now outnumber men at university level by two to one. The life stories suggest that these contemporary gender differences are partly based on the inheritance of earlier social capital, in terms of ideas of femininity and masculinity and what kinds of work are suitable for women and men: ideas which then helped to shape their educational behaviour.

There is a fit in these hints with the particular position of Caribbean women in terms of educational and professional success. They are the only ethnic group where women are more occupationally successful than men and the only minority group where the women achieve on a par with majority women. The findings are also congruent with those in the quantitative analysis that stress the importance of partnership in achieving professional or managerial class positions. The possession of social capital, which supports, through example, attitude, and use of networks the transitions of men and women into particular educational and occupational routes, can be productive in some contexts, but may also prove counterproductive. Even if couples achieve "success" in Britain through the women's position, this has implications in a society where "women's" jobs tend to be less well-rewarded than "men's". 

of Migrant Ethnic Minorities

\section{Attitudes to Housing: an Alternative Path to Success and Return}

The life stories indicate that, independently of their occupational level, there was also another upward path through which migrants could rise. This was through their housing strategy. The older generation of migrants typically came from a rural Jamaica in which, as we have seen, one crucial attitude was the importance of owning land of your own. After migration this attitude along with use of and commitment to family networks led some as city-dwellers to buy their own houses. These earlier migrants had in this respect a big advantage over their successors, because in Britain in the 1950s to 1970s there was plenty of cheap run-down housing to be bought even in London. A shrewd buy at this time could prove a crucial long-term financial and cultural boost for the family. It is striking how right from the start some migrants to Britain bought houses in neighbourhoods where there were few or no other black people, and this is a process which has continued. Eventually, however, two distinct patterns emerged among these Jamaican families in Britain. On the one hand there were those who wanted to buy their houses and who tended live away from large clusters of other black migrants. On the other hand were those families who fully integrated into the local white working class culture, in the course of time becoming eligible for council housing, and through that embedded in a local lower class culture with relatively poor educational and occupational chances, in a form of "segmented" assimilation (Portes et al., 2005).

Buying a house was also an effective solution to the housing discrimination which most earlier migrants faced. Rufus Rawlings was driven by the difficulties he found in renting, especially because his wife Ursula was white, to buy a 15-room house in (then working-class and wholly white) Islington, which he restored and filled with lodgers. For those with building skills it was possible not only to buy a house but also to transform and improve it. Rufus did a lot of decorating and improving to his Islington house, and he eventually sold it at a substantial profit, enabling him to return with Ursula to Jamaica to live in some style in a big hilltop house with an adjoining bar overlooking the sea.

Building a house in Jamaica is part of the dream of return. Indeed, the island today is peppered with three-storey concrete houses being constructed by returnees, often over a period of several years, making new futures for their later years. Typically migrants only wanted to return if they could do so as successes (see also Byron, 1999). And house-buying and building activities have allowed many manual workers as well as professionals to return in style. However, where the focus is on "back home" there are likely to be fewer incentives for gaining recognition in terms of local measures of success or of investing in local 
networks or adapting to local norms (Shields and Wheatley Price, 2002; Merkle and Zimmermann, 1992).

We should note two final points about returnees to Jamaica. Firstly, they escape the survey data, and including them might improve the mobility profiles of Jamaican migrants. Secondly, by selling their much more valuable houses in Britain to enable building for the move back, it becomes impossible for returnees to transmit most of the capital which they have accumulated to their children: yet another possible reason why the children of non-manual migrants have fared unevenly, rather than consolidated at a middle class level.

\section{Conclusions, reflections and next steps}

This paper has used complementary quantitative and qualitative data sources to examine the role of family background in shaping outcomes for minority ethnic groups in Britain. The quantitative evidence shows how there are major unanswered questions regarding ethnic groups' divergent patterns of intergenerational social mobility. The qualitative data on Jamaican migrants suggests various ways in which family social capital may be shaping these outcomes: the influence of pre-migration occupational and landholding backgrounds, social networks before and after migration, extended family structures, attitudes to education, housing strategies, and the continuing dream of return. We believe that research specifically addressed to mobility would reveal many other relevant factors. We have drawn on the ideas of Coleman and Bourdieu in developing the role of social capital in explaining mobility processes. However, neither of these theorists presents us with a concept that is fully utilisable in the context of migrant ethnic minority communities. Thus, we have retained a more fluid conception of family social capital tied fully neither to Coleman's stress on closure nor Bourdieu's restriction to the active maintenance of social networks to retain privilege. Nevertheless, we consider we have demonstrated the potential of our exploration of family social capital in tandem with analysis of the role of family class background to account for at least part of the missing information contained within findings of "ethnic penalties" and for illuminating differences between groups. We have stressed the importance of paying attention to what migrants bring with them and transmit down generations, not just in economic and human capital terms, but also the more intangible aspects of norms, attitudes and networks. We then need to understand in more detail how these assets are shaped, distorted or rendered ineffective by the structures, norms, values and prejudices which face them in the country of migration in order to refine and focus the types of explanation we have presented here. 

of Migrant Ethnic Minorities

To achieve that, a programme of research with the second generation resident in Britain is, we feel, the necessary next step. Building on Bertaux and Thompson's (1997) approach, we therefore propose undertaking a series of detailed interviews with members of a number of Britain's minority ethnic groups, drawn from a nationally representative sample source. We would use these interviews to develop our understanding of how family migration histories and associated family social capital intersect with individual British life courses and the social and institutional constraints that have contributed to them (including discrimination, deindustrialisation and patterns of geographical disadvantage). We would do this across a number of ethnic groups. By such means we would aim to develop an explanatory framework which would allow us to distinguish general processes associated with social mobility and the transmission of family social capital and the role of migration histories from characteristics and processes associated with particular ethnic groups. This qualitative research undertaking would continue to be prompted, complemented and challenged by the analysis of quantitative data in a joint approach that we consider is necessary for adequately engaging with these complex and important questions.

\section{Acknowledgements}

We are grateful to ONS for allowing us to use the ONS Longitudinal Study and to CeLSIUS (and Julian Buxton in particular) for support in its use. Neither ONS nor CeLSIUS bear any responsibility for the results and interpretations presented here. Lucinda Platt is also grateful to the Joseph Rowntree Foundation for funding the research on which the analysis of the ONS Longitudinal Study draws, and to the Department of Sociology at the University of Essex for allowing time to conduct the research.

1 See, for example, the establishment of the Equalities Review in 2005: http://www.theequalitiesreview.org.uk/

2 ONS have identified measures summarising different dimensions of social capital across a range of surveys (see http://www.statistics.gov.uk/socialcapital/project.asp; see also Harper, 2002). And many researchers have operationalised such measures in analyses of the role of social capital in a range of outcomes. However, such operationalisations are contentious, and the measurement issues are fraught with difficulty and debate. Instead, we would argue that our broad conception of family social capital, alongside its location at the family rather than the individual level, makes it inherently more susceptible to qualitative rather than quantitative investigation. Moreover, the quantitative source employed here, currently the only longitudinal source covering England and Wales which has sufficient sample sizes to enable the analysis of 
minority group mobility, has only limited variables and none summarising any aspects of social capital.

${ }^{3}$ For further discussion of the data and variables see Platt, 2005. 


\title{
CHAPTER THIRTEEN
}

\author{
ASSESSING SOCIAL CAPITAL AND CARE \\ PROVISION IN MINORITY ETHNIC COMMUNITIES: \\ A COMPARATIVE STUDY OF CARIBBEAN AND \\ ITALIAN TRANSNATIONAL FAMILIES
}

\section{TRACEY REYNOLDS AND ELISABETTA ZONTINI}

\section{Introduction}

Edwards et al (2003: 2) define social capital as "the values that people hold and the resources that they can access, which both result in and are the result of collective and socially negotiated ties and relationships". In this chapter we focus on care as a social capital resource that circulates within families and kin groups. Through the analysis of the practices of Caribbean and Italian families, we examine how informal care is reciprocated within ethnic minority groups in the UK and abroad. This cross-cultural and transnational approach enables us to identify how caring relationships affect family lives and relationships across two culturally, ethnically and racially distinct groups, who experienced economic migration and settlement in the UK at different historical times. It is also important to understand that the enduring nature of family bonds and their meanings to family members are intergenerational and transnational in context. By focusing on different forms of care circulating within trans-cultural and intergenerational family and kin networks, this discussion reveals many nuances of family life and the processes by which cultural norms, values, attitudes and behaviour are transmitted, transformed and maintained across generations and geographical distance. In relation to ethnic minority and transnational families, the type of practical caring work undertaken within these social networks has scarcely been studied in detail (Goulbourne and Solomos 2003). When it has 
been considered at all, there seems to be a consensus in the social capital literature that migration undermines caring reciprocal relationships within families (Coleman 1990a; Putnam 2000).

Our notion of caring reciprocal relationships is premised on understanding caring commitments, responsibility and obligations as complex, morally negotiated interactions that occur within family networks. Sevenhuijsen's (2000) view that caring relationships are achieved rather than ascribed, is important in determining how people negotiate everyday patterns of care. We focus on two important elements of family caring networks: "caring about" and caring for family members. In doing so we critically explore how social capital is utilised within Caribbean and Italian families to negotiate and interact within their networks of care and responsibility and between local and transnational contexts. The analysis also shows how moral complexities concerning caring practices, social and economic conditions, and racial/ethnic and gender differences shape care provision.

This chapter is based on research we have undertaken in two projects within the Ethnicity strand of the Families \& Social Capital ESRC Research Group: "Caribbean Young People, Social Capital and Diasporic Family Relationships" (Reynolds 2004) and Italian Families and Social Capital: Rituals and the Provision of Care in British-Italian Transnational Families (Zontini 2004a). The Caribbean study aims to investigate the experiences of Caribbean young people in the UK in order to understand some key ways in which they utilise social capital within their family relationships and community networks as a social resource in ethnic identity formation. The project is based on in-depth qualitative interviews with 30 second and third generation Caribbean young people (age between 16-30 years old), primarily living in London but also in other large urban areas of Birmingham, Manchester and Nottingham, and 50 kinship/family members in UK, and the Caribbean (Barbados, Guyana and Jamaica) across all age groups. In tandem, the Italian project explores various aspects of family life and social capital. These include the functioning of mutual and reciprocal relations related to care, the role of rituals and the formation of transnational identities. It explores how trust and reciprocity operate within and beyond families, the significance of norms and obligations, and the implications of caring for and caring about. The material has been collected through participant observation and 50 qualitative in-depth interviews in a number of sites, both in the UK (London, Bedford, Peterborough, Aylesbury) and in Italy with people of different generations ranging from teenagers to elderly people.

Our analysis begins with a theoretical overview concerning caring networks and family relationships. It is within these debates that we position our subsequent examination of Caribbean and Italian families. We then examine how caring about operates in transnational families by identifying the diverse 
Assessing Social Capital and Care Provision in Minority Ethnic Communities: 219 A Comparative Study of Caribbean and Italian Transnational Families

range of kin work performed within geographically dispersed families. Our discussion on caring for highlights reciprocal caring networks that feature intergenerational care (e.g. grandparents, parents and children) as well as intragenerational care (e.g. siblings). Linked to this is the fact that everyday patterns of care responsibilities and obligations are negotiated in relation to moral contexts. We conclude with a summary of our discussions and preliminary findings.

\section{Theoretical overview}

Social capital theorists such as Coleman (1990a) and Bourdieu (1997) focus on families as sites where social capital is generated. They also draw attention to the fact that social capital is a resource that needs constant investment. In Coleman's words, "social relationships die out if not maintained; expectations and obligations wither over time; and norms depend on regular communication" (Coleman 1990a: 321). From this premise authors such as Putnam (2000) and Coleman (1990a) perceive that migrant families are lacking social capital because of the weakening of social and familial relationships resulting from geographical and social mobility. However, our analysis contests this placebased notion of social capital and supports research that shows how migrant families continue to invest in their social relationships irrespective of geographical distance (Bryceson and Vourela 2002). Care provision acts as a social resource through which support networks are maintained across geographical boundaries and as well as across a variety of family structures (Reynolds and Zontini 2006).

A second assumption challenged in this chapter is the conventional understanding of care as one-directional, originating from a single source, and flowing from a care-giver (the "haves") to a care-receiver (the "have nots") (Ackers and Stalford 2004; Sevenhuijsen 2000). In social policy terms, this viewpoint is supported by a discourse of kinship care that focuses on those people who are dependent and in need of financial and personal care. For example, within health and social care fields, care services primarily focus on particular stages of the life course - young children and elderly people and also those perceived as sick, disabled, relatively poor and facing socio-economic disadvantage (Edwards et al. 1999; Williams 2004). Related to this dependency model of care is the idea that as individuals become more upwardly mobile and independent, they regard themselves as being less in need of care and support, giving rise to increasing individualisation in society (Beck 1992). A wealth of studies have examined this phenomena in relation to the changing nature of social and moral ties that bind individuals and family networks together (see Beck and Gernsheim 2002; Irwin 1999; McRae 1997). It is suggested that on the 
one hand, families are becoming increasingly fragmented, fractured and dispersed, and on the other, that individualisation gives rise to diverse family arrangements and more personal autonomy.

Our analysis challenges the dependency model of care, and the notion that people are less in need of care as they become more individualised, on two levels. First, our data clearly illustrates that Caribbean and Italian families have caring relationships that are reciprocal and multi-directional. Family members are active both in giving and receiving care provision, irrespective of their social and economic status. We identified three ways in which reciprocal relationships work in families: (1) inter-generationally (between parents and children, grandparents and grand-children, uncles and aunts and nephews, and so on.); (2) intragenerationally (between siblings, cousins); and (3) trans-nationally (when reciprocity operates among family members across geographical boundaries).

Secondly, our findings indicate that there is little evidence to suggest that family members are less involved in caring relationships as a result of growing individualisation. Indeed, individualisation is a dominant aspect of Caribbean society where there exists greater autonomy for individuals to choose their lifestyles, family forms and living arrangements. This is readily apparent in the more fluid, "loose", dynamic and diverse forms of Caribbean family networks and household patterns compared to western ones. However, Caribbean people continue to be embedded in their family relationships. They have been successful in sustaining their family connections and providing collective and individual responsibility for care within this individualised framework because the individualised self is understood as relational and situational to others within their networks. In contrast, in Italian and Southern European families, despite increased diversity in living arrangements, the individual is still understood as interconnected and interwoven within the family. Italian families have been going through structural changes, which include the disappearance of the traditional extended family. Whilst extended households are no longer common in Southern Europe, family members continue to live close to one another, maintaining important economic and emotional links. What strikes many observers of Italian society is the importance attributed to the family, and its supposed stability and cohesion. Italy has recently been described as having a distinctive pattern of personal relationships and social networks in respect to other European societies, characterised by a particularly strong intergenerational solidarity (Finch 1989a).

There are stark cultural differences concerning the ways in which this relationship between the individual and the family is articulated: Caribbean as relational and Italians as interconnected, but commonality exists in the way in which individuals from both ethnic groups are embedded in webs of personal relationships and utilise social capital as a resource (Griffiths 1995). Care 
Assessing Social Capital and Care Provision in Minority Ethnic Communities: 221 A Comparative Study of Caribbean and Italian Transnational Families

provision represents an important family and social resource for connecting and relating to other family members. This understanding of caring networks that views the individual as relational, interconnected and embedded in their personal relationships chimes with feminist scholars who recognise that care is "a social process of daily human activity" (Sevenhuijsen 2002: 136) that frames our daily interactions (Clement 1996; Griffiths 1995; Finch 1989b; Fisher and Tronto 1990; Mackenzie and Stoljar 2000; Thorne and Yalom 1992).

Feminist scholars have differentiated between two forms of family care providing a useful starting point for our analysis: caring about and caring for (Ackers and Stalford 2004; Finch 1989b; Fisher and Tronto 1990). Caring about encompasses contact and emotional support and refers to emotional functions connected with sociability, advice, comfort and self-validation. Examples of caring about activities include communication by telephone, letters, emails, visits, participation in family decision-making and financing the purchase of care (Di Leonardo 1992). Caring for refers to concrete, "hands-on" care-giving on a personal level (Ackers and Stalford 2004; Finch and Groves 1983).

A moral dimension is also crucial to understanding these caring about and caring for kin relationships within family/kinship networks. Finch and Mason (1993) champion the concept of "kinship morality" to suggest that a set of moral discourses informs our behaviour towards kin. Similarly Williams (2004: 55) suggests that people negotiate their relationships within these moral guidelines and act as moral agents involved in negotiating "the proper thing to do" in and through their commitments to others. These caring commitments "cross the boundaries of blood, marriage, residence, culture and country" (ibid). Distinctions between the differing dimensions of care are important for exploring the daily caring practices of our respondents, and for exploring differences according to ethnicity/race, gender, generation, locations, and so on.

\section{"Caring about" in minority ethnic families}

Caring about family members and kin work seem to assume a crucial relevance in the context of migration and geographically dispersed families. The very existence of transnational families does, in fact, rest on kin ties being kept alive and maintained, in spite of great distances and prolonged separations, (Mand 2006; Reynolds 2004, Zontini 2004a\&b). Bryceson and Vourela (2002) have recently highlighted this, advancing two concepts to study transnational family making, namely "frontiering" and "relativizing". The first refers to "the ways and means transnational family members use to create familial space and network ties in a terrain where affinal connections are relatively sparse" (Bryceson and Vourela 2002: 11). The second refers to the ways "individuals establish, maintain or curtail relational ties with specific family members" (ibid 
2002: 14). Goulbourne and Chamberlain (2001: 42), in their study of transnational Caribbean families, have found that "geographical distance is no barrier to being a "close" family, and respondents in their study stressed the importance of transnational links in maintaining the "tightness" of the emotional bonds, and the level of "trust" expected and experienced between family members". Goulbourne (2002: 196) also returns to this theme in a later study where he highlights that transnational care between family members reinforces "continuity and bonding across distance". This is especially important when generational differences and cultural divides mark the potential to produce distance between family members. For a number of minority ethnic families in the UK, migration represents the social context in which much of the caring work and responsibility takes place within family networks (Goulbourne and Solomos 2003; Peach 1991). Migration creates and maintains reciprocal caring relationships between those family members left behind and those who migrated elsewhere in search of better opportunities. These transnational caring networks also work to reinforce ethnic identity and cultural belonging.

In our studies, we found that multi-directional "caring about" practices, obligations and responsibilities operated within the family networks in a number of ways. Caring about tasks and responsibilities ranged from providing small favours or money loans, to telephone calls to family members to give advice, support, or just merely "checking in". They also included organising regular family meals (e.g. with married children and their families); family celebrations (such as birthdays, Christmas and Easter dinners); regular visits "home" (i.e., to the Caribbean and Italy); hosting kin in the UK; and gift-giving. We found that family members devote considerable time and energy to these tasks, despite the geographical distance. We have adopted the term cultural remittance to advance the theory of caring about relationships. Cultural remittance represents people's emotional attachments and represents the ways in which migrants abroad utilise their family links to maintain cultural connections to their place of origin (Burman 2002). Other forms of cultural remittance include owning and building property "back home", the celebration of cultural rituals and national events in the new country of residence and keeping abreast of national news "back home" through the internet and newspapers. Cultural remittance reinforces ethnic identity and is viewed as a sign of the continued commitment to the kin left behind and a commitment to keeping kin together. The most common type of "kin-keeping" or keeping kinship ties alive occurred between siblings; parents and children and grandparents and grandchildren. 
Assessing Social Capital and Care Provision in Minority Ethnic Communities: 223

A Comparative Study of Caribbean and Italian Transnational Families

\section{Examples of Kin-keeping: telephone calls and family visits "home"}

The commitment of keeping the family together was discussed by many respondents in the Caribbean and Italian study. The easiest and most frequent way in which caring about is articulated in the families studied is through telephone calls, (although Caribbean and also Italian young people are increasingly turning to email and the internet to keep in contact with their cousins and other relatives that are close in age to them). Frequent and regular telephone conversations are an important way to keep families together, updating scattered members with what is going on in the lives of each other, providing emotional support and even directing and organising more hands on care from other family members. However, in both studies young people seem to rely on their parents to initiate these phone calls and generally speak to their kin when the phone is passed on to them by their parents.

Mum will say "have you phoned granny to wish her 'happy birthday' or 'happy Christmas", then I'll phone her and say "hi granny" and we'll chat then [....] if I answer [phone] I'll talk to her before I pass it on to my mum or mum gets me to speak to her when she's finished. (Stacy, Caribbean study, interview location: London, October 2003)

The most important way in which kin connections are kept for both first and second generation and between new and old migrants is the frequent visit "home" (Baldassar 2001). The visit "home" is very important for renewing and confirming ethnic identity for first generation migrants and their children. Such visits are strongly linked to the presence of kin. First and second-generation Italians use their visits home to invest in properties in Italy (which are looked after by their kin) and which they use when they visit on their annual holidays. Many first generation Caribbean migrants "return" to the Caribbean to settle after they reach retirement age (Abernaty 2001, Goulbourne 2002). In the Caribbean study, first generation migrants who have recently retired invested in property "back home" in preparation for their return as well as for family visits

With regards to second generation Caribbeans and Italians, our analysis indicates that their educational and career choices are influenced by this "need" to spend time in their respective territories. The quotation by Marta shows this:

I've worked on and off, nothing fantastic, waitressing, in the market, waitressing, a lot of waitressing, that sort of stuff, I'm not a big, I wasn't a career woman, I used to work for 11 months and then go to Italy for a month, cos you could do that then, and then come back and get another job, years ago you could do that, [...] I used to go to Italy, all the friends are up there, all the cousins are up there 
for the holidays, spend all staying out hanging about. (Marta, Italian study, interview location: London, November 2003)

The second generation Caribbean young people also identified the emotional and psychological support they got from these visits home. It allowed them to develop a positive sense of well-being and of belonging in the face of racial discrimination, inequality and exclusion. The second generation Italians also valued the visits home as an important resource in renewing ethnic identity. However, in contrast to the second generation Caribbean, they balanced the positive value they gained from these trips with the obligation they felt to do this trip, the pain and anxiety (caused by the anticipation of separation) and the unsettlement provoked by the experience of the visit.

These differing attitudes of the second generation Caribbeans and Italians can be best explained by the distance and proximity of these family visits "home". With the exception of a few respondents who made annual visits "home", the majority of second generation Caribbean young people made infrequent visits (e.g. every other year, every three years, five years and so on). In many instances their parents had returned and settled in an area within the Caribbean where they did not have any familial roots or kinship ties. Therefore, whilst they valued their strong family bonds in the Caribbean, they were less attached to their familial place of origin. As a result of these factors, they were less likely to experience anxiety and guilt or a sense of obligation in making these visits compared to second generation Italians who visited the family home on an annual basis, or sometimes on a number of occasions within the calendar year, and who still maintained strong familial ties to their parents' place of origin.

\section{"Caring for" in minority ethnic families}

Multi-directional caring for practices, obligations and responsibilities operated within the family networks of the Caribbean and Italian families. Their accounts of daily activities and family relationships provided a wealth and range of examples of transnational care provision between family members. Most commonly cited were care between siblings; grandparents and grandchildren; parents and children and affluent and less wealthy family members and involved domestic, childcare and financial assistance and remittances. Sometimes their caring exchanges reflected specific and regular tasks and responsibilities, but more often than not, care took the form of less defined everyday activities that were not generally thought of as care provision. The respondents' reluctance in clearly recognising what they do as care provision within the family demonstrates the fact that reciprocal caring exchanges are part of everyday living that go to the heart of personal relationships. Often these reciprocal 
Assessing Social Capital and Care Provision in Minority Ethnic Communities: 225 A Comparative Study of Caribbean and Italian Transnational Families

exchanges are immediate and concurrent (exchanging caring services at the same time) or they occur at different times and stages in a person's life course (i.e. providing care now in exchange for future care later or past care received).

\section{Intergenerational care}

Caribbean family literature highlights how grandparents/senior family relatives caring for dependent children left behind by parents who have migrated for better economic opportunities represents a significant cultural and historical tradition (Brodber 1974; Reynolds 2005; Russell-Browne et al. 1997; Senior 1991). A large number of migrating mothers belong to low-income socioeconomic groups and do not have the economic means or support networks readily available to take their children with them. Consequently, they consider that the child's best interest is served by being left behind and cared for by relatives.

Grandmothers (as well as grandfathers), and other older relatives who lived in the UK and have now re-migrated to the Caribbean, are still on hand to provide caring support. The relative ease and affordability of air travel facilitates regular and frequent visits across geographical distances by grandparents as care-givers and care-receivers. Goulbourne and Chamberlain's (2001) study refers to the "flying grandmothers" syndrome to represent grandmothers and other senior female family members who regularly criss-cross the Atlantic in order to visit family members in the UK and the USA and Canada and provide them with practical childcare assistance and emotional support as and when required. Equally, their grandchildren may visit them in the Caribbean during school holidays so that they can provide childcare.

Daniel: Every summer she [mum] sent me to stay with grandparents and cousins in JA until I was about 15. Every summer my grandmother look after me,

Tracey: And what things did you do there?

Daniel: Me and my cousins we'd pick oranges and ackee off the tree with her (grandmother), and we helped her prepare the food and stuff. And the kids in Jamaica are trained with more manners and respect for olders. [...]Every Saturday morning, I'd have to get up early and go to the market, with my gran, shopping. She watched all the soaps [television soap operas] [...] it was my job to set the recorder, I taught her how to use it because she didn't know how to work the video-recorder

(Daniel, Caribbean study, interview location: Manchester, November 2003).

Daniel's recollection of his summer holidays spent with his grandparents in Jamaica and the activities undertaken during his visit, highlights how intergenerational learning and mutual exchange of knowledge between grandparent and grandchild is an important facet of care provision. Aside from 
childcare provided, in her role as carer Daniel's grandmother transmits cultural norms and social values (i.e., good manners and social etiquette) and educates him about life in Jamaica. From Daniel's perspective, in turn, he is able to teach his grandmother new skills, such as setting the video recorder to record her favourite television programmes. Other young people in the study also identified their role and responsibility towards their grandparents (and senior kinship members) in developing new skills and building confidence in using new forms of information technology. They regularly demonstrated to senior kin how to use email, the internet, CD/DVD players and digital cameras, and loaned them the use of their equipment. Although intergenerational learning and exchange is not regarded as care provision in the strictest sense, the caring obligations and responsibilities that emerge from this help maintain the emotional bonds and family connections that bridge the generational gap.

The Italian migrant narrative has parallels with the Caribbean migrant experience. When first generation labour migrant women arrived in the UK, they bore the heavy burden of working full-time in factories, whilst having sole responsibility for house, husband and children. As a result of migration these women were initially cut off from their kin networks of support. They received little help with childcare even though their husbands and friends played a more prominent role than they would have done in Italy. Sometimes, like their Caribbean counterparts, they became "transnational mothers" sending their children to school in Italy, often in the hope of returning permanently to Italy. When plans to return did not materialise, these children or young adults had to adapt back to life in the UK, after having spent several years away from the country and their immediate family. This first generation also helped their children financially, usually saving large sums for their weddings and for buying their first home. In the UK the children of Italian migrants' had to learn to look after themselves quickly. They also carried out important tasks for their parents (such as translations, forms filling, etc.).

We started integrating speaking English and then obviously if they ever needed to go anywhere we would always have to go with them.[...] If my parents had to go to a Doctor or to the Hospital or to do anything and sometimes even to the shops [...] I would have to go with them and interpret what was going on. (Francesco, Italian study, interview location: Bedford, March 2004)

First generation Italian migrant women, who missed out on looking after their children when they were young due to their work commitments, are now heavily involved with their grand-children. Grandfathers too seem to play a significant, although different, role. Some grandparents even change their retirement plans to fulfil their role. In case of their children's divorce their 
Assessing Social Capital and Care Provision in Minority Ethnic Communities: 227 A Comparative Study of Caribbean and Italian Transnational Families

support becomes especially crucial. They provide housing, babysitting and financial support.

She said we'll live together and it was the best thing that could have happened to me and my children because I was able to go to work and so I could support them $[(\ldots])$ and I was able to afford all the classes $[\ldots]$ the swimming and the clarinet and everything because I was with my Mum and I didn't have to pay rent [...]. Italian [...] it's the culture and I had security and if I ever wanted to go out in the evening I knew the children were at home. (Cristina, Italian project, interview location: London, November 2003).

"Flying grandmothers" also exist in Italian families, as in the case of Rita, who travels to Italy to her grand-daughter every five or six weeks.

It's 11 years now that I am faithfully there every 5 or 6 weeks at the most. [....] it's not something that I have to do, it's an enjoyment cos I really want to see her growing up and I want to enjoy her while I can. [...]I take her shopping and buy her whatever she needs and you know how we are? We like to spoil our grandchildren $[\ldots]$ everything is pleasure and it's not because I have to. (Rita, Italian study, interview location: London, December 2003)

These examples of reciprocal caring exchanges identified above, and previously in the discussion of Caribbean families, point to grandparents as an important resource in terms of the emotional and financial support they provide. They also show how the grandparent-grandchild interaction is significant in maintaining kinship ties and family networks (for example, see Gray 2005; Wolf 2004). In both Caribbean and Italian families most grandparents acknowledged that they derived satisfaction and personal pleasure from looking after their grandchildren. However, not all grandparents enjoy this baby-sitting role. Some also expressed dissatisfaction with the expectation that they would provide free childcare for their grandchildren and this became a source of tension in the family.

Care for the elderly also seems to take place trans-nationally. In the Caribbean, the relatively elderly population of retired returnees creates additional demands for health and social care provision. Inadequate social and health care infra-structure across much of the region means that it falls to family members in the UK and US to provide basic medical care as well as the daily hands-on aspect of this care work. This lack of social welfare support at state policy level in caring for elderly and sick people creates additional burdens and stress on family members who also have to meet these health and social care demands.

First generation Italian migrants in the UK are also preoccupied with their responsibility for caring for ageing parents left in Italy. Often their care is devolved to other kin still living in Italy. For middle-class professional migrants, 
there is the expectation that they will travel often to Italy so that they can continue to be fully involved in the care of ageing parents. Adult children with ageing parents living in the UK are also torn as to how best to care for them. While the Italian ideal is that the elderly should be cared for at home by family members, many have placed their parents in residential care. This has produced feelings of guilt in several of those interviewed because they feel they are going against cultural values and norms concerning family care.

\section{Caring for siblings}

Siblings often provide help and support to each other, but expectations vary according to gender. Male siblings tended to involve themselves more with financial support, whilst female siblings identified childcare as their primary caring work in sibling relationships. Tamara reflects on how her uncle, who migrated from the Caribbean to the UK in the early 1960s, provided financial support to his younger brother and sisters and, in so doing, enabled them to move out of poverty in Jamaica during the 1970s:

My parents were able to move up into middle-class because my uncle in London helped to educate his younger brothers and sisters. He worked as a bus driver for over thirty years, and send would money back. He also helped to put my five younger brothers and sisters through school, because we all went to good school in Kingston, but it was private school, [ .] so that we all have a decent education, we've all got degrees and we're all doing professionals jobs [...] People often forget that it's the working-class who help to build middle-class in Jamaica, it was down to my uncle that we became middle-class. (Tamara, Caribbean study, interview location: Jamaica, June 2003)

Female siblings regularly participated in childcare for younger siblings and their siblings' children (i.e., nephews and nieces)

7,8 , or 9 around that age I was looking after myself with my sister and stuff. Cos my sister was 3 years older so she could look after me and she used to come up to my old school and pick me up so in Year 6 or Year 7 or Years 5 and 6, my sister came to pick me up from my school and took me home. [....]My Mum was working and my Dad was working. I think if I was my sister at the time I don't think I would have done it! [Laughs]. (Peter, Italian study, interview location: London, February 2004)

This gendered nature of sibling caring responsibilities reflects a wider aspect of kin work, namely that care is a gendered activity, with men and women focusing on its different aspects (Di Leonardo 1984; Mand 2002). In both studies, there are gender differences concerning the type of care people provide and the ways in which they express their caring commitments. Female kin are 
heavily involved in providing practical domestic caring work, childcare and contributing to "kin-keeping" (Bornat et al. 1999; Williams 2004). This includes facilitating contact and maintaining family ties between family members who are geographically dispersed or estranged from one another (i.e., continuing relationship with ex-partners' family members) and where there are cultural and generational differences (i.e., between grandparents and grandchildren). Male kin are much more likely to provide financial care assistance or financial remittance by, for example, sending money to help pay for repairs, goods or services and buying in carers or helpers for family members in need. Financial remittance involves the return of money and financial goods by migrants to family members in their country of origin and is also another important social dimension of "caring for" within transnational family networks (see Reynolds and Zontini 2006; Zontini 2004b).

\section{Caring boundaries and obligations}

What is clear from our analysis of reciprocal caring exchanges is that underpinning these personal networks, which are transnational, intergenerational, intra-generational, and also vary according to gender, there are social and material constraints, as well as norms and values that dictate the kind of care that should be done in the family. These are tied to moral boundaries and to obligations individuals have to their family as well as to the gendered expectations they have to subscribe to certain norms and values. Finch and Mason's (1993) notion of "kinship morality" points to the fact that a set of moral discourses informs our behaviour towards kin. People negotiate their relationships within these moral guidelines and according to context (Williams 2004). In both studies young people's expectation of caring responsibility and the sense of obligation they felt towards their parents was openly discussed. They all agreed that they would contribute towards care provision when their parents got older and/or experience ill health. Although their justifications varied as to the reasons why they would provide care, common themes running throughout the young people's accounts were that "it was the right thing to do", "they owed their parents", "it is expected of them", "no other option", "Its not even up for discussion", and "it's a given I will do it". It could be suggested that the young people's strong sense of personal obligation and expectation to provide care for their parents is based on certain norms and values where it is expected that children will reciprocate care to their parents to repay them for the sacrifices they made in bringing them up and to return the care they received. This behaviour is typical of what Komter (2005) has called "delayed reciprocity". 
In contrast to young people's accounts, the older respondents had direct experience with caring for sick and elderly parents and they described the tensions, burden and feelings of guilt this brought them. As a result, the expectation and obligation to care was more muted compared to young people's accounts. Many of the respondents in the Caribbean study did not take it as an unconditional fact or unquestioned assumption that they would automatically care for elderly parents or elderly relatives. Instead these respondents took a more much pragmatic approach to family care provision. Their involvement in care was premeditated on the changing moral and cultural contexts in which they found themselves, the strength of their particular kinship connections, the consideration of the needs of others in their family unit or household, and the social and economic resources that they had available at any given time. Reciprocating care to those who had previously cared for them or to those from whom they expect to get care back was also an important element in who they decided to care for (see also Komter 2005).

The main beneficiaries of care provision by the research participants were family members who cared for them when they were children or later in life as adults. For example, in the Caribbean study, Jocelyn, is a grandmother who is now retired. She spends half the year in the UK and the remainder of the year in Guyana. As a child Jocelyn lived with her aunt and now helps to care for her by giving her money for medical bills and dialysis treatment. She also buys her medical equipment (egg, blood pressure monitoring machine), and has arranged for a live-in nurse to stay with her aunt. Jocelyn's mother is also ill but she chooses not to contribute towards her mother's care because she does not feel a sense of obligation or responsibility for her. The fact that Jocelyn provides care for her aunt while doing nothing for her mother has caused tension and a family rift between her aunt and her mother who are no longer on speaking terms. Similarly, another respondent, Latoya, recollects that her mother funded her brothers' visit to the UK so he could receive hospital treatment because he had previously cared for her as child and assisted her with her migration to the UK.

In Italian families norms and obligations towards elderly care seem less negotiated and linked to past experiences of care than in the Caribbean families. Both Marta and Silvia, two second generation professional women, felt the obligation to care for their parents even though they felt neglected as children by their parents and had several problems with them when they were young. The notion of "prescribed altruism" - that is the strongly felt inner norm of being obliged to demonstrate solidarity with aged family members (Finch and Mason 1993) - seems relevant for interpreting these Italian practices.

Complex negotiations occur within family relationships regarding kinship responsibility and care provision. This is likely to be further exacerbated where family members live great distances apart. Finch and Mason (1993) distinguish 
between explicit and implicit processes of negotiation occurring within family relationships concerning decisions over which family members will undertake the caring work. Explicit negotiations signify and involve open and clear discussions, often referred to as "family get togethers" or "family conferences". Implicit negotiations involve decisions and negotiations that occur without open discussion. Explicit negotiations occurred more often in Caribbean families, and implicit negotiations were found more in Italian families, although both types of negotiations were identified in both Caribbean and Italian families.

Explicit discussions between family members either happen face-to-face or on the telephone (with individual family members or teleconferencing) and do not usually include all family members but a selected few (Finch and Mason 1993). In the Caribbean study, the young people were able to clearly identify family members, or the "key players", who were usually involved in this negotiation process. The young people in the study also used family discussions to keep abreast of family events and strengthen kinship bonds. The "key players" were generally family members who are regarded as the most respected and/or senior family members. Important factors for choosing the key players involved the inter-relating factors of age and gender (i.e., oldest male sibling); socio-economic status (i.e., affluent family member with most money and resources) or professional/educational status (i.e., most educated). It was noted that other family members are also involved in these discussions - although not necessarily as "key players"- including those in close contact with each other and those who live with or in close contact with the family members requiring care. Also present in these negotiations is the family "link person". This represents the family member who acts as the family conduit, passing information and news between family members and connecting those living in different part of the world or country. These family discussions are rarely egalitarian, whereby family members present have equal say about decisions. More often than not other family members are informed of decisions made by the "key players" after they have made them. In addition, it was also clear that those family members involved in decision-making processes may not themselves be directly involved in the practical day-to-day aspects of care provision.

Implicit negotiations could be "tacit" or unspoken agreements between family members, occurring for a number of reasons. First, there is the "obvious" and "taken for granted" person who provides help where necessary or needed; so that the negotiations remain unacknowledged (Finch and Mason 1993). Below, married couple Paolo and Marcella describe how they became the family's main carers because they had no children themselves and have had a "career" as carers, therefore it was expected of them to care for their elderly relatives: 
Paolo: In 1960 we moved here [...] primarily because Marcella and I were getting married and I was looking after my mother when my father died and so I could continue to look after my mother when we moved into this big house [...]. We have no children but we believe we were destined to look after all the old people of the family because we looked after her mother and father and we looked after my mother and my uncle and older relatives we looked after.

Marcella: We'd never dreamed that it should be any different really.

(Paolo and Marcella, Italian study, interview location: London, December 2003)

In other family situations, who this "taken for granted person" is also depends on their seniority within the family, or the geographical distance between them and the relative in need. Implicit negotiations also involve those caring decisions that are sometimes taken unilaterally by individuals to avoid potential conflicts with other family members.

\section{Conclusion}

In this chapter we have focused on care as a social capital resource circulating in families. Specifically, we have shown how caring reciprocal relationships operate in ethnic minority families, taking into account both their local and transnational commitments. The different forms of care circulating within trans-cultural and intergenerational kin networks, encompass caring about and caring for, and reinforce the boundaries within which responsibilities and obligations are negotiated. This cross-cultural comparative analysis reveals both similarities and differences between (as well as within) Caribbean and Italian transnational families. In both groups individuals are enmeshed in a complex web of relationships linking them to wider kin groups located in a variety of geographical contexts and to their wider communities both in the UK and abroad. Contrary to what social capital theorists such as Putnam (1996a) and Coleman (1990a) predict, our analysis on care provision illustrates that geographical distance of family members living in the Caribbean, Italy, the UK and elsewhere, does not necessarily influence the decision to care and the resources made available. However, as we have illustrated, this transnational dimension affects negotiations concerning the moral boundaries and responsibilities of care.

In particular, we found caring about to be similar for both groups studied (for example, family visits "home" and regular long distance telephone calls are a central feature of family life ). This is probably due to the migration experience itself, which resulted in family separation across geographical locations. As a consequence of migration, individuals of both group place great importance on kin-keeping and devote time and energy to this activity. Cultural remittances are another important element used by both Italians and Caribbeans 
to maintain cultural connections to their place of origin and renovate their ethnic identity. Caring for is, in both groups, multi-directional, flowing across and within the generations as well as countries. We clearly demonstrate that care is an everyday activity in which all of our interviewees are involved. However, not everybody is equally involved as care-giver or care-receiver. Care is both a gendered and a selective activity with men and women involved in different areas of care. There are also differences in the way that care is allocated and negotiated within families. Caribbean families tend to have more open and explicit discussions whereas in Italian families they tended to be more implicit. We believe this reflects the more negotiated nature of Caribbean family responsibilities and the more prescribed nature of Italian ones.

By comparing the experiences of two distinct ethnic groups, we have shown that while norms and values are important in shaping caring practices, they are also fluid and subject to change, and to other factors, such as social and material conditions. Reciprocal caring exchanges underpin these caring networks which are transnational, inter-generational, intra-generational, and also vary according to gender as well as familial and cultural/historical norms and expectations. These factors are significant in determining the level of social and economic resources available to the individual and family for care provision, and the tensions that exist between them. By understanding social capital as locality based, and operating solely within the confines of local networks, we believe that Putnam and Coleman overlook the complex negotiations, resources and opportunities that exist in the day-to-day realities of transnational family networks, like those we have explored in our study of Caribbean and Italian families. In our view, this points to the need to reassess a-historic, static and locality based notions of social capital in order to recognise the important resources circulating amongst ethnic minorities in the UK and abroad. 


\section{REFERENCES}

Abernaty, F. 2001. The dynamics of return migration to St. Lucia. In Caribbean Families in Britain and the Trans-atlantic World, edited by H. Goulbourne, and M. Chamberlain. London: Macmillan.

Ackers, H.L. and Stalford, H.E. 2004. A Community for Children? Children, citizenship and internal migration in the EU. Aldershot: Ashgate.

Adkins, L. 2002. Revisions: Gender and sexuality in late modernity, Buckingham: Open University Press.

- 2005a. Social capital: the anatomy of a troubled concept. Feminist Theory 6:195-211.

- 2005b. The new economy property and personhood. Theory. Culture and Society, 22 (1): 111-130.

Adler, G. 1885. Umfang, methode und ziel der musikwissenschaft. Vierteljahrschaft für Musikwissenschaft 1: 5-20.

Agnes, C., P. Emerton, et al. 2005. Laws for Insecurity? A report on the Federal Government's proposed counter-terrorism measures, Civil Rights Network.

Aldridge, S. 2001. Social Mobility: A discussion paper. London: Cabinet Office, Performance and Innovation Unit, April.

Aldridge, S., D. Halpern and S. Fitzpatrick. 2002. Social Capital: A discussion paper. Performance and Innovation Unit, April.

Allatt, P. 1993. Becoming privileged: the role of family processes. In Youth and Inequality edited by I. Bates, and G. Riseborough. Buckingham: Open University Press.

- 1996. Consuming schooling: choice, commodity, gift and systems of exchange. In Consumption Matters, edited by S. Edgell, K. Etherington and A. Ward. Oxford: Blackwell/Sociological Review.

Altman, I. and Low, S. 1992. Place Attachment. New York: Plenum Press.

Amato, P.R., and Booth, A. 1997. A Generation at Risk: Growing up in an era of family upheaval. Cambridge, MA: Harvard University Press.

American Federation of Teachers 1990. How worksite schools and other school reforms can generate social capital: an interview with James Coleman. American Federation of Teachers, 35-45.

Anheier, H. and Kendall, J. 2002. Interpersonal trust and voluntary associations: examining three approaches. British Journal of Sociology 53 (3): 343-63.

Annen, K. 2001. Social capital, inclusive networks and economic performance. Journal of Economic Behaviour and Organisation 50: 449-463. 
Ansdell, G. 1997. Musical elaborations: what has the new musicology to say to music therapy? British Journal of Music Therapy 11 (2): 36-44.

-. 2001. Musicology: misunderstood guest at the music therapy feast. In Music Therapy in Europe, edited by D. Aldridge, G. di Franco, E. Ruud and T. Wigram. Rome: ISMEZ/Onlus.

-. 2002. Community music therapy and the winds of change: a discussion paper. In Contemporary Voices in Music Therapy: Communication, Culture and Community, edited by C. Kenny and B. Stige. Oslo: Unipub forlag.

Ansdell, G., M. Pavlicevic and S. Procter. (2004) Presenting the Evidence: A guide for music therapists responding to the demands of clinical effectiveness and evidence-based practice. London: Nordoff-Robbins Music Therapy Centre.

Ansell, C.K. 2001. Schism and Solidarity in Social Movements: The politics of labor in the French Third Republic. Cambridge: Cambridge University Press.

Anwar, M. 1979. The Myth of Return: Pakistanis in Britain. London: Heinemann.

Arthurson, K. 2002. Creating inclusive communities through balancing social mix: a critical relationship or tenuous link? Urban Policy and Research 20 (3): 245-262.

Arts Council England. 2004. Cultural Medicine: Investment in cultural capital for health. London: Arts Council England.

Australian Broadcasting Company (ABC). 2005. Artists, journalists voice antiterrorism laws concerns, ABC News Online.

Badcock, B. 1997. Recently observed polarising tendencies and Australian cities. Australian Geographical Studies 35 (3): 243-259.

Baldassar, L. 2001. Visits Home: Migration experiences between Italy and Australia. Melbourne: Melbourne University Press.

Bankston, C.L., and M. Zhou. 1995. Effects of minority-language literacy on the academic achievement of Vietnamese youths in New Orleans. Sociology of Education 68: 1-17.

Bankston, C.L., and M. Zhou. 2002. Social capital and immigrant children's achievement. Schooling and Social Capital in Diverse Cultures 13: 13-39.

Baron, S., J. Field and T. Schuller, eds. 2000. Social Capital: Critical perspectives. Oxford: Oxford University Press.

Beazley, K. 2001. Assisting the very youngest Australians. Paper presented to the Australian Early Childhood Association Conference, University of Sydney.

Beck, U. 1992. Risk Society: Towards a new modernity. London: Sage.

Beck, U. and E. Beck-Gernsheim. 2002. Individualisation. London: Sage. 
Becker, G.S. 1957. The Economics of Discrimination. Chicago: University of Chicago Press.

—. 1964. Human Capital. New York: Columbia University Press.

- 1976. The economic approach to human behavior. In The Economic Approach to Human Behavior, edited by G.S. Becker. Chicago: University of Chicago Press.

- 1981. A Treatise on the Family. Cambridge, MA: Harvard University Press.

-. 1990. Interview with Richard Swedberg, In Economics and Sociology: Redefining their boundaries: Conversations with economists and sociologists, edited by R. Swedberg. Princeton NJ: Princeton University Press.

Becker, G.S. and K.M. Murphy. 2001. Social Economics: Market behavior in a social environment. Cambridge, MA: Belknap Press.

Beeson, M. and A. Firth. 1998. Neoliberalism as a political rationality: Australian public policy since the 1980's. Journal of Sociology 34 (3): 215231.

Bengtson, V.L. and R.A. Harootyan. 1994. Intergenerational Linkages: Hidden connections in American society. New York: Springer.

Berger, B. and P.L. Berger. 1983. The War Over the Family: Capturing the middle ground. Garden City, NY: Anchor Press.

Berger, P. and H. Kellner. 1975. Marriage and the construction of reality. In Life as Theatre edited by D. Brisset and C. Edgley, 219-223. New York, NY: Aldine DeGruyter.

Bertaux, D. and P. Thompson. 1997. Pathways to Social Class: A qualitative approach to social mobility. Oxford: Clarendon Press.

Blackaby, D.H., D.G. Leslie, P.D. Murphy and N.C. O’Leary. 1999. Unemployment among Britain's ethnic minorities, Manchester School, 67 (1): $1-20$.

Blackaby, D.H., D.G. Leslie, P.D. Murphy and N.C. O'Leary. 2005. Born in Britain: How are native ethnic minorities faring in the British labour market? Economics Letters 88: 370-375.

Blair, T. 2001. Speech on the Government's Agenda for the Future, 8 February. Available at http://www.pm.gov.uk/output/Page1579.asp.

—. 2002. New Labour and community. Renewal 10 (2): 9-14.

-. 2005. Speech to Faithworks. Guardian Unlimited. March 22.

Blood, R.O. and D. Wolfe. 1960. Husbands and Wives: The dynamics of married living. New York: Free Press.

Blunkett, D. 2004. New challenges for race equality and community cohesion in the 21st Century. Speech given to the Institute of Public Policy Research, July 7. 
Boix, C. and D. Posner. 1998. Social capital: explaining its origins and effects on government performance. British Journal of Political Science 29 (3): 686-93.

Borjas, G. 1992. Ethnic capital and intergenerational mobility, Quarterly Journal of Economics 107: 123-50.

Bornat, J., B. Dimmock, D. Jones and S. Peace. 1999. Generational ties in the 'new' family: changing contexts for traditional obligations. In The New Family? edited by E.B Silva and C. Smart. London: Sage.

Botsman, P. and M. Latham, Eds. 2001. The Enabling State: People before bureaucracy. Annandale: Pluto Press Australia.

Bott, E. 1957, rev. edn 1971. Family and Social Networks. London: Tavistock.

Bougarel, X. 1996. State and communitarianism in Bosnia and Herzegovina. In A Study in Fragmentation, Despair and Rebirth edited by D. Dyker and I. Vejvoda, 86-115. New York: Addison Wesley Longman.

Bourdieu, P. 1973. Cultural reproduction and social reproduction. In Knowledge, Education, and Cultural Change, edited by R. Brown, 71-112. London: Tavistock.

-. 1977. Outline of a Theory of Practice, trans. R. Nice. Cambridge: Cambridge University Press.

-. 1980. Le capital social - notes provisoires. Actes de la Recherche en Sciences Sociales 31: 2-3.

-. 1984. Distinction: A Social Critique of the Judgement of Taste, trans. R. Nice. Cambridge, MA: Harvard University Press.

- 1986. The forms of capital. In The Handbook of Theory: Research for the sociology of education, edited by J.G. Richardson, 241-258. New York: Greenwood Press.

- 1987. What makes a social class? On the theoretical and practical existence of groups. Berkeley Journal of Sociology 32: 1-16.

—. 1988. Homo Academicus, trans. P. Collier. Stanford: Stanford University Press.

—. 1990. The Logic of Practice. Cambridge: Polity Press.

- 1996. The State Nobility: Elite schools in the field of power, trans. L.C. Clough. Stanford: Stanford University Press.

- 1997. The forms of capital. In Education: Culture, economy, society, edited by A.H. Halsey, H. Lauder, P. Brown and A.S. Wells, 46-58. Oxford: Oxford University Press.

—. 1998. Acts of Resistance: Against the new myths of our time. Cambridge: Polity Press.

-. 1998. Practical Reason: On the theory of action. Stanford: Stanford University Press. 
Bourdieu, P. and J.C. Passeron. 1977. Reproduction in Education, Society, and Culture. London: Sage.

Bourdieu, P. and J.C. Passeron. 1979. The Inheritors: French students and their relation to culture, trans. R. Nice. Chicago: University of Chicago Press.

Bourdieu, P. and L. Wacquant. 1992. An Invitation to Reflexive Sociology. Cambridge: Polity Press.

Bradbury, T.N. and B.R. Karney. 2004. Understanding and altering the longitudinal course of marriage. Journal of Marriage and Family 66: 862879.

Bramble, T. 2004. Contradictions in Australia's 'miracle economy'. Journal of Australian Political Economy 54: 5-31.

Brodber, E. 1974. The Abandonment of Children in Jamaica. Institute of Social and Economic Research, University of West Indies.

Bronfenbrenner, U. 1979. The Ecology of Human Development: Experiments by nature and design. Cambridge, MA: Harvard University Press.

Brooks-Gunn, J. and G. Duncan, eds. 1997. The Consequences of Growing Up Poor. New York: Russell Sage Foundation.

Brown, B.B. and D.D. Perkins. 1992. Disruptions in place attachment. In Place Attachment, edited by I. Altman and S. Low, 279-304. New York: Plenum Press.

Brown, B.B., D.D. Perkins and G. Brown. 2003. Place attachment in a revitalizing neighborhood: individual and block levels of analysis. Journal of Environmental Psychology 23 (3): 259-271.

Brown, G. 2004. Speech by the Chancellor of the Exchequer at the British Council Annual Lecture. July 7. Available at:

http://www.hmtreasury.gov.uk/newsroom_and_speeches/press/2004/press_6 3 04.cfm.

Bryant, B.K. 1985. The Neighborhood Walk: Sources of support in middle childhood. Monographs of the Society for Research in Children 50 (3 Serial No. 210).

Bryceson, D. and U. Vuorela, Eds. 2002. The Transnational Family. New European frontiers and global networks. Oxford: Berg.

Burgess, E.W. 1948. The family in a changing society. American Journal of Sociology 53: 417-422.

Burman, J. 2002. Remittance; or diasporic economies of yearning. Small Axe 12 (2): 49-71.

Burt, R. 1992. Structural Holes: The social structure of competition. Cambridge, MA: Harvard University Press.

- 2000. The network structure of social capital. In Research on Organizational Behaviour, edited by R.I. Sutton and B.M. Staw, vol. 22. Greenwich, CT: Jai Press. 
Burton, L.M. and R.L Jarrett. 2000. In the mix, yet on the margins: the place of families in urban neighborhood and child development research. Journal of Marriage and the Family 62: 1114-1135.

Byron, M. 1999. The Caribbean-born population in 1990s Britain: who will return? Journal of Ethnic and Migration Studies 25 (2): 281-97.

Caplan, N., M.H. Choy and J.K. Whitmore. 1991. Children of the Boat People: A study of educational success. Ann Arbor, MI: University of Michigan Press.

Card, D. 2005. Is the new immigration really so bad? Economic Journal 115 (507): F300-F323.

Castells, M. 1996. The Rise of the Network Society. Oxford: Blackwell.

Chisholm, L., P. Buchner, H.-H. Kruger and P. Brown, Eds. 1990. Childhood, Youth and Social Change: A comparative perspective. London: Falmer.

Claibourn, M.P. and P.S. Martin. 2000. Trusting and joining? An empirical test of the reciprocal nature of social capital. Political Behavior 22 (4): 267-291.

Clark, K. and J. Lindley. 2004. Immigrant labour market assimilation and arrival effects: evidence from the Labour Force Survey. Paper presented at Royal Economics Society. Available at: http://ideas.repec.org/p/ecj/ac2004/68.html.

Clement, G. 1996. Care, Autonomy and Justice: Feminism and the ethic of care. Colorado: Westview Press.

Coard, B. 1971. How the West Indian Child is Made Educationally Subnormal in the British School System. London: New Beacon Books.

Cohen J. 1999. Trust, voluntary association and workable democracy: the contemporary American discourse on civil society. In Democracy and Trust, edited by M. Warren, 208-248. Cambridge: Cambridge University Press.

Coleman J.S. 1984. Introducing social structure into economic analysis. American Economic Review 74 (2): 84-88.

- 1987. Norms as social capital. In Economic Imperialism: The economic approach outside the field of economics, edited by G. Radnitzky and P. Bernholz. New York: Paragon House Publishers.

- 1988. Social capital in the creation of human capital. American Journal of Sociology 94, S95-S120.

- 1990a. Foundations of Social Theory, London: Harvard University Press.

-. 1990b. Equality and Achievement in Education. Boulder, CO: Westview Press.

-. 1990c. How worksite schools and other schools reforms can generate social capital: An interview with James Coleman. American Federation of Teachers, 35-45.

Colley, L. 1999. Britishness in the 21st Century. Millenium Lecture, December 8. Available at http://www.number-10.gov.uk/output/Page3049.asp. 
Comaroff, J. and J.L. Comaroff. 2000. Millenial capitalism: first thoughts on a second coming. Public Culture 12 (2): 291-343.

Commonwealth of Australia. 2005a. Anti-Terrorism Bill (No. 2) 2005: A Bill for an Act to amend the law relating to terrorist acts, and for other purposes, Parliament of the Commonwealth of Australia.

- 2005b. Higher Education Support Amendment (Abolition of Compulsory Up-front Student Union Fees) Bill 2005, Parliament of the Commonwealth of Australia.

-. 2005c. Provisions of the: Employment and Workplace Relations Legislation Amendment (Welfare to Work and Other Measures) Bill 2005 Family and Community Services Legislation Amendment (Welfare to Work) Bill 2005, Parliament of the Commonwealth of Australia.

—. 2005d. The Workplace Relations Amendment (Work Choices) Bill 2005, Parliament of the Commonwealth of Australia.

-. 2005e. Work Choices: A simpler, fairer, national Workplace Relations System for Australia. Canberra: Australian Government.

Conley, D. 2004. The Pecking Order: Which siblings succeed and why. New York: Pantheon Books.

Conn, M.K. 2000. Seeking a Place to Be: New York City Youth of Color in the Late 1980s. Doctoral Dissertation in Environmental Psychology, Graduate Center, City University of New York.

Connolly, P. 1998. Racism, Gender Identities and Young Children. London: Routledge.

Cook, K.S., E.R.W. Rice and A. Gerbasi. 2004. The emergence of trust networks under uncertainty: the case of transitional economies - insights from social psychological research. In Creating Social Trust in PostSocialist Transition, edited by J. Kornai, B. Rothstein and S. RoseAckerman, 193-212. New York: Palgrave Macmillan.

Cook, N. 1998. Music: A very short introduction. Oxford: Oxford University Press.

Cook, T.D., M. Herman, M. Phillips and R.J. Setterston Jr.. 2002. Some ways in which neighborhoods, nuclear families, friendship groups and schools jointly affect changes in early adolescent development. Child Development 73: 1283-1309.

Coontz, S. 2005. Marriage, A History: From obedience to intimacy, or how love conquered marriage. New York: Viking Press.

Coronil, F. 2000. Towards a critique of globalcentrism: speculations on capitalism's nature. Public Culture 12 (2): 351-374.

Corsaro, W. 1994. Discussion, debate, and friendship processes: peer discourse in U.S. and Italian nursery schools. Sociology of Education 67: 1-26.

Costello, P. 2003a. Building Social Capital. Sydney: Sydney Institute. 
-. 2003b. Is Faith A Lost Cause? Sydney: Anglicare.

—. 2003c. Transcript: interview with Neil Mitchell, Radio 3AW.

Cowan, C.P. and P.A. Cowan. 1999. When Partners Become Parents: The big life change for couples. New York: Erlbaum.

Cox, E. 1995. A Truly Civil Society. The Boyer Lectures. Sydney: ABC Books.

Crosnoe, R., and G.H. Elder Jr. 2004. Family dynamics, supportive relationships, and educational resilience during adolescence. Journal of Family Issues 25: 571-602.

Crow, G. and G. Allan. 1994. Community Life. Brighton: Harvester Wheatsheaf.

Crow, G., G. Allan and M. Summers. 2002. Neither busybodies nor nobodies: managing proximity and distance in neighbouring relations. Sociology 36 (1): $127-147$.

Daniel, W.W. 1968. Racial Discrimination in England. Harmondsworth: Penguin.

Dasgupta, P. 2000. Economic progress and the idea of social capital. In Social Capital: A multifaceted perspective, edited by P. Dasgupta and I. Serageldin. Washington, D.C.: World Bank.

- 2002. Social capital and economic performance: analytics, revision of: Dasgupta, Partha 2000. "Economic Progress and the Idea of Social Capital". In Social Capital: A multifaceted perspective. Edited by P. Dasgupta and I. Serageldin. Washington, DC: World Bank. Available at http://www.econ.cam.ac.uk/faculty/dasgupta/soccap.pdf.

Dasgupta, P. and I. Serageldin, Eds. 2000. Social Capital: A multifaceted perspective. Washington, D.C.: The World Bank.

Della Porta, D. 1995. Social Movements, Political Violence, and the State. New York: Cambridge University Press.

DeNora, T. 2000. Music in Everyday Life. Cambridge: Cambridge University Press.

-. 2003. After Adorno. Cambridge: Cambridge University Press.

Di Leonardo, M. 1992. The female world of cards and holidays: women, families and the work of kinship. In Rethinking the Family: Some feminist questions, edited by B. Thorne and M. Yalom. Boston: Northern University Press.

Diani, M. and D. McAdam. Eds. 2003. Social Movements and Networks: Relational approaches to collective action. Oxford: Oxford University Press. Diani, M. and D. McAdam. 2001. Social capital as social movement outcome. In Beyond Tocqueville: Civil society and the social capital debate in comparative perspective, edited by B. Edwards, M.W. Foley and M. Diani. Hanover, NH: University Press of New England. 
Djipa, D., M. Muzur and P. Franklin Lytle. 1999. Consultations With the Poor: National synthesis report, Bosnia and Herzegovina. Washington, D.C.: The World Bank.

Dunn, J. and J. Brown. 1994. Affect expression in the family, children's understanding of emotions, and their interactions with others. Developmental Psychology 40:120-137.

Dunn, J. and R. Plomin. 1990. Separate Lives: Why siblings are so different. New York: Basic Books.

Durkheim, E. 1933. The Division of Labor in Society. New York: Free Press.

-. 1951. Suicide: A study in sociology. Glencoe, IL: Free Press.

Eade, J., T. Vamplew and C. Peach. 1996. The Bangladeshis: the encapsulated community. In Ethnicity in the 1991 Census: Volume 2: The Ethnic Minority Populations of Britain, edited by C. Peach, 150-60. London: HMSO.

Eaton, J.W. and R.J. Weil. 1955. Culture and Mental Disorders. Glencoe, IL: Free Press.

Edwards, B., M.W. Foley and M. Diani, Eds. 2001. Beyond Tocqueville: Civil society and the social capital debate in comparative perspective. London: University Press of New England.

Edwards, J. 2000. Born and Bred. Oxford: Clarendon.

Edwards, J., A. Oakley and J. Popay. 1999. Service users' and 'providers' perspectives on welfare needs. In Welfare Research: A critical review, edited by F. Williams. London: UCL Press.

Edwards, R. 2003. Introduction: themed section on social capital, families and welfare policy. Social Policy and Society, 2 (4): 305-308.

- 2004. Present and absent in troubling ways: family and social capital debates. Sociological Review 52: 1-21.

- 2005. Gender and generation in studying social capital, and the concerns of the Families \& Social Capital ESRC Research Group. Paper presented to Sosial og Kulturell Kapital Seminar, NOVA, Oslo, Norway, 16-17 March.

Edwards, R., J. Franklin and J. Holland. 2003. Families and Social Capital: Exploring the issues. Families \& Social Capital ESRC Research Group Working Paper No. 1, London: South Bank University.

Egerton, M. 2002. Family transmission of social capital: differences by social class, education and public sector employment. Sociological Research Online 7 (3). Available at http://www.socresonline.org.uk/7/3/egerton.html.

Eggertsson, T. 2004. Norms in economics, with special reference to economic development. In Social Norms, edited by M. Hechter and K.-D. Opp. New York: Russell Sage Foundation.

Eisenberg, A.R. 1992. Conflicts between mothers and their young children. Developmental Psychology 38: 21-43. 
Elder, G.H., Jr., and R.D. Conger. 2000. Children of the Land. Chicago: University of Chicago Press.

Elster, J. 1989. Social norms and economic theory. Journal of Economic Perspectives 3 (4): 99-117.

Erikson, R and J.H. Goldthorpe. 1993. The Constant Flux: A study of class mobility in industrial societies. Oxford: Clarendon.

Esser, H. 2004. Does the "new" immigration require a "new" theory of intergenerational integration? Intergenerational Migration Review 38 (3): 1126-1159.

Estroff, S.E. 1995. Brokenhearted lifetimes: ethnography, subjectivity and psychosocial rehabilitation. International Journal of Mental Health 24 (1): 82-92.

Etzioni, A. 2001. On social and moral revival. The Journal of Political Philosophy 9 (3): 356-371.

Evans, P. 1996. Government action, social capital and development: reviewing the evidence of synergy. World Development 24 (6):1119-1132.

Family and Community Services (FACS) 2004. Stronger Families and Communities Strategy (SFCS) 2004-2008, FACS.

Farr, J. 2004. Social capital: a conceptual history. Political Theory 32 (1): 6-33.

Fehr, E. and U. Fischbacher. 2004. Social norms and human co-operation. Trends in Cognitive Sciences 8 (4):185-190.

Field, J. 2003. Social Capital. London: Routledge.

Finch, J. 1989a. Kinship and friendship. In British Social Attitude, edited by R. Jowell, J. Witherspoon and L. Brook. Special International Report, Aldershot: Gower.

—. 1989b. Family Obligation and Social Change. Cambridge: Polity Press.

Finch, J. and D. Groves. 1983. A Labour of Love: Women, work and caring. London: Routledge.

Finch, J. and J. Mason. 1993. Negotiating Family Responsibilities. London: Routledge.

Fine, B. 2003. Social Capital Versus Social Theory: Political economy and social science at the turn of the millenium. London and New York: Routledge.

- 2005. If social capital is the answer, we have the wrong questions. In Social Capital, Civil Renewal and Ethnic Diversity, Proceedings of a Runnymede Trust Conference, 75-82. London: Central Books.

Fine, B. and F. Green. 2000. Economics, social capital, and the colonization of the social sciences. In Social Capital: Critical perspectives, edited by S. Baron, J. Field and T. Schuller. Oxford: Oxford University Press. 
Fisher, B. and J. Tronto. 1990. Towards a feminist theory of caring. In Circles of Care: Work and identity in women's lives, edited by E.K. Abel and M.K. Nelson. New York: New York Press.

Florida, R. 2003. The Rise of the Creative Class. Melbourne: Pluto Press.

Foley, M.W. and B. Edwards. 1999. Is it time to disinvest in social capital? Journal of Public Policy, 19 (2): 141-73.

Frankenberg, R. 1957. Village on the Border. London: Cohen and West.

—. 1966. Communities in Britain. London: Penguin.

Fraser, N. 1998. From redistribution to recognition? Dilemmas of justice in a 'post-socialist' age. In Feminism and Politics, edited by A. Phillips, 430460. New York: Oxford University Press.

Fries, S., L. Tatianna and S. Polanec. 2003. The 2002 Business Environment and Enterprise Peformance Survey: Results from a survey of 6,100 firms. European Bank for Reconstruction and Development Working Paper No. 84. Fukuyama, F. 1995. Trust: The social virtues and the creation of prosperity. London: Penguin.

- 2001. Social capital, civil society and development. Third World Quarterly 22 (1): 7-20.

Furstenberg, F.F. 1993. How families manage risk and opportunity in dangerous neighborhoods. In Sociology and the Public Agenda, edited by W.J. Wilson, 231-258. Newbury Park, CA: Sage.

-. 2003. Growing up in American society: income, opportunities and outcome. In Social Dynamics of the Life Course: Transitions, institutions, and interrelations, edited by W.R. Heinz and V.W. Marshall, 211-233. New York: Aldine de Gruyter.

Furstenberg, F.F. and S. Kaplan. 2004. Social capital and the family. In The Blackwell Companion to Sociology, edited by J. Scott, J. Treas and M. Richards, 218-232. Malden, MA: Blackwell.

Furstenberg, F.F., T. Cook, J. Eccles, G.H. Elder Jr. and A. Sameroff. 1999. Managing to Make It: Urban families in high-risk neighborhoods. Chicago: University of Chicago Press.

Gans, H.J. 1962. The Urban Villagers. New York: Free Press.

Geddes, J. 2004. Art and mental health: building the evidence base. In For Art's Sake? edited by J. Cowling. London: Institute for Public Policy Research.

Genoff, R. 1999. An Innovative City: Economic plan. Adelaide: City of Playford.

George, S. 1999. A short history of neo-liberalism. Paper presented to the Conference on Economic Sovereignty in a Globalizing World, New York.

Gibson, J.J. 1979. Ecological Approaches to Visual Perception. Boston: Houghton Mifflin. 
Giddens, A. 1991. Modernity and Self Identity: Self and society in the late modern age. Cambridge: Polity Press.

-. 1998. The Third Way. London: Polity Press.

—. 2000. The Third Way and its Critics. Cambridge: Polity Press.

—. 2001. The Global Third Way Debate. Cambridge, Polity Press.

Gilbert, M. 1989. On Social Facts. Princeton NJ: Princeton University Press.

Gillies, V. 2005. Raising the 'meritocracy': parenting and the individualization of social class. Sociology 39 (5): 835-853.

Gittell, R. and Vidal, A. 1998. Community Organising: Building social capital as a development strategy. Thousand Oaks, CA: Sage.

Glaeser, E.L., D. Laibson, J.A. Scheinkman and C.L. Soutter. 1999. What is Social Capital? The determinants of trust and trustworthiness. National Bureau of Economic Research.

Goehr, L. 1992. The Imaginary Museum of Musical Works: An essay in the philosophy of music. Oxford: Clarendon Press.

Goldthorpe J.H. with C. Llewellyn and C. Payne. 1987. Social Mobility and Class Structure in Modern Britain, 2nd edition. Oxford: Clarendon Press.

Goode, W.J. 1964. The Family. Englewood Cliffs, NJ: Prentice-Hall.

Goodenow, C. 1993. The psychological sense of school membership among adolescents: Scale development and educational correlates. Psychology in the Schools 30 (1): 79-90.

Goodhart, D. 2004. Discomfort of strangers, The Guardian, February 24. Accessible at :

http://www.guardian.co.uk/comment/story/0,1154650,00.html.

Goodwin, J. and H. O'Connor. 2005. Exploring complex transitions: looking back at the 'golden age' of from school to work. Sociology 39 (2): 201-220.

Gottman, J.M. and L.J. Krokoff. 1989. The relationship between marital interaction and marital satisfaction: a longitudinal view. Journal of Consulting and Clinical Psychology 57: 47-52.

Gouk, P. 2000. Musical Healing in Cultural Contexts. Aldershot: Ashgate.

Goulbourne, H. 2002. Caribbean Transnational Experience. London: Pluto Press.

Goulbourne, H. and J. Solomos. 2003. Families, ethnicity and social capital. Social Policy and Society 2 (4): 329-338.

Goulbourne, H. and M. Chamberlain, Eds. 2001. Caribbean Families in the Trans-Atlantic World. London: Macmillan.

Gould, R. 1995. Insurgent Identities: Class, community and protest in Paris from 1848 to the Commune. Chicago: University of Chicago Press.

Gould, R.V. 2003. Why do networks matter? Rationalist and structuralist interpretations. In Social Movements and Networks: Relational approaches 
to collective action, edited by M. Diani and D. McAdam. Oxford: Oxford University Press.

Gouldner, A.W. 1960. The norm of reciprocity: a preliminary statement. American Sociological Review 25: 161-178.

Government of South Australia. 2004. South Australia's Strategic Plan: Creating opportunity, moving forward together, Government of South Australia.

Granovetter, M. 1973. The strength of weak ties. American Journal of Sociology 78 (6):1360-1380.

-. 1985. Economic action, social structure, and embeddedness. American Journal of Sociology 91: 481-510.

- 2005. The impact of social structure on economic outcomes. Journal of Economic Perspectives 19 (1): 33-50.

Gray, A. 2005. The changing availability of grandparents as carers and its implications for childcare policy in the UK. Journal of Social Policy 34 (4): 557-577.

Green, L. 2003. Music education, cultural capital, and social group identity. In The Cultural Study of Music, edited by M. Clayton, T. Herbert and R. Middleton. London: Routledge.

Griffiths, M. 1995. Feminism and the Self: The web of identity. London: Routledge.

Grootaert, C. 1998. Social Capital: The missing link? Social Capital Initiative Working Paper No. 3. Washington DC: The World Bank.

Grootaert, C. and T. Bastelaer. 2002. Understanding and Measuring Social Capital: A multidisciplinary tool for practitioners. Washington DC: The World Bank.

Grootaert, C., D. Narayan, V. Nyhan-Jones and M. Woolcock. 2002. Integrated Questionnaire for the Measurement of Social Capital. Washington, D.C.: The World Bank.

Hall, P.A. 1999. Social capital in Britain. British Journal of Political Social Science 29: 417-61.

Halpern, D. 2005. Social capital and policy in a multi-ethnic Britain. In Social Capital, Civil Renewal and Ethnic Diversity, Proceedings of a Runnymede Trust Conference, 61-74. London: Central Books.

-. 2005. Social Capital. Cambridge: Polity Press.

Hanifan, L.J. 1916. The rural community centre. Annals of the American Academy of Political and Social Science 67: 130.

Hardin, R. 1984. Collective Action. Baltimore: John Hopkins University Press.

-. 1993. The street-level epistemology of trust. Politics and Society 21 (4): 505-529. 
-. 2000. Democratic epistemology and accountability. Social Philosophy and Policy 17 (1): 110-126.

-. 2002. Trust and Trustworthiness. Vol. IV, Russell Sage Foundation Series on Trust. New York, NY: Russell Sage.

Hardt, M. 1999. Affective labour. Boundary 26 (2): 89-100.

Harper, R. 2002. The Measurement of Social Capital in the United Kingdom. London: Office for National Statistics.

Harriss, J. 2002. Depoliticizing Development: The World Bank and social capital. London: Anthem Press.

Hart, R. 1979. Children's Experience of Place. New York: Irvington.

Hase, S., R.A. Phelps, H.M. Saenger and J. Gordon-Thomson. 2004. Sun, surf and scrub: dimensions of social disadvantage in communities in the Northern Rivers Region of NSW. Australasian Journal of Business and Social Inquiry $2(1): 1-15$.

Hatton, T.J. and S. Wheatley Price. 2005. Migration, migrants and policy in the United Kingdom. In European Migration: What do we know?, edited by K. Zimmerman. Oxford: Oxford University Press.

Heath, A. and D. McMahon. 1997. Education and occupational attainments: the impact of ethnic origins. In Ethnicity in the 1991 Census: Volume Four: Employment, Education and Housing among the Ethnic Minority Populations of Britain, edited by V. Karn. London: Office for National Statistics.

Heath, A. and D. McMahon. 2005. Social mobility of ethnic minorities. In Ethnicity, Social Mobility and Public Policy: Comparing the US and UK, edited by G.C. Loury, T. Modood and S. Teles, 393-413. Cambridge: Cambridge University Press.

Heath, A. and J. Ridge. 1983. Social mobility of ethnic minorities. Journal of Biosocial Science Supplement 8: 169-84.

Heath, A. and S. Yu. 2005. Explaining ethnic minority disadvantage. In Understanding Social Change, edited by A.F. Heath, J. Ermisch and D. Gallie. Oxford: Oxford University Press.

Hechter, M. and K.-D. Opp. 2004a. Introduction. In Social Norms, edited by M. Hechter and K.-D. Opp. New York: Russell Sage Foundation.

Hechter, M. and K.-D. Opp. 2004b. What have we learned about the emergence of social norms? In Social Norms, edited by M. Hechter and K.-D. Opp. New York: Russell Sage Foundation.

Hedstrom, P. and R. Swedberg, Eds. 1998. Social Mechanisms: An analytical approach to social theory. New York: Cambridge University Press.

Heelas, P., S. Lash and P. Morris, Eds. 1996. Detraditionalisation. Oxford: Blackwell. 
Heft, H. 1988. Affordances of children's environments: a functional approach to environmental description. Children's Environments Quarterly 5 (3): 29-37.

Helliwell, J. 2003. Immigration and Social Capital: Issue paper, Issues Paper for the OECD/PRI Conference on Immigration and Social Capital, Montreal, November 23-25.

Henderson, S. 2005. Sticks and smoke: growing up with a sense of the city in the countryside. Young 13 (4): 363-379.

Herf, J. 1984. Reactionary Modernism: Technology, culture and politics in Weimar and the Third Reich. Cambridge: Cambridge University Press.

Hirschman, A.O. 1970. Exit, Voice and Loyalty: Responses to decline in firms, organizations, and states. Cambridge, Mass.: Harvard University Press.

Hochschild, A.R. 1983. The Managed Heart: Commercialization of human feeling. Berkeley: University of California Press

Holland, J., J. Weeks and V. Gillies. 2003. Families, intimacy, and social capital. Social Policy and Society 2: 339-348.

Holland, J., R. Thomson, S. Henderson, S. McGrellis and S. Sharpe. 2000. Catching on, wising up and learning from your mistakes: young people's accounts of moral development. The International Journal of Children's Rights 8: 271-294.

Hooghe, M. and D. Stolle. 2003. Generating Social Capital. New York: Palgrave.

Hordern, P., Ed. 2000. Music as Medicine: The history of music therapy since antiquity. Aldershot: Ashgate.

Howard, J. 1998. Address by the Prime Minister. World Economic Forum Dinner, Grand Hyatt Hotel Melbourne.

-. 2000. Quest for a decent society. The Australian: 11.

Huston, T.L. 2000. The social ecology of marriage and other intimate unions. Journal of Marriage and the Family 62: 298-320.

Inglehart, R. 1990. Culture Shift in Advanced Industrial Society. Princeton NJ: Princeton University Press.

-. 1999. Trust, well-being and social capital. In Democracy and Trust, edited by M. Warren, 88-120. Cambridge: Cambridge University Press.

Irwin, S. 1999. Resourcing the family: gendered claims and obligations and issues of explanation. In The New Family?, edited by E.B Silva and C. Smart. London: Sage.

Jackson, B. 1968. Working Class Community. Harmondsworth: Penguin.

Jacobs, J. 1961. The Death and Life of Great American Cities. New York: Vintage.

James, A. and Prout, A. 1990, 1997 2nd edition. Constructing and Reconstructing Childhood. London: Falmer Press. 
James, S.A., A.J. Schulz and J. van Olphen. 2001. Social capital, poverty, and community health: an exploration of linkages. In Social Capital and Poor Communities, edited by S. Saegert, J.P. Thompson and M.R. Warren, 165188. New York: Russell Sage Foundation.

Jayasuriya, K. 2003. Howard, Tampa and the Politics of Reactionary Modernisation. City University of Hong Kong.

Johnson, C. 1988. Ex Familia. New Brunswick, NJ: Rutgers University Press.

Johnson, S., J. McMillan and C. Woodruff. 2002. Courts and relational contracts. The Journal of Law, Economics and Organization 18 (1): 221-77.

Kalmijn, M. 1998. Intermarriage and homogamy: causes, patterns, and trends. Annual Review of Sociology 24: 395-421.

Kao, G. 2002. Race and ethnic differences in parental college aspirations for youth. In Research in Sociology of Education: Schooling and social capital in diverse cultures, edited by B. Fuller and E. Hannum, 13, 85-104. Boston: JAI/Elsevier Science.

Kerman, J. 1985. Musicology. London: Fontana.

Kilpatrick, S., B. Loechel, et al. 2002. Generating Jobs in Regional Tasmania: A social capital approach - final approach. Launceston: University of Tasmania.

King, J. and F. Stilwell. 2005. The industrial relations 'reforms': an introduction. The Journal of Australian Political Economy 56 (A Special Issue of the Journal of Australian Political Economy: Whose Choices? Analysis of the Current Industrial Relations 'Reforms' Protected By What?): 5-12.

Knack, S. and P. Keefer. 1997. Does social capital have an economic payoff? A cross-country investigation. Quarterly Journal of Economics 112 (4):12511288.

Komter, A.E. 2005. Social Solidarity and the Gift. Cambridge: Cambridge University Press.

Kovalainen, A. 2004. Rethinking the revival of social capital and trust in social theory: possibilities for feminist analyses of social capital and trust. In Engendering the Social: Feminist encounters with social theory, edited by B.L. Marshall and A. Witz. Maidenhead and New York: Open University Press.

Kozol, J. 1992. Savage Inequalities: Children in America's schools. New York: Harper Perennial.

Krishna, A. 2002. Active Social Capital: Tracing the roots of development and democracy. New York: Columbia University Press.

Krishna, A. and E. Schreder. 1999. Cross-Cultural Measures of Social Capital: A tool and results from India and Panama. Social Capital Initiative Working Paper No. 21. Washington DC: World Bank. 
Krishna, A. and N. Uphoff. 1999. Mapping and Measuring Social Capital: A conceptual and empirical study of collective action for conserving and developing watersheds in Rajasthan, India. Social Capital Initiative Working Paper No. 13. Washington DC: World Bank.

Kuran, T. 1995. Private Truths, Public Lies: The social consequences of preference falsification. Cambridge, MA: Harvard University Press.

Kymlicka, W. 2002. Contemporary Political Philosophy. 2nd Edition, Oxford: Oxford University Press.

Kyttä, M. 2004. The extent of children's independent mobility and the number of actualized affordances as criteria for child-friendly environments. Journal of Environmental Psychology 24 (2), 179-198.

Lareau, A. 2001. Embedding capital in a broader context: the case of familyschool relationships. In Social Class, Poverty, and Education, edited by B. Biddle and P. Hall, 77-100. London: RoutledgeFalmer.

- 2003. Unequal Childhoods: The importance of social class in family life. Berkeley, CA: University of California Press.

Latham, M. 1996. Civilising Global Capital: New thinking for Australian Labor. St. Leonards: Allen \& Unwin.

-. 2000. If Only Men Were Angels: Social capital and public policy in Australia. Melbourne, Institute of Family Studies.

Lauglo, J. 2000. Social capital trumping class and cultural capital? Engagement with school among immigrant youth. In Social Capital: Critical perspectives, edited by S. Baron, J. Field and T. Schuller, 142-67. Oxford: Oxford University Press.

Law Council of Australia. 2005. Legal Profession Opposes Anti-Terror Bill. Law Council of Australia.

Lee, O. 1998. Culture and democratic theory: toward a theory of symbolic democracy. Constellations 5 (4): 433-455.

Lefeber, L. 2000. Classical vs neoclassical economic thought in historical perspective: the interpretation of processes of economic growth and development. History of Political Thought XXI (3): 525-542.

Leonard, M. 2004. Bonding and bridging social capital: reflections from Belfast. Sociology 38 (5): 927-944.

Leventhal, T. and J. Brooks-Gunn. 2000. The neighborhoods they live in: the effects of neighborhood residence on child and adolescent outcomes. Psychological Bulletin 126: 309-337.

Lewandowski, J.D. 2000. Thematizing embededdness: reflexive sociology as interpretation. Philosophy of the Social Sciences 30 (1): 49-66.

-. 2001. Interpreting Culture: Rethinking Method and Truth in Social Theory. London: University of Nebraska Press. 
Li, Y., A. Pickles and M. Savage. 2005. Social capital and social trust in Britain. European Sociological Review 21 (2): 109-123.

Li, Y., M. Savage and A. Pickles. 2003. Social inequalities in associational involvement in England and Wales (1972-1999). British Journal of Sociology 54 (4): 497-526.

Li, Y., M. Savage, G. Tampubolon, A. Warde and M. Tomlinson. 2002. Dynamics of social capital: trends and turnover in associational membership in England and Wales: 1972-1999. Sociological Research Online, 7(3).

Lin, N. 1999. Building a network theory of social capital. Connections 22 (1): 28-51.

-. 2001. Social Capital: A theory of social structure and action. Cambridge: Cambridge University Press.

Lin, N., K. Cook and R. Burt, Eds. 2001. Social Capital: Theory and research. New York: Aldine de Gruyter.

Lochner, K.A., I. Kawachi, R.T. Brennan and S.L. Buka. 2003. Social capital and neighborhood mortality rates in Chicago. Social Science and Medicine 56: 1797-1805.

Lomnitz, L.A. and D. Sheinbaum. 2004. Trust, social networks and the informal economy: a comparative analysis. Review of Sociology of the Hungarian Sociological Association 10 (1): 5-26.

Lowe, P. and J. Goyder. 1983. Environmental Groups in Politics. London: Allen and Unwin.

Lury, C. 2003. The game of loyalt(o)y: diversions and divisions in network society. Sociological Review 51 (3): 301-320.

Lyons, M. 1997. The Capacity of Non-Profit Organisations to Contribute to Social Capital Formation Under Market Style Government Regimes. Sydney: University of Technology Sydney.

Mackenzie, C. and N. Stoljar, Eds. 2000. Relational Autonomy: Feminist perspectives on autonomy, agency and the social self. New York: Oxford University Press.

Mand, K. 2002. Place, gender and power in transnational Sikh marriages. Global Networks: A journal of transnational affairs. Special issue: Transnational Households and Rituals 2 (3): 233-248.

-. 2006. South Asian Families and Social Capital: Rituals of Care and Provision. Families \& Social Capital ESRC Research Group Working Paper No. 17, London: London South Bank University.

Marcuse, H. 1964. One Dimensional Man: Studies in the ideology of advanced industrial society. Boston, Beacon.

Mare, R. 1991. Five decades of educational assortative mating. American Sociological Review 56: 15-32. 
Markman, H.J. 1981. Prediction of marital distress: a 5-year follow-up. Journal of Consulting and Clinical Psychology 56: 210-217.

Markward, M., L. McMillan and N. Markward. 2003. Social support among youth. Children and Youth Services Review 25 (7): 571-587.

Marx, K. 1887. Das Kapital. Moscow: Progress Publishers.

Matthews, M.H. 1992. Making Sense of Place. UK: Harvester Wheatsheaf.

Mattsson, K.T. and S. Stenbacka. 2003. Gendered social capital - a case study of sports and music associations in Leksand and Rättvik, Sweden. Paper presented at the 43rd Congress of the European Regional Science Association, University of Jyväskylä, Finland. Available at: http://ideas.repec.org/p/wiw/wiwrsa/ersa03p291.html

Mayer, M. 2003. The onward sweep of social capital: causes and consequences for understanding cities, communities and urban movements. International Journal of Urban and Regional Research 27 (1): 110-132.

McAdam, D. and R. Paulsen. 1993. Specifying the relationship between social ties and activism. American Journal of Sociology 99 (3): 640-667.

McAdam, D. and D. Snow, Eds. 1997. Social Movements: Readings on their emergence, mobilisation and dynamics. California: Roxbury Publishing Company.

McAdam, D., S. Tarrow and C. Tilly. 2001. Dynamics of Contention. Cambridge: Cambridge University Press.

McClure, P. 2000. Participation Support for a More Equitable Society: Final report for the Reference Group on Welfare Reform. Department of Family and Community Services.

McDowell, L. 1997. Capital Culture: Gender at work in the city. Oxford: Blackwell.

McGrellis, S., S. Henderson, J. Holland, S. Sharpe and R. Thomson. 2000. Through the Moral Maze: A quantitative study of young people's values. London: the Tufnell Press.

McPherson, M., L. Smith-Lovin and J.M. Cook. 2001. Birds of a feather: homophily in social networks. Annual Review of Sociology 27: 415-444.

McRae, S., Ed. 1997. Changing Britain: Families and households in the 1990s. Oxford: Oxford University Press.

Merkle, L. and Zimmermann, K.F. 1992. Savings, remittances and return migration. Economics Letters 38: 77-81.

Micheli, G. A. 2000. Kinship, family and social network: the anthropological embedment of fertility change in southern Europe. Demographic Research 3 , article 13 .

Miller, A.S. and T. Mitamura. 2003. Are surveys on trust trustworthy? Social Psychology Quarterly 66 (1): 62-70. 
Modood, T. 1997. Employment. In Ethnic Minorities in Britain: Diversity and disadvantage, edited by T. Modood, R. Berthoud, et al., 83-149. London: PSI.

-. 2004. Capitals, ethnic identity and educational qualifications. Cultural Trends 13 (2): 87-105.

Modood, T., R. Berthoud and J. Lakey, J. Nazroo, P. Smith, S. Virdee and S. Beishon, Eds. 1997. Ethnic Minorities in Britain: Diversity and disadvantage. London: Policy Studies Institute.

Morrow, V. 1999. Conceptualising social capital in relation to the well being of children and young people: a critical review. The Sociological Review 47 (4): 744-765.

-. 2001. Using qualitative methods to elicit young people's perspectives on their environments: some ideas for community health initiatives. Health Education Research: Theory and practice 16 (3): 255-268.

-. 2004. Networks and neighbourhoods: children's accounts of friendship, family and place. In Social Networks and Social Exclusion: Sociological and policy issues, edited by C. Phillipson, G. Allan and D. Morgan. Aldershot: Ashgate.

Mosher, M. 2002. Are civil societies the transmission belt of ethical tradition? In Alternative Conceptions of Civil Society, edited by Si Chambers and W. Kymlicka, 207-230. Princeton NJ: Princeton University Press.

Murray, A. (2005). Australian Democrats' Minority Report, Parliament of Australia.

Narayan, D. and M.F. Cassidy. 2001. A dimensional approach to measuring social capital: development and validation of a social capital inventory. Current Sociology 49 (2): 59-102.

Narayan, D. and L. Pritchett. 1997. Cents and Sociability: Household income and social capital in rural Tanzania. Washington DC: World Bank.

Nettl, B. 1999. The institutionalization of musicology: perspectives of a North American ethnomusicologist. In Rethinking Music, edited by N. Cook and M. Everist. Oxford: Oxford University Press.

New York State Education Department. 2004. 2003-2004 Annual School Report for New York City Public Schools. Available at New York City Department of Education.

Nisbet, R.A. 1953. The Quest for Community. New York: Oxford University Press.

North, D.C. 1990. Institutions, Institutional Change and Economic Performance. Cambridge: Cambridge University Press.

O'Brien, M., D. Jones, D. Sloan and M. Rustin. 2000. Children's independent spatial mobility in the urban public realm. Childhood 7: 257-277. 
OECD. 2001. The Well-Being of Nations: The role of human and social capital. Centre for Educational Research and Education.

Ogilvie, S. 2004. How does social capital affect women? Guilds and communities in early modern Germany. American Historical Review 109 (2): 325-359.

O'Neill, O. 2002. A Question of Trust. BBC Radio 4. Available from: http://www.bbc.co.uk/radio4/reith2002/.

O'Neill, P. and N. Moore. 2005. Real institutional responses to neoliberalism in Australia. Geographical Research 43 (1): 19-28.

Onyx, J. and P. Bullen. 1997. Measuring Social Capital in Five Communities in New South Wales: An analysis. Melbourne: Centre for Australian Community Relations and Management.

Opp, K.-D. 2000. Norms. In International Encyclopedia of the Social and Behavioral Sciences edited by N. Smelser. Oxford: Elsevier Science.

Paddison, M. 1995. Adorno's Aesthetics of Music. Cambridge: Cambridge University Press.

Pahl, R. 1970. Patterns of Urban Life. London: Longman.

Park, R.E. 1950. Race and Culture. New York: The Free Press.

Parke, P.D. and N. Bhavnagri. 1989. Parents as managers of children's peer relationships. In Children's Social Networks and Social Supports, edited by D. Belle, 159-241. New York: Wiley.

Parsons, T. 1942. Age and sex in the social structure of the United States. American Sociological Review 7: 604-616.

Pavlicevic, M. and Ansdell, G., Eds. 2004. Community Music Therapy. London: Jessica Kingsley Publishers.

Paxton, P. 2002. Social capital and democracy. American Sociological Review 67: 254-277.

-. 1999. Is social capital declining in the United States? A multiple indicator assessment. American Journal of Sociology 105: 88-127.

Peach, C. 1991. The Caribbean in Europe: Contrasting patterns of migration and settlement in Britain, France and the Netherlands. Centre for Research in Ethnic Relations Research Paper 15. Coventry: University of Warwick,.

Percy-Smith, B. 1999. Multiple Childhood Geographies: Giving voice to young people's experience of space. Doctoral Thesis. University College Northampton.

Perry, M. 1999. Small Firms and Network Economies. New York: Routledge.

Phillips, T. 2004. Multiculturalism's legacy is 'have a nice day' racism: the mere celebration of diversity does nothing to redress inequality. The Guardian, 28 May. Available at: http://www.guardian.co.uk/comment/story/0,3604,1226527,00.html 
Pickering, P. 2003. The choice that minorities make: strategies of negotiation with the majority in post-war Bosnia-Herzegovina. In New Approaches to Balkan Studies, edited by D. Keridis, E. Elias-Bursac and N. Yatromanolakis, 255-309. Dulles, VA: Brassey's.

Pitt, M.M., S.R. Khanker and J. Cartwright. 2003. Does Micro-Credit Empower Women? Evidence from Bangladesh. World Bank Policy Research Working Paper 2998.

Platt, L. 2002. Parallel Lives? Poverty among minority ethnic groups in Britain. London: CPAG.

-. 2005. Technical Appendix to Migration and Social Mobility. York: Joseph Rowntree Foundation/York Publishing Services. Available at: www.jrf.org.uk.

Platteau, J.-P. 2000. Institutions, Social Norms, and Economic Development. Amsterdam: Harwood Academic Publishers.

Pocock, B. 2005. The Impact of The Workplace Relations Amendment (Work Choices) Bill 2005 (or "Work Choices") on Australian Working Families, Industrial Relations Victoria.

Popenoe, D. 1989. Disturbing the Nest: Family change and decline in modern societies. New York: Aldine de Gruyter.

Porter, M.E. 1990. The Competitive Advantage of Nations. London: MacMillan Press.

Portes, A. Ed. 1996. The New Second Generation. New York: Russell Sage Foundation.

- 1998. Social capital: its origins and applications in modern sociology. Annual Review of Sociology 24: 1-24.

-. 2000a. Social capital: promises and pitfalls of its role in development. Journal of Latin American Studies 32 (2): 529-539.

- 2000b. The two meanings of social capital. Sociological Forum 15: 1-11.

Portes, A., P. Fernández-Kelly and W. Haller. 2005. Segmented assimilation on the ground: the new second generation in early adulthood. Ethnic and Racial Studies 28 (6): 1000-1040.

Portes, A. and P. Landolt. 1996. The downside of social capital. The American Prospect 26: 18-21.

Portes, A. and R. Rumbaut. 1996. Immigrant America: A portrait. Berkeley, CA: University of California Press.

PRI: Policy Research Initiative. 2003. Privy Council Office, Government of Canada, Draft Discussion Paper: 'Social Capital: Building on a Networkbased Analysis', October.

- 2004. Privy Council Office, Government of Canada, Synthesis Report 'Expert Workshop on the Measurement of Social Capital for Public Policy', June 8. 
- 2005. Privy Council Office, Government of Canada, Social Capital as a Public Policy Tool: Project Report, September.

Procter, S. 2004. Playing politics: community music therapy and the therapeutic redistribution of musical capital for mental health. In Community Music Therapy, edited by M. Pavlicevic and G. Ansdell. London: Jessica Kingsley Publishers.

Pusey, M. 1991. Economic Rationalism in Canberra: A nation building state changes its mind. New York: Cambridge University Press.

Putnam, R.D. 1993. The prosperous community: social capital and public life. The American Prospect 13: 35-41.

-. 1995. Bowling alone: America's declining social capital. Journal of Democracy 6 (1): 65-78.

- 1996a. The decline of civil society: how come? So what? The John L. Manion Lecture, Canadian Centre for Management Development, Ottawa, Ontario, 22 February, 1-28.

- 1996b. The strange disappearance of civic America. American Prospect 24: 34-48.

-. 2000. Bowling Alone: The collapse and revival of American community. New York: Simon \& Schuster.

- 2001. A better society in a time of war. New York Times, October 19: A19.

—. 2002. Bowling together. The American Prospect 13 (3): 11.

Putnam, R.D. and K.A. Goss. 2002. Introduction. In Democracies in Flux: The evolution of social capital in contemporary society, edited by R.D. Putnam, 3-21. Oxford: Oxford University Press.

Putnam, R.D. with R. Leonardi and R. Nanetti. 1993. Making Democracy Work: Civic traditions in modern Italy. Princeton, N.J.: Princeton University Press.

Radcliffe, S.A. 2004. Geography of development: development, civil society and inequality - social capital is (almost) dead? Progress in Human Geography 28 (4): 517-27.

Raffo, C. and Reeves, M. 2000. Youth transitions and social exclusion: developments in social capital theory. Journal of Youth Studies 3 (2): 147166.

Raiser, M. 1999. Trust in Transition. Working Paper No.39, European Bank for Reconstruction and Development.

Rankin, B. 2001. Marimba music building social and cultural capital. New Era in Education 82 (1): 22-24.

Rankin, K. 2002. Social capital, microfinance, and the politics of development. Feminist Economics 8 (1): 1-24.

Rauch, J.E. 2001. Business and social networks in international trade. Journal of Economic Literature 39: 1177-203. 
Reay, D. 1998. Rethinking social class: qualitative perspectives on gender and social class. Sociology 32 (2): 259-275.

-. 2000. A useful extension of Bourdieu's conceptual framework? Emotional capital as a way of understanding mother' involvement in their children's education. Sociological Review 48 (4): 568-585.

-. 2004. 'Mostly roughs and toughs': social class, race and representation in inner city schooling. Sociology 38 (5): 1005-1023.

Reay, D., J. Davis, M. David and S. Ball. 2001. Choices of degree or degrees of choice? Class, 'race' and the higher education choice process. Sociology 35 (4): 855-874.

Reynolds, T. 2004. Families, Social Capital and Caribbean Young People's Diasporic Identities. Families \& Social Capital ESRC Research Group Working Paper No. 11. London: London South Bank University.

-. 2005. Caribbean Mothers: Identity and experience in the UK. London: the Tufnell Press.

Reynolds, T. and E. Zontini. 2006. A Comparative Study of Care Provision Across Caribbean and Italian Transnational Families. Families \& Social Capital ESRC Research Group Working Paper No. 16. London: London South Bank University.

Richter, M. 2004. Localist and globalist music-making as social capital among street workers in a Jogjakartan budget-tourist quarter. Paper presented at the 15th Biennial Conference of the Asian Studies Association of Australia. Available at:

http://coombs.anu.edu.au/ASAA/conference/proceedings/Richter-MASAA2004.pdf

Roberts, E. 1995. Women and Families: An oral history, 1940-1970. Oxford: Blackwell.

Robinson, V. 1990. Roots to mobility: the social mobility of Britain's black population, 1971-87. Ethnic and Racial Studies 13:2: 274-286.

Rose, D. and D. Pevalin, Eds. 2003. A Researchers's Guide to the National Statistics Socio-Economic Classification. London: Sage.

Rose-Ackerman, S. 2001. Trust and honesty in post-socialist societies. KYKLOS 54: $415-44$.

Rossi, S. and P. Rossi. 1990. Of Human Bonding. New York: Basic Books.

Rothstein, B. and Stolle, D. 2001. Social capital and street-level bureaucracy: an institutional theory of generalised trust. Paper presented at the ESF Conference 'Social Capital: Interdisciplinary Perspectives', Exeter, September 15-20.

Russell-Browne, P, B. Norville and C. Griffith. 1997. Childshifting: a survival strategy for teenage mothers. In Caribbean Families: Diversity amongst 
ethnic groups, edited by J. Roopnarine, and J. Brown. Westport CT: Greenwood Publishing Group.

Saguaro Seminar on Civic Engagement in America. 2000. Better Together. Cambridge MA: John F. Kennedy School of Government.

Sanbonmatsu, J. 2001. Letters to the Editor. New York Times, October 25: A20.

Sander, T.H. and R.D. Putnam. 2002. Walking the civil talk after September 11.

The Christian Science Monitor, February 19.

Sandler, T. 1992. Collective Action: Theory and applications. Ann Arbor: University of Michigan.

Savage, M. 2000. Class Analysis and Social Transformation. Milton Keynes: Open University Press.

-. 2004. Rethinking Class, Identities, Cultures and Lifestyles. Basingstoke: Palgrave.

Savage, M., G. Bagnall, B.J. Longhurst. 2005. Globalisation and Belonging. London: Sage.

Schaefer-McDaniel, N.J. 2004. Conceptualising social capital among young people: toward a new theory. Children, Youth and Environments 14 (1): 140150.

Schenker, H. 1971. Beethoven's Fifth Symphony. In Beethoven: Symphony No. 5 in C Minor, edited by E. Forbes. New York: Norton.

Schuller, T., S. Baron and J. Field. 2000. Social capital: a review and critique. In Social Capital: Critical perspectives, edited by S. Baron, J. Field and T. Schuller, 1-38. Oxford: Oxford University Press.

Sedaitis, J.B. 1997. Network dynamics of new firm formation: developing Russian commodity markets. In Restructuring Networks in Post-Socialism: Legacies, linkages, and localities, edited by G. Grabher and D. Stark, 13757. Oxford; New York: Oxford University Press.

Sen, A.K. 1990. Gender and co-operative conflicts. In Persistent Inequalities, edited by I. Tinker. New York: Oxford University Press.

Senior, O. 1991. Working Miracles: Women's lives in the English speaking Caribbean. London: James Currey Publishing.

Sevenhuijsen, S. 2000. Caring in the Third Way: the relation between obligation, responsibility and care in the Third Way discourse. Critical Social Policy 20 (1): 5-37.

Shields, M.A. and S. Wheatley Price. 2002. The English language fluency and occupational success of ethnic minority immigrant men living in English metropolitan areas. Journal of Population Economics 15: 137-60.

Shukra, K, L. Back, M. Keith, A. Khan and J. Solomos. 2004. Race, social cohesion and the changing politics of citizenship. London Review of Education 2(3): 187-195. 
SIGN Methodology Review Group. 1999. Report on the Review of the Method of Grading Guideline Recommendations. Edinburgh: Scottish Intercollegiate Guidelines Network.

Simmel, G. 1949. The sociology of sociability. The American Journal of Sociology 55 (3): 254-261.

Skeggs, B. 1997. Formations of Class and Gender: Becoming respectable. London: Sage.

—. 2004. Class, Self, Culture. London: Routledge.

Small, C. 1998. Musicking. Hanover, NH: Wesleyan University Press

Smith, D.J. 1977. Racial Disadvantage in Britain: The PEP Report. Harmondsworth: Penguin.

Smith, S. and J. Kulynych. 2002. It may be social, but why is it capital? The social construction of social capital and the politics of language. Politics and Society 30 (1): 149-186.

Snow, D., L. Zurcher and S. Ekland-Olson. 1980. Social networks and social movements: a microstructural approach to differential recruitment. American Sociological Review 45: 787-801.

Sobel, J. 2002. Can we trust social capital? Journal of Economic Literature 40 (1): 139-154.

Social Exclusion Unit. 2004. Mental Health and Social Exclusion. London: Office of the Deputy Prime Minister.

Socialist Equity Party. 2005. Australia's "Anti-Terrorism" Bill: The Framework for a Police State. World Socialist Web Site. Available at: http://www.wsws.org.

Soumi, S.J. 1991. Adolescent depression and depressive symptoms: insights from longitudinal studies with Rhesus monkeys. Journal of Youth and Adolescence 20: 273- 287.

Spies-Butcher, B. 2002. Tracing the rational choice origins of social capital: is social capital a neo-liberal 'Trojan horse'? Australian Journal of Social Issues 37 (1): 173.

Spoehr, J. 2005a. The Fear Factor. Workers Online. Available at http://www.labor.net.au/workers.

—. 2005b. Workplace: Fightback revisited. Australian Policy Online. Available at http://www.nla.gov.au.

Sroufe, L.A., B. Egeland, and E.A. Carlson. 1999. One social world: the integrated development of parent-child and peer relationships. Child Psychology 30: 241- 261.

St. Vincent De Paul Society (SVDPS). 2005. Senate Inquiry Into Welfare to Work Legislation. St. Vincent De Paul Society.

Stack, C. 1974. All Our Kin. New York: Harper \& Row. 
Stige, B. and Kenny, C. 2002. Introduction - the turn to culture. In Contemporary Voices in Music Therapy: Communication, culture and community, edited by C. Kenny and B. Stige. Oslo: Unipub forlag.

Stilwell, F. 1996. Against the stream: progressive currents. Social Alternatives 15 (4): 46-49.

Stilwell, F. 2000. Changing Track: A new political and economic direction for Australia. Annandale: Pluto Press.

Stolle, D. 2001. 'Getting to trust': an analysis of the importance of institutions, families, personal experiences and group membership. In Social Capital and Participation in Everyday Life, edited by P. Dekker and E. Uslaner. London: Routledge.

-. 2003. The sources of social capital. In Generating Social Capital: Civil society and institutions in comparative perspective, edited by M. Hooge and D. Stolle. New York: Palgrave Macmillan.

Stone, M. 1981. The Education of the Black Child in Britain: The myth of multicultural education. Glasgow: Fontana.

Stone, W. 2001. Measuring Social Capital: Towards a theoretically informed measurement framework for researching social capital in family and community life. Research Paper No. 24. Melbourne: Australian Institute of Family Studies.

Strathern, M. 1981. Kinship at the Core: An anthropology of Elmdon, a village in the north-west of Essex in the 1960s. Cambridge: Cambridge University Press.

Szreter, S. 2002. The state of social capital: bringing back in power, politics and history. Theory and Society 31: 573-621.

Szreter, S. and M. Woolcock. 2004. Health by association? Social capital, social theory and the political economy of public health. International Journal of Epidemeology 33: 650-667.

Tarrow, S. 1996. Making social science work across time and space: a critical reflection on Robert Putnam's 'Making Democracy Work'. American Political Science Review 90 (2): 389-97.

Thatcher, M. 1987. Epitaph for the Eighties: There is no such thing as society. Women's Own Magazine. October 31.

Thompson, E.P. 1966. The Making of the English Working Class. London: Vintage Books.

Thompson, P. 1980. Des récits de vie et l'analyse du changement social. Cahiers internationaux de sociologie, LXIX: 249-68 (republished in English, 1981. Life histories and the analysis of social change. In Biography and Society, edited by D. Bertaux, 289-306. Beverly Hills: Sage.)

- 1984 . The family and child-rearing as forces for economic change: towards fresh research approaches. Sociology 18: 515-29. 
-. 2004. Researching family and social mobility with two eyes: some experiences of the interaction between qualitative and quantitative data. International Journal of Social Science Methodology 7 (3): 237-257.

Thompson, P. and E. Bauer. 2000. Jamaican transnational families: points of pain and sources of resilience. Wadabagei: a Journal of the Caribbean and its Diaspora Summer/Fall: 1-37.

Thompson, P. and E. Bauer. 2003. Evolving Jamaican migrant identities: contrasts between Britain, Canada and the United States. Special issue on Caribbean families, Community, Work and Family 6 (1): 89-102.

Thompson, P. and E. Bauer. 2004. "She's always the person with a very global vision": the gender dynamics of migration, narrative interpretation, and the case of Jamaican transnational families. Gender and History 16 (2): 1-42.

Thomson, R. 2004. Tradition and Innovation: Case histories in changing gender identities. Unpublished PhD Thesis, London South Bank University.

Thomson, R. and J. Holland. 2002. Imagined adulthood: resources, plans and contradictions. Gender and Education 14 (4): 337-350.

Thomson, R. and J. Holland. 2003. Hindsight, foresight and insight: the challenges of longitudinal qualitative research. International Journal of Social Research Methodology, Theory and Practice. Special issue on Longitudinal Qualitative Methods. 6 (3): 233-244.

Thomson, R. and J. Holland. 2005. 'Thanks for the memory': memory books as a methodological resource in biographical research, Qualitative Research 5 (2): 201-291.

Thomson, R., S. Henderson and J. Holland. 2003. Making the most of what you've got? Resources, values and inequalities in young people's transitions to adulthood. Educational Review 55 (1): 33-46.

Thorne, B. 1993. Gender Play: Girls and boys in school. New Brunswick, NJ: Rutgers University Press.

Thorne, B. with M. Yalom, Eds. 1992. Rethinking the Family: Some feminist questions. Boston: Northern University Press.

Thrift, N. 1998. Virtual capitalism: the globalization of reflexive business knowledge. In Virtualism: A new political economy, edited by J. Carrier and D. Miller. Oxford: Berg.

Tilly, C. 1978. From Mobilization to Revolution. Reading, Mass.: AddisonWesley.

-. 2004. Contention and Democracy in Europe, 1650-2000. Cambridge: Cambridge University Press.

Tocqueville, A. de. 1969. Democracy in America, trans. G. Lawrence. New York: Harper.

Tonkiss, F. 2000. Trust, social capital and the economy. In Trust and Civil Society, edited by F. Tonkiss and A. Passey. London: Macmillan Press. 
Tuomela, R. 1995. The Importance of Us: A philosophical study of basic social notions. Stanford: Stanford University Press.

Unger, D. and M. Sussman, Eds. 1990. Families in Community Settings: Interdisciplinary perspectives. New York: Haworth Press.

Uphoff, N. 2000. Understanding social capital: learning from the analysis and experience of participation. In Social Capital: A multifaceted perspective, edited by P. Dasgupta and I. Serageldin. Washington DC: World Bank.

US Census Bureau. 2000. United States Census 2000: American factfinder. Available at www.factfinder.census.gov.

Uslaner, E.M. 2001. Producing and consuming trust. Political Science Quarterly 115 (4): 569-590.

-. 2001. Volunteering and social capital: how trust and religion shape civic participation in the United States. In Social Capital and Participation in Everyday Life, edited by P. Dekker and E. M. Uslaner. London: Routledge.

-. 2002. The Moral Foundations of Trust. Cambridge: Cambridge University Press.

-. 2003. Trust and civic engagement in East and West. In Social Capital and the Transition to Democracy, edited by G. Badescu and E.M. Uslaner, 8194. London: Routledge.

Uzzi, B. 1996. The sources and consequences of embeddedness for the economic performance of organizations: the network effect. American Sociological Review 61: 674-98.

Vallet, L.-A. 2005. What can we do to improve the education of children from disadvantaged backgrounds? Paper prepared for the ECSR Conference, Comparative European Studies: Assessing ten years of sociological research 1995-2005, 25-26 November, Institut d'Études Politiques, Paris.

Wacquant, L. 2004a. Pointers on Pierre Bourdieu and democratic politics. Constellations 11 (1): 3-15.

- 2004b. Body and Soul: Notebooks of an apprentice boxer. Oxford: Oxford University Press.

Warde, A., G. Tampubolon, B. Longhurst, K. Ray, M. Savage and M. Tomlinson. 2003. Trends in social capital: membership of associations in Great Britain, 1991-1996. British Journal of Political Science 33: 515-525.

Warren, M.E. 2001. Democracy and Association. Princeton: Princeton University Press.

Waters, M. 1996. Ethnic and racial identities of second-generation black immigrants in New York City. In The New Second Generation, edited by A. Portes. New York: Russell Sage Foundation.

Watson, D. 2003. Death Sentence: The decay of public language. Milsons Point NSW: Random House Australia.

—. 2004. When words hide the truth. The Age. Melbourne. 
Weber, M. 1978. Economy and Society. Edited by G. Roth and C. Wittich. Berkeley: University of California Press.

Welch, M. 2006. The war on sedition: Anglosphere allies crack down on speech in the name of fighting terror. Reason Online. Available at http://www.reason.com/0602/co.mw.the.shtml.

Weller, C.E., R.E. Scott, et al. 2001. The Unremarkable Record of Liberalised Trade: After 20 years of global economic deregulation, poverty and inequality are as pervasive as ever, Briefing Paper. Washington DC: Economic Policy Institute.

Wellman, B. and S. Wortley. 1990. Different strokes from different folks: community ties and social support. American Journal of Sociology 96: 558588.

Whiting, E. and R. Harper. 2003. Young People and Social Capital. London: Office for National Statistics.

Williams, A. 2001. Constructing Musicology. London: Ashgate.

Williams, F. 2004. Rethinking Families. London: Calouste Gulbenkion Foundation.

Winch, R.F. 1958. Mate Selection: A study of complementary needs. New York: Harper.

Wolf, D. 2004. Valuing informal elder care. In Family Time: The social organization of care, edited by N. Folbre and M. Bittman. London: Routledge.

Woolcock, M. 1998. Social capital and economic development: toward a theoretical synthesis and policy framework. Theory and Society 27 (2): 151208.

-. 1999. Managing Risk, Shocks, and Opportunity in Developing Economies: The role of social capital. Washington, D.C.: World Bank.

- 2001. The place of social capital in understanding social and economic outcomes. Canadian Journal of Policy Research 2: 11-7.

Woolcock, M. and D. Narayan. 2000. Social capital: implications for development theory, research and policy. The World Bank Research Observer 15 (2): 225-49.

World Bank and European Bank for Reconstruction and Development EBRD. 2002. Business Environment and Enterprise Performance Survey. Available at http://info.worldbank.org/governance/beeps2002/

World Bank. 2002. Bosnia and Herzegovina: Local level institutions and social capital study. Available at:

http://www.worldbank.org/participation/BosnizMainReport.pdf

Wuthnow, R. 2002. Bridging the privileged and the marginalized? In Democracies in Flux: The evolution of social capital in contemporary society, edited by R.D. Putnam, 59-102. Oxford: Oxford University Press. 
Wyn, J. and P. Dwyer. 1999. New directions in research on youth in transition. Journal of Youth Studies 2 (1): 5-21.

Young, C. 2001. The dark side of a war-inspired civic virtue. Boston Globe, October 31: A23.

Zelizer, V. 1985. Pricing the Priceless Child: The changing social value of children. New York: Basic Books.

Zontini, E. 2004a. Italian Families and Social Capital: Rituals and the provision of care in British-Italian transnational families. Families \& Social Capital ESRC Research Group Working Paper No. 6. London: London South Bank University.

- 2004b. Immigrant women in Barcelona: coping with the consequences of transnational lives. Journal of Ethnic and Migration Studies 30 (6): 11131144. 


\section{CONTRIBUTORS}

Barbara Arneil is an associate professor in political science at the University of British Columbia. Her most recent research is a book entitled Diverse Communities: The Problem With Social Capital (Cambridge University Press, 2006) and a co-edited volume on the reconciliation of sexual equality with cultural protections entitled Sexual Justice/Cultural Justice (Routledge, forthcoming).

Iva Božović is a $\mathrm{PhD}$ candidate in Political Economy and Public Policy at the University of Southern California. Her research focuses on the impact of social networks on the performance of small and medium size enterprises, and the broader role of social capital in the economic transition of South-Eastern Europe.

Keri Chiveralls is a $\mathrm{PhD}$ candidate with the Australian Institute for Social Research at the University of Adelaide. Her doctoral studies in Social Inquiry/Anthropology focus on social capital in Australian regional development. Her research interests include urban and regional development studies, the political economy of globalisation and counter-globalisation protest movements.

Rosalind Edwards is Professor in Social Policy and Director of the Families \& Social Capital ESRC Research Group, London South Bank University. Her main research interests focus on families, latterly especially in relation to social capital, and she has written widely on a range of aspects of family life.

Jane Franklin is Senior Research Fellow with the Families \& Social Capital ESRC Research Group, and Lecturer in Social and Policy Studies, London South Bank University. Her current work focuses on social theory and politics, feminist theory in late modernity, and critiques of communitarian and social capital perspectives.

Frank F. Furstenberg is the Zellerbach Family Professor of Sociology at the University of Pennsylvania. His current research projects focus on the family in the context of disadvantaged urban neighbourhoods, adolescent sexual behaviour, cross national research on children's well-being, urban education and 
the transition from adolescence to adulthood. He is current Chair of the MacArthur Foundation Research Network on Transitions to Adulthood.

Janet Holland is Professor of Social Research and Co-director of the Families \& Social Capital ESRC Research Group at London South Bank University. Her research interests focus on youth, gender, sexuality and family life. She is also interested in feminist theory and methodology.

Joseph D. Lewandowski is a US Fulbright Scholar in the Institute of Political Science at the Charles University (Prague). $\mathrm{He}$ is the author of Interpreting Culture: Rethinking Method and Truth in Social Theory (University of Nebraska Press, 2001) and numerous articles in Political Theory and the Philosophy of Social Science.

Yaojun Li is a Reader in Sociological Analysis, Birmingham University. His research interests are in social mobility and social stratification, socio-political engagement, ethnicity, work-life, and statistical analysis. Recent publications have appeared in many top sociology journals. He has conducted funded research for the ESRC and other Government agencies.

Lucinda Platt is Lecturer at the University of Essex. She teaches and researches in the areas of social policy, inequality, and ethnicity, with a particular focus on child poverty and ethnic minority disadvantage.

Simon Procter is a music therapist working in mental health services. He is Research Assistant at the Nordoff-Robbins Music Therapy Centre, London, part of the Sociology of the Arts working group at Exeter University, and Editor of the British Journal of Music Therapy.

Pedro Ramos Pinto is completing a $\mathrm{PhD}$ at the Faculty of History, Cambridge University, on urban grassroots movements in Lisbon during Portugal's transition to democracy. He is interested in social capital in relation to social movements, civil society and forms of grassroots political participation in historical and international perspective.

Tracey Reynolds is a Senior Research Fellow in the Families \& Social Capital ESRC Research Group at London South Bank University. She is interested in parenting and family relationships, especially in relation to racial/ethnic identities, and the black family. She is the author of Caribbean Mothers: Identity and Experience in the UK (The Tufnell Press, 2005). 
Mike Savage is Professor of Sociology at the University of Manchester, where he is co-director of the ESRC Centre for Research on Socio-Cultural Change (CRESC). His research interests are in social stratification, urban change, and historical sociology.

Nicole Schaefer-McDaniel is a doctoral candidate in Environmental Psychology at the Graduate Center of the City University of New York. Originally from Germany, her research interests include social capital in children, children's health, and neighbourhood effects on children.

Gindo Tampubolon is a research associate at the ESRC Centre for Research on Socio-Cultural Change, University of Manchester. His interests revolve around methods and substances of social networks, social capital and cultural capital. He has also published on medical innovation and economic development.

Paul Thompson is Research Professor in Sociology at the University of Essex and a Research Fellow at the Young Foundation. He is Founder-Editor of Oral History and Founder of the National Life Story Collection at the British Library. $\mathrm{He}$ is a pioneer of oral history in Europe and author of the international classic The Voice of the Past.

Elisabetta Zontini is a Research Fellow in the Families \& Social Capital ESRC Research Group at London South Bank University, and Visiting Fellow at the International Gender Studies Centre, Oxford University. She has published on gender and migration in Southern Europe, and her current work is on Italian families, rituals and care provision in a transnational world. 


\section{INDEX}

Adler, Guido 149, 152

Adorno, Theodor 151-152

aesthetic 22-25

anomie 96

arts 147-149, 154, 161

associations - see voluntary association

Australia 8

Becker, Gary 15-17, 27n

belonging 180

black and ethnic minorities - see

ethnicity

Blair, Tony 6-7, 30, 36, 42-44, 48

Bosnia Herzegovina 7, 8-9, 113-128

Bourdieu, Pierre 2-6, 8, 9, 16, 19-20, 27n, 28n, 44-46, 48, 49, 53, 54, 57, 70,

$71,73,96,130,149,153,164,168$,

176, 193, 194, 219

Bott, Elizabeth 18

Britain/UK 7, 42-44

Britishness 7, 42-44, 48

Bronfenbrenner, Uri 104

Bush, George W. 6, 30, 36, 38-41

Canada 7-8, 44-48

capacity 3, 54-69

capitals

- $\quad$ cultural $73,130,153,166-7$

- $\quad$ economic $16,73,130,166$

- human 111, 195

- $\quad$ symbolic 130

care $12,217-219,223$

Caribbean 218, 220, 222-225, 228

caring 217-233

- $\quad$ about 218, 221-233

- $\quad$ for $218,221,224-229$

- $\quad$ networks 218

- $\quad$ practices 209,218, 233

- relationships 218 children/young people 3, 5, 101-102, 103, 106, 108, 163-177, 178-190

citizenship/citizen 38-40, 61

civic renewal $7,35,37-39,41,42$

civic society $29,34,36.40,47$

civic involvement/engagement 72,74 , 75-76, 82, 96, 112, 117, 131

class - see social class

Coleman, James 2-6, 15-17, 27n, 32, 50n, 55, 57, 63, 71, 96, 130, 163, 178$180,194,219,233$

collective action $3,54-59,64-65,68$, 80-82

Colley, Linda 44, 48

communitarian $30,55,68,122$

community $30,55,68,102-103,133$,

134, 140, 161, 170-172, 174

conflict $11,21,22,63-64$

consensus 11, 108

Coontz, Stephanie 99

cooperation 63-66, 68

cultural remittance 222

culture 49

democracy 17-18, 29, 32, 66

DeNora, Tia 152, 159-160

detraditionalisation 165

development

- economic $112,129,131,132$, $133,134,137,138$

- regional 129-145

disadvantage - see inequality

diversity $33-34,38,45,46,48$

divorce 100, 108

Durkheim, Emile 95-96, 99

economic restructuring 113

education (see also schools, university)

$73,210-212$ 
ethnic minority - see ethnicity ethnic identity - see ethnicity and identity ethnicity $71,87,116,118,122-124$, 179, 192, 199-214, 217-233

ethnomusicology 152

exchange 99, 105

faith - see religion

faith-based initiatives $30,38,40-41$, 48

family/families 3, 11, 95-110, 165, 172, 174, 206-210, 217-233

family system 98-100, 105, 209-210

feminism 4-5

Frankfurt Institute of Social Research 151

friendship/friends 184-189

Fukuyama, Francis 163

functionalist $8,46-47$

gender 49, 85, 87, 179, 188, 194, 207,

212, 218, 228-229

generation 105,179

globalisation 129

governance 129,131

habitus/field 19, 21, 89, 90

health $148,155,160-161,227$

housing 213

human action 14, 16, 17, 20

identity 42-44, 48, 61, 64-66, 68, 152, 165-167

IMF (International Monetary Fund)

131

immigration 102

individual 104-5, 220

individualism 89

individualisation 165,220

inequality/disadvantage $4,6,70,91$, 129, 135, 140, 142, 191, 194

Inglehart, Ronald 33, 71

Italy/Italian 71-72, 104, 220, 224, 226228
Jackson, Brian 87

judicial system 125-126

Kerman, Joseph 150

kin/kinship 12, 97, 102-103, 221, 223, 229

liberal $30,33,36-37$

- neo-liberalism 135, 137, 141

loyalty 188

marriage 99-100, 108

Marshall, T.H. 37

Marxist 16, 19-29, 21-22, 26

measurement 10,106

methodology 9-10, 56, 58, 106-109, 155

migrants 191-216

migration 191-216, 222

mobility

- geographical 11-12, 201-215, 217-219

- $\quad$ residential 179,188

- $\quad$ social 11-12, 191-215

- $\quad$ spatial 183-190

multicultural/multiculturalism 5, 8, 33, 37, 45-46, 191

musicking 10, 151-160

musicology 149-153

neighbourhood 11, 179-190

neo-liberalism - see liberal

networks - see social networks

New Labour 42,141

norms 3,14, 16-19, 55, 57-60, 62-63,

$65,69,96,108,157,171$

Northern Ireland 170, 172

nostalgia $37,43,47$

obligations 108

OECD 8, 31, 46

opportunity cost 120

parents/parenting 101, 103, 105, 184, 187, 189

place $171,179-180$ 
policy

- $\quad$ economic 6-9, 129, 132, 137

- $\quad$ social $6-9,76,142-143$

political economy 138

power 19-20, 48-49, 61, 65-66, 68

practice 9-12, 19-20, 21

production function 111

Progressive Era 34, 42

psychology 100,180

public/private 165

Putnam, Robert 2-6, 15, 17, 27n, 28-

48, 50n, 51n, 55, 61, 96, 131, 147-8, $153,163,171,179-180,188,194,219$, 233

randomised control trials (RCTs) 155

rational action/choice 9, 16-17, 71,

$116,130,131,137,138$

rational reductionism 20

reciprocity $31,103,157,180,230$

religion/faith $7,31,35,40-42,100$,

102, 104

republican $31,37,66$

resources 44-46, 48, 53-54, 56, 59, 73-

$120,96,105,168,220-221,233$

Saguaro Seminar 36, 40, 148

Schenker, Heinrich 150

school 101, 174, 180, 184, 186, 189

Simmel, Georg 5, 15, 22-26

Small, Christopher 151-152

sociability $5,10,15,22-26$

social, the 4, 6, 29-48

social capital

- $\quad$ bonding $8,11,18,57-61,64,111$ $128,135,171,179,188,222$

- $\quad$ bridging $8-9,11,16-17,18,57-$ 61, 64, 101,111-128, 135, 171, 179

- definition 2-5, 14-20, 53-57, 95$98,107,163$

- family $10,12,103-105,192-215$

- $\quad$ high $97-100,106,107$

- $\quad$ linking 58, 61, 66, 135-136

- $\quad$ low 34

- negative $55-56,63,120,133,134$ social change 2,5

social class $19-20,21,25,73,75,85$, 196-206

- $\quad$ middle class $85,89,170,174$, 189

- $\quad$ working class $11,82-90,102$, 170,172

social cohesion 32

social exclusion 174

social identity - see identity

social justice 46,49

social movements 75

social networks $10,16,44-46,48,53$ -

54, 55, 57-60, 62-63, 65, 69, 70-94,

111-128, 167-170, 172, 180, 218

social structures 19-20, 219

social theory 165

social ties $57-60,219$

sociology $96,100,164$

Stack, Carol 103

stratification 70,74

structural holes 135

Third Way 4, 6, 8, 30, 129, 137, 138, 141

Tocqueville, Alexis de 17-19, 29, 32, 72, 95,96

trade unions 75,82

transition to adulthood 164-5

transnational 11,217-233

Trojan horse 72,136

trust $70,72,76,96,118,157,179$,

184, 186

- $\quad$ generalised $8,16,18,33,54-55$, $112,117-118,127$

- $\quad$ institutionalised 126

- $\quad$ interpersonal 71, 119

trustworthiness $31,54,112$

university 171,176

USA/America 7, 38-41

USA Freedom Corps 38-40, 50n

values $31,39,42-44,165,171$

voluntary association/s 18, 21, 23, 7093 
Wacquant, Loic 26

weak ties 57, 135

welfare state 6

well-being 224 women - see gender

World Bank 7-8, 11, 46, 113-121, 131, $132,134,135,136,138$

young people - see children 